\title{
Scientific paper sessions
}

\author{
(original and unedited texts as received by the authors)
}

Friday, September 18, 2009 - Terpsichore Room

TE1

11:50-13:00 - Imaging of brain tumors - multimodality approach I

TE1:1

CONTRAST AGENT LEAKAGE EFFECTS: PITFALLS

IN TUMOR MR PERFUSION ASSESSMENT IN THE CNS, EVALUATING ANTIOANGIOGENIC TREATMENT

\section{VARALLYAY $^{1,2}$, EA. NEUWELT $^{2}$, L. SOLYMOSI $^{1}$}

${ }^{1}$ UNIVERSITÄTSKLINIKUM WÜRZBURG DEPT. OF NEURORADIOLOGY, WÜRZBURG, GERMANY, ${ }^{2}$ OREGON HEALTH AND SCIENCE UNIVERSITY DEPT. OF NEUROLOGY, PORTLAND, OR, USA

\section{PURPOSE}

Antiangiogenic therapy has been increasingly used in patients with malignant brain tumors. Treatment response criteria based on changes in contrast enhancement are not reliable in these cases as antiangiogenic therapy primarily alters vascular permeability. Changes in relative cerebral blood volume ( $\mathrm{rCBV}$ ) is a promising measure in evaluating treatment response. However, this measure is also influenced by contrast agent extravasation as occurs in tumors with highly permeable blood vessels. This study analyzed the utility of a blood pool ultrasmall superparamagnetic iron oxide (USPIO) compound and compared it to low molecular weight gadolinium based contrast agents (GBCA) in tumor perfusion measurement throughout antiangiogenic treatment.

METHODS

Ten athymic rats with intracranial U87 human glioma tumors underwent dynamic T2* weighted MRI using a 12 tesla instrument. IV. Bolus of USPIO ferumoxytol $(n=5)$ or GBCA $(n=5)$ was injected to assess rCBV in this extremely leaky tumor model. Following MRI, animals were treated with bevacizumab, an antibody targetting VEGF. MRI was repeated $24 \mathrm{~h}$ post treatment. Signal intensity-time (SI(t)) curves were analyzed, changes in rCBV values were studied in GBCA and USPIO groups pre- and post treatment.

RESULTS

GBCA extravasation resulted in an premature recovery of the SI(t) curve, and a leakage dependent tumor rCBV underestimation, which was most prominent at baseline. Post treatment, as vascular permeability decreased, this underestimation became less prominent, resulting in an artifactual increase in $\mathrm{rCBV}$ as a result of antiangiogenic therapy. Since the large molecular weight nanoparticle ferumoxytol did not rapidly extravasate, this artifact did not influence rCBV measurements

\section{CONCLUSIONS}

For longitudinal assessment of rCBV during the course of antiangiogenic therapy, the use of intravascular contrast agents such as USPIO should be considered.

\section{TE1:2}

\section{PERFUSION CT OF BRAIN TUMORS CAN BE PERFORMED WITH 25 ML OF CONTRAST MATERIAL USING 64-DETECTOR CT}

K. TSUCHIYA, M. IMAI, M. YOSHIDA, H. TATEISHI, T. NITATORI

KYORIN UNIVERSITY, DEPARTMENT OF RADIOLOGY, TOKYO, JAPAN

\section{PURPOSE}

Perfusion imaging using CT can reportedly work as a tool to evaluate the vascularity of brain neoplasms. We evaluated the feasibility of perfusion $\mathrm{CT}$ of brain tumors on a 64-detector-row system with a contrast agent dose of $25 \mathrm{~mL}$.

METHODS

Our patient group comprised 20 consecutive patients with a preoperative brain tumor (eight with high-grade glioma, one with low-grade glioma, six with meningioma, three with brain metastasis, one with lymphoma, and one with hemangioblastoma) examined on a 64-detector-row CT. We performed perfusion CT at four sections that included the tumor using $25 \mathrm{~mL}$ of contrast agent $(300$ or $350 \mathrm{mgI} / \mathrm{mL}$ ) followed by a saline flush of $40 \mathrm{~mL}$ at a rate of $3 \mathrm{~mL} / \mathrm{sec}$. Other scanning parameters included $80 \mathrm{kV}$, $100 \mathrm{~mA}, 2 \mathrm{~mm} \times 16$ collimation, $4 \times 8 \mathrm{~mm}$ sections $(2 \mathrm{~mm} \times$ 4 stacks), and $1.5 \mathrm{sec} /$ rotation for duration of 60 seconds. Perfusion maps of cerebral blood volume (CBV), cerebral blood flow (CBF), and mean transit time were generated by the deconvolution method. They were visually assessed by two neuroradiologists using a three-point grading scale regarding vascularity. In six patients, comparative assessment with perfusion MR study was additionally done.

\section{RESULTS}

In all patients of both groups, we obtained perfusion maps that allowed assessment of tumor perfusion. Patients with high-grade glioma, meningioma, and hemangioblastoma showed hyperperfusion (sum of CBV and CBF scores was 5 or more), while one patient with low-grade glioma and one of three patients with metastasis presented hypoperfusion (sum of CBV and CBF scores was 4 or less). These patterns were compatible with findings on MR perfusion study.

\section{CONCLUSION}

Perfusion CT providing hemodynamic information of brain tumors can be performed with $25 \mathrm{~mL}$ of contrast material. 
TE1:3

\section{DIFFERENTIATION OF TUMOR RECURRENCE AND POSTTREATMENT RADIATION EFFECT: COMPARISON OF MRI COMBINED WITH PERFUSION MR/MR SPECTROSCOPY AND FDG PET}

\author{
S. KIM, S.J. KIM, H.K. LIM, C.G. CHOI
}

UNIVERSITY OF ULSAN COLLEGE OF MEDICINE, ASAN MEDICAL CENTER, SEOUL, SOUTH KOREA

\section{PURPOSE}

To compare the diagnostic performance of conventional MRI combined with perfusion-weighted imaging(PWI) and proton MR spectroscopy (MRS) with that of fluorine-18-fluorodeoxyglucose(FDG) positron emission tomography(PET) in differentiation of tumor recurrence and posttreatment radiation effect(PTRE) in brain tumors.

METHODS

This retrospective study included twenty-eight patients who underwent resection of glioma and adjuvant radiotherapy, and subsequently developed enhancing mass on follow-up MRI. Both MRI including PWI/MRS and FDG-PET were preformed in all patients. Final diagnosis was confirmed either at biopsy(n=20) or by imaging follow-up for at least 6 months $(\mathrm{n}=8)$. The maximum relative cerebral blood volume $(\mathrm{rCBV})$ and Choline/Creatine( $\mathrm{Cho} / \mathrm{Cr}$ ) ratio were measured. A neuroradiologist evaluated the conventional MRI and scored impression with four scales(1:probable PTRE, 2:possible PTRE, 3:possible recurrence, 4: probable recurrence). The same scoring system was applied to combination of conventional MRI and PWI/MRS. We attempted to define cutoff value for $\mathrm{rCBV}$, Cho/Cr ratio using ROC curve. A nuclear medicine physician evaluated PET images and scored metabolic activity of abnormality with five scales by visual comparison with contralateral normal gray and white matter. We assessed the area under the ROC curve (AUC) of conventional MRI alone and combined with PWI/MRS, and FDG PET to compare the diagnostic performance of MRI and FDG-PET, and to evaluate added value of PWI/MRS and FDG-PET.

RESULTS

The ROC curve showed that $\mathrm{rCBV}>1.5$ (sensitivity $78.9 \%$, specificity $88.9 \%$ ) and $\mathrm{Cho} / \mathrm{Cr}>4.5$ (sensitivity $52.9 \%$, specificity $77.8 \%$ ) was optimal for predicting tumor recurrence. FDG-PET had superior diagnostic performance than conventional MRI (AUC 0.833 vs 0.822, P-value $<0.005$ ). Conventional MRI combined with PWI/MRS had superior diagnostic performance than FDG-PET(AUC 0.915, P-value $<0.001$, sensitivity $82.4 \%$, specificity $88.9 \%$ ). FDG-PET did not show added value to the MRI combined with PWI (AUC 0.924 vs 0.936, P-value $<0.001)$.

CONCLUSIONS

FDG-PET had higher diagnostic performance in differentiating between tumor recurrence and PTRE than conventional MRI alone, but conventional MRI combined with PWI/MRS had higher performance than FDG-PET.

\section{TE1:4}

THE ROLE OF MAGNETIC RESONANCE SPECTROSCOPY IN EXTRAAXIAL BRAIN LESIONS

E. KAPSALAKI, I. TSOUGOS, E. KOUSI, K. FOUNTAS, I. FEZOULIDIS

UNIVERSITY HOSPITAL OF LARISSA, LARISSA, GREECE
PURPOSE

Meningiomas are the most common extraaxial brain lesions. Occasionally, differentiation between benign and malignant meningiomas as well as other dural based extraaxial lesions preoperatively may be helpful in their prompt surgical planning. The purpose of our present study is to evaluate the role of Magnetic Resonance Spectroscopy (MRS) in evaluating and differentiating between benign and malignant meningiomas and other extraaxial lesions.

METHOD AND MATERIALS

Seventeen patients with extraaxial brain lesions were prospectively examined on a 3 Tesla (Signa HDx, GE, Milwaukee, USA) MR unit. Routine brain MRIs, diffusion and perfusion imaging as well as single voxel $1 \mathrm{H}$ MR spectroscopy were performed. Voxel was centered in the middle of the lesion and the smallest possible voxel size was obtained. Post processing was performed on an external workstation (Advantage Windows 4.3, GE, Milwaukee, USA).

\section{RESULTS}

Imaging features of all brain tumors were suggestive primarily of meningiomas. The histological diagnosis of our lesions were 7 benign meningiomas, 2 malignant meningiomas, 3 metastatic lesions, 4 plasmacytomas and 1 glioma.

Perfusion MRI in meningiomas shows a rapidly perfusing lesion. MRS of meningiomas typically show marked reduction in NAA and $\mathrm{Cr}$ and an increase in Cho. In approximately $70 \%$ of the cases a detection of amino acids resonances such as elevated glutamate (Glx) and Alanine (Ala) was notable. Ala appears to be a specific marker of meningiomas and is not identified in metastatic lesions. Furthermore, an unidentified resonance around $3.8 \mathrm{ppm}$ was consistently revealed in many meningiomas, while the presence of lipids suggested tumor necrosis and the diagnosis of malignant or anaplastic meningioma. CONCLUSION

MRS can be helpful in characterizing and differentiating malignant from benign meningiomas and meningiomas from other extraaxial lesions.

\section{TE1:5}

\section{RADIOLOGIC FEATURES OF CYSTIC AND NONCYSTIC GLIOBLASTOMAS}

$\underline{\text { H. HWANG }}{ }^{1}$, SJ $\mathrm{CHOI}^{1}$, NR $\mathrm{KIM}^{2}$, SW $\mathrm{LEE}^{1}$, JH KIM ${ }^{1}$, $\mathrm{HY} \mathrm{CHOI}^{1}$, HS KIM ${ }^{1}$

${ }^{1}$ DEPARTMENT OF RADIOLOGY, GACHON UNIVERSITY GIL MEDICAL CENTER, INCHEON, SOUTH KOREA, ${ }^{2}$ DEPARTMENT OF PATHOLOGY, GACHON UNIVERSITY GIL MEDICAL CENTER, INCHEON, SOUTH KOREA

The aim of this study is to review the different radiologic features of glioblastoma multiforme (GBM) with and without cystic changes (cystic and noncystic GBM). Twenty-one cases of GBM were collected retrospectively; these tumors were pathologically confirmed as GBM by total, subtotal mass removal, or stereotactic biopsy.

Based on preoperative magnetic resonance (MR) imaging studies, tumors were classified as cystic GBM if more than $30 \%$ of their volume appeared to be liquid and the tumors maintained a smooth inner margin in the cystic wall; otherwise, they were considered to be noncystic GBM. The volumes of tumor \& cystic portions were estimated by maximum width from contrast-enhanced T1-weighted MR images. The maximum thickness of edema was considered to be the maximum width of the T2-weighted MR images. Seven cases were classified as cystic and fourteen were noncystic GBMs. There 
was a statistically significant difference in age (Mann-Whitney U test; $\mathrm{P}<0.05$ ) between the patients with cystic tumors (median, 34 years; range, 15-50 years) and those with noncystic tumors (median, 52 years; range, $37-80$ years).

Cystic GBMs had a well-defined tumor interface, less than $2 \mathrm{~cm}$ thick cystic walls and less than $1.5 \mathrm{~cm}$ thick peritumoral edema compared to the noncystic GBMs (Fisher's exact test; $\mathrm{P}<0.05$ ).

For patients with cystic GBMs, median survival time after surgery was 43.8 months. Patients with noncystic GBMs had a median survival time of 12.5 months. (log-rank test; $\mathrm{P}<0.05$ ).

Thus, the prognosis for cystic GBM was significantly better than that for noncystic GBM, possibly because cystic GBM showed comparatively little infiltration of the peritumoral brain parenchyma.

\section{TE1:6}

DIAGNOSIS OF CAVERNOUS SINUS BENIGN TUMORS BASED ON THEIR RESPONSES TO RADIATION

\author{
W. GUO ${ }^{1}, \mathrm{HC} \mathrm{CHEN}^{1}, \mathrm{HM} \mathrm{WU}^{1}, \mathrm{HC} \mathrm{PAN}^{2}$
}

${ }^{1}$ DEPARTMENT OF RADIOLOGY, TAIPEI VETERANS GENERAL HOSPITAL, TAIPEI, TAIWAN, ${ }^{2}$ NEUROLOGICAL INSTITUTE, TAIPEI VETERANS GENERAL HOSPITAL, TAIPEI, TAIWAN

\section{PURPOSE}

The current study was conducted for feasibility analysis of making a diagnosis of cavernous sinus benign tumors exclusively based on imaging by evaluating tumor response to radiation.

METHODS

227 patients ( $\mathrm{F} / \mathrm{M}=140 / 87 ; 47,14-83 \mathrm{y} / \mathrm{o})$ with tumors at cavernous sinus regions, diagnosed by imaging $+/-$ operation, and received radiosurgery by using the Gamma Knife were retrospectively reviewed. The patients were followed up regularly by MR imaging (mean 63, 5-163 months). They were 9 cavernous hemangiomas (CH), 82 meningiomas, 21 neuromas and 115 pititary tumor (PT). Loss follow up, mortality and tumor progression/no response necessitated another treatment were defined as the study endpoints of volumetry. Group comparisons were made by using the $t$ test, analysis of variance (ANOVA) for continuous data, and the Chi square test for categorical data. $\mathrm{P}$ values $<0.05$ were considered significant.

RESULTS

No statistical significance of the tumor response patterns regarding gender, age, and initial tumor volumes was found. Tumor response (with at least $65 \%$ volume reduction) after radiosurgery was found in $78 \%, 9 \%, 24 \%$, and $30 \%$, respectively, of $\mathrm{CH}$, meningiomas, neuromas and PT at the last follow-up. After radiosurgery, $\mathrm{CH}$, menigniomas and PT straight decrease in volume over time by $82.7 \%$, $26.8 \%$ and $39.1 \%$, respectively, at the last follow-up. Most neuromas showed initial tumor volume increase and gradually decrease afterwards. Temporal-wise $\mathrm{CH}$ shrunk most prompt and meningiomas responded slowest $(\mathrm{p}=0.000)$. By the end of first post-radiosurgical year all $\mathrm{CH}$ regressed with $>65 \%$ volume reduction.

CONCLUSIONS

Benign tumors at cavernous sinus regions respond differently to radiosurgery. The response patterns in tumor shrinkage serve as a clue for imaging diagnosis of these clinically diverse tumors. They are helpful for further minimizing therapeutic-relevant invasiveness, particularly in the ear that imaging-guided treatment is becomeing the trend of brain tumor management.
TE1:7

\section{USING A BLOOD POOL CONTRAST AGENT FOR MAGNETIC RESONANCE PERFUSION IMAGING IN BRAIN TUMORS WITH DISRUPTED BLOOD BRAIN BARRIER - A FEASIBILITY STUDY}

$\underline{\text { A. FÖRSCHLER }}^{1}$, A. GRAMS ${ }^{2}$, J. GEMPT $^{3}$, C. ZIMMER $^{1}$

${ }^{1}$ DEPARTMENT OF NEURORADIOLOGY, KLINIKUMRECHTS DER ISAR, MUNICH, GERMANY, ${ }^{2}$ DEPARTMENT OF DIAGNOSTIC AND INTERVENTIONAL RADIOLOGY AND NEURORADIOLOGY, ESSEN, GERMANY, ${ }^{3}$ DEPARTMENT OF NEUROSURGERY, KLINIKUMRECHTS DER ISAR, MUNICH, GERMANY

\section{PURPOSE}

Measuring the regional cerebral blood volume (CBV) using susceptibility weighted dynamic contrast enhanced magnetic resonance imaging (dMRT) is a well-established method to estimate the malignancy of brain tumors. In case of a disruption of the blood brain barrier (BBB) dMRT underestimates the CBV because of an extravasation of the contrast agent. In comparison to established contrast agents blood pool contrast agents remain in the intravascular space for a longer time period. The goal of this study was to evaluate the usability of the blood pool contrast agent gadofosveset trisodium (Vasovist, Bayer Vital) for magnetic resonance perfusion imaging. MATERIAL AND METHODS

8 patients with intracranial contrast enhancing space occupying lesions underwent dMRT two times on two consecutive days (40 dynamics, TR/ TE shifted: $17 / 25$, resolution: $1,8 \times 18, \times 4 \mathrm{~mm}^{3}$, scan time $1: 18 \mathrm{~min}$.) using two different contrast agents $(4 \mathrm{ml} / \mathrm{min}$.). Gadofosveset $(0,12 \mathrm{ml} / \mathrm{kg} \mathrm{KG})$ was compared to gadopentetat dimeglumin (Magnevist, Bayer Vital, $0,2 \mathrm{ml} / \mathrm{kg} \mathrm{KG}$ ): In healthy tissue and within the tumor the width of the bolus, the signal drop during first pass and the residual signal reduction after the bolus passage were measured.

RESULTS

All examinations revealed evaluable parameter maps with sufficiently good signal to noise ratio. The signal drop during first pass and the residual signal reduction after the bolus passage were significantly lower in gadofosveset than in gadopentetat $(p<0,05)$. The decline of the residual signal reduction within the tumor was significantly more pronounced than the decline of the signal loss during the first pass $(\mathrm{p}<0,05)$ and is therefore partially due to the reduced extravasation. The width of the bolus did not significantly differ. CONCLUSION

Despite of the smaller T2* contrast the bloodpool contrast agent gadofosveset is suitable for dMRT in case of a disrupted BBB. Further studies have to proof the validity of the CBV values achieved that way.

\section{TE1:8}

\section{THE DIFFERENTIATION OF CLASSIC MEDULLOBLASTOMAS (MB) AND MEDULLOBLASTOMA VARIANTS BASED ON MAGNETIC RESONANCE (MR) IMAGING FEATURES: A MULTICENTER STUDY}

J. FRUEHWALD-PALLAMAR ${ }^{1}$, S. PUCHNER ${ }^{1}$, A. ROSSI ${ }^{2}$,

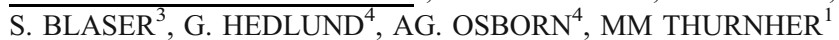

${ }^{1}$ MEDICAL UNIVERSITY VIENNA / VIENNA GENERAL HOSPITAL, VIENNA, AUSTRIA, ${ }^{2}$ GASLINI CHILDREN'S HOSPITAL GENOVA, GENOVA, ITALY, ${ }^{3}$ THE HOSPITAL FOR SICK CHILDREN, TORONTO, CANADA, ${ }^{4}$ THE UNIVERSITY OF UTAH, SCHOOL OF MEDICINE, SALT LAKE CITY, UT, USA 


\section{PURPOSE}

Anaplastic medulloblastoma and medulloblastoma with extensive nodularity (MBEN) were added as new variants in the 2007 WHO classification of tumours of the central nervous system (CNS). The purpose of this retrospective multicenter study was to define the spectrum of MRI findings in MB variants and compare those with classic MB.

\section{MATERIALS AND METHODS}

MR examinations and clinical and pathology reports from 4 institutions, for a total of 28 patients with histologically proven diagnosis of MB, were retrospectively analyzed. The location, size, margins, signal intensities, enhancement pattern, hemorrhage, calcifications, edema, diffusion characteristics, and the presence of hydrocephalus were evaluated.

RESULTS

Twenty-eight patients, 16 male 12 female (mean age, 12.6 years) were included. Of the 28 tumors, 21 were located in the region of the 4 th ventricle; 7 were found ;5/28 were MBEN; 6/28 were a desmoplastic/ nodular variant; and one was a large cell MB. Classic MB was predominantly hyperintense on T2WI (with intratumoral cysts), and hypointense on T1WI, with subtle (5/13) or marked but inhomogeneous enhancement. In MB-EN, cortex isointensity was present on T2WI, a low signal on T1WI with marked enhancement (a central scar-like pattern), and a multinodular appearance. Anaplastic MBs were hyperintense on T2WI with intense enhancement. All CMB and variants had restricted diffusion with low $\mathrm{ADC}$ values. Hemorrhage was seen in 4 patients with CM, and in one patient with large cell MB. Hydrocephalus was present in 20/28 patients.

CONCLUSION

The expanded histological spectrum, with the currently recognized $4 \mathrm{MB}$ variants, showed overlapping MRI features for classic MB and $M B$ variants. Certain MRI characteristics may favor MBEN and desmoplastic/nodular MB variants. Anaplastic and large cell MB did not show any distinctive imaging features.

\section{TE1:9}

THE ROLE OF PERFUSION-WEIGHTED CEREBRAL BLOOD VOLUME MEASUREMENTS FOR PREDICTING SHORT-TERM OUTCOME AND RECURRENT DISEASE IN GLIOMAS: COMPARISON WITH THE WHO-GRADING

\author{
S. BISDAS ${ }^{1}$, Z. RUMBOLDT ${ }^{2}$, M.V. SPAMPINATO ${ }^{2}$, P. GIGLIO ${ }^{2}$,

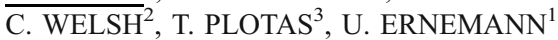

${ }^{1}$ UNIVERSITY HOSPITAL OF TÜBINGEN, TÜBINGEN, GERMANY, ${ }^{2}$ MEDICAL UNIVERSITY OF SOUTH CAROLINA, CHARLESTON, USA, ${ }^{3} \mathrm{CT}$ AND MRI PELOPONISSOU, CORINTH, GREECE

\section{PURPOSE}

To determine whether the relative cerebral volume measurements (rCBV) in gliomas may serve as a surrogate or an adjunct to histopathological WHO-grading in predicting one-year survival and recurrence.

METHODS

Thirty-five patients with astrocytomas (WHO-grade I-IV) underwent MR perfusion-weighted CBV measurements. The mean CBV value of a $6 \times 6$-pixel region of interest (ROI) and the value of a single-pixel ROI with the maximum CBV across all tumor slices were normalized relative to the normal contralateral cerebral tissue (rCBVmean, rCBVmax). Karnofsky performance score (KPS) and progression free survival (PFS) were recorded. Receiver Operating Characteristic (ROC) curves and Kaplan-Meier survival analysis were conducted separately for the CBV alone and in conjunction with WHO-grade.

\section{RESULTS}

The rCBVmean and rCBVmax in the astrocytomas were $3.4 \pm 2.7$ and $3.7 \pm 2.4$. PFS correlated with $\mathrm{rCBV}$ parameters $(\mathrm{r}=-0.64$ to -0.68 , $\mathrm{p}<0.007)$. WHO-grade correlated with $\mathrm{rCBV}$ values $(\mathrm{r}=0.67, \mathrm{p}=$ $0.0001)$. rCBVmax $>4.25$ was found to be a significant cut-off value for recurrence prediction with $78 \%$ sensitivity and $96 \%$ specificity, $(\mathrm{p}=0.0001)$; $\mathrm{rCBV} \max <3.8$ was a significant predictor for one-year survival (94\% sensitivity, $74 \%$ specificity, $\mathrm{p}=0.0002$ ). WHO-grade was also predictor for recurrence and one-year survival (equal pvalues). The relative risk for shorter PFS was 10 times higher for rCBVmax $>4.2(p=0.0006)$ and 6.5 times for WHO-grade $>$ II $(p=$ 0.045). The combined CBV-WHO-grade classification enhanced the predictive value for recurrence/progression $(\mathrm{p}<0.0001)$.

CONCLUSION

rCBV values in astrocytomas are predictive for recurrence and oneyear survival and appear to be more accurate than histopathology grading.

TE1:10

\section{DIFFERENTIATION BETWEEN HIGH-GRADE GLIOMAS AND SOLITARY METASTASES USING PERFUSION AND DIFFUSION WEIGHTED MR IMAGING}

\section{A. ZIMNY, M. GUZINSKI, P. SZEWCZYK, A. CZARNECKA, M. SASIADEK}

Department of General and Interventional Radiology and Neuroradiology, Wroclaw Medical University, Wroclaw, POLAND

\section{PURPOSE}

To evaluate the usefulness of perfusion (PWI) and diffusion weighted (DWI) MR imaging in the differentiation between primary high-grade gliomas and solitary metastases.

MATERIALS AND METHODS

Twenty nine prospective patients with histopathologically confirmed brain tumors (19 high-grade gliomas - 13 glioblastomas multiforme GBMs, 6 anaplastic astrocytomas - AAs; and 10 solitary metastases) underwent preoperative 1.5 T MR imaging including PWI and DWI. PWI sequence was performed using Dynamic Susceptibility Contrast (DSC) method (i.v. contrast $-0.3 \mathrm{mM} / \mathrm{kg}, 5 \mathrm{ml} / \mathrm{sec}$ ) and DWI included echo-planar spin-echo sequence $(b=1000 \mathrm{~mm} 2 / \mathrm{s})$. Values of maximum relative blood volume (max. $\mathrm{rCBV}$ ) and apparent diffusion coefficient (ADC) in $10-3 \mathrm{~mm} 2 / \mathrm{s}$ were calculated in the same locations within the enhancing parts of tumors and perienhancing regions.

\section{RESULTS}

Max. $\mathrm{rCBV}$ and $\mathrm{ADC}$ values in the enhancing parts of tumors and in the regions of pure edema were of no significant differences between highgrade gliomas and metastases. In all GBMs and in 5 of 6 AAs peritumoral nonenhancing areas with abnormal signal on T2 images showed also regions of significantly $(\mathrm{p}<0.001)$ increased $\mathrm{rCBV}(1.95+/-$ $0.58)$ and decreased $\mathrm{ADC}$ values $(0.88+/-0.1)$ compared to the pure edema $(\mathrm{rCBV}=0.56+/-0.09$ and $\mathrm{ADC}=1.5+/-0.2)$ indicative for areas of tumor infiltration. In all metastases no regions of tumor infiltration within edema were found.

CONCLUSIONS

PWI and DWI techniques can be used to differentiate between high-grade gliomas, especially GBM, and metastases on the basis of analysis of $\mathrm{rCBV}$ and $\mathrm{ADC}$ values in the perienhancing peritumoral regions. 
TE2

14:50-16:00 - Inflammatory, demyelinating and degenerative diseases of the brain I

TE2:1

\section{LATERALISATION OF HIPPOCAMPAL DYSFUNCTION IN MELANCHOLIC AND PSYCHOTIC MAJOR DEPRESSION? PRELIMINARY RESULTS BASED ON VOLUMETRIC ANALYSIS IN A MAGNETIC RESONANCE IMAGING STUDY}

K. VASILOPOULOU, M. PAPATHANASIOU, F. BOUFIDOU, P. OULIS, C. NIKOLAOU, L. LYKOURAS

2ND DEPARTMENT OF PSYCIATRY, ATTIKON GENERAL HOSPITAL, ATHENS, GREECE

Hypothalamic-Pituitary-Adrenal axis, pituitary gland (PG) and hippocampal function are implicated in the pathophysiology of depression in numerous studies. Only few of them have examined neuroanatomical factors in relation to biochemical factors in the subtypes of depression. In this study we examined the volumes of PG and hippocampal formation in relation to clinical variables of major depression, Hamilton Scale for Depression (HAM-D) score, Minimental State Examination (MMSE) score and plasma cortisol levels, in order to detect specific alterations of these variables for the melancholic and the psychotic subtype of major depression. Magnetic Resonance Imaging was used to measure the volumes in 31 patients with major depression, 16 with melancholic and 11 with psychotic features. We found a significant positive correlation between the volumes of the right hippocampus and MMSE score in melancholic patients and a significant negative correlation between the volumes of the left hippocampus and the volumes of PG and HAM-D score. MMSE score correlated inversely with plasma cortisol levels in the patients with psychotic depression. Our results differentiate melancholic from psychotic depression, in terms of hippocampal volume and cognitive function and suggest a possible lateralisation of hippocampal dysfunction in these subtypes of major depression.

TE2:2

CORRELATION BETWEEN APOLIPOPROTEIN EPSILON GENOTYPE AND REGIONAL GRAY MATTER VOLUME LOSS: ONE-YEAR FOLLOW-UP AFTER CONVERSION FROM MILD COGNITIVE IMPAIRMENT TO ALZHEIMER'S DISEASE

M. SPAMPINATO $^{1}$, S BISDAS $^{2}, \mathrm{~J}_{\text {MINTZER }}^{1}, \mathrm{~J} \mathrm{KOONCE}^{1}$, Z RUMBOLDT

${ }^{1}$ MEDICAL UNIVERSITY SOUTH CAROLINA, CHARLESTON, SC, USA, ${ }^{2}$ DIAGNOSTIC AND INTERVENTIONAL NEURORADIOLOGY KARLS EBERHARD UNIVERSITY, TUBINGEN, GERMANY

\section{PURPOSE}

Apolipoprotein epsilon 4 has been strongly linked with Alzheimer's disease (AD). Our goal was to examine the influence of epsilon 4 allele carrier status on the rate of regional gray matter (GM) volume loss in patients with new diagnosis of $\mathrm{AD}$ over a twelve-month period.

\section{METHODS}

Thirty subjects (19 males, mean age 74.5) with documented conversion from mild cognitive impairment $(\mathrm{MCI})$ to $\mathrm{AD}$ were divided into carriers (19 subjects) and non carriers of the epsilon 4 allele (11 subjects). These two groups were not significantly different in age, gender distribution, and cognitive profile. Two brain MRIs obtained at the time of clinical conversion from $\mathrm{MCI}$ to $\mathrm{AD}$ and twelve months after conversion were available for each subject. Volumetric magnetization prepared rapid gradient echo (MPRAGE) sequences were submitted to preprocessing (including spatial normalization, segmentation, modulation, and smoothing) using voxel-based morphometry in statistical parametric mapping (Welcome Department of Imaging Neuroscience). Smoothed modulated normalized GM maps were then submitted to statistical analysis. Comparison between longitudinal data acquired at baseline and after 12 month was conducted using paired t-test. A p-value of 0.05 (corrected for multiple comparisons) was considered significant.

\section{RESULTS}

Epsilon 4 carriers showed significant GM volume loss in the bilateral hippocampi, caudate nuclei, left parietal cortex, and right frontoinsular and temporal cortex during the first year after clinical diagnosis of AD. There were no significant changes in GM volume in non carriers of the epsilon 4 allele during the first year after conversion from $\mathrm{MCI}$ to $\mathrm{AD}$.

CONCLUSION

Prior clinical longitudinal studies have shown that epsilon 4 carrier status is associated with more rapid cognitive decline in $\mathrm{AD}$. We found that also the rate of GM atrophy in certain brain areas may be increased in epsilon 4 carriers compared to non carriers during the first year after MCI to AD conversion.

\section{TE2:3}

PAIN STIMULATION TO FACIAL STRUCTURES EVOKES ELEVATED INSULAR GLUTAMINE CONCENTRATIONS IN PATIENTS WITH TEMPOROMANDIBULAR DISORDERS (TMD) AS DEMONSTRATED BY 1H PROTON SVS MR SPECTROSCOPY

A DEEBAJAH $^{1}$, A OVERGAARD $^{2}$, G GERSTNER $^{1,5}$, E ICHESCO $^{1}$, RH GRACELY ${ }^{1,3}$, RE HARRIS $^{4}$, DJ CLAUW ${ }^{4}$, PC SUNDGREN ${ }^{2,6}$

${ }^{1}$ UNIVERSTITY OF MICHIGAN, DEPARTMENT OF BIOLOGIC AND MATERIAL SCIENCES, SCHOOL OF DENTISTRY, ANN ARBOR, MI, USA, ${ }^{2}$ DIAGNOSTIC CENTER FOR IMAGING AND FUNCTIONAL MEDICINE, UMAS, UNIVERSITY OF LUND, MALMÖ, SWEDEN, ${ }^{3}$ DEPARTMENT OF ENDODONTICS, UNIVERSITY OF NORTH CAROLINA, CHAPEL HILL, NC, USA, ${ }^{4}$ DEPARTMENT OF ANAESTHESIOLOGY, UNIVERSITY OF MICHIGAN, ANN ARBOR, MI, USA, ${ }^{5}$ DEPARTMENT OF PSYCHOLOGY, UNIVERSITY OF MICHIGAN, ANN ARBOR, MI, USA, ${ }^{6}$ DEPARTMENT OF RADIOLOGY, UNIVERSITY OF MICHIGAN, ANN ARBOR, MI, USA

\section{PURPOSE}

To test the hypothesis that glutamate (Glu), glutamine (Gln) concentrations in the insula, a sensory-processing region, is significantly increased in TMD subjects.

MATERIAL AND METHODS

Subjects: Ten patients, with inclusion criteria for TMD, and 10 age and gender matched controls (HC) with no documented TMD, acute or chronic pain were included and had general screening, psychophysical testing, and neuroimaging. 
Pain stimulation: An apparatus that is compatible with the scanner environment delivered 120 precise computer-controlled pressure applications to selected face sites to evoke pain. Direct measures of clinical symptoms was made using the Box scale and the McGill Pain Questionnaire (a) prior to the study, (b) with the subject was in the scanner before experiments begin (pre-test), and (c) after the 120 pressure applications have been performed (post-test).

Imaging protocol: The MRI protocol included standard structural images, and single voxel spectroscopy (SVS) using PRESS, TR $3000 \mathrm{~ms}$, TE $30 \mathrm{~ms}, 90$ degree flip angle, NEX 8, FOV $16 \mathrm{~cm}$, with a volume of interest (VOI) of $2 \times 2 \times 2 \mathrm{~cm}$ placed in left and right posterior insula prior and post pain testing and analyzed using commercial software (LCModel; Oakville, ON, Canada).

RESULTS

The mean concentrations of Gln, and Glu were overall higher in the TMD patients compared to $\mathrm{HC}$ both pre- and post pain testing. The Gln and the combined Glu + Gln (Glx) concentrations were significant higher in the TMD subjects in the right posterior insula compared to $\mathrm{HC}$ prior to pain testing, $\mathrm{p}=0.005$, and $\mathrm{p}=0.017$, respectively. The TMD patients had significantly higher mean pain scores for faces testing $(\mathrm{p}=0.041)$.

CONCLUSION

This preliminary prospective study suggests that the excitatory neurotransmitter glutamine might play a role in pain-related plastic changes in TMD. Future studies have to be conducted to evaluate if Gln can be an important biomarker and a useful endpoint for clinical trials in chronic pain management.

TE2:4

\section{VOXEL-BASED VOLUMETRIC ANALYSIS OF WHITE MATTER ABNORMALITY IN MILD ALZHEIMER DISEASE AND MILD COGNITIVE IMPAIRMENT USING DIFFUSION TENSOR IMAGING}

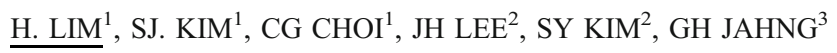

${ }^{1}$ DEPARTMENT OF RADIOLOGY AND RESEARCH INSTITUTE OF RADIOLOGY, UNIVERSITY OF ULSAN COLLEGE OF MEDICINE, ASAN MEDICAL CENTE, SEOUL, SOUTH KOREA, ${ }^{2}$ DEPARTMENT OF PSYCHIATRY, UNIVERSITY OF ULSAN COLLEGE OF MEDICINE, ASAN MEDICAL CENTER, SEOUL, SOUTH KOREA, ${ }^{3}$ DEPARTMENT OF RADIOLOGY, KYUNGHEE EAST-WEST NEO MEDICAL CENTER, KYUNGHEE UNIVERSITY, COLLEGE OF MEDICINE, SEOUL, SOUTH KOREA

\section{PURPOSE}

To evaluate white matter abnormality on diffusion tensor MR imaging in mild Alzheimer disease (AD) using statistical parametric mapping and to compare with that of mild cognitive impairment (MCI) and cognitive normal $(\mathrm{CN})$ control.

\section{MATERIALS AND METHODS}

Diffusion tensor imaging was obtained with a $1.5 \mathrm{~T}$ MR system in 28 patients with $\mathrm{AD}, 13$ with $\mathrm{MCI}$ and $26 \mathrm{CN}$ patients. Patients were selected on the bases of clinical criteria. Fractional anisotropy (FA) and trace diffusivity (D) maps were generated and processed with SPM5 to make voxel-based comparisons of FA and trace D among the three groups. RESULTS

For FA, there was significant difference between $\mathrm{AD}$ and $\mathrm{CN}$, and in $\mathrm{AD}$ group, FA was reduced in both temporal lobe white matter mainly in medial temporal area and partly in both frontal lobes. There was no significant difference in FA between $\mathrm{AD}$ and $\mathrm{MCI}$ or between MCI and $\mathrm{CN}$. For D, there was significant difference between $\mathrm{AD}$ and $\mathrm{CN}$, and in $\mathrm{AD}$ group, trace values were increased in both frontal and temporal lobes, limbic lobes, anterior cingulate, parahippocampal gyrus and thalamus. There was slight difference in D between MCI and $\mathrm{CN}$, but the areas with increased $\mathrm{D}$ were scattered in both frontal and temporal lobes. Between $\mathrm{AD}$ and MCI, there was no significant difference in D.

CONCLUSION

Voxel-based analysis revealed decreased FA and increased D in multifocal areas of both temporal and frontal lobes in mild AD compared to $\mathrm{CN}$ group. However, there was no significant difference in FA and D between $\mathrm{AD}$ and MCI. Areas with increased D were much larger than the areas of decreased FA in $\mathrm{AD}$ compared to $\mathrm{CN}$ group. DTI data can reveal white matter abnormalities between mild $\mathrm{AD}$ and $\mathrm{CN}$, but not between mild $\mathrm{AD}$ and $\mathrm{MCI}$.

\section{TE2:5}

\section{MEDIAL TEMPORAL LOBE ATROPHY SCORE: A LOCALLY DERIVED MEASURE WITH STRONG GLOBAL IMPLICATIONS}

L. KOZAK ${ }^{1}$, I GYURICZA ${ }^{2}$, T GYORKE ${ }^{3}$, L SZIDONYA ${ }^{3}$, J GYEBNAR $^{3}$, T KOVACS ${ }^{4}$, G RUDAS $^{1}$, P BARSI ${ }^{1,5}$

${ }^{1}$ SEMMELWEIS UNIVERSITY - MR RESEARCH CENTER, BUDAPEST, HUNGARY, ${ }^{2}$ STATE HEALTH CENTRE - DEPARTMENT OF RADIOLOGY, BUDAPEST, HUNGARY, ${ }^{3}$ SEMMELWEIS UNIVERSITY - DEPARTMENT OF DIAGNOSTIC RADIOLOGY AND ONCOTHERAPY, BUDAPEST, HUNGARY, ${ }^{4}$ SEMMELWEIS UNIVERSITY - DEPARTMENT OF NEUROLOGY, BUDAPEST, HUNGARY, ${ }^{5}$ SEMMELWEIS UNIVERSITY CARDIOVASCULAR CENTRE, MRI LABORATORY, BUDAPEST, HUNGARY

\section{PURPOSE}

Semi-quantitative medial temporal lobe atrophy scoring (MTAS) according to Scheltens' criteria is proven to correlate with manual hippocampus (HC) volumetry, and neuropsychology in Alzheimer disease (AD). We investigated how MTAS correlates with automated gray matter volumetry, and the Mini Mental State Examination (MMSE).

METHODS

$20 \mathrm{AD}$ patients (probable AD according to NINCDS-ADRDA), and 11 age-matched healthy controls were examined at $1.5 \mathrm{~T}$ with standard MRI protocol containing axial GRE T2*W, FLAIR, 3DMPRAGE and coronal T2W sequences, the latter with thin slices perpendicular to HC. Patients' average age was $74 \pm 11$ years and their MMSE >21 (mild dementia) at first examination. MMSE was performed at the time of MR examinations. MTAS was done bilaterally on the $\mathrm{T} 2 \mathrm{~W}$ coronal images, by expert neuroradiologist. Quantitative volumetry was performed on 3D-MPRAGE images using SPM5; it consisted of brain normalization, segmentation, gray matter parcellation according to AAL template (116 regions), and volumetric normalization to total brain volume. Group-wise comparisons and correlation analysis were performed.

\section{RESULTS}

We found strong correlations between the bilateral MTAS $(r=0.917$, $\mathrm{p}<0.001$ ), and between MTAS and MMSE (left: $\mathrm{r}=-0.5874, \mathrm{p}<$ 0.0001 ; right: $\mathrm{r}=-0.5753, \mathrm{p}<0.0001)$. MTAS showed significant progression over time (left: $\mathrm{r}=0.4384, \mathrm{p}<0.05$; right: $\mathrm{r}=0.3809, \mathrm{p}<$ 
0.05). There were strong correlations between MTAS and HC volumes (left: $r=-0.7644, p<0.0001$; right: $r=-0.7944, p<0.0001$ ), MTAS and volumes of temporal lobe parts, the insulae, the caudates, and parietal structures; and moderate correlations between MTAS and frontal, parietal, occipital regions, and the cerebellum. The total cerebrospinal fluid (CSF) volumes were also correlated with MTAS (left: $\mathrm{r}=0.4135, \mathrm{p}<0.05$; right: $\mathrm{r}=0.4026, \mathrm{p}<0.05$ ).

CONCLUSIONS

We conclude that even though MTAS is a locally derived semiquantitative measure, it provides information on global brain atrophy by being highly correlated with global loss of gray matter volume, and global increase of CSF volume. Moreover, we proved that automated volumetry methods have similar clinical relevance as MTAS.

\section{TE2:6}

\section{LEUKOARAÏOSIS AND MESIOTEMPORAL ATROPHY IN MILD COGNITIVE IMPAIRMENT}

\section{HENRY FEUGEAS, E SCHOUMAN CLAEYS}

BICHAT CLAUDE BERNARD UNIVERSITY HOSPITAL, PARIS, FRANCE

\section{PURPOSE}

There is a known relationship between extensive leukoaraïosis and mesiotemporal atrophy in older patients with mild cognitive impairment (MCI). However, this has been observed using visual rating of mesiotemporal atrophy or hippocampal measurements and it is uncertain whether this association reflects a "mixed" underlying pathology, combining microvascular disease and Alzheimer's disease (AD), or a pure microvascular mesiotemporal damage. Entorhinal atrophy may be a more specific biomarker of $\mathrm{AD}$ than previously used indicators of mesiotemporal atrophy. Thus, our purpose was to evaluate the relationship between entorhinal atrophy and leukoaraïosis in elderly MCI patients. METHODS

72 MCI patients enrolled into a longitudinal study on AD (MRI CODE) underwent an MR examination. MR analysis included a standardized and reproducible visual analysis of structural brain changes and measurements of the entorhinal cortex and intracranial areas using three dimensional MR sequences. Absolute and relative values of left and right entorhinal measurements were compared between two groups of patients, without any significant leukoaraïosis and with confluent subcortical leukoaraïosis, respectively.

RESULTS

Though these two groups of patients showed similar demographic characteristics, they did not show any difference in terms of entorhinal atrophy.

CONCLUSIONS

MCI patients with severe leukoaraïosis do not show any significant entorhinal atrophy, which supports a predominant vascular origin of mesiotemporal atrophy in this condition.

\section{TE2:7}

\section{VENTRICULAR ENLARGEMENT IN MILD COGNITIVE IMPAIRMENT}

\section{HENRY FEUGEAS, E SCHOUMAN CLAEYS}

BICHAT CLAUDE BERNARD UNIVERSITY HOSPITAL, PARIS, FRANCE

\section{PURPOSE}

Ventriculomegaly in Mild Cognitive impairment (MCI) is associated with a higher risk of progression to Alzheimer's disease (AD). However, it is unclear whether it reflects AD-related brain atrophy or non specific brain atrophy, whether it is an atrophic ventricular enlargement or a subclinical form of hydrocephalus; in other terms, it is not known whether it is related to entorhinal MR atrophy or not, whether it is related an increase or a decrease in craniospinal compliance.

METHODS

MR measurements of the entorhinal atrophy and the intracranial dynamics were compared in two groups of MCI patients from a longitudinal study on AD (the MRI CODE study); these groups differed in terms of marked ventricular enlargement but not in terms of age.

\section{RESULTS}

MCI patients with marked ventriculomegaly did not show any significant reduction in their entorhinal cortex MR measurements despite a higher frequency of progression to AD. No significant difference in terms of CSF stroke volumes, relative craniospinal compliance ratios, total cerebral blood and superficial venous flow rates, was detected between the two groups. However, marked ventricular enlargement was associated with a significant reduction in the deep venous flow rates.

CONCLUSIONS

Variable changes in entorhinal atrophy and craniospinal compliance behind ventricular enlargement suggest a non specific biomarker of brain damage in MCI; the associated reduction in deep venous flow rates may reflect deep white matter atrophy or compression, whereas the high clinical value of this non specific biomarker may result from the heterogeneity of the "Alzheimer syndrome".

\section{TE2:8}

\section{HIPPOCAMPAL ATROPHY ON 3T MRI IS A MARKER OF COGNITIVE DETERIORATION AND DEMENTIA IN PARKINSON'S DISEASE, APPLICABLE WITH AUTOMATED CLASSIFICATION PROCEDURES}

B. GOMEZ-ANSON ${ }^{1}$, O LOPEZ-MOUREL ${ }^{2}$, R ROTGER ${ }^{1}$, GC MONTE $^{3}$, J PAGONABARRAGA ${ }^{4}$, G LLEVARIA ${ }^{4}$, S KLOPPEL $^{5}$, E GRANELL $^{1}$, Y VIVES ${ }^{2}$, J RUSCALLEDA-NADAL ${ }^{1}$

${ }^{1}$ NEURORADIOLOGY, RADIOLOGY, HOSPITAL SANTA CREU I SANT PAU, BARCELONA, SPAIN, ${ }^{2}$ PIC, IFAE, UNIVERSITAT AUTONOMA, BARCELONA, SPAIN, ${ }^{3}$ FUNDACIO CLINIC/IDIBAPS/HOSPITAL CLINIC, BARCELONA, SPAIN, ${ }^{4}$ NEUROLOGY, HOSPITAL SANTA CREU I SANT PAU, BARCELONA, SPAIN, ${ }^{5}$ NEUROLOGY, FREIBURG UNIVERSITAT, FREIBURG, GERMANY

\section{PURPOSE}

Cognitive impairment and dementia is integral to Parkinson's disease (PD), and hippocampal atrophy (HA) may begin early [1,2].

\section{OBJECTIVES}

To investigate HA on $3 \mathrm{~T}$ MRI along the progression of cognitive impairment in PD. To evaluate the ability of HA to classify among patients using automated diagnostic procedures.

MATERIAL AND METHODS

Prospective study of 46 PD patients (16 CgInt, 15 MCD, 15 PDD), matched for age and education. Cognitive impairment was assessed by the Clinical Dementia Rating scale (CDR), CDR1 and DSM-IV- 
TR criteria. Hippocampal volumes (HVs) were calculated using ITKSNAP (same observer: $\mathrm{ICC}=0.93 ; \mathrm{p}=0.02$ ) on $3 \mathrm{~T}$ (Philips Intera 2.1) MRI (3DMPRAGE). Statistics included ANCOVA, correlations (Spearman's Rho), and a General Lineal Model (significance at $\mathrm{p}<0.01)$. Voxel-Based Morphometry (VBM), and the Support Vector Machine (SVM) [3] were implemented.

RESULTS

ANCOVA, with disease duration as a covariate, showed total HVs to decrease between groups (F 6.08; $\mathrm{p}<0.005$ ). Post-hoc showed right $(p=0.01)$, left $(p=0.003)$, and total HVs $(0.006)$ to decrease in PDD compared to MCI and CgInt. Two tailed bivariate correlations showed a tendency between total HVs and memory tests (Rho=0.419; $\mathrm{p}=0.006)$. VBM analysis showed decreased grey matter concentration in both hippocampi (uncorrected $\mathrm{p}<0.005$ ). SVM achieved a $70 \%$ accuracy for separating PDD from CgInt.

CONCLUSIONS

$\mathrm{HA}$ is selectively detected in the transition from MCI to dementia, and seems a potential biomarker of cognitive deterioration in PD, that may be used with automated diagnostic procedures.

REFERENCES

1) Williams-Gray $\mathrm{CH}$, et al. Brain. 2007; 130: 1787-1798.

2) Pagonabarraga J, et al. Mov Disord. 2008 May 15; 23:998-1005.

3) Klöppel S, et al. Brain. 2008 Mar;131(Pt 3):681-9. Epub 2008 Jan 17.

Funding: SERAM 07; Spanish Ministry of Health (FISS PI 07/ 0770).

\section{TE2:9}

\section{BRAIN CHANGES ON 3 T MRI AND MRS IN FRAGILE X PREMUTATION CARRIERS: EVIDENCE FOR PREFRONTAL DYSFUNCTION}

B. GOMEZ-ANSON $^{1}$, O LOPEZ-MOUREL ${ }^{2}$, J PAGONABARRAGA $^{3}$, GC $\mathrm{MONTE}^{4}, \mathrm{M} \mathrm{MILA}^{4}$, L RODRIGUEZ-REVENGA ${ }^{4}$, Y VIVES $^{2}$, J SANCHEZ-GONZALEZ ${ }^{5}$, M DEJUAN-DELAGO ${ }^{1}$, J RUSCALLEDA-NADAL ${ }^{1}$

${ }^{1}$ NEURORADIOLOGY, HOSPITAL SANTA CREU I SANT PAU, BARCELONA, SPAIN, ${ }^{2}$ PIC, IFAE, UNIVERSITAT AUTONOMA, BARCELONA, SPAIN, ${ }^{3}$ NEUROLOGY, HOSPITAL SANTA CREU I SANT PAU, BARCELONA, SPAIN, ${ }^{4}$ FUNDACIO CLINIC, IDIBAPS, HOSPITAL CLINIC, BARCELONA, SPAIN, ${ }^{5}$ PHILIPS IBERIA MEDICAL SYSTEMS, MADRID, SPAIN

\section{PURPOSE}

To search for brain changes on $3 \mathrm{~T}$ MRI and spectroscopy (MRS) in Fragile X Premutation carriers (FXpre), with or without the fragile X tremor ataxia syndrome (FXTAS), and their correlation to cognition. MATERIALS \& METHODS

Prospective study of 34 subjects (21 FXpre, aged 33-80, and 13 controls), matched for age and sex. $3 \mathrm{~T}$ (Philips Intera 2.1) MRI included 3D FLAIR, 3D MPRAGE, MRS, and SVS 1HMRS Glutamate and GABA editing technique (1). Metabolite concentrations from prefrontal (PF) and left dorsolateral (DLPF) regions were quantitated with LC Model. MRI findings (2) were assessed. Neurological and neuropsychological evaluations (executive, memory, attention, global intelligence, and conductual symptoms) were performed. Statistical analysis included group-comparisons (Student's t-test and one-way ANOVA), and regression analysis (Spearman's Rho; significance at $\mathrm{p}=0.05$ ).

RESULTS

MRI findings were: middle cerebellar peduncle, brainstem, and cerebral white matter hyperintensities, cerebellar, brainstem and cerebral atrophy. In the PF, Glutamate values were reduced in FXpre compared to controls (Fxpre: $216 \pm 88 ; \mathrm{C}: 314 \pm 130 ; \mathrm{p}=0.017$ ), similarly to $\mathrm{CrPCr}$ (Fxpre: $5.3 \pm$ 0.7; C: $5.9 \pm 0.4 ; p=0.01$ ). On neuropsychology, there was evidence of dysfunction in FXpre in prefrontal (Frontal System Behavior Scale, FrSBe: FXpre: $58.43 \pm 10.3 ; \mathrm{p}=0.08$ vs $\mathrm{C}$ : $49.33 \pm 5.4$ ) and left hippocampal (Auditory Verbal Learning Test, AVLT; Fxpre: 9.52 \pm 3.7 ; $\mathrm{p}=0.03$ vs $\mathrm{C}: 12.17 \pm 1.9)$ functions. On regression analysis, Glutamate correlated to $\mathrm{PF} \mathrm{Cr}+\mathrm{PCr}(\mathrm{Rho}=0.39 ; \mathrm{p}=0.039)$, and to neuropsychology. CONCLUSIONS

There are MRI and MRS changes already present in the PF of FXpre. These reflect impairment of related brain functions. $3 \mathrm{~T}$ MRI and MRS may provide biomarkers, which could be clinically useful. REFERENCES

1) K.W. Waddell , et al. Magnetic Resonance Imaging 2007; 25:1032-1038.

2) Rodriguez-Revenga L, et al. Mol Neurobiol. 2007 Jun;35 (3):324-8.

Funding: Spanish Ministry of Health (FISS PI 07/ 0770)

TE2:10

\section{A BLINDED RADIOLOGICAL STUDY OF MR FINDINGS IN PATHOLOGICALLY CONFIRMED PROGRESSIVE SUPRANUCLEAR PALSY (PSP), MULTIPLE SYSTEM ATROPHY (MSA) AND PARKINSON'S DISEASE (PD)}

C. MICALLEF ${ }^{1}$, L MASSEY $^{5,2}$, D PAVIOUR $^{5,2}$, S O'SULLIVAN $^{2}$, $\mathrm{J} \mathrm{HOLTON}^{2}$, T REVESZ ${ }^{2}$, D BURN ${ }^{4}, \mathrm{~A} \mathrm{LEES}^{5,2}, \mathrm{~N} \mathrm{FOX}^{3}$, H. R JAGER ${ }^{1}$

${ }^{1}$ LYSHOLM DEPT OF NEURORADIOLOGY, NHNN, UCLH, LONDON, UNITED KINGDOM, ${ }^{2}$ QUEEN SQUARE BRAIN BANK FOR NEUROLOGICAL DISORDERS, LONDON, UNITED KINGDOM, ${ }^{3}$ DEMENTIA RESEARCH GROUP, UCL INSTITUTE OF NEUROLOGY, LONDON, UNITED KINGDOM, ${ }^{4}$ CLINICAL AGEING RESEARCH UNIT, NEWCASTLE UNIVERSITY, NEWCASTLE, UNITED KINGDOM, ${ }^{5}$ SARA KOE PSP RESEARCH CENTRE, LONDON, UNITED KINGDOM

\section{OBJECTIVE}

To describe the accuracy of MRI-diagnosis and specific findings in pathologically confirmed PSP, PD and MSA.

\section{BACKGROUND}

Clinicopathological studies in PSP, MSA and PD indicate a significant misdiagnosis rate. Few MR studies are published with pathological confirmation of the clinical diagnosis.

METHODS

1.5 T MR images were available in 24 donors to the Queen Square Brain Bank with a histopathological diagnosis (14 PSP,7 MSA,3 PD) and 9 living age-matched controls. Images were reviewed by an experienced neuroradiologist, blinded to the histological and clinical diagnoses. For each study the reviewer had to decide whether the findings were highly suggestive of MSA, PSP or neither. The 
presence or absence of 37 abnormalities reported with MSA and PSP was documented systematically.

RESULTS

Mean disease duration at MR imaging of the whole pathological cohort was 6.3 yrs.

Of the PSP and MSA groups, 7/14 were correctly identified radiologically. Of the MSA group, 4/7 were correctly identified radiologically. None of the MSA cases were diagnosed as PSP and vice-versa. None of the PD and controls were diagnosed as MSA/PSP. For the correctly identified PSP and MSA cases, mean disease duration at imaging was 5.5 yrs and 6.6 yrs, respectively.

For the non-identified PSP and MSA cases, mean disease duration at imaging was 7.3 yrs and 8.5 yrs, respectively.

In the PSP cohort, the most frequent radiological findings were dilatation of the $3 \mathrm{rd}$ ventricle (13/14) followed by atrophy of the tectal plate (12/14) and cortical atrophy (10/14).

In the MSA cohort, the most frequent radiological findings were cerebellar atrophy (4/4) followed by MCP hyperintensity (3/4), putaminal atrophy (3/4) and dilataion of the $3 \mathrm{rd}$ ventricle (3/4).

CONCLUSION

Pre-mortem MRI studies allow correct identification of pathologically proven MSA/PSP only in $\sim 50 \%$ of cases but with a high specificity. Disease duration at imaging appears not a major factor for establishing a positive MRI diagnosis.

\section{TE3}

\section{6:55-17:45 - Imaging in epilepsy}

\section{TE3:1}

\section{USE OF FMRI PARADIGMS FOR THE STUDY OF MEMORY-RELATED MEDIAL TEMPORAL LOBE ACTIVATIONS: APPLICATION TO TEMPORAL LOBE EPILEPSY (TLE)}

C. ROSAZZA ${ }^{1}$, F. GHIELMETTI ${ }^{1}$, L. D'INCERTI ${ }^{1}$, L. MINATI ${ }^{1,2}$, F. DELEO ${ }^{1}$, A. RIVA ${ }^{1}$, AR. GIOVAGNOLI ${ }^{1}$, R. SPREAFICO ${ }^{1}$, MG. BRUZZONE ${ }^{1}$, F. VILLANI ${ }^{1}$

${ }^{1}$ FONDAZIONE IRCCS ISTITUTO NEUROLOGICO 'CARLO BESTA', MILANO, ITALY, ${ }^{2}$ PSYCHIATRY DEPT., BRIGHTON AND SUSSEX MEDICAL SCHOOL, BRIGHTON, UNITED KINGDOM

\section{PURPOSE}

Patients undergoing unilateral temporal lobectomy are at risk of memory impairments. The aim of the present study is to investigate whether simple memory encoding paradigms can be used in a preoperative setting to elicit robust activations in the hippocampus and parahippocampal gyrus and to determine the lateralization of verbal and non-verbal memory. We also studied the contribution of the anterior and posterior portions of the hippocampus and parahippocampal gyrus.

METHODS

The study was conducted on 16 healthy subjects and on 10 patients with medically refractory left temporal lobe epilepsy with eventrelated fMRI, using three memory encoding tasks with words, objects and faces. Hippocampus and parahippocampal gyrus have been divided into anterior and posterior. A whole-brain and a ROI-based analysis of these two structures have been performed.

\section{RESULTS}

In the control group, both second-level group analysis and ROI-based analysis showed, overall, left-lateralized activation with words, bilateral activation with objects and right-lateralized activation with faces. In particular, significant hippocampal activations were observed with all three categories of stimuli, and the head of hippocampus was generally more engaged than its body and tail (Rosazza et al., 2009). TLE patients showed more right-lateralized activations with words and with objects than controls. Moreover, also for the patients, both second-level group analysis and ROI-based analysis revealed a stronger engagement of the head of the hippocampus, irrespective of the hemisphere.

CONCLUSIONS

The use of these three undemanding memory tasks can be considered as a tool to assess the functional status of the medial temporal lobe in a preoperative setting.

TE3:2

\section{HIPPOCAMPAL MALROTATION: PATHOLOGY OR VARIATION}

$\underline{\text { S. NAIR }}{ }^{1}, \mathrm{~J}_{\text {MCLEAN }}{ }^{2}, \mathrm{~J}_{\text {MACFARLANE }}{ }^{2}, \mathrm{D}_{\text {HADLEY }}{ }^{1}$, C SANTOSH $^{1}$, J BHATTACHARYA ${ }^{1}$

${ }^{1}$ DEPARTMENT OF NEURORADIOLOGY, INSTITUTE OF NEUROSCIENCES, SOTHERN GENERAL HOSPITAL, 1345 GOVAN ROAD, GLASGOW, G51 4TF, GLASGOW, UNITED KINGDOM, ${ }^{2}$ DEPARTMENT OF CLINICAL PHYSICS, INSTITUTE OF NEUROSCIENCES, SOTHERN GENERAL HOSPITAL, 1345 GOVAN ROAD, GLASGOW, G51 4TF, GLASGOW, UNITED KINGDOM

\section{BACKGROUND}

Hippocampal malrotation (HM) is well recognised in series of patients with epilepsy. However it is sometimes seen in healthy individuals too. It is not clear whether HM is a pathological entity or a normal developmental variant of no clinical significance. There has been no previous series assessing the frequency of $\mathrm{HM}$ in normal individuals. We therefore studied and analysed 168 hippocampi in proved normal healthy volunteers with high-resolution $3 \mathrm{~T}$ MR imaging.

MATERIAL AND METHODS

Eighty four (M: F=61:23, age range 19-67 yrs, mean age $43.5 \mathrm{yrs}$ ) healthy individuals with no previous history of neurological disease, head injury or psychiatric disorder were evaluated. All underwent thorough psychological and neurological testing (SCID test, neurocognitive battery,general health questionnaire etc). All the images were acquired on a $3 \mathrm{~T}$ MR scanner. The MR imaging protocol included a 3D T1 weighted FSPGR and high resolution T2 weighted FSE imaging with sections coronal and sagittal to the plane of hippocampi and a matrix size of $512 \times 512$ zipped to $1024 \times 1024$ and FOV of $20 \times 20 \mathrm{cms}$ giving an acquired pixel size of $0.39 \times 0.39 \mathrm{~mm}$ RESULTS

$38 \%(32 / 84)$ of subjects showed HM. No significant difference in gender preponderance was seen. The HM was seen on left side in $81 \%(26 / 32)$, bilateral in $15 \%(5 / 32)$ and isolated right side in $3 \%(1 /$ 32) of subjects. The characteristic features of HM include incomplete inversion of the hippocampus, distortion of internal hippocampal architecture, an abnormal angle of the collateral sulcus, abnormal 
position and size of the fornix and an abnormal configuration of the temporal horn.

CONCLUSION

There is a spectrum of variations seen within normal hippocampal development. We conclude that HM is a feature in the normal healthy population, much commoner than previously realised, with unexpected lateralisation and is probably not related to epilepsy.

TE3:3

\section{THE USE OF TRACTOGRAPHY DERIVED \\ FROM DIFFUSION TENSOR IMAGING (DTI-TR) TO CHECK WHITE MATTER (WM) CONNECTIONS IN EPILEPTICS WITH HEMISPHEROTOMY OR WITH MALFORMATIONS OF CORTICAL DEVELOPMENT (MCD)}

P. BARSI ${ }^{1}$, A. ALTMANN ${ }^{2}$, M. HEGYI ${ }^{3}$, M. NEUWIRTH ${ }^{3}$, ZS. SIEGLER ${ }^{3}$, A. FOGARASI ${ }^{3}$, G. RUDAS ${ }^{1}$

${ }^{1}$ SEMMELWEIS UNIVERSITY, MR RESEARCH CENTRE, BUDAPEST, HUNGARY, ${ }^{2}$ ST. JÁNOS'S HOSPITAL, CHILD EPILEPSY CENTRE, BUDAPEST, HUNGARY, ${ }^{3}$ HRC BETHESDA CHILDREN'S HOSPITAL, DEPT. OF NEUROLOGY, BUDAPEST, HUNGARY

\section{PURPOSE}

To demonstrate the potential role of DTI-TR in different aspects of surgical treatment of childhood epilepsy.

METHODS

6 children (mean age $6.6+/-3.5$ yrs) were studied by the standard epilepsy MR protocol including corTSE-T2/FLAIR perpendicular to hippocampi, 3D-volume-T1 and DTI (TR/TE/ET/thickness/directions: $8307 / 60 / 63 / 2 \mathrm{~mm} / 32$ ) on $3 \mathrm{~T}$ (Philips Achieva). 3 patients were studied for possible residual interhemispheric WM connections after hemispherotomy (1 Rasmussen-encephalitis, 2 complex MCDs). 3 patients were studied for the possible cause of focal epilepsy, proven to be MCDs. The DTI-TRs were made by Philips Fibertrack program. RESULTS

Residual interhemispheric connections were determined and more clearly visualized by DTI-TR than with MRI. In 2 children of the preoperative MCD group, DTI-TR showed relative isolation of the lesion in regard to WM connections with other brain regions, probably explaining the focal nature of the seizures without a tendency for generalisation in one child, and corresponding to epileptologically successful removal of the lesion in the other one, originally supposed to have generalized or bilateral focal epilepsy. In the third case, the clinical problem of the seizure activity arising in the right frontal lobe while the complex MCD (including agenesis of the corpus callosum, bilateral frontal polymicrogyria, left porencephaly and possible open lip schizencephaly) being more severe in the left one could be explained by the scarcity of WM connections of the left frontal lobe with other brain regions while extensive connections from the right one. Homogeneous semiology of seizures in each case of the second group was also in favour of isolation with simplified routes of seizure spread.

CONCLUSIONS

DTI-TR clearly shows residual WM connections between the cerebral hemispheres after hemispherotomy. It helps to perceive the full extent of MCDs and provides useful information on their WM connections that helps surgical planning and to understand peculiar features of the epilepsy syndrome.
TE3:4

\section{SURGICALLY TREATED MESIAL SCLEROSIS: MAGNETIC RESONANCE IMAGING EVALUATION AND CLINICAL OUTCOME}

S. COSTA PEREIRA ${ }^{1}$, G. SANTOS ${ }^{1}$, O. BRITO ${ }^{1}$, F. SALES ${ }^{2}$,

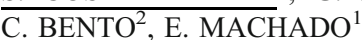

${ }^{1}$ UNIVERSITY HOSPITAL OF COIMBRA - NEURORADIOLOGY, COIMBRA, PORTUGAL ${ }^{2}$ UNIVERSITY HOSPITAL OF COIMBRA EPILEPSY UNIT, COIMBRA, PORTUGAL

\section{PURPOSE}

Magnetic resonance imaging (MRI) is an essential part of the evaluation of patients with mesial temporal sclerosis submitted to epilepsy surgery. The aim of this study was to correlate the extent of the surgical removal of the hippocampus with clinical outcome.

METHODS

We studied the surgical outcome in a group of 21 consecutive patients with medically refractory epilepsy due to mesial temporal sclerosis. Surgery consisted of anterior temporal lobectomy and amygdalohippocampectomy.

The extent of surgical removal of hippocampus was calculated using MRI, by subtracting the pre and postoperative number of consecutive $1.5 \mathrm{~mm}$-thick slices containing the hippocampus. Clinical outcomes were assessed at least one year after surgery using Engel's classification and correlated with hippocampal resection rates.

\section{RESULTS}

Average hippocampal removal was highest in class I patients (37.7\%). In class II, III and IV, average removal was of $20.7 \%, 9.8 \%$ and $5 \%$, respectively.

In class I patients $(n=13)$, we found removal rates higher than $33 \%$ in $67 \%$ of them. The lowest rate in this group was $12.5 \%$.

Class II patients $(n=4)$ presented removal rates ranging from 15 to $30 \%$.

In class III patients $(n=3)$ the highest removal rate was $14 \%$.

The single class IV patient presented a removal rate of $5 \%$.

CONCLUSIONS

In our study, a better clinical outcome was associated with higher rates of hippocampal resection, which was found to be statically significant. Clinical improvement and minimal hippocampal removal were also observed, reflecting the presence of other type of surgical variables, which were not investigated in the present study.

\section{TE3:5}

\section{HIGH-RESOLUTION MR-IMAGING OF HIPPOCAMPAL SCLEROSIS IN PATIENTS WITH FOCAL EPILEPSY AT 7 TESLA}

T. BREYER ${ }^{1}$, M.U. SCHLAMANN ${ }^{1,2}$, S. MADERWALD ${ }^{1,2}$, O. KRAFF $^{1,2}$, F. WOERMANN ${ }^{3}$, J.M. THEYSOHN ${ }^{1,2}$, A. EBNER $^{3}$, M. FORSTING ${ }^{1,2}$, M.E. LADD ${ }^{1,2}$, I. WANKE ${ }^{1,2}$

${ }^{1}$ INSTITUTE FOR DIAGNOSTIC UND INTERVENTIONAL RADIOLOGY AND NEURORADIOLOGY, ESSEN UNIVERSITY HOSPITAL, ESSEN, GERMANY, ${ }^{2}$ ERWIN L. HAHN INSTITUTE FOR MAGNETIC RESONANCE IMAGING, UNIVERSITY OF DUISBURG-ESSEN, ESSEN, GERMANY, ${ }^{3}$ MR-CENTER AND MARA CLINIC I, BETHEL EPILEPSY CENTER, BIELEFELD, GERMANY 


\section{PURPOSE}

Curative neurosurgical treatment options for patients with focal epilepsies demand accurate anatomical identification of the epileptogenic lesion by MR imaging. The most typical lesion in severe temporal epilepsies refractory to pharmacoligical treatment is an unilateral hippocampal sclerosis (HS). On the other hand a HS can be secondary to other ipsilateral epileptogenic foci. Therefore, the purpose of this study is to implement and test an adopted imaging protocol at 7 Tesla in patients with known hippocampal sclerosis focussed on maximum spatial resolution and scan time.

MATERIAL AND METHODS

Six patients with known hippocampal sclerosis were investigated with coronal T1-, T2-, T2*- and FLAIR-weighted sequences at 7 Tesla (Magnetom $7 \mathrm{~T}$, Siemens, Erlangen; 8-channel transmit/ receive-head coil, Rapid Biomedical, Würzburg). The overall measurement time did not exceed 90 minutes per patient. The depiction of the hippocampus and its internal structures (hippocampal sulcus, dentate gyrus, CA1-4) was compared to corresponding 1.5 Tesla images.

RESULTS

The maximum spatial resolution in this study was $0.2 \times 0.2 \mathrm{~mm} 2$ in $\mathrm{T} 2{ }^{*}$ - and $0.5 \times 0.5 \mathrm{~mm} 2$ in all other sequences. In contrast to 1.5 Tesla, especially the hippocampal sulcus and the dentate gyrus were best visualized in T2*-weighted images. In 5 of 6 patients the sulcus hippocampalis, the intrahippocampal CA1-4-regions could be identified. In 4 of 6 patients individual regional patterns of hippocampal atrophy are detectable. Nevertheless, strong susceptibility effects also increased artifacts and accordingly in one patient the hippocampus could not be analyzed properly.

CONCLUSION

Ultrahigh-resolution imaging at 7 Tesla is promising in epilepsy. Strong $\mathrm{T} 2 *$-contrasts together with very high spatial resolution may allow the presurgical differentiation of distinct regional patterns of atrophy. In future, this method may help improving presurgical patient selection and may increase the detection of very small intrahippocampal lesions decreasing the number of 'MR-negative' patients with severe epilepsy of temporal semiology.

\section{TE3:6}

\section{INTEGRATION OF ADVANCED STRUCTURAL AND FUNCTIONAL IMAGING TECHNIQUES IN EPILEPSY WHERE CONVENTIONAL INVESTIGATIONS ARE INCONCLUSIVE}

\author{
$\underline{\text { HM KARAKAS }^{1}}{ }^{,}$ET TALI $^{1}$, S KARAKAS $^{2}$
}

${ }^{1}$ GAZI UNIVERSITY - DEPARTMENT OF RADIOLOGY SECTION OF NEURORADIOLOGY, ANKARA, TURKEY, ${ }^{2}$ HACETTEPE UNIVERSITY - COGNITIVE PSYCHOPHYSIOLOGY RESEARCH UNIT, ANKARA, TURKEY

\section{PURPOSE}

Epilepsy, fundamentally a functional disorder, has generally been approached by neuroradiologists solely on structural findings. However, not in few cases the structural substrate is beyond the resolution of routine techniques. In many others, suspected epileptogenic foci, determined by clinical semiology and electrophysiological studies do not overlap with detected lesions, giving contradictory results in regard to lateralization. In this study, the impact of integrated use of advanced and multimodal techniques on surgical decision are presented with case-based approach.

\section{METHODS}

14 patients with ages between 12 and 36 years with equivocal clinical and electrophysiological (video-EEG) findings regarding localization and suspected dual pathologies have been extensively studied with structural MRI; FMRI to determine basic sensorimotor, higher cognitive systems, and language dominance; MRI-EEG/ERP to determine seizure loci and spatiotemporal dynamics of neurocognitive sytems; MR-tractography to evaluate degeneration of limbic circuitry and surgical proximity of possible mass lesions to major bundles; MR spectroscopy to determine comorbid disorders and hippocampal kindling; PET/CT and ictal SPECT to determine cerebral metabolism. Voxel based morphometry (VBM) was employed on structural and nuclear datasets. Complete neurologic/neuropsychologic evaluation also included neurophysiologic testing and invasive monitoring when needed.

\section{RESULTS}

FMRI and DTI showed compensatory resource allocation for primary motor cortex and primary motor speech area in two different patients. MRS detected accompanying mild cognitive impairment in a patient and bilateral hippocampal sclerosis in another. In one patient ipsilateral speech dominace with hand laterality is observed. One patient had contradictory findings in MRI/MRS and other physiological methods.

\section{CONCLUSIONS}

Evaluation of epileptic patients may be very complicated. Integrated use of advanced/multimodal techniques that combine structural and physiological data provide confident data on lateralization, hemispheric dominance, and shows allocated resources. MRS and VBM of PET and MRI data have additional advantage of showing bilaterality, whereas MRI-EEG/ERP shows widely disseminated cognitive activity of epileptic brain.

\section{TE3:7}

\section{VOXEL BASED MORPHOLOGY IN PATIENTS WITH CRYPTOGENIC OCCIPITAL EPILEPSY}

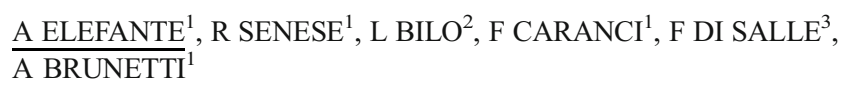

${ }^{1}$ DIAGNOSTIC IMAGING DEPT. NEURORADIOLOGY UNIVERSITY FEDERICO II, NAPOLI, ITALY, ${ }^{2}$ NEUROLOGY DEPARTMENT, UNIVERSITY FEDERICO II, NAPOLI, ITALY, ${ }^{3}$ DIAGNOSTIC IMAGING DEPT. NEURORADIOLOGY UNIVERSITY OF PISA, PISA, ITALY

\section{PURPOSE}

Voxel-based-morphometry (VBM) permits the identification of global and regional differences in brain structures. The diagnosis of cryptogenic epilepsy is based on evidence of EEG abnormalities in the absence of visually detectable abnormalities at MRI Our study was aimed at the detection of potential abnormalities at VBM analysis in patients with cryptogenic occipital epilepsy and negative MRI.

METHODS

Eleven patients (7F and $4 \mathrm{M}$, age range 14-43) with cryptogenic occipital epilepsy and 11 age-matched controls underwent MRI at 1.5 $\mathrm{T}$ and subsequent VBM analysis. MR data from T1-weighted MPRAGE sequence (TR/TE/NEX 8.8/ 4.76/2, flip angle $25^{\circ}$, matrix $512 \times 512,160$ sagittal slices slice thickness $=1 \mathrm{~mm}$; in-plane resolution $0.5 \times 0.5 \mathrm{~mm} 2$ ) were processed with $\mathrm{SPM} 2$ inspected and analyzed by BrainVoyager QX 1.10 .2 


\section{RESULTS}

VBM analysis in patients with cryptogenic occipital epilepsy showed focal areas of reduced gray matter concentration (GMC) in the occipital lobes (primary and associative visual cortices, Brodmann areas 17 and 19, respectively). Moreover, other small areas of reduced GMC were evident in the frontal cortex. The analysis revealed also areas of increased GMC in the midbrain tegmentum and in the lateral geniculate body.

CONCLUSION

With careful consideration of the known caveats of VBM analysis, our results suggest that subtle cerebral abnormalities not evident at visual analysis can be detected in occipital cryptogenic epilepsy and that structural abnormalities in focal epilepsy can extend beyond the epileptogenic focus, involving distant, functionally related, brain areas. Furthermore, the observed midbrain grey matter abnormalities could be related to an adaptation of the mesencephalic structures to the electrical stimulus of the epileptic discharge in the visual cortex.

\section{Friday, September 18, 2009 - Hesperides Room}

\section{HE1}

11:50-13:00 - Interventional - aneurysms

\section{HE1:1}

LEO PLUS TM SELF-EXPANDABLE STENT IMPLANTATION IN ENDOVASCULAR TREATMENT OF INTRACRANIAL ANEURYSMS

\section{ORAN, C. CINAR}

EGE UNIVERSITY MEDICAL SCHOOL, DEPARTMENT OF RADIOLOGY, IZMIR, TURKEY

\section{PURPOSE}

Intracranial stenting alone or in combination with endosaccular coiling is an emerging therapeutic alternative for the endovascular treatment of wide-necked or fusiform intracranial aneurysms.

METHODS

Between May 2008 and May 2009, 16 consecutive patients whose intracranial aneurysms were judged not suitable for simple coiling, have been selected for endovascular treatment by using new intracranial stent (Leo Plus, Balt, Montmorency, France). Aneurysms (two ruptured, 14 unruptured) were located on the carotid siphon $(n=8)$, the internal carotid artery bifurcation $(n=1)$, the petrous segment of internal carotid artery $(n=1)$, the anterior communicating artery $(n=1)$, the V4 segment of vertebral artery $(n=1)$, and the basilar artery trunk $(\mathrm{n}=4)$. Aneurysm diameter size varied from 5 to $40 \mathrm{~mm}$. RESULTS

Endovascular treatment was successfully performed and led to an excellent immediate 30-day outcome in all but one patient. The stent could be navigated within cerebral arteries without any exchange procedure in all but one patient. Total 22 stents were precisely positioned in all 16 cases. Stent diameter and length size varied from 3,5 to $5,5 \mathrm{~mm}$ and 25 to $75 \mathrm{~mm}$, respectively. Four patients were treated with stent implantation alone, while the remaining 12 were treated with combination of stenting and coiling. There was only one occasion of acute stent thrombosis as a technical complication. No procedure-related clinical complication occurred.

CONCLUSION

The Leo Plus stent appears useful for endovascular treatment of widenecked or fusiform intracranial aneurysms. The advantages of this intracranial self-expanding stent system are the ability of precise positioning across the aneurysm neck and the availability of wide range of diameter and length sizes.

\section{HE1:2}

\section{MANAGEMENT OF DISTAL DISSECTING BRAIN ANEURYSMS}

\section{A. MIRONOV}

CREIGHTON UNIVERSITY-DEPARTMENT OF RADIOLOGY, OMAHA, NE, USA

\section{PURPOSE}

The scope of acquired symptomatic dissecting aneurysms of the distal brain arteries includes infection (bacterial, fungal), neoplastic origin (cardiac myxoma, chorioncarcinoma), and postpartum cerebral angiopathy. The purpose of the study is to analyze the imaging characteristic and the treatment options in 10 cases from different pathogenesis with symptomatic distal dissecting aneurysms.

\section{METHODS}

Nine patients (age: 10-42 years) underwent clinical evaluations, imaging studies, and catheter angiographies. The clinical presentations included brain hemorrhage ( 7 acute, 1 chronic), seizures, and neurologic deficit. Two patients had history for choriocarcinoma; two presented a chronic medical history for cardiac myxoma; in one case there was brain hemorrhage after delivering of her third child; and in 5 patients there was no relevant previous medical history - the clinical records suggested infectious origin. In 4 cases there were pathological exams. The pathomorphological change of the vessels did not correlate always with the clinical presentation.

\section{RESULTS}

The cases with cardiac myxoma showed intermittent occlusions of large vessels with distal fusiform aneurysms; the course of disease was chronic progressive even after removal of cardiac myxoma. The patients with proven choriocarcinoma developed acute, partially recurrent hemorrhage due to multifocal distal microaneurysms. After specific treatment by chemotherapy and radiation they experienced completely recovering of aneurysmal lesions. The patient with postpartum cerebral angiopathy developed acute brain hemorrhage due to distal microaneurysm at lenticulostriate perforators, preceded by intermittent occlusion of large brain vessels. In follow-up there was a favorable clinical course with complete recovering of aneurysmal lesion. The patients with infectious aneurysms developed sudden brain hemorrhage and seizures due to large distal aneurysmal lesions. These aneurysms were considered for endovascular treatment by parent vessels occlusions.

\section{CONCLUSION}

The distal dissecting aneurysms in course of neoplastic and postpartum angiopathy tend to have favorable outcome by conservative treatment. The infectious aneurysms should be considered for endovasal treatment.

\section{HE1:3}

\section{SILK STENT - USAGE RELATED DIFFICULTIES AND HOW TO AVOID THEM}

\section{Z. KULCSAR ${ }^{1}$, I. WANKE $^{1,2}$, D. RÜFENACHT ${ }^{1}$}

${ }^{1}$ KLINIK HIRSLANDEN, NEUROZENTRUM, ZURICH, SWITZERLAND, ${ }^{2}$ UNIVERSITY HOSPITAL OF ESSEN, NEURORADIOLOGY, ESSEN, GERMANY 


\section{BACKGROUND AND PURPOSE}

Flow diverter stents provide an attractive therapeutic modality for intracranial aneurysms that are difficult to treat or pose a high regrowth rate with the current recognized methods. Our aim was to analyze our initial clinical and technical experience with the SILK stent.

MATERIALS AND METHODS

Overlooking SILK (braided, closed cell design) stent implantation cases of our own and our case-proctoring experience, altogether comprising 46 cases, we identified certain differences and technical difficulties related to the device usage as compared with regular intracranial stents. These were stratified based on the different stages of usage.

RESULTS

Three major categories were defined: 1 . antiplatelet treatment; 2 . stent size selection; 3 . stent deployment. Antiplatelet regime, prior and after stent implantation, proved to be of crucial importance. To avoid thromboembolic complications, these procedures require higher pretreatment dosage and longer term continuation of clopidogrel after implantation, as compared to the currently accepted regimen for regular intracranial stents. The selection of proper stent sizes, both in length and diameter had a significant impact on treatment success. Both over- and undersizing of stents showed potential for deployment related problems. The specific "push and pull" technique required for SILK stent deployment differs significantly from techniques used for regular stent placement. Overexertion of these may cause not proper opening of the stent, stent invagination or vessel wall injury. Provided their high mesh density, flow diverters not properly open may lead to important flow changes or thrombosis of the treated vessel.

\section{CONCLUSION}

The specific design and structural characteristics of the SILK stent require an adapted technical approach and pharmaceutical regime as compared to former intracranial stent experience. Complying with the suggested recommendations will increase success rates, whilst ignoring them may lead to deployment related problems and complications.

\section{HE1:4}

FLOW DIVERTER TREATMENT FOR TINY, UNCOILABLE, RUPTURED INTRACRANIAL ANEURYSMS: SILK STENT EXPERIENCE

\section{Z. KULCSAR ${ }^{1}$, S. WETZEL ${ }^{2}$, A. GRUBER ${ }^{3}$, I. WANKE ${ }^{1}$, D. RÜFENACHT ${ }^{1}$}

${ }^{1}$ KLINIK HIRSLANDEN, NEUROZENTRUM, ZURICH, SWITZERLAND, ${ }^{2}$ UNIVERSITY HOSPITAL, NEURORADIOLOGY, BASEL, SWITZERLAND, ${ }^{3}$ UNIVERSITY HOSPITAL, NEUROSURGERY, VIENNA, AUSTRIA

\section{BACKGROUND AND PURPOSE}

Tiny, ruptured aneurysms of less than $2 \mathrm{~mm}$ that are not amenable for endovascular coiling pose significant treatment difficulties. Since the advent of flow diverters, these new endovascular reconstruction devices provide a new treatment option for these lesions.

PATIENTS AND METHODS

Three female patients presented with acute subarachnoid hemorrhage. A tiny aneurysm of less than $2 \mathrm{~mm}$ was identified in each as responsible for bleeding. The aneurysms were located at the intradural portion of the internal carotid artery in two cases, and on the tip of the basilar artery in one patient. As a first step all patients underwent an unsuccessful endovascular treatment effort with selective coiling or regular stenting. Two to four weeks after initial bleeding patients were premedicated with antiplatelet therapy, and endovascular treatment with a SILK stent was performed; no coils were added. RESULTS

Silk stent deployment was successful in all cases. One of the aneurysms was excluded from circulation immediately after stent deployment. In the two other cases contrast material stagnation was observed in the aneurysm sac after deployment. Transient thrombotic events were observed in the case of the basilar artery aneurysm after stent deployment that resolved after administration of intra-arterial tirofiban infusion. There was no treatment related morbidity in this small series, and none of the aneurysms reruptured after SILK implantation during a clinical follow up of at least 3 months (range $3-9$ months). Imaging follow up is yet available for two cases, showing complete vessel remodelling.

CONCLUSION

In very small $(<2 \mathrm{~mm})$ aneurysms endovascular treatment is an extreme challenge but rerupture needs to be prevented. Using a Silk stent without additional coiling was efficient in preventing rerupture during the follow up. Not always providing an immediate effect, flow diverters may show a promising treatment alternative for tiny, "uncoilable" ruptured aneurysms.

\section{HE1:5}

\section{UNILATERAL AGENESIS OF THE INTERNAL CAROTID ARTERY PRESENTED AS TRANSIENT ISCHAEMIC ATTACK}

\author{
O. KIRITSI $^{1}$, K. TSITAS $^{2}, \underline{\text { A. ANASTASIOU }}{ }^{1}$
}

${ }^{1}$ HIPPOKRATION GENERAL HOSPITAL , RADIOLOGY DEPARTMENT, THESSALONIKI, GREECE, ${ }^{2}$ GENERAL HOSPITAL KOZANI, THESSALONIKI, GREECE

\section{PURPOSE}

We report a case of a patient with right internal carotid artery (ICA) agenesis and fetal type collateral circulation presented as transient ishaemic attack.

METHODS

The patient underwent $\mathrm{CT}$ and MR imaging of the brain and MR angiography of the carotid system and the brain vessels.

\section{RESULTS}

CT scans at skull base level with bone settings showed absence of the right carotid canal. MR imaging of the brain revealed signal void of the intracranial portion of the right ICA. Source image of a 3D-TOF MRA of the cerebral arteries showed flow within the left ICA and the basilar artery; the right ICA is not discernible. A maximum intensity projection reconstruction confirmed the agenesis of the right ICA, with the right middle cerebral artery fed through a dilated posterior communicating artery $(\mathrm{PCoA})$ and the right anterior cerebral artery supplied by the anterior communicating artery (ACoA) (fetal type of collateral flow). A maximum intensity projection reconstruction of the extracranial portion of the carotid system confirmed the agenesis of the right ICA with the right carotid bifurcation not identified. The vertebral arteries were dilated.

CONCLUSIONS

$\mathrm{CT}$ is the ideal imaging modality to study the carotid canal in cases of dysgenesis of the ICA. MR angiography has been the most extensively used tool to investigate patients with dysgenesis of the ICA. If enlarged anastomotic vessels can be detected on MRI or MRA, the diagnosis of ICA dysgenesis is almost definitive. In conclusion, in patients with agenesis of the ICA non invasive imaging techniques are currently the mainstay of diagnosis. 
HE1:6

\section{ANIMAL EXPERIMENTAL APPLICATION OF A NEW SELF-EXPANDING STENT IN THE ENDOVASCULAR THERAPY OF SIDE-WALL ANEURYSMS}

\author{
M. SCHUMACHER ${ }^{1}$, A. KEULER $^{1}$, K. FÖRSTER ${ }^{2}$, W. MAILÄNDER $^{3}$, \\ F. REQUEJO ${ }^{4}$
}

${ }^{1}$ UNIVERSITY HOSPITAL FERIBURG, DEP. OF NEURORADIOLOGY, FREIBURG, GERMANY, ${ }^{2}$ UNIVERSITY HOSPITAL FERIBURG, DEP. HEART SURGERY, FREIBURG, GERMANY, ${ }^{3}$ ACANDIS, PFORZHEIM, GERMANY, ${ }^{4}$ NATIONAL PEDIATRIC HOSPITAL J P GARRAHAM, BUENOS AIRES, ARGENTINA

\section{INTRODUCTION}

Free coiling or coiling with temporary balloon protection or protection by means of a stent positioned in a carrier vessel has been used thus far for endoluminal elimination of side-wall aneurysms. We are presenting a new stent system and the first in vitro and animalexperimental studies performed on the mini-pig to evaluate the application characteristics, hemodynamic influence on the vessel and aneurysm, the passability with coil catheters through the stent mesh and the biological changes in the vessel and the experimental aneurysm.

MATERIAL AND METHOD

The flexibility and radial strength of the self-expanding stent were tested in vitro. Stents were placed over 14 surgically-constructed sidewall aneurysms in mini-pigs and their placement and release behavior and the passability through the stent strut analyzed. The stent systems under investigation were implanted 2-3 weeks after aneurysm construction. Angiographic controls were made after $2(n=4), 4(n=$ 4) and $6(n=6)$ months, and finally preparations of the stent-bearing vessels were harvested for histological examination.

RESULTS, DISCUSSION AND CONCLUSION

In vitro, the stents showed high flexibility and could be positioned even through curves without creasing. The radial strength was comparable to current standard products despite the fine-mesh structure.

The in-vivo trials in mini-pigs showed reliable initial placement, navigability and curve flexibility. Moreover, there was significant flow canalization in the carrier vessel and clearly reduced flow into the aneurismal sack. Secondary coiling with probing of a microcatheter through the stent mesh could be performed without problems.

The angiographic long-term results, histological analyses and resultant conclusions of the study, which is still running, will be presented in September 2009.

\section{HE1:7}

\section{RECONSTRUCTIVE ENDOVASCULAR TREATMENT OF COMPLEX INTRACRANIAL ANEURYSM WITH FLOW DIVERTER SILK: PRELIMINARY EXPERIENCE}

\section{K. KADZIOLKA, E. LUIS DE SOUZA, L. ESTRADE, A. LEAUTAUD, L. PIEROT}

CHU REIMS, REIMS, FRANCE

\section{BACKGROUND AND PURPOSE}

We report our experience with Flow Diverter Silk for reconstructive endovascular treatment (EVT) of complex intracranial aneurysms.
PATIENTS AND METHOD

A retrospective review of 6 consecutive patients with intracranial aneurysm who were treated with stent Silk at our institution. We treated 3 saccular and 3 fusiform aneurysm. In 2 cases previous conventional EVT failed. The aneurysm was located at the internal carotid artery(3), anterior communicating artery(1), vertebral artery(2). All patients are followed up with MR and DSA at 3-12 months following treatment. RESULTS

Stent deployment was possible in all cases. In one case we noticed the narrowing of stent lumen as the result of stent twist in the arterial curve during deployment and positioning, with no clinical sequel observed so far. Endovascular treatment was well tolerated. Mortality was $0 \%$. There was no significant morbidity. None of the patients experienced any additional ischemic or hemorrhagic events during procedure and follow up period. CONCLUSION

Endovascular reconstructive treatment with use of Flow Diverter Silk offers a promising and safe therapeutic option for fusiform and giant aneurysm. Although initial clinical and radiological results are favorable, further studies are needed to evaluate the long-term clinical and radiological outcome: vessel patency and aneurysm occlusion rate.

\section{HE1:8}

COMBINED TREATMENT WITH STENTING AND COILING FOR CEREBRAL COMPLEX ANEURYSM: PRELIMINARY EXPERIENCE ABOUT 20 ANEURYSMS TREATED BY NEWS GENERATIONS INTRACRANIAL STENTS

\author{
M. MUTO, G. GUARNIERI, G. AMBROSANIO, P. VASSALLO, \\ A. LAVANGA
}

NEURORADIOLOGY SERVICE CARDARELLI HOSPITAL, NAPLES, ITALY

\section{PURPOSE}

To illustrate our preliminary experience about the combined treatment of stenting and coiling for complex cerebral aneurysm(AA) by news stents(Enterprise ${ }^{\circledR}$, Leo Plus ${ }^{\circledR}$, Solitare ${ }^{\circledR}$, Wingspan ${ }^{\circledR}$, Silk $\left.^{\circledR}\right)$.

MATERIAL AND METHODS

18 patients, 20 AA,were treated by stenting and coiling. Same pts. were affected by sacciform wide-necked partially thrombosed aneurysms, others by fusiforms. 6 ruptured AA were treated on early treatment, while others 14 on election's day. For 4/20 coiling was performed by Jailing technique and in 3 cases also a remodelling technique was performed. Pts with ruptured AA were previously administrated with heparin's protocol during and post-treatment more ASA $(500 \mathrm{mg})$ after stenting. Pts with unruptured AA were previously administrated with plavix for 7 days before. Postintervention medical therapy was plavix and aspirin for 5 months, then aspirin(100 mg).MRA and DSA at 6-12 months were performed RESULTS

Treatment was successfully performed. The stent could be navigated within cerebral arteries without any exchange procedure, and thanks to its retractability, it was precisely positioned. No procedure-related complication occurred. Complete occlusion aneurysm was observed in 14/20 AA, partial occlusion with residual sac in 2/20.At 4 months collect's rest was observed in $4 / 20$ with a increase of residual sac at one year in one case,treated by coiling. At 1 year,MRA showed reduction of the rest in one case and a stable collect' rest in other one. CONCLUSIONS

Stenting + coiling for sacciform wide-necked, or fusiform aneurysms is safe procedure without complication. Medical-therapy pre-post procedure associated to follow-up are necessary to establish occlusion rate. 
HE1:9

BLOOD BLISTER-LIKE ANEURYSMS

OF THE SUPRACLINOID INTERNAL CAROTID ARTERY: CLINICAL, ANGIOGRAPHIC AND THERAPEUTIC ASPECTS

$\underline{\text { A. BIONDI }^{1}}$, S. PESCHILLO $^{2}$, B DAUMAS-DUPORT $^{3}, \mathrm{H} \mathrm{DESAL}^{3}$

${ }^{1}$ PITIÉ-SALPÊTRIÈRE HOSPITAL-DEPARTMENT OF NEURORADIOLOGY, PARIS, FRANCE, ${ }^{2}$ LA SAPIENZA UNIVERSITYDEPARTMENT OF NEUROSURGERY, ROME, ITALY, ${ }^{3}$ GUILLAUME ET RENÉ LAENNEC HOSPITAL-DEPARTMENT OF NEURORADIOLOGY, NANTES, FRANCE

\section{PURPOSE}

Blood Blister-Like (BBL) Aneurysms of the supraclinoid Internal Carotid Artery (ICA) are rare and extremely dangerous lesions. According to pathological studies, these aneurysms seem to be dissecting in origin. The purpose of our study was to analyze the angiographic findings, treatment and outcome in these lesions.

\section{METHODS}

14 patients presenting with subarachnoid hemorrhage due to a BBL aneurysm were included in the study. There were 12 women and 2 men ranging in age from 20 to 67 years (mean age: 41.5 ys.). Eight patients were treated by endovascular approach (coiling in 1 patient, ballon-assisted coiling in 3, stenting/coiling in 4), 4 patients were treated by surgery and in 2 patients the endovascular treatment was performed after failure of surgery. In 3 patients, repeated angiographies showed changes of the aneurysm morphology .

RESULTS

Good clinical and anatomic results were obtained in 6 patients (endovascular treatment in 4 and surgical in 2). Good clinical outcome was observed in 2 patients despite residual lesion. Mild/ poor clinical outcome in 3 patients. Three patients died. In 2 patients, angiography after treatment ( 1 endovascular $/ 1$ surgical) showed progression of dissecting phenomena.

CONCLUSION

The optimum treatment of BBL aneurysms is still not known. Despite different therapeutic strategies, these lesions are often associated with high morbidity and mortality rates. Limitations of the endovascular treatment, including stenting and parent artery occlusion, are also due to acute hemorrhagic presentation. Better understanding and careful analysis of these lesions is needed in order to improve clinical and angiographic results.

\section{HE2}

14:50-16:00 - Interventional - aneurysms and AVMs

\section{HE2:1}

CLINICAL AND ANGIOGRAPHIC OUTCOMES FOLLOWING BALLOON ANGIOPLASTY AND STENTING OF VENOUS SINUS OCCLUSION COUPLED WITH DURAL ARTERIOVENOUS FISTULAS

H. TAJIRI, T. MORI, T. IWATA, T. UESUGI, M. NAKAZAKI

SHONAN KAMAKURA GENERAL HOSPITAL, KAMAKURA, JAPAN
PURPOSE

The purpose of our retrospective study is to investigate the feasibility, safety, effectiveness and outcome of balloon angioplasty and stenting of venous sinus occlusion coupled with dural arteriovenous fistulas (DAVFs).

METHOD

Inclusion criteria for analysis were patients (1) who were admitted to our institution from January 2008 to March 2009, (2) who presented some neurological symptoms, (3) with venous sinus occlusion coupled with DAVFs displayed on angiograms, (4) who underwent balloon angioplasty and/or stenting of venous sinus occlusion. Procedural success, complications, clinical symptoms, 3-months angiographic and clinical outcomes were investigated.

\section{RESULT}

During the study period, five patients were included for analysis. Cerebral angiography showed the transverse-sigmoid (T-S) sinus occlusion in three cases and inferior petrous sinus (IPS) occlusion in two cases. Venous sinus occlusion was recanalized successfully in 5 cases. Venous sinus stenting was performed in four cases and balloon angioplasty alone in one case. Successful recanalization immediately diminished reflux into cerebral cortical or deep veins from venous sinus and venous sinuses drained antegradely into the internal jugular vein. Neurological symptoms were improved. No procedural complications occurred. No neurological symptoms have recurred for 3 months after procedures. Three of the five patients underwent follow-up angiography at 3 months, demonstrating that stent thrombosis and retrograde drainage into cerebral veins recurred in one case and sinuses remained to drain retrogradely in two cases.

\section{CONCLUSION}

Successful balloon angioplasty and/or stenting of venous sinus occlusion coupled with DAVFs normalized cerebral venous drainage and improved neurological symptoms immediately. However, stent thrombosis and persistent retrograde drainage limits may limit long-term outcome.

HE2:2

\section{BRAIN AVM TREATMENT BY TRANSMENINGEAL APPROACH}

\section{S. SALEME, C. CRUSIUS, J. THERON, P. COURTHEOUX}

CHU DE CAEN - DEPARTMENT OF NEURADIOLOGY, CAEN, FRANCE

\section{PURPOSE}

We report our experience in the treatment of brain AVM using the transmeningeal approach whenever present.

METHODS

From January 2008 to March 2009 seven patients with brain AVM have been treated by Onyx using the meningeal anastomosis as the first approach. This recruitement of meningeal branches is searched for during all BAVM angiographic exploration.

RESULTS

We achieved complete exclusion of the nidus uniquely from a meningeal brach injection in two cases. In the other 5 cases, even though we couldn't reach a complete exclusion, the meningeal approach allowed the injection of a large quantity of Onyx. No complication was observed. CONCLUSION

In our opinion, the transmeningeal approach allows the diffusion of Onyx into the nidus. We find this approach particularly interesting in cases of brain AVM with arterial supply en passage. 
HE2:3

IMMEDIATE ANATOMICAL RESULTS

AFTER THE ENDOVASCULAR TREATMENT

OF UNRUPTURED INTRACRANIAL ANEURYSMS: ANALYSIS OF THE ATENA SERIES

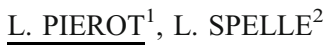

${ }^{1} \mathrm{CHU}$ REIMS, REIMS, FRANCE, ${ }^{2} \mathrm{CHU}$ TOULOUSE, TOULOUSE, FRANCE

\section{PURPOSE}

This study aimed to assess the efficacy of endovascular treatment for unruptured intracranial aneurysms in light of immediate postoperative anatomical results in a prospective, multicenter study (ATENA).

\section{MATERIALS AND METHODS}

Postoperative anatomical results from digital subtraction angiography were evaluated with the Montreal scale by the treating physician and by two anonymous, independent, experienced neuroradiologists.

RESULTS

The analysis included 622 patients (449 females, 173 males; age: $22-$ 83 years, mean: $51.2+/-11.3$ ) harboring 694 aneurysms. Evaluation of the postoperative anatomical results by the two independent reviewers indicated total occlusions in 437 (63.0\%), neck remnants in 156 $(22.5 \%)$, and aneurysm remnants in $101(14.6 \%)$ aneurysms. Several factors favorably affected the quality of aneurysm occlusion with treatment, including patient age $(<65$ years old; $\mathrm{p}<0.0001)$, aneurysm

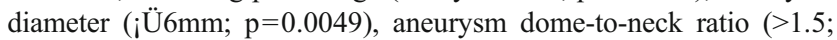
$\mathrm{p}=0.0388$ ); and endovascular technique (coiling or remodelling compared to stenting; $\mathrm{p}=0.0001$ ).

CONCLUSIONS

The endovascular treatment of unruptured aneurysms provided satisfactory postoperative occlusion rates, with a high percentage of complete occlusion or neck remnants $(85.4 \%)$. Postoperative anatomical results were significantly affected by aneurysm size and neck size, but not aneurysm location.

\section{HE2:4}

\section{IMMEDIATE ANATOMICAL RESULTS AFTER THE ENDOVASCULAR TREATMENT OF RUPTURED INTRACRANIAL ANEURYSMS: COMPARISON OF RESULTS WITH GDC AND MATRIX COILS IN CLARITY SERIES}

L. PIEROT ${ }^{1}$, C. COGNARD ${ }^{2}$, R. ANXIONNAT ${ }^{3}$, F. RICOLFI $^{4}$, AND CLARITY INVESTIGATORS

${ }^{1}$ CHU REIMS, REIMS, FRANCE, ${ }^{2} \mathrm{CHU}$ TOULOUSE, TOULOUSE, FRANCE, ${ }^{3} \mathrm{CHU}$ NANCY, NANCY, FRANCE, ${ }^{4} \mathrm{CHU}$ DIJON, DIJON, FRANCE

\section{PURPOSE}

To compare the quality of immediate anatomical results after the endovascular treatment of ruptured aneurysms using GDC and Matrix coils in CLARITY series.

METHODS

Postoperative anatomical results were evaluated on DSA, anonymously and independently by two experienced neuroradiologists. Two different scales were used: the Montreal scale and a new scale specifically designed for the present study (Clarity scale).

RESULTS

401 aneurysms were treated using GDC coils and 373 using Matrix coils. Immediate anatomical results (Montreal scale) were not significantly different with GDC or Matrix coils. In GDC group, result was complete occlusion for 197 aneurysms (49.1\%), neck remnant for 155 aneurysms (38.7\%), and aneurysm remnant for 49 aneurysms (12.2\%). In Matrix group, result was complete occlusion for 168 aneurysms (44.9\%), neck remnant for 171 aneurysms (45.7\%), and aneurysm remnant for 35 aneurysms (9.4\%). Similar results were obtained using Clarity scale.

The factors affecting the quality of aneurismal occlusion have been studied in both GDC and Matrix groups.

CONCLUSIONS

The postoperative occlusion after endovascular treatment of ruptured aneurysms is satisfying with a high percentage of complete occlusion or neck remnant in both GDC $(87.8 \%)$ and Matrix $(90.6 \%)$ groups.

\section{HE2:5}

\section{CLARITY STUDY: COMPARISON OF CLINICAL RESULTS OF THE ENDOVASCULAR TREATMENT OF RUPTURED ANEURYSMS USING GDC AND MATRIX COILS}

L. PIEROT $^{1}$, C. COGNARD ${ }^{2}$, R. ANXIONNAT ${ }^{3}$, F. RICOLFI $^{4}$, AND CLARITY INVESTIGATORS

${ }^{1}$ CHU REIMS, REIMS, FRANCE, ${ }^{2} \mathrm{CHU}$ TOULOUSE, TOULOUSE, FRANCE, ${ }^{3} \mathrm{CHU}$ NANCY, NANCY, FRANCE, ${ }^{4} \mathrm{CHU}$ DIJON, DIJON, FRANCE

\section{PURPOSE}

To evaluate the clinical results of the endovascular treatment of ruptured intracranial aneurysms using GDC and Matrix coils.

\section{MATERIALS AND METHODS}

A prospective, multicenter registry was conducted in France from October 2006 to June 2007 in 19 neurointerventional centers to compare the endovascular treatment of ruptured aneurysms with GDC and Matrix coils. 405 patients were treated with GDC coils and 377 with Matrix coils.

\section{RESULTS}

Endovascular treatment failed in $3 / 405$ cases $(0.7 \%)$ in GDC group and in $2 / 377$ cases $(0.5 \%)$ in Matrix group. Adverse events related to the treatment were encountered in $71 / 405$ patients $(17.5 \%)$ in GDC group and in 68/377 patients (18.0\%) in Matrix group. Thromboembolic events were encountered in 54/405 patients (13.3\%) in GDC group and $45 / 377$ patients $(11.9 \%)$ in Matrix group, intraoperative rupture in 15/405 patients (3.7\%) in GDC group and 19/377 patients $(5.0 \%)$ in Matrix group, and early rebleeding in $2 / 405$ patients $(0.5 \%)$ in GDC group and 4/377 (1.1\%) in Matrix group. Finally morbidity and mortality to the treatment were respectively $4.0 \%(16 / 405)$ and $1.5 \%(6 / 405)$ in GDC group and 4.0\% (15/377) and 1.3\% (5/377) in Matrix group.

\section{CONCLUSION}

Clarity study demonstrates that the immediate safety of the endovascular treatment of ruptured intracranial aneurysms using GDC and Matrix coils is similar with low morbidity and mortality with both types of coils. 
HE2:6

\section{TRANS-ORBITAL EMBOLIZATION OF RECURRENT OR RESIDUAL TRAUMATIC CAROTID CAVERNOUS FISTULAS}

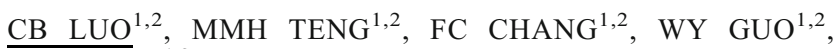
$\overline{\mathrm{CY} \mathrm{CHANG}}^{1,2}$

${ }^{1}$ DEPARTMENT OF RADIOLOGY, TAIPEI VETERANS GENERAL HOSPITAL, TAIPEI, TAIWAN, ${ }^{2}$ DEPARTMENT OF RADIOLOGY, NATIONAL YANG-MING UNIVERSITY SCHOOL OF MEDICINE, TAIPEI, TAIWAN

\section{PURPOSE}

Endovascular embolization of traumatic carotid-cavernous fistulas (TCCFs) has become an optimal treatment with promising results. However, Endovascular management of recurrent or residual TCCFs remains a challenge because the access route to the fistulae maybe blocked by previous deposited embolic materials. The purpose of this study is to present our experiences of trans-orbital embolization of recurrent and residual TCCFs after endovascular or surgical management.

METHODS

Over a 10-year period, a total of 36 patients with recurrent or residual TCCFs were referred for embolization. Among these, 15 patients $(10$ men and 5 women, mean age: 36 years) were treated by trans-orbital approach with direct puncture of the cavernous sinus or ophthalmic vein with deposition of embolic materials into fistula/cavernous sinus because failure to access the fistula by trans-vascular route. Six residual TCCFs occurred after coil embolization (4) or the balloons detached $(n=2)$; while 9 recurrent TCCFs were found after surgical management $(n=6)$ or coil embolization $(n=3)$. Trans-orbital embolization involved coil and liquid adhesives in 10, coils alone in 5 . RESULTS

All recurrent or residual TCCFs were successfully occluded by transorbital approach. There was no significant procedural-related complication such as subarachnoid hemorrhage, injury of eyeball, optic nerve or massive intra-orbital hemorrhage leading to blindness. Ten patients had minor orbital hemorrhage with spontaneous absorption within two weeks. Two had transient diplopia and gradually relief within 6 months. There was no recurrent or residual fistula in an average of 16-month follow up. CONCLUSIONS

Trans-orbital embolization of the recurrent or residual TCCFs is an alternative, particularly in those TCCFs failed to access by transvascular route. It was proved feasible, safe and efficient in these limited numbers of cases.

HE2:7

COMBINED TRANSARTERIAL AND TRANSVENOUS ENDOVASCULAR TREATMENT WITH USE OF ONYX AND COILS OF COMPLEX DURAL ARTERIOVENOUS FISTULAS :A CASE SERIES REPORT

E. DE SOUZA, K. KADZIOLKA, L. ESTRADE, A. LEAUTAUD, L. PIEROT

\section{CHU REIMS DEPARTMENT OF RADIOLOGY, REIMS, FRANCE}

\section{BACKGROUND}

Treatment of complex dural arteriovenous fistulas (DAVF) is usually made by a transarterial approach with Onyx injection. However, in some complicated cases, complete occlusion via transarterial approach might not be achieved and the transvenous approach with use Coils and Onyx is mandatory for the completion of treatment.

\section{MATERIALS AND METHOD}

We present retrospective analysis of 3 consecutive patients with intracranial complex DAVFs who were treated using combined technique with Onyx via transarterial microcatheterization and a combination of detachable coils and Onyx via transvenous approach. RESULTS

A total of 4 procedures were performed in 3 patients. In 2 cases transarterial and transvenous microcatheterization were performed at the same session, in one case transarterial approaches was performed as a first therapeutic option and then was completed in second time via transvenous approach. In two cases with simultaneous combined approach the complete resolution of the DAVFs on immediate posttreatment angiography was achieved. Patient having uncompleted treatment after transarterial microcatheterization was reembolized via transvenous combination of Onyx and coils with complete occlusion of the fistula. There was no significant morbidity or mortality. CONCLUSION

In our small series experience, the combined simultaneous transarterial and transvenous endovascular treatment of complex DAVFs with Onyx and Coils is feasible, safe, and very effective.

\section{HE2:8}

\section{INTRACRANIAL ANEURYSMS TREATED BY STENT-ASSISTED EMBOLIZATION. EVALUATION OF THE PROCEDURE SAFETY USING 3 TESLA DIFFUSION-WEIGHTED MR IMAGING}

A. BIONDI, M. MEHRPOUR, A. DRIER, N. SOUROUR, B. JEAN, F. DI MARIA, D. DORMONT

PITIÉ-SALPÊTRIÈRE HOSPITAL-DEPARTMENT OF NEURORADIOLOGY, PARIS, FRANCE

\section{PURPOSE}

To evaluate the frequency of silent thromboembolic events associated with stent-assisted endovascular procedures of intracranial aneurysms using 3 Tesla ( $3 \mathrm{~T}$ ) diffusion-weighted (DW) MR imaging.

METHODS

A consecutive and prospective series of twenty-five patients with aneurysms treated with stent-assisted coil placement (22 cases) or stenting alone (3 cases) was included. Stents used were 16 Neuroform3, 2 Enterprise and 7 Silk. In order to assess the result of the stent-assisted procedure, a 3 T MR study with our standard stroke protocol (DW, T2*, Flair and 3D TOF MRA) is performed from 24 to 72 hours after the treatment in patients without clinical complications. Parameters of the DWI were: $5 \mathrm{~mm}$ slices thickness, a $280 \times 210 \mathrm{~mm}$ FOV, $160 \times 128$ matrix, $\mathrm{TE}=60.8 \mathrm{~ms}, \mathrm{TR}=7000 \mathrm{~ms}$ and $\mathrm{b}$ factor $1000 \mathrm{~s} / \mathrm{mm} 2$. Two neuroradiologists independently reviewed MR studies. Diagnosis of procedurerelated infarctions was based on visualization of hyperintense area on DWIs, confirmed on ADC maps. Small hyperintensity with normal ADC were also rated as ischemic lesions since diminution of ADC in small lesions can be missed on ADC maps because of partial volume effect. RESULTS

Embolic lesions were noted on the DW images of 5 of 25 patients (20\%). Four patients had one/two lesions located ipsilateral to the side of the aneurysm and one patients had multiple ones. No lesions were observed in 6 cases treated with balloon-assisted coil placement before the deployment of the stent. 


\section{CONCLUSION}

With a meticulous endovascular procedure, the additional use of stents in treating intracranial aneurysms does not appear to increase the frequency of silent thromboembolic events even on a 3 T MR unit allowing higher resolution DW images.

\section{HE2:9}

\section{ENDOVASCULAR TREATMENT OF SYMPTOMATIC INTRACRANIAL DURAL FISTULAE WITH ONIX}

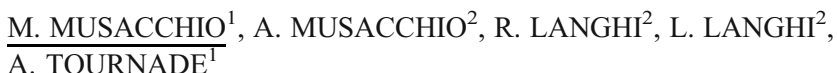

${ }^{1}$ HÔPITAUXCIVILS DE COLMAR - NEURORADIOLOGY, COLMAR, FRANCE, ${ }^{2}$ SANATORIO SANTA FE - NEURORADIOLOGY, SANTA FE, ARGENTINA

\section{PURPOSE}

To assess feasibility and efficacy of endovascular treatment of symptomatic intracranial dural fistulae using Onix.

\section{METHODS}

3 patients ( 2 females, 1 male), aged from 43 to 57 years, presented with symptomatic intracranial dural fistulae (2 intracranial haemorrhages, 1 venous thrombosis). Admission $\mathrm{CT}$ scan showed subarachnoideal haemorrhage in 2 cases, and left cerebellar oedema in one. Cerebral angiography demonstrated multipedicular fistulae, 2 of them draining into cerebellar cortical veins and one into the right basal vein of Rosenthal. 1 patient underwent 2 prior endovascular treatments allowing incomplete devascularisation of the fistula. Endovascular procedures were performed under general anaesthesia (1 case) or neuroleptoanalgesia ( 2 cases), with intravenous heparin (unique bolus, $50 \mathrm{IU} / \mathrm{kg}$ ).

RESULTS

Embolization was realized via a single meningeal feeder. Even if positioning of the microcatheter into the shunt wasn't possible due to fistulous anatomy, proximal injection of Onix into the arterial pedicle allowed occlusion of the fistulous vein, distally situated, and all its arterial feeders. Complete exclusion of fistula was achieved in 1 session in 2 cases, and in 2 sessions in one patient (middle line topography fistula, with bilateral vascularisation). No complications were observed in peroperative period. Patients were asymptomatic during clinical follow-up. No revascularisation was detected in late angiographic control. CONCLUSION:

Endovascular treatment of intracranial dural fistulae using Onix is feasible, allowing exclusion of the shunt, even in complex, multipedicular malformations. Long-distance angiographic follow-up is mandatory in order to detect eventual revascularisation.

\section{HE3}

16:55-17:45 - Interventional - stroke I

HE3:1

PREDICTIVE FACTORS FOR UNSUCCESSFUL RECANALIZATION OF ENDOVASCULAR TREATMENT FOR BASILAR ARTERY OCCLUSION IN HYPERACUTE ISCHEMIC STROKE PATIENTS

\section{H. TAJIRI, T. MORI, T. IWATA, T. UESUGI, M. NAKAZAKI}

SHONAN KAMAKURA GENERAL HOSPITAL, KAMAKURA, JAPAN

\section{PURPOSE}

The purpose of our retrospective study is to find predictive factors for unsuccessful endovascular recanalization of basilar artery occlusion in hyperacute ischemic stroke patients.

METHODS

Inclusion criteria for retrospective analysis were patients as follows, (1)study period was from 2004 to 2008, (2)who were admitted to our institution within 24 hours, (3)who were diagnosed BAO by emergency MRA(eMRA) which causes serious neurological symptoms, (4)NIHSS score was 5 or more on admission, (5)no extensive high signal intensity on MR diffusion-weighted images(DWI), (6) who underwent emergency endovascular treatment(EET) within 24 hours from symptom onset. They were assigned to two groups according to procedural results: success group(S:TIMI grade 2 or 3 ) and unsuccess group(U:TIMI grade 0 or 1). We accessed NIHSS score on admission(NIHSS-adm), NIHSS score on the 7th day (NIHSS-7th), modified Rankin Scale(mRS) on admission(mRS-adm) and $\mathrm{mRS}$ at 3 months(mRS-3 m), estimated length of BAO on eMRA; long lesion defined as approximately half or more occlusion of the BA and short lesion as less than half, and onset to treatment time(hours).

\section{RESULTS}

During the study periods, consecutive 18 patients underwent EET for acute BAO. Recanalization was not achieved in 5 patients. In group $\mathrm{S}$ $(n=13)$ and $U(n=5)$, median NIHSS-adm was 14 and 33, median NIHSS-7th was 6 and 35, median mRS-adm was 5 and 5,mRS-3 m was 2.5 and 5 ,onset to treatment time was 6.7 and 2.0 , respectively. In group $\mathrm{U}$, all patients had long lesion, although in group $\mathrm{S}$ eight patients had short lesions. In group S, both NIHSS and mRS were improved statistically significantly, however in group $U$, neither of them was improved.

CONCLUSIONS

Successful recanalization can improve patients' clinical outcome, although unsuccessful EET was not able to improve clinical outcome. Predictive factors for unsuccessful EET were sudden onset and early arrival, high NIHSS score on admission, and estimated long lesion of BAO on EMRA.

\section{HE3:2}

\section{UNPROTECTED CAS, OUTCOME PREDICTORS; SINGLE CENTER EXPERIENCE}

\section{$\underline{\text { O. MANSOUR }}^{1,2}$}

${ }^{1}$ FREIBURG UNIVERSTY HOSPITAL , NEUROCENTER, NEURORADIOLOGY DEPART., FREIBURG, GERMANY, ${ }^{2}$ ALEXANDRIA, UNIV. HOSPITAL, NEUROLOGY DEPART, ALEXANDRIA, EGYPT

\section{OBJECTIVE}

The scientific discussion regarding the benefit of protection versus non protection in stenting of carotid artery (CAS) is still controversy since sufficient data comparing both treatment options are not available. To contribute further data to this important open question and because of the difficulty in conducting a randomized controlled study of protected versus unprotected CAS, we report our experience with carotid stent placement without the use of protection devices.

MATERIAL AND METHODS

This retrospective study was conducted on 243 patients (172 men; median age 69 years) who underwent CAS in 245 artery stenosis between 2003 and 2007. The etiology of the 245 lesions ( 2 bilateral 
treated in staged procedures) was de novo stenosis in $214(87.3 .0 \%)$ and postsurgical restenosis in $31(12.7 \%) .187$ patients, $(76.3 \%)$ were symptomatic. 157 patients $(64.61 \%)$ had comorbidities that placed them on the (NASCET) high-risk cohort for endarterectomy.

RESULTS

Primary stent placement was successful in 193 of 245 lesions in 243 patients. In $52(21.2 \%)$ patients with tight stenosis, severe calcifications or a preocclusive stenosis predilatation was necessary. During the initial 30 day follow-up, neurological complications persisted in 8 patients $(3.2 \%$.) .The degree of stenosis decreased from a mean of $82,9 \% \pm 10.9 \%$ before the procedure to a mean of $13,2 \% \pm 9,72 \%$ immediately after stent placement. Freedom from restenosis was observed in $85.5 \%$ at 3 years. Retreatment was indicated in $16 / 245$ $(6.5 \%)$ of our restenotic patients. 3 types of restenosis were differentiated in our cohort; firstly, tandem type restenosis, in $(5 / 35)$ patients, secondly, the more common type $(n=18 / 35)$ was "in-stent" restenosis, while the third type, "end-stent " restenosis, was in $(12 /$ 35) patients .

\section{CONCLUSIONS}

Carotid stent placement without the use of distal protection devices was safe and effective with a relatively low incidence of periprocedural complications.

\section{HE3:3}

\section{STENT-SPECIFIC GUIDELINES FOR FOLLOW-UP IMAGING AFTER CAS}

S. PILGRAM-PASTOR, A.M.J. FRÖLICH, M.N. PSYCHOGIOS, P. SCHRAMM, M. KNAUTH

DEP. OF NEURORADIOLOGY, UNIVERSITY HOSPITAL, GÖTTINGEN, GERMANY

\section{INTRODUCTION}

Carotid artery stenting (CAS) requires adequate follow-up investigations to detect in-stent thrombosis or intimal hyperplasia. Current standard procedures are duplex ultrasonography, which is userdependant and digital substraction angiography, which requires ionizing radiation. The purpose of this study was to explore stentspecific imaging characteristics to help develop standard recommendations for follow-up imaging after CAS. Use of the latest CT technology reduces movement, breath and pulsatile artefacts. For MR imaging, use of surface coils improves spatial resolution and signal intensity. Stent-related artefacts, however, still limit in-stent lumen visibility with both modalities.

METHODS AND MATERIALS

Cervical vessel anatomy was closely approximated by a vascular flow phantom. CT angiography (CTA) and Contrast-enhanced MR angiography (CE-MRA) were performed on five different stent types in different diameters. For CTA, we used a 128-slice CT scanner (Siemens Somatom Definition AS+). For CE-MRA we used a fourchannel surface carotid coil in a 3 Tesla scanner (Siemens Tim Trio). Image analysis included assessment of artificial lumen narrowing, instent lumen visibility and artefact patterns.

\section{RESULTS}

For all stents examined, CTA offered superior image quality regarding artificial lumen narrowing and in-stent lumen visibility. For CE-MRA, results depended heavily on stent material and geometry. Carotid stents which provided best in-stent lumen visibility and minimal artefacts (Acculink ${ }^{\circledR}$, Precise ${ }^{\circledR}$ and Zilver ${ }^{\circledR}$ ) were made of nitinol and had rather large cell sizes. On the other hand, stents with smaller cell sizes or non-nitinol alloy stents proved more challenging, especially with CE-MRA.

CONCLUSION

The results provide an important step towards the development of standard guidelines for CAS follow-up imaging. While MR imaging is still limited by stent-related artefacts, use of carotid surface coils markedly improves image quality. For certain stents, comparable results can be achieved with CE-MRA and CTA. Thus, future imaging guidelines should include stent-specific pathways.

\section{HE3:4}

\section{CHANGE OF PLATELET REACTIVITY TO ANTIPLATELET THERAPY AFTER STENTING PROCEDURE FOR CEREBRAL ARTERY STENOSIS: VERIFYNOW ANTIPLATELET ASSAY BEFORE AND AFTER STENTING}

\section{S. KIM, D.H. LEE, H.K. LIM, S.U. KWON, C.G. CHOI, D.C. SUH}

UNIVERSITY OF ULSAN COLLEGE OF MEDICINE, ASAN MEDICAL CENTER, SEOUL, SOUTH KOREA

\section{PURPOSE}

VerifyNow antiplatelet assay performed to determine the effect of antiplatelet agents before and after stenting for cerebral artery stenosis. We evaluate the relationship between change of platelet reactivity to antiplatelet therapy and occurrence of clinical event after stenting in a prospective study.

METHODS

Among the 25 consecutive patients from october 2008 to march 2009, twenty enrolled the inclusion criteria. Our preferred antiplatelet regimen was aspirin (100 mg daily) and clopidogrel (300 mg of loading dose followed by $75 \mathrm{mg}$ daily). VerifyNow antiplatelet assay performed before and after stenting for cerebral artery stenosis. The test results were reported as asprin-reaction unit (ARU) for aspirin and P2Y12 reaction units (PRU), baseline (BASE), and percentage inhibition for the P2Y12 assay. We recorded intraprocedural in-stent thrombosis, immediate thromboembolic complication, and ischemic events in 1-month follow-up.

RESULTS

The mean ARU of aspirin assay was $434.3 \pm 63$ (range, 350-586) before stenting. For clopidogrel, the mean of the BASE, PRU, and percentage inhibition was $341.65 \pm 43.8$ (range, 279-454), 236.45 \pm 74.4 (rage, 56-325), and $31.3 \pm 21.5 \%$ (range, $0-57$ ) before stenting. After stenting, the mean ARU, BASE, PRU, and percentage inhibition was 471.9 \pm 59.2 (range, 389-573), 365.4 $\pm 52.4(288-453$ ), $260.6 \pm 81.8$ (range, $81-370$ ), and $30 \pm 20.3 \%$ (range $0-79$ ). There are significant changes of ARU, BASE, and PRU before and after stenting. One immediate thromboembolic event was observed in poor-response group after stenting. There was no in-stent thrombosis and ischemic event in 1-month follow-up.

CONCLUSIONS

We observed the change of platelet reactivity to antiplatelet therapy after stenting procedure for cerebral stenosis. There was no statistically significant between change of platelet reactivity and significant thromboembolic events. However, the result shows possibility of thromboembolic complication after stenting in poor antiplatelet responders.

CLINICAL RELEVANCE/APPLICATION

We are demonstrative of the change of platelet reactivity after stenting, so that we are aware of possibility of thromboembolic complication after stenting procedure for cerebral stenosis. 


\section{HE3:5}

IA THROMBOLYSIS IN ACUTE ISCHEMIC STROKE: CHARACTERISTICS OF THE POTENTIAL POPULATION IN ATTICA

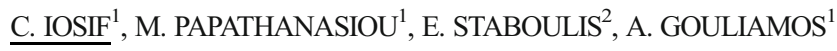

${ }^{1}$ DEPARTMENT OF RADIOLOGY, ATTIKON UNIVERSITY HOSPITAL, ATHENS KAPODISTRIAN UNIVERSITY, ATHENS, GREECE, ${ }^{2}$ DEPARTMENT OF NEUROLOGY, ATTIKON UNIVERSITY HOSPITAL, ATHENS KAPODISTRIAN UNIVERSITY, ATHENS, GREECE

\section{INTRODUCTION}

These are preliminary results of a multi-center, hospital-based study aiming to estimate the potential benefit from the introduction of intraarterial thrombolysis for the treatment of acute ischemic stroke in Attica, capital region of Greece.

MATERIALS AND METHOD

Acute ischemic stroke patients, who presented at the emergencies of 4 general public hospitals, were retrospectively registered in an electronic database. The database included 21 elements concerning demographics, time of presentation, clinical status, imaging, treatment and socioeconomic factors. The results were statistically and clinically analyzed.

RESULTS

During one calendar year (2005), 907 patients were registered. No patient was treated by intra-arterial thrombolysis or mechanical thrombolysis due to lack of a dedicated stroke center and $0,8 \%$ were treated with intra-venous thrombolysis with rt-PA. At discharge $22 \%$ of patients were minimally dependent, $38 \%$ were of medium dependence, 33\% were severely dependent and 9\% were dead. Average LOS was 16 days. $34 \%$ of the patients arrived within the 6-hour window and $19 \%$ were considered as potential candidates for thrombolysis.

CONCLUSION

A multidisciplinary dedicated acute stroke center is important for improving stroke management in Attica.

HE3:6

CEREBRAL AUTOREGULATIVE IMPAIRMENT MEASURED AT BRAIN TISSUE LEVEL WITH ARTERIAL SPIN LABELING MRI IN PATIENTS WITH A CAROTID ARTERY STENOSIS

$\underline{\text { R. BOKKERS }}^{1}$, M.J. VAN OSCH ${ }^{2}$, H.B. VAN DER WORP ${ }^{3}$, G.J. VAN DER BORST ${ }^{4}$, W.P. MALI ${ }^{1}$, J. HENDRIKSE ${ }^{1}$

${ }^{1}$ UNIVERSITY MEDICAL CENTER UTRECHT - DEPARTMENT OF RADIOLOGY, UTRECHT, THE NETHERLANDS, ${ }^{2}$ LEIDEN UNIVERSITY MEDICAL CENTER - C.J. GORTER CENTER FOR HIGH-FIELD MRI - DEPARTMENT OF RADIOLOGY, LEIDEN, THE NETHERLANDS, ${ }^{3}$ UNIVERSITY MEDICAL CENTER UTRECHT - DEPARTMENT OF NEUROLOGY, UTRECHT, THE NETHERLANDS, ${ }^{4}$ UNIVERSITY MEDICAL CENTER UTRECH DEPARTMENT OF VASCULAR SURGERY, UTRECHT, THE NETHERLANDS

\section{PURPOSE}

In patients with a stenosis of the internal carotid artery (ICA), impairment of the dilatory capacity of the brain vasculature is an important measure of hemodynamic compromise. Herein, we noninvasively assessed the cerebral autoregulative status at brain tissue level with arterial spin labeling (ASL) perfusion MRI in patients with a symptomatic ICA stenosis.

METHODS

Twenty-three patients $(69.0 \pm 7.9$ years $)$ with a symptomatic ICA stenosis and 20 healthy control subjects $(66.8 \pm 6.3$ years $)$ underwent perfusion and flow territory selective ASL MRI before and 15 minutes after intravenous administration of $14 \mathrm{mg} / \mathrm{kg}$ acetazolamide at $3 \mathrm{~T}$. The cerebrovascular reactivity was measured at tissue level, throughout the brain, in the gray-matter fed by the individual ICA's and basilar artery. For region-of-interest placement, probabilistic graymatter segmentations were combined with segmented ASL flow territory maps.

\section{RESULTS}

The cerebrovascular reactivity was, respectively, $35.9 \pm 3.0 \%$ and $44.6 \pm 3.5 \%$ in the flow territory of the symptomatic and non-stenosed ICA, and $47.9 \pm 3.1$ in the healthy control group. The cerebrovascular reactivity was lower in the flow territory of the symptomatic stenosed ICA when compared to the control group (mean difference, $-12.0 \%$; $95 \%$ confidence interval (CI), $-20.7--3.3$ ). There was no difference between the flow territory of the non-stenosed and stenosed ICA $(-8.7 \%$; $95 \%$ CI,$-18.0-0.6)$, and the healthy control group $(4.7 \%$; $95 \% \mathrm{CI},-12.9-6.3)$.

CONCLUSION

ASL perfusion MRI demonstrated impaired cerebrovascular reactivity in the flow territory of the ICA artery in patients with an ipsilateral symptomatic stenosis. With ASL-MRI it is possible to non-invasively visualize and quantify autoregulative impairment at brain tissue level.

Friday, September 18, 2009 - Thalia Room

TH1

11:50-13:00 - Inflammatory and demyelinating diseases of the brain II

\section{TH1:1}

\section{VOXEL-BASED MORPHOMETRY AND DIFFUSION TENSOR IMAGING OF THE OPTIC PATHWAY IN PRIMARY OPEN-ANGLE GLAUCOMA}

AK ZIKOU $^{1}$, G KITSOS $^{2}$, LC TZAROUCHI ${ }^{1}$, L ASTRAKAS ${ }^{1}$, $\overline{\text { MI ARGYROPOULOU }}^{1}$

${ }^{1}$ UNIVERSITY OF IOANNINA, MEDICAL SCHOOL, DEPARTMENT OF RADIOLOGY, IOANNINA, GREECE, ${ }^{2}$ UNIVERSITY OF IOANNINA, MEDICAL SCHOOL, DEPARTMENT OF OPHTHALMOLOGY, IOANNINA, GREECE

\section{PURPOSE}

Neuropathological studies in experimental and human glaucoma have shown degenerative changes in the optic pathway. The purpose of this study was to assess optic pathway in primary open-angle glaucoma 
(POAG) by using Voxel-Based Morphometry (VBM) and Diffusion Tensor Imaging (DTI).

METHODS

Eighteen patients (aged 59.1 \pm 10.9 years) with disease duration $7.7 \pm$ 5.3 years and eighteen aged-matched controls were studied. The imaging protocol consisted of: T1-weighted high resolution $(1 \mathrm{~mm} \times$ $1 \mathrm{~mm} \times 1 \mathrm{~mm}$ )

3-dimensional spoiled gradient echo sequence (repetition time[TR]= $25 \mathrm{~ms}$, echo time $[\mathrm{TE}]=4,6 \mathrm{~ms}$, acquisition matrix $=256 \times 228$, field of view $[\mathrm{FOV}]=220 \mathrm{~mm}$ ), and a multi-slice, spin-echo planar diffusion weighted (TE: $131 \mathrm{msec}$, TR: $9807 \mathrm{msec}$, matrix size: $112 \times 128$, thickness: $3 \mathrm{~mm}$, FOV: $230 \mathrm{~mm}$, $\max$ b-value: $700 \mathrm{sec} / \mathrm{mm} 2$ ) sequence. Data pre-processing and analysis were performed using MAT-LAB 7.0 and Statistical Parametric Mapping SPM 5.

RESULTS

VBM revealed in patients a significant reduction: 1) of gray matter in the left geniculate nucleus and the left visual cortex (B17, B18) 2) of white matter in the intracranial part of the optic nerves and the chiasm $(p<0.001)$. A significant bilateral decrease of the Fractional Anisotropy (FA) index was observed in patients in the cuneus, precuneus, middle temporal gyrus and the left orbital gyrus $(\mathrm{p}<0.001)$.

CONCLUSIONS

VBM reveals atrophy and DTI neurodegeneration of the optic pathway in patients with POAG.

\section{TH1:2}

\section{CENTRAL NERVOUS SYSTEM INVOLVEMENT IN PRIMARY SJOGREN'S SYNDROME: ASSESSMENT OF GREY AND WHITE MATTER CHANGES BY MRI}

\section{$\underline{\text { L. TZAROUCHI }}^{1}$, N TSIFETAKI ${ }^{2}$, S KONITSIOTIS $^{3}$, AK ZIKOU $^{1}$,}

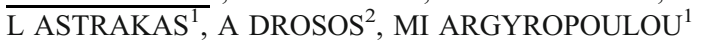

${ }^{1}$ UNIVERSITY OF IOANNINA, MEDICAL SCHOOL, DEPARTMENT OF RADIOLOGY, IOANNINA, GREECE, ${ }^{2}$ UNIVERSITY OF IOANNINA, MEDICAL SCHOOL, DEPARTMENT OF RHEUMATOLOGY, IOANNINA, GREECE, ${ }^{3}$ UNIVERSITY OF IOANNINA, MEDICAL SCHOOL, DEPARTMENT OF NEUROLOGY, IOANNINA, GREECE

\section{PURPOSE}

Involvement of the central nervous system (CNS) has been reported in primary Sjogren's syndrome (pSS), but there is still controversy concerning the prevalence and type of CNS disease. The purpose of the present study was to evaluate via Magnetic Resonance Imaging (MRI) the grey and white matter structures of patients with pSS.

\section{METHODS}

Fifty-two patients ( 1 male, 51 females), free from central nervous system symptoms and signs aged 39-78 years (mean; 63.07, SD; 19.6) with disease duration $2-28$ years (mean; 10.5 , SD; 5.75) and 35 age and sex-matched controls were studied with axial fluidattenuation-inversion-recovery (FLAIR) sequence $(6.300 \mathrm{msec} /$ $120 \mathrm{msec} / 2.150 \mathrm{msec}, \mathrm{TR} / \mathrm{TE} / \mathrm{IR}$ ) and with three-dimensional T1weighted $(25 \mathrm{msec} / 4.6 \mathrm{msec} / 300 \mathrm{TR} / \mathrm{TE} / \mathrm{flip}$ angle) sequence. White matter hyperintensities (WMH) were assessed on FLAIR images and brain atrophy was evaluated on T1-weighted by using Statistical Parametric Mapping (SPM5) and applying Voxel-Based Morphometry (VBM).

\section{RESULTS}

WMH were observed in $80.8 \%(42 / 52)$ of patients and in $48.6 \%$ (17/35) of controls. The total number of WMH $<2 \mathrm{~mm}$ was significantly higher in patients $(n=407)$ than in controls $(n=88)$, $\mathrm{p}<0.05$. In addition, a greater number of $\mathrm{WMH}>2 \mathrm{~mm}$ was found in patients $(n=139)$ when compared to controls $(n=35)$, $\mathrm{p}<0.05$.

A diffuse pattern of grey matter loss was observed in patients compared to controls mainly in the cerebellar hemispheres, in the motor and sensory cortex, the occipital lobes, the thalamus, the caudate nucleus and the putamen in both hemispheres. White matter volume was decreased in the corresponding areas of grey matter atrophy $(\mathrm{P}<0.001)$.

CONCLUSIONS

Brain MRI reveals the presence of WMH, grey and white matter atrophy in patients with pSS, possibly explained by cerebral vasculitis associated with decreased cerebral blood flow.

\section{TH1:3}

\section{OEDEMATOUS BRAIN HEMIATROPHY IN LATE-ONSET PARRY-ROMBERG SYNDROME WITH REFRACTORY FOCAL EPILEPSY}

$\underline{\text { M. SAFRONOVA }}^{1}$, I. MATOS $^{2}$, J. RESENDE PEREIRA $^{1}$

${ }^{1}$ HOSPITAL PEDRO HISPANO - NEURORRADIOLOGIA, MATOSINHOS, PORTUGAL, ${ }^{2}$ UNIDADE HOSPITALAR DE MIRANDELA - NEUROLOGIA, MIRANDELA, PORTUGAL

\section{INTRODUCTION}

Parry-Romberg syndrome (PRS) is an uncommon acquired disorder. It commonly appears in the first two decades of life and is characterized by slowly progressive facial hemiatrophy of the skin, subcutaneous tissue, muscle and underlying bony structure. Involvement of the central nervous system occurs infrequently. When it does, the most common manifestation is epilepsy, followed by migraine and facial pain. Few neuroimaging reports in PRS are available.

CASE REPORT

A 73-year-old woman first noted left facial atrophy at the age of 48. The hemifacial atrophy was progressive and followed by speech disturbance and reduced left eye vision. At the age of 68 the patient presented with right sensory partial seizures with postictal right Todd's paresis. The seizure frequency increased progressively despite medication. On neurological exam, the patient had normal cognition with disartry and dysphasy, left eye amaurosis, left facial atrophy and hyperpigmentation, right hemiparesis, right limbs atrophy and brisk right deep tendon reflexes. Electroencephalogram showed an asymmetric pattern with slower electrical activity on the left. MR scan revealed white matter hyperintensity of the left brain hemisphere on T2, with ipsilateral enlargement of the lateral ventricle. Left hemispheric sulci were effaced, there was blurring of the white-gray interface and white matter showed increased ADC. On MR, enophtalmy and hemifacial atrophy were also noted. 


\section{CONCLUSIONS}

The cause of epilepsy in PRS is not clarified and, therefore, no suitable treatment exists. It has been firstly ascribed to cortical dysgenesis. However, its steroid and immunosuppressor responsiveness suggests that chronic autoimmune encephalitis may be responsible for it, although no associated serum autoantibodies have been found. In the case here reported, the presence of vasogenic oedema argues in favour of a neuroinflammatory process as the cause. Its chronicity would cause the progressive hemispheric atrophy. Although the neurological involvement in PRS is not frequent, MRI should be included in standard diagnostic procedures.

\section{TH1:4}

CHANGES IN BRAIN VOLUME AND T2 LESION LOAD FOLLOWING LIVER TRANSPLANTATION OVER A 8-YEAR PERIOD

\author{
A. ROVIRA, R. GARCIA-MARTINEZ, J. ALONSO, E. HUERGA, \\ J. CÓRDOBA
}

\section{HOSPITAL VALL D'HEBRON, BARCELONA, SPAIN}

\section{PURPOSE}

The aim of this study was to assess brain changes at long term following liver transplantation (LTx).

METHODS

Thirty-five patients who underwent LTx between April 1998 and December 2001 were included in a prospective study. Twenty-two alive patients (age: $62 \pm 11$ years, 19 males) with good liver function were reassessed after 7.7 years. Patients were studied shortly before LTx (pre-LTx), 6-12 months (short-term post-LTx) and 7-10 years after LTx (long-term post-LTx). MR imaging measured the volume of ventricles (VV), an indirect index of brain volume and volume of T2 focal white matter lesions (FWML). Neuropsychologic tests evaluated attention, motor function, executive function and memory.

RESULTS

1) Short-term post-LTx (short post-LTx vs pre-LTx): The VV (cm3) increased by $8 \%$. Fourteen patients exhibited FWML that decreased the volume by $19 \%$, which can be explained by reversible brain edema in these areas. Neuropsychologic tests improved indicating reversal of minimal hepatic encephalopathy. No association was found between change in VV and HE prior to LTx. In contrast, the decrease in FWML showed a tendency to be higher in those with prior HE.

2) Long-term post-LTx (long vs short post-LTx): The VV increased by $22 \%$ and the volume of FWML increased by $49 \%$. Neuropsychologic tests remained stable, except for memory that showed deterioration. Among patients with larger changes in FWML $(>13 \%)$ pharmacologic treatment for arterial hypertension was more common ( $88 \%$ vs $33 \%$, $\mathrm{p}=0.05)$ and creatinine tended to be higher $(1.37 \pm 0.21$ vs $1.19 \pm 0.15 \mathrm{mg} / \mathrm{dl}, \mathrm{p}=0.06)$.

\section{CONCLUSION}

Following LTx patients develop a decrease in brain volume despite a successful outcome of liver function. The initial decrease probably reflects disappearance of brain edema related to HE. The decrease at long term is part of a degenerative process in part caused by small vessel cerebrovascular disease.

\section{TH1:5}

\section{NAA AND GLUTAMATE AS NEURONAL BIOMARKERS IN SYSTEMIC LUPUS ERYTHEMATOSUS AND (SLE) AND NEUROPSYCHIATRIC SYSTEMIC LUPUS ERYTHEMATOSUS (NPSLE) PATIENTS. A SINGLE VOXEL 1H MR SPECTROSCOPY STUDY}

\author{
JE PERRY ${ }^{1}$, RE HARRIS ${ }^{2}$, G BEYER $^{1}$, P CAGNOLI $^{3}$, S GEBARSKI $^{1}$,

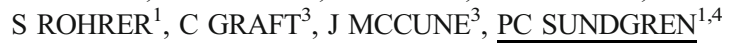

${ }^{1}$ UNIVERSITY OF MICHIGAN, DEPARTMENT OF RADIOLOGY, ANN ARBOR, MI, USA, ${ }^{2}$ UNIVERSITY OF MICHIGAN, DEPARTMENT OF ANAESTHESIOLOGY, ANN ARBOR, MI, USA, ${ }^{3}$ UNIVERSITY OF MICHIGAN, DEPARTMENT OF INTERNAL MEDICINE, ANN ARBOR, MI, USA, ${ }^{4}$ UNIVERSITY OF LUND, DIAGNOSTIC CENTER FOR IMAGING AND FUNCTIONAL MEDICINE, MALMÖ, SWEDEN

\section{PURPOSE}

to investigate metabolic concentrations and ratios in specific brain regions in patients with systemic lupus erythematosus without neuropsychiatric symptoms (SLE) and with symptoms (NPSLE) compared to healthy controls (HC).

MATERIAL AND METHODS

SUBJECTS

20 SLE patients with no neurological symptoms (18 females, 2 men, aged range 21.0-61.0, mean 39.4), 16 NPSLE (16 females, aged range 25.2-67.3, mean 41.5), and 20 (HC) (17 females, 3 men, aged range 18.8-61.0, mean 40.7).

METHODS

All subjects had conventional MRI of the brain, and SVS MR Spectroscopy (PRESS, TR $2000 \mathrm{~ms}$, TE $30 \mathrm{~ms}, 2 \times 2 \times 2 \mathrm{~cm}$ voxel size) placed in frontal white matter (FWM), basal ganglia (BG) and in occipital gray matter (OGM).

RESULTS

The concentration of NAA were significantly lower in the FW in the SLE patients, and in the FW and BG in the NPSLE patients compared to $\mathrm{HC}, \mathrm{p}=0.015, \mathrm{p}<0.001$, and $\mathrm{p}=0.01$, respectively. The Cho concentration were significantly lower in the FW in SLE patients compared to HC $(\mathrm{p}=0.004)$ and significantly higher in NPSLE patients compared to SLE $(p=0.014)$. In the BG the $\mathrm{Cr}$ concentration were significantly higher in NPSLE compared to HC and SLE patients, $p=0.01$ and $p=0.005$, respectively. The Glu was significantly lower in the SLE group with active SLE compared to inactive SLE patients $(\mathrm{p}=0.014)$.

The NAA/Cr ratios were significantly lower in NPSLE patients compared to $\mathrm{HC}$ in FW and BG and lower compared to SLE in BG, $\mathrm{p}<0.004, \mathrm{p}<0.001$, and $\mathrm{p}=0.006$, respectively. The $\mathrm{Glu} / \mathrm{Cr}$ ratio were significantly lower in NPSLE compared to HC $(\mathrm{p}<0.04)$ and when compared to SLE patients $(\mathrm{p}<0.05)$.

\section{CONCLUSION}

There is a reduction or destruction of neurons in patients with SLE regardless of neuropsychatric symptoms as seen by the significant decrease in the NAA. The glu-gln cycle between astrocytes and neurons might be effected by the reduction of neurons in the SLE population. 


\section{TH1:6}

IMPROVED SUSCEPTIBILITY WEIGHTED IMAGING WITH CONTRAST AGENT IN DEGENERATIVE BRAIN DISEASE

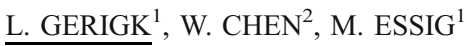

${ }^{1}$ GERMAN CANCER RESEARCH CENTER, HEIDELBERG, GERMANY, ${ }^{2}$ THE THIRD MILITARY MEDICAL UNIVERSITY, CHONGQING, CHINA

\section{PURPOSE}

Susceptibility weighted imaging (SWI) is a sensitive method for the detection of microbleeds, iron depositions and calcifications, which can be found in neurodegenerative diseases. The purpose of this study was to investigate whether gadolinium contrast agents can improve signal-to-noise and contrast-to-noise ratios of SWI in patients with ageing associated cognitive decline (AACD).

\section{METHODS}

As part of a study protocol in patients with suspected AACD, a SWI sequence (TE 20, TR $28 \mathrm{~ms}$ ) was acquired before or after intravenous application of Gd-BOPTA (Multihance) in a standard dose of $0.1 \mathrm{mmol} / \mathrm{kg}$ body weight. In a blinded read, the delineation of the basal ganglia was graded into 0 corresponding to no visible structure, 1 to a barely visible, 2 to a visible but poorly delineated and 3 to a well visible, perfectly delineated structure. The signal-to-noise ratio (SNR) was calculated against the background signal and the contrastto-noise ratio $(\mathrm{CNR})$ against brain tissue.

RESULTS

The delineation of the basal ganglia was rated with median values of 1 for native and 3 for contrast enhanced SWI. In the quantitative evaluation, the SNR increased with Gd-BOPTA from 24.3 to $26.7(10.1 \%)$ in the putamen, from 24.4 to $27.8(14.0 \%$ ) in the substantia nigra and from 26.3 to $28.4(7.9 \%)$ in the thalamus. The CNR increased from 0.12 to 0.16 $(30.7 \%)$ in the putamen, from 0.13 to $0.17(28.6 \%)$ in the substantia nigra and from 0.09 to $0.13(50.6 \%)$ in the nucleus ruber.

CONCLUSION

T1-shortening contrast agents like Gd-BOPTA can improve the visibility and delineation of the basal ganglia in patients with neurodegenerative diseases like AACD. The contrast agent increases the SNR and CNR, which possibly lead to improved detection rates for small lesions like microbleeds, which have been identified to be a risk factor for cognitive decline.

\section{TH1:7}

EVALUATION OF TEMPORAL LOBE INVOLVEMENT (TLI) BY MRI IN DIFFERENT CLINICAL FORMS OF MULTIPLE SCLEROSIS (MS)

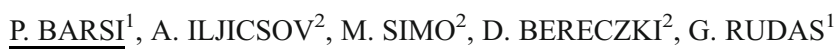

${ }^{1}$ SEMMELWEIS UNIVERSITY - MR RESEARCH CENTRE, BUDAPEST, HUNGARY, ${ }^{2}$ SEMMELWEIS UNIVERSITY - DEPT. OF NEUROLOGY, BUDAPEST, HUNGARY

\section{PURPOSE}

To develop an MRI protocol measuring TLI in MS and evaluate the data in different clinical forms of MS.
METHODS

On $3 \mathrm{~T}$ MR (Philips Achieva), MRI protocol (sagFLAIR3mm, axiTSE-PD-T23mm in callosal plane, DWI and contrast enhanced 3D-GRE-T1) was completed with corTSE-T23mm perpendicular to TL. Mean disease duration (DD) of 53 patients ( 37 women, mean age $36.7+/-9.3 \mathrm{yrs})$ was $58.8+/-49.8 \mathrm{mths} .7 \mathrm{had}$ clinically isolated syndrome (CIS), 22 relapsing-remitting (RR), 9 clinically benign RR (RR-B), 8 primary (PP) and 7 secondary progressive (SP). White and T1-black lesions were counted in superior-middle-inferior temporal, fusiform, parahippocampal gyri, subiculum, central, paraventricular white matter in T-pole, amygdala, hippocampal head-body-tail.

RESULTS

Plaques were exactly localized on different sequences/planes. No significant difference in lesion load (LL) of CIS and RR occurred. RR$B$ had significantly higher LL than RR, even if patients with $\mathrm{DD}<$ 48mths excluded. RR-B had significantly higher LL than PP, changed only with exclusion of patients with $\mathrm{DD}<48$ mths and one RR-B making SD high, probably for not considering spinal cord, frequently involved in PP. PP had significantly higher LL than CIS or RR. SP had significantly higher LL, especially T1-black, than other groups. No significant difference among groups evolved in LL with increasing DD in first 8 years, but substantial increase in LL appeared with DD $>96 \mathrm{mths}$, probably due to high proportion of SP in long DD group. CONCLUSIONS

The protocol properly evaluates TLI in MS, reflects disease activity in clinical groups and in relation to DD. Lack of significant difference between CIS and RR is importantly proving similar disease progression, though silent in CIS. Only TLI was observed, but significantly larger LL in RR-B compared to RR may reflect its apparent benign nature and the necessity of treating RR-B patients. We correlate data with whole brain LL and results of psychological memory tests, a work in progress.

\section{TH1:8}

DIFFERENCES OF CEREBRAL LESION DISTRIBUTION AND LESION LOAD IN CHILDREN WITH ACUTE DISSEMINATED ENCEPHALOMYELITIS (ADEM) WITH DIFFERENT INFECTIOUS ORIGIN SEEN ON MAGNETIC RESONANCE IMAGING (MRI)

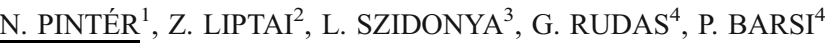

${ }^{1}$ SEMMELWEIS UNIVERSITY, HEART CENTER, DEPARTMENT OF DIAGNOSTIC RADIOLOGY, BUDAPEST, HUNGARY, ${ }^{2}$ SZENT LÁSZLÓ HOSPITAL, DEPARTMENT OF NEUROLOGY, BUDAPEST, HUNGARY, ${ }^{3}$ SEMMELWEIS UNIVERSITY, DEPARTMENT OF DIAGNOSTIC RADIOLOGY AND ONCOTHERAPY, BUDAPEST, HUNGARY, ${ }^{4}$ SEMMELWEIS UNIVERSITY, MR RESEARCH CENTER, BUDAPEST, HUNGARY

PURPOSE

To compare cerebral lesion distribution (LD) and lesion load (LL) in different clinical forms of ADEM.

METHODS

17 children (11male,6female,mean age: $6.33+3$ years) with ADEM underwent MRI by using conventional sequences and diffusion weighted imaging on a $3 \mathrm{~T}$ Philips scanner. 16 of them had an infectious disease preceding the neurological symptoms. Patient subgroups were based on presence of previous infectious disease (6 varicella [Var],11 other[nVar]) and on presence of neurological symptoms on a $30+21$ months follow-up 
(5 positive and 12 negative cases). Lesions in different cerebral regions were registered. We compared cerebral LL and LD in different subgroups. Diffusion data were available for apparent diffusion coefficient (ADC) measurement in 4 cases.

RESULTS

We found a higher basal ganglia (52\%) and deep gray matter (64\%) involvement compared to literature. No enhancement and haemorrhage was seen. $\mathrm{nVar}$ had significantly higher lesion load than Var patients $(\mathrm{p}<$ 0.001). Insular (I), subinsular (SI) and thalamic (T) involvement was characteristic of nVar, significantly less frequent in Var patients (I:p $<$ 0.001, SI:p $<0.005, \mathrm{~T}: \mathrm{p}<0.005$ ). No significant correlation of LL or LD and final clinical state at follow-up was found. ADC in the normal appearing white matter (NAWM) and in lesions of 4 patients showed that ADC in NAWM was significantly lower than in lesions $(\mathrm{p}<0.001)$, except for one case, where ADC was increased in the frontal NAWM and therefore suspicious of monophasic multiple sclerosis.

CONCLUSION

Smaller LL, the lack of insular and subinsular involvement and a smaller thalamic involvement are characteristic of ADEM caused by varicella. No significant correlation between LD and LL of cerebral involvement and final state of the patient has been detected.

\section{TH1:9}

\section{ATYPICAL BRAIN MAGNETIC RESONANCE IMAGING LESIONS OF THE WHITE MATTER FOLLOWING HAART-INDUCED IMMUNE RECONSTITUTION}

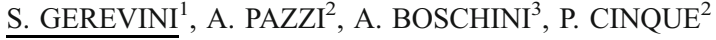

${ }^{1}$ NEURORADIOLOGY SERVICE, HEAD AND NECK DEPARTMENT, SAN RAFFAELE HOSPITAL, MILANO, ITALY, ${ }^{2}$ DEPARTMENT OF INFECTIOUS DISEASES, SAN RAFFAELE HOSPITAL, MILANO, ITALY, ${ }^{3}$ PATRIGNANO MEDICAL CENTER, RIMINI, ITALY

Immune restoration diseases include a spectrum of systemic disorders characterized by atypical presentation, usually with inflammatory features and temporarily related to viro-immunological response to HAART. Since atypical CNS lesions, mainly involving the white matter, are observed in HAART-treated patients, objective of this study was to identify and describe possible cases of immune reconstitution CNS disease (CNS-IRD). We retrospectively reviewed 166 cases of CNS diseases with at least one brain MRI performed in the year following HAART initiation. Possible cases of CNS-IRD were selected for responding to the following criteria: 1) Start of a new HAART 1-12 months before onset of CNS manifestations in patients naive for antiretroviral therapy or who withdrew previous therapy for at least 3 months. 2) HAART-associated increase of CD4 cell counts and/or decrease of HIV-1 RNA plasma level to undetectable or of at least two logs. 3) MRI lesions of new onset involving the white matter, consistent with inflammation but not resembling opportunistic CNS diseases or HIV-related manifestations. We identified 8 cases responding to the criteria, which were divided into 2 groups based on MRI signal alteration: "vasculitis like lesions" (5) and "leukoencephalitis" (3) Patients with vasculitis-like lesions presented with focal neurologic signs and multiple MRI lesions 27 months after starting HAART. All patients improved both clinically and radiologically either spontaneously or following corticosteroids. Patients with leukoencephalitis showed diffuse white matter signal alteration in the absence of new clinical symptoms or signs 69 months after starting HAART. Increase in median CD4 cells and decrease in median viral load was present in both cathegories. In 2 patients spontaneous radiological improvement was observed. We have characterized a spectrum of CNS diseases characterized by inflammatory MRI features accompanied by mild to moderate neurological symptoms and signs and associated with viroimmunological response to HAART.

\section{TH1:10}

\section{SERUM VITAMIN B12, FOLATE LEVELS AND THEIR ASSOCIATION WITH CORTICAL LESIONS AND CLINICAL PARAMETERS IN MULTIPLE SCLEROSIS}

M. GAVRA ${ }^{1}$, M. PAPATHANASIOU ${ }^{1}$, K. VOUMVOURAKIS ${ }^{2}$,

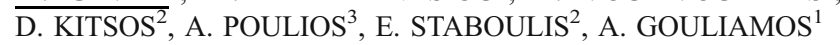

${ }^{1}$ 2ND DEPARTMENT OF RADIOLOGY, UNIVERSITY OF ATHENS, ATTIKON UNIVERSITY HOSPITAL, ATHENS, GREECE, ${ }^{2}$ 2ND DEPARTMENT OF NEUROLOGY, UNIVERSITY OF ATHENS, ATTIKON UNIVERSITY HOSPITAL, ATHENS, GREECE, ${ }^{3}$ DEPARTMENT OF PSYCHOLOGY, UNIVERSITY OF ATHENS, ATHENS, GREECE

\section{PURPOSE}

Multiple sclerosis (MS) patients with cognitive pathology may have low serum vitamin B12 and folate levels. To investigate B12 and folate levels in MS patients and to study the relationship between these and cortical lesions, cognitive, cerebellar function and disability. METHODS

Thirty-six MS patients were enrolled in the study and underwent brain MR imaging at 1.5 Tesla. Patients' cognitive and cerebellar function was estimated by the Multiple Sclerosis Functional Composite (MSFC) scale and disability by the Expanded Disability Status Scale (EDSS). Axial DIR sequence was used to identify and classify cortical lesions in three anatomic regions: intracortical, mixed graywhite matter and juxtacortical. The Pearson $r$ coefficient was used to investigate the correlation between vitamin B12 and folate levels with MRI and clinical parameters.

\section{RESULTS}

No correlations were found between vitamin B12 and folate levels with the number of cortical lesions either in total or in each category. No correlations were also found between vitamin B12 and folate levels with cognitive function. There was a significant inverse correlation $(r=-0,36, p<0,05)$ between EDSS and folate. Also there was a strong inverse correlation between folate and cerebellar function, as measured by 9 HOLE PEG TEST $(r=-0,40, p<0,05)$. CONCLUSIONS

Although B12 and folate deficiency contribute to clinical disability in patients with MS, the contribution of this deficiency to cognitive function was not established and warrants further evaluation.

\section{TH1:11}

HYPOPLASIA OF LUMBAR VERTEBRA L5 WITH SPONDYLOLYSIS: ANALYSIS OF LUMBAR VERTEBRAL BODY VOLUME BY CT VOLUMETRY

\author{
E. WILLEMS, B. DE DOBBELAER, F. DE KEYZER, G.E. WILMS
}

UNIVERSITY HOSPITAL LEUVEN, LEUVEN, BELGIUM 


\section{PURPOSE}

To examine volumetric differences of vertebral bodies L3, L4 and L5 in normal patients and patients with suspected hypoplasia L5.

\section{MATERIALS AND METHODS}

CT of the lumbar spinal canal was performed in 51 consecutive patients without vertebral pathology and 8 patients with bilateral spondylolysis and visually hypoplastic appearance of lumbar vertebra L5, with reduction of the anteroposterior diameter and wedging. CT volumetry was performed with a semi-automated program (SpineVolume, University Hospital Leuven) to measure lumbar vertebral body volume of L3, L4 and L5.

RESULTS

In the control group the average vertebral body volume of L3 was $39.3+/-7.3 \mathrm{~cm} 3,40.2+/-7.2 \mathrm{~cm} 3$ for L4 and $38.1+/-6.8 \mathrm{~cm} 3$ for L5. In patients with suspected hypoplasia L5 the average body volume was $41.8+/-7.9 \mathrm{~cm} 3$ for L3, $42.0+/-7.3 \mathrm{~cm} 3$ for L4 and $36.4+/$ $-5.8 \mathrm{~cm} 3$ for L5.

None of the vertebral body volumes was significantly different between both groups. However, there was a significant difference between the ratio L5/L4 $(\mathrm{P}<0.0001)$ between both groups. The mean ratio L5/L4 in the control group was $94.7+/-4.4 \%$, while the ratio for the hypoplastic L5 group was $86.9+/-2.4 \%$.

CONCLUSION

No significant differences in the vertebral body volume for L3, L4 and L5 could be found between patients in the control group and patients with suspected hypoplasia, due to inter-patient variations.

However, the ratio between the body volumes of L5 and L4 is significantly different between both groups. L5 proved to be on average $13 \%$ smaller than L4 in the group with bilateral spondylolysis and visually hypoplastic L5 whereas the difference in the control group was only $5 \%$.

TH2

\section{4:50-16:00 - Pediatric neuroradiology II}

TH2:1

\section{PERIVENTRICULAR LEUKOMALACIA IN PRETERM CHILDREN: ASSESSMENT OF GREY AND WHITE MATTER AND CEREBROSPINAL FLUID CHANGES BY MRI}

L. TZAROUCHI ${ }^{1}$, L ASTRAKAS ${ }^{2}$, AK ZIKOU ${ }^{1}, \mathrm{~V}$ XYDIS $^{1}$,

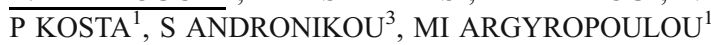

${ }^{1}$ UNIVERSITY OF IOANNINA, MEDICAL SCHOOL, DEPARTMENT OF RADIOLOGY, IOANNINA, GREECE, ${ }^{2}$ UNIVERSITY OF IOANNINA, MEDICAL SCHOOL, DEPARTMENT OF MEDICAL PHYSICS, IOANNINA, GREECE, ${ }^{3}$ UNIVERSITY OF IOANNINA, MEDICAL SCHOOL, CHILD HEALTH DEPARTMENT, INTENSIVE CARE UNIT, IOANNINA, GREECE

\section{PURPOSE}

There is evidence of brain plasticity in patients with periventricular leukomalacia (PVL), but changes of individual grey matter (GM) areas have never been evaluated. The purpose of the present study was to assess total volume of GM, white matter (WM) and cerebrospinal fluid (CSF) and individual volume of $116 \mathrm{GM}$ areas in patients with PVL.

\section{METHODS}

Using a T1-weighted three-dimensional spoiled gradient-echo sequence, total GM, WM and CSF volume was evaluated in 10 preterm born subjects (gestational age $31.7 \pm 4.2$ weeks and corrected age $27.8 \pm 21.7$ months) with MRI findings of focal PVL and in 46 age-matched preterm controls. Volumes of 116 GM areas were calculated after their segmentation using the Voxel Based Morphometry Toolboxes and the Individual Brain Atlas Statistical Parametric Mapping (IBASPM) software package.

RESULTS

Total CSF volume was higher $(300.8 \pm 56.2 \mathrm{~cm} 3)$ and WM volume was lower in PVL patients $(182.1 \pm 40.5 \mathrm{~cm} 3)$ than in normal subjects $(219.0 \pm 61.8 \mathrm{~cm} 3,222.9 \pm 67.2 \mathrm{~cm} 3$, respectively), $\mathrm{p}<0.05$. No significant difference was found in total GM volume. Significant volume differences were found between patients and controls in specific GM areas: Frontal Superior Orbital $(3.6 \pm 0.6 \mathrm{~cm} 3,3.1 \pm$ $0.7 \mathrm{~cm} 3, \mathrm{p}=0.03)$, Posterior Cingulum $(2.0 \pm 0.5 \mathrm{~cm} 3,1.5 \pm 0.2 \mathrm{~cm} 3, \mathrm{p}$ $<0.001)$, Lingual gyrus $(9.7 \pm 1.7 \mathrm{~cm} 3,8.2 \pm 1.3 \mathrm{~cm} 3, \mathrm{p}=0.003)$, Putamen $(2.5 \pm 0.6 \mathrm{~cm} 3,1.7 \pm 1.4 \mathrm{~cm} 3, \mathrm{p}<0.001)$, Thalamus $(2.6 \pm$ $0.9 \mathrm{~cm} 3,1.8 \pm 0.4 \mathrm{~cm} 3, \mathrm{p}<0.001)$, respectively.

CONCLUSIONS

Patients with PVL present increased CSF and decreased WM volume. GM segmentation reveals increased volume of the putamen, thalamus and of individual GM areas related with the WM the most affected from PVL. Presence of reactive gliosis associated with mechanisms of brain structural plasticity may explain the findings.

\section{TH2:2}

\section{PATTERN ANALYSIS OF FETAL BRAIN ASYMMETRY}

$\underline{\text { G. KASPRIAN }^{1}}$, G. LANGS ${ }^{1}$, PC. BRUGGER ${ }^{2}$, D. PRAYER ${ }^{1}$

${ }^{1}$ MEDICAL UNIVERSITY OF VIENNA, DEPARTMENT OF RADIOLOGY, VIENNA, AUSTRIA, ${ }^{2}$ MEDICAL UNIVERSITY OF VIENNA, CENTER OF ANATOMY AND CELLBIOLOGY, VIENNA, AUSTRIA

\section{PURPOSE}

This is the first in utero MR study to revisit fetal brain asymmetry by characterizing early interhemispheric variability using shape analysis and biometry.

METHODS

Fetal MR examinations (1.5 Tesla) in 133 cases without structural brain abnormality (mean age 27.5 gestational weeks) were retrospectively analyzed. Linear measurements of the length of the TL (TLL), the temporal pole (TP), the height (TLH) and the sulcal depth of the forming superior temporal sulcus (STS) were performed bilaterally using sagittal and coronal T2-weighted(w) sequences. In 22 cases the shape of the fetal hemispheres on corresponding coronal images was defined by landmarks. Shape variation was assessed by comparing the right/left hemispheric patterns after group-wise registration with an automatically generated template using principal component analysis (PCA) in MATLAB.

\section{RESULTS}

A paired $\mathrm{t}$ test showed significant right/left hemispheric differences of TLL and TPL $(\mathrm{p}<0.001) .31(72 \%)$ cases showed a longer 
left TLL, compared to $12(28 \%)$ cases with longer right TLL. The $\operatorname{TLH}(\mathrm{p}=0.009)$ and the STS $(\mathrm{p}<0.001)$ were significantly higher/ deeper in the right hemisphere. The right sided STS formed earlier than the left STS and was found to be deeper in 59, equal in 11 and shallower in 3 cases compared to the left TL. Analysis of shape variation elucidated coefficients, providing a fully automated discrimination between the right and left fetal hemisphere without a priori information.

CONCLUSION

Biometry and fully automated shape analysis using PCA are able to detect and describe interhemispheric variability opening a new and exciting field for the assessment of fetal brain morphology and pathology.

\section{TH2:3}

\section{IN UTERO DTI AND SPECTROSCOPY IN ZELLWEGER DISEASE}

G. KASPRIAN $^{1}$, R. WASICKY ${ }^{2}$, P. BRUGGER ${ }^{3}$, M. LANGER $^{4}$, D. PRAYER ${ }^{1}$

${ }^{1}$ MEDICAL UNIVERSITY OF VIENNA, DEPARTMENT OF RADIOLOGY, VIENNA, AUSTRIA, ${ }^{2}$ MEDICAL UNIVERSITY OF VIENNA, DEPARTMENT OF CLINICAL NEUROLOGY, VIENNA, AUSTRIA, ${ }^{3}$ MEDICAL UNIVERSITY OF VIENNA, CENTER OF ANATOMY AND CELLBIOLOGY, VIENNA, AUSTRIA, ${ }^{4}$ MEDICAL UNIVERSITY OF VIENNA, DEPARTMENT OF FETO-MATERNAL MEDICINE, VIENNA, AUSTRIA

\section{PURPOSE}

To demonstrate the feasibility of in utero diffusion tensor imaging (DTI), tractography and single voxel spectroscopy in the prenatal diagnosis of Zellweger disease.

METHODS

2 fetuses (30 and 35 gestational weeks) were imaged using a 1.5 Tesla MR and T2-weighted, T1 weighted and diffusion-weighted sequences in three orthogonal planes. Additionally, single-shot echo planar diffusion-tensor sequences $(32$ gradient encoding directions, $\mathrm{b}$ value $=$ $700 \mathrm{~s} / \mathrm{mm}^{2}$, slice thickness $4.5 \mathrm{~mm}$, FOV 230) and a single voxel spectroscopy (TE $31 \mathrm{~ms}$ and $144 \mathrm{~ms}$ ) of the frontal white matter(WM) were acquired. Data of 40 fetuses (aged between 18-36 GW) and 5 age matched fetuses without structural brain abnormalities served as normal controls.

RESULTS

In both cases T2-weighted images showed bilateral frontal polymicrogyria and mild ventriculomegaly. T2-w and T1w sequences depicted subtle signal abnormalities of the fetal frontal white matter. Compared to age matched controls, tractography was not able to visualize the regular pattern of callosal connectivity especially in the forceps minor area, paralleling the abnormal FA values and the abnormal lactate and lipid peaks displayed by single voxel spectroscopy. In both cases the diagnosis of Zellweger disease was confirmed by biochemical and genetical testing. Moreover in one case neuropathological correlation was available.

CONCLUSION

This is the first study to show the feasibility of modern neuroimaging methods (DTI and spectroscopy) in the prenatal diagnosis of a rare metabolic disorder. Abnormal white matter development can be readily detected, prior to the onset of myelination.
TH2:4

\section{QUANTIFICATION AND CORRELATION OF CEREBRAL SPINAL FLUID FLOW AT THE CRANIOVERTEBRAL JUNCTION AND WITHIN THE CEREBRAL AQUEDUCT IN NORMAL CONTROLS AND CHIARI I MALFORMATIONS: A PROSPECTIVE STUDY}

J. BAPURAJ, D J QUINT, F LONDY, JM MYLES, S KHALATBARI, KM MURASCKO, C MAHER, T HOBAN, M MICHELOTTI, S ROHRER

UNIVERSITY HOSPITAL, UNIVERSITY OF MICHIGAN, ANN ARBOR, MI, USA

11 normal healthy volunteers and 8 patients of with symptomatic Chiari I malformations were imaged on a 3 Tesla MRI scanner. Subsequent to localization, two phase contrast scans were performed perpendicular to the craniovertebral junction (CVJ) and aqueduct of Sylvius. Scan parameters were: TR \& TE $=$ min (typically $12.3 \mathrm{~ms} / 8.2 \mathrm{~ms}$ ), averages $=2$, flip angle $=10^{\circ}$, FOV $=$ $250 \times 180 \mathrm{~mm}$ using a $252 \times 179$ matrix and $4 \mathrm{~mm}$ slices, scans were flow compensated. Fifteen temporal phases over the cardiac cycle were acquired using a peripheral-pulse oxygenation signal for retrospective triggering. Scans were repeated performed with the patient's neck in flexion, extension and neutral positions for a total of six phase contrast scans. Velocity encoding was optimized per patient.CSF flow velocities were calculated at the CVJ and within the aqueduct for all three head positions. A statistical model of the CSF flow dynamics was developed in order to evaluate differences in location and position using a Cosinor transformation

RESULTS

CSF flow was well categorized by the Cosinor model $(\mathrm{p}<.0001)$. The flows were significantly different between 2 locations and between patients and normal controls. The maximum absolute mean velocity in $\mathrm{cm} / \mathrm{sec}$ for the control patients in the neutral position was $1.1(.5)$ for the aqueduct and 1.9 (.5) for the CVJ of the controls versus 2.1 (1.1) and 3.0 (1.5) for the Chiari I patients. The change in flow in the aqueduct wais delayed as compared to the CVJ.

\section{CONCLUSION}

Data suggests that patients with symptomatic Chiari I malformations demonstrate increased CSF flow rates in both the aqueductal and foramen magnum with a trend towards higher flow rates and with more variation at the latter level; it is possible that this observation might represent a marker for Chiari patients who could benefit from surgery.

\section{TH2:5}

\section{HIPPOCAMPAL DEVELOPMENT DURING THE 23RD TO 36TH GESTATIONAL WEEKS. AN ULTRASOUND STUDY}

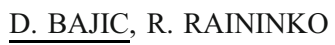

DEPARTMENT OF RADIOLOGY, UNIVERSITY HOSPITAL UPPSALA, UPPSALA, SWEDEN 


\section{PURPOSE}

During fetal development, the hippocampal structures infold around the hippocampal sulcus into the temporal lobe. The hippocampal shape resembles the adult at 21 st gestation weeks (GW). The inversion is incomplete if the hippocampal form in the coronal slices is round or pyramidal. We have shown earlier that incomplete hippocampal inversion (IHI) is found in $19 \%$ of the common population. The aim of this study is to document the fetal hippocampal development by studying infants born preterm.

METHODS AND MATERIAL

We analyzed cranial US examinations, from a 3-year-period and excluded children with brain pathology, such as haemorrhage grade II-IV, periventricular leukomalacia or hydrocephalus. Our material consisted of 160 children born $<34 \mathrm{GW}$. We evaluated the hippocampal form in coronal slices. A rounded form (the ratio between the horizontal and vertical diameters of the hippocampal body „T 1) was considered the sign of IHI. RESULTS

The age at examination was $23-24 \mathrm{GW}$ in 24 children, $25-28 \mathrm{GW}$ in 72 children, and $29-36 \mathrm{GW}$ in 64 children. IHI was found in $50 \%$, $25 \%$ and $14 \%$, respectively. The frequency difference between the children $<25$ weeks and ,d 25 weeks was statistically highly significant $(\mathrm{p}<0.001, £ \mathrm{q} 2$ test). Bilateral IHI was most common in the youngest age groups: 7 in 24 infants at 23-24 GW and 11 in 136 infants at $25-36 \mathrm{GW}$. The difference was statistically significant ( $\mathrm{p}$ 0.003). Unilateral IHI was situated mostly on the left side in all age groups, only 3 on the right.

CONCLUSION

In $50 \%$ of the infants, hippocampal inversion was not completed up to GW 24. From 25 FGW onwards, the frequency of IHI is similar to that in adult population. Hippocampal inversion seems to continue longer than presumed in the earlier studies based in small materials of aborted fetus. Unilateral IHI is usually left-sided.

\section{TH2:6}

\section{MRI OF FETAL INTRACEREBRAL HEMORRHAGE}

U. ASENBAUM ${ }^{1}$, PC. BRUGGER ${ }^{2}$, G. KASPRIAN ${ }^{1}$, B. ULM $^{3}$, A. MESSERSCHMIDT ${ }^{4}$, D. PRAYER ${ }^{1}$

${ }^{1}$ DEPARTMENT OF NEURORADIOLOGY, UNIVERSITY CLINICS OF RADIODIAGNOSTICS, MEDICAL UNIVERSITY OF VIENNA, AUSTRIA, VIENNA, AUSTRIA, ${ }^{2}$ CENTER OF ANATOMY AND CELL BIOLOGY, MEDICAL UNIVERSITY OF VIENNA, AUSTRIA, VIENNA, AUSTRIA, ${ }^{3}$ DEPARTMENT OF OBSTETRICS AND MATERNAL-FETAL MEDICINE, MEDICAL UNIVERSITY OF VIENNA, AUSTRIA, VIENNA, AUSTRIA, ${ }^{4}$ DIVISION OF GENERAL PEDIATRICS AND NEONATOLOGY, DEPARTMENT OF PEDIATRICS AND ADOLESCENT MEDICINE, MEDICAL UNIVERSITY OF, VIENNA, AUSTRIA

\section{PURPOSE}

Prenatal appearance and postnatal outcome of fetal intracerebral hemorrhage (ICH) detected by in-vivo MRI.

\section{METHODS}

21 fetuses aged from 18-39 gestational weeks who underwent fetal MRI were included. MRI was performed using a $1.5 \mathrm{~T}$ superconducting system, and a sense cardiac coil. Ultrafast T2-weighted fast spin-echo sequences, T1-weighted gradient -echo sequences, diffusion-weighted sequences, and echoplanar sequences were per- formed with a slice-thickness of 3-5 $\mathrm{mm}$, in 3 orthogonal section planes. Evaluation included identification of blood-breakdown products (BBP), associated changes, such as brain-edema and/or widening of ventricles, and/or tissue loss. Classification of intraventricular hemorrhage (IVH) was done following the Burstein criteria (Grade IIV). For follow-up, postnatal imaging studies and/or clinical assessment was available in 10 cases.

\section{RESULTS}

BBP were identified in 11 cases within the ventricles and/or in the ependyma and in 7 fetuses within the parenchyma. In 2 cases no BBP were detected, but associated findings suggested the former presence of ICH. These changes consisted of: ventricular enlargement, tissue loss and brain-edema. In 3 cases the pregnancy was terminated, 2 fetuses died intrauterine. 10 were born alive (1 Grade I, 2 Grade II, 2 Grade II-III, 2 Grade IV, 3 primary parenchymal hemorrhage), 2 are still pregnant (2 IVH II-III). 4 cases were lost to follow up.

\section{CONCLUSION}

ICH can readily be identified by in-vivo fetal MRI. In contrast to postnatal ICH, grade IV IVH and/or extended parenchymal involvement is not necessarily associated with adverse outcome. Prognostic criteria of fetal ICH will have to be established in the future.

\section{TH2:7}

\section{PRENATAL DEVELOPMENT OF THE SUBDURAL SPACE IN FETAL MRI}

\author{
M. SCHMOOK $^{1}$, P. BRUGGER ${ }^{2}$, G. KASPRIAN ${ }^{1}$, S. NEMEC ${ }^{1}$, \\ D. PRAYER ${ }^{1}$
}

${ }^{1}$ MEDICAL UNIVERSITY OF VIENNA - DEPARTMENT OF MUSCULOSCELETAL AND NEURORADIOLOGY, VIENNA, AUSTRIA, ${ }^{2}$ MEDICAL UNIVERSITY OF VIENNA - DEPARTMENT OF SYSTEMATIC ANATOMY, VIENNA, AUSTRIA

\section{PURPOSE}

The subdural space (sds) is known to be undepictable in mature individuals, becoming visible only in pathological conditions like subdural hematoma. Reporting fetal MRIs, we repeatedly noticed that the sds was fluid filled without evidence of intracranial pathology. The purpose of this retrospective study was to evaluate the detectability of the sds with in vivo fetal MRI.

METHODS

MRI studies of 40 fetuses who underwent MRI for extra central nervous system pathologies were assessed. Fetal age ranged from gw (gestational week) 19-39 (average \pm std gw 28 \pm 6 ). MRI was performed on a $1.5 \mathrm{~T}$ magnet using a cardiac coil. T2-weighted SSFSE sequences through the fetal head were used to screen for and quantify the sds. For statistical analysis scatter plots as well as linear and non linear regressions using examination planes (axial, coronal, sagittal and oblique) and gw as predictors were assessed. RESULTS

The sds was fluid filled and detectable in $93 \%$, with no significant influence of $\mathrm{gw}$ on detectability $(\mathrm{p}>0.05)$. If detectable, its maximum diameter ranged from 2 to $6.5 \mathrm{~mm}$ (average \pm std $4.4 \mathrm{~mm} \pm 1.3$ ). There was a significant quadratic relation between the maximum diameter in axial plane and the gestational week $(p=0.023)$, with higher widths in gw 25-32. Oblique planes showed a signifcantly lower detectabillity of the subdural space than orthogonal planes $(\mathrm{p}=0.026)$. 


\section{CONCLUSION}

The sds is physiologically filled with cerebrospinal fluid in prenatal life, which may be visualized by in-utero MRI.

The findings provide new information about prenatal meningeal development and may serve as a basis to recognize pathologies involving meninges and/or CSF circulation.

\section{TH2:8}

\section{MAGNETIC RESONANCE IMAGING FINDINGS IN HUNTER DISEASE}

R. MANARA ${ }^{1}$, R. MARDARI ${ }^{1}$, E. PRIANTE ${ }^{1}$, M. GRIMALDI ${ }^{2}$, L. ASTARITA $^{3}$, P. CONCOLINO ${ }^{4}$, A. ROSSI ${ }^{5}$, A. RAMPAZZO ${ }^{1}$,

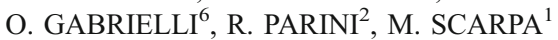

${ }^{1}$ NEURORADIOLOGIC UNIT, PADUA, ITALY, ${ }^{2}$ NEURORADIOLOGIC UNIT, MONZA, ITALY, ${ }^{3}$ UNIVERSITY HOSPITAL, NAPOLI, ITALY, ${ }^{4}$ UNIVERSITY HOSPITAL, CATANZARO, ITALY, ${ }^{5}$ GASLINI, GENOVA, ITALY, ${ }^{6}$ UNIVERSITY HOSPITAL, ANCONA, ITALY

Hunter syndrome (MPS II) is a rare X-linked recessive lysosomal storage disorder caused by iduronate-2-sulphatase deficiency. Despite a frequent neurological involvement, MRI studies on MPS II patients are limited.

\section{METHODS}

We evaluated 49 brain and cervical MRI of 21 Italian patients (20 males, mean age 7,5 years, age range 20 months to 19 years); 10 patients had more than 1 MRI scan (mean follow up 2,5 years). Subarachnoidal spaces enlargement, ventriculomegaly and perivascular space enlargement were scored according to Lee's scale; white matter abnormalities were scored 0-3 according to centrum semiovale involvement; skull, pituitary, posterior fossa, vertebral and disk abnormalities were recorded. Finally, spinal stenosis and myelopathy consequent to soft-tissue thickening posterior to the odontoid peg were evaluated.

RESULTS

Mild, moderate and severe ventriculomegaly was found in 1, 9 and 9 patients, respectively; subarachnoidal spaces enlargement was graded mild, moderate and severe in 3, 5 and 8 patients; perivascular space enlargement was scored 1,2 and 3 in 4, 5 and 11 patients, respectively. White matter abnormalities were present in all patients (grade 1, 2 and 3 in 7,8 and 6 cases, respectively). Tecal thickening $(>10 \mathrm{~mm})$ was found in 4 patients; J-shaped sella in 19; enlarged cisterna magna in 11; small posterior fossa in 3; Chiari 1 malformation in 2; craniosynostosis in 5; mild or severe dens dysplasia in 11 and 4; dural thickening $>10 \mathrm{~mm}$ in 2; platyspondylia in 17; disc anomalies in 17; kyphosis in 4, scoliosis in 3, lordosis in 2.

During the follow-up ventriculomegaly worsened in 3 patients, subarachnoidal spaces enlargement, white matter abnormalities and spinal stenosis in 1 patient each, while perivascular space enlargement and disk abnormalities did not change significantly. CONCLUSIONS

MRI abnormality spectrum in Hunter disease is wide; a global MRI score will help to quantify and follow-up neurological involvement.
TH2:9

\section{MRI OF JUVENILE ALEXANDER'S DISEASE}

R. ZIMMERMAN, L. BILANIUK, E. SCHWARTZ, A. POLLOCK, D. ZARNOW, T. FEYGIN, K. SHEKDAR, A. VOSSOUGH CHILDREN'S HOSPITAL OF PHILADELPHIA - DEPARTMENT
OF RADIOLOGY, PHILADELPHIA, PA, USA

\section{PURPOSE}

To review the MRI findings in four pediatric cases of the rare juvenile Alexander's disease.

MATERIAL \& METHODS

Four pediatric patients with either biopsy and/or genetic evaluation substantiating the imaging findings of juvenile Alexander's disease between ages 5 and 11 years were evaluated by MRI. They were compared to a variety of other pathologies imaged by MRI, as to differential diagnosis.

\section{RESULTS}

The most characteristic feature of all cases was the presence of symmetric bilateral foci of high signal intensity on T2 and FLAIR, which showed contrast enhancement. These lesions were found in the brain stem in the medullae, pons, and cerebellar peduncles. Clinical correlation was the presence of prolonged nausea and vomiting leading to imaging. CONCLUSION

Juvenile Alexander's disease has a characteristic appearance in the posterior fossae on MRI, that should not be confused with acute disseminated encephalomyelitis, brain stem glioma, or other pathologies.

\section{TH2:10}

\section{DEVELOPMENT OF FETAL EYE MOVEMENTS ASSESSED BY MRI}

R. WOITEK ${ }^{1}$, P.C. BRUGGER ${ }^{2}$, G. KASPRIAN ${ }^{1}$, C. LINDNER $^{1}$, F. STUHR ${ }^{1}$, D. PRAYER ${ }^{1}$

${ }^{1}$ MEDICAL UNIVERSITY OF VIENNA, DEPARTMENT OF RADIOLOGY, VIENNA, AUSTRIA, ${ }^{2}$ MEDICAL UNIVERSITY OF VIENNA, DEPARTMENT OF SYSTEMATIC ANATOMY, VIENNA, AUSTRIA

\section{PURPOSE}

To evaluate whether different types of fetal eye movements can be demonstrated using dynamic MR-sequences. MATERIALS AND METHOD

Following the eye movements classification of Birnholz (Science. 1981, 213:679-81) we assessed: short single linear deviation of the bulbs to the periphery as type I, single prolonged deviation of the bulbs as type II, deviations with rotatory compoments as type III and nystagmoid movements as type IV. No eye movements at all were classified as type 0 .

\section{RESULTS}

In 36 fetuses from 18-40 gestational weeks (GW) with presumed normal brain development eye movements were studied during MRexaminations. Fetal MRI was done for clinical purposes on a $1.5 \mathrm{~T}$ 
system using a sense cardiac coil. Dynamic steady-state free precession sequences (slice thickness 15-20 mm) with 6 frames/ second, and subsequent calculation for real-time appearance, were acquired 2-5 times in axial and/or coronal plane for 35 seconds. Fetuses were divided into groups: GW 18-23 (6 cases), 24-32 (17 cases), and 33-40 (13 cases).

In fetuses from GW 18-23 only type I (3) and type 0 movements (3) occured. In GW 24-32 type I movements were seen in 4, type II in 6, type III in 6 , type IV in 1 . Type 0 was seen in 5 . Fetuses between GW 33 to 40 . This group of fetuses displayed type II movements (4), type III movements (4) and type IV movements (3).

CONCLUSION

The development of fetal eye movements can be recorded in-vivo using dynamic MR sequences. Age- related eye movement patterns can be recognized, reflecting maturational changes in the brainstem. These assessments may be helpful in the diagnosis of malformations associated with impairment of brainstem functions, such as, molartooth malformations, hydrocephalus and Chiari II malformations.

\section{TH3}

\section{6:55-17:45 - Demyelinating diseases III}

TH3:1

\section{MRI PERFUSION WEIGHTED IMAGING (PWI) IN PATIENTS WITH CLINICALLY ISOLATED SYNDROME (CIS) CONVERTED TO MULTIPLE SCLEROSIS (MS) : INCREASED PERFUSION COMPARED TO THE NON- CONVERTED CIS PATIENTS}

E. PAPADAKI ${ }^{1}$, E. AMANAKIS ${ }^{1}$, V. MASTORODIMOS ${ }^{2}$, K.

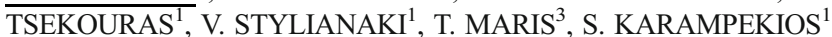

${ }^{1}$ UNIVERSITY HOSPITAL , DEPARTMENT OF RADIOLOGY, HERAKLION, GREECE, ${ }^{2}$ UNIVERSITY HOSPITAL , DEPARTMENT OF NEUROLOGY, HERAKLION, GREECE, ${ }^{3}$ UNIVERSITY HOSPITAL , DEPARTMENT OF MEDICAL PHYSICS, HERAKLION, GREECE

\section{PURPOSE}

To investigate possible hemodynamic differences among :a) the CIS patients that have converted to clinically definite MS (CIS-conv) b) those that remain CIS 2 years after the first MRI exam.

MATERIAL-METHODS

30 patients with CIS (17 CIS-conv) were studied at an $1.5 \mathrm{~T} \mathrm{MR}$ scanner. A dynamic susceptibility contrast PWI technique was applied and absolute values of relative cerebral blood volume (rCBV) and relative cerebral blood flow (rCBF) were estimated. 480 measurements were performed concerning normal appearing white matter of the CIS $($ NAWM-CIS $=104)$ and the CIS-conv (NAWM-CISconv=136), and, also, the thalami, caudate nuclei, putamen ,genu and splenium of the corpus callosum of the CIS (THAL-CIS $=26$, CAUD-CIS $=26$, PUT$\mathrm{CIS}=26$ and CALL-CIS $=26$ ) and the CIS-conv (THAL-CISconv $=34$, CAUD-CISconv $=34$, PUT-CISconv $=34$ and CALL-CISconv $=34$ ). The $\mathrm{rCBV}$ and $\mathrm{rCBF}$ values of the different estimated regions of the CIS and the CIS-conv patients were compared with student's t-test. RESULTS

NAWM-CISconv is characterized by significantly higher rCBV and rCBF values compared to the respective values of NAWM-CIS $(p=$
0,022 and $p=0,01$ respectively), while the $\mathrm{rCBV}$ values of THALCISconv and PUT-CISconv are significantly higher compared to the respective values of THAL-CIS and PUT-CIS ( $p=0,04$ and $p=0,006$ respectively). There is no significant difference between the $\mathrm{rCBV}$ and rCBF values of CAUD-CISconv and CAUD-CIS $(p=0,15$ and $p=0,6$ ), or between CALL-CISconv and CALL-CIS ( $\mathrm{p}=0,08$ and $\mathrm{p}=0,52)$. CONCLUSION

At the first MRI exam, the NAWM, basal ganglia and thalami of patients with CIS converted to MS are characterized by increased rCBV and $\mathrm{rCBF}$ values compared to the respective values of the patients that remain CIS 2 years afterwards. This finding suggests that severe diffuse perivascular inflammation of the white and deep gray matter in patients with CIS predisposes the evolution to clinically definite MS, and the PWI quantitative parameters may be used as prognostic factors in patients with CIS suggestive of MS.

\section{TH3:2}

\section{APPLICATION OF A PERFUSION WEIGHTED IMAGING (PWI)MRI TECHNIQUE IN PATIENTS WITH CLINICALLY ISOLATED SYNDROME (CIS) SUGGESTIVE OF MULTIPLE SCLEROSIS(MS) : DIFFUSE WHITE AND DEEP GRAY MATTER DISEASE}

E. PAPADAKI ${ }^{1}$, E. AMANAKIS ${ }^{1}$, V. MASTORODIMOS ${ }^{2}$,

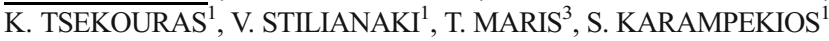

${ }^{1}$ UNIVERSITY HOSPITAL-DEPARTMENT OF RADIOLOGY, HERAKLION, GREECE, ${ }^{2}$ UNIVERSITY HOSPITALDEPARTMENT OF NEUROLOGY, HERAKLION, GREECE, ${ }^{3}$ UNIVERSITY HOSPITAL-PEPARTMENT OF MEDICAL PHYSICS, HERAKLION, GREECE

\section{PURPOSE}

To investigate possible hemodynamic impairment at the earliest clinical stages of MS : in patients with CIS suggestive of multiple sclerosis.

MATERIALS AND METHODS

30 patients with CIS and 10 healthy volunteers were studied at an $1.5 \mathrm{~T}$ MR scanner (Siemens, Vision plus). A PWI technique was applied and absolute values of relative cerebral blood volume ( $\mathrm{rCBV}$ ) and relative cerebral blood flow (rCBF) were estimated. 640 measurements were performed concerning normal white matter of the healthy volunteers $(\mathrm{NWM}=80)$, normal appearing white matter of the patients (NAWM= 240), and, also, the thalami, caudate nuclei, putamen ,genu and splenium of the corpus callosum of the normal subjects $($ THAL-No $=$ $20, \mathrm{CAUD}-\mathrm{No}=20, \mathrm{PUT}-\mathrm{No}=20$ and CALL-No $=20)$ and the patients (THAL-CIS $=60$, CAUD-CIS $=60$, PUT-CIS $=60$ and CALL-CIS $=60$ ). The absolute values of $\mathrm{rCBV}$ and $\mathrm{rCBF}$ of the different estimated regions were compared with student's t-test.

\section{RESULTS}

NAWM is characterized by significantly higher $\mathrm{rCBV}$ and $\mathrm{rCBF}$ values compared to the respective values of NWM ( $p=0,005$ and 0,01 respectively), while the $\mathrm{rCBV}$ and $\mathrm{rCBF}$ values of CAUD-CIS and PUT-CIS were significantly higher compared to the respective values of CAUD-No and PUT-No ( $p=0,002$ and $0,001, p=0,01$ and 0,03 ). There is no statistically significant difference between the $\mathrm{rCBV}$ and $\mathrm{rCBF}$ values of THAL-No and THAL-CIS ( $\mathrm{p}=0,1$ and 0,3 respectively), or between CALL-CIS and CALL-No ( $\mathrm{p}=0,33$ and 0,52 respectively). 


\section{CONCLUSION}

NAWM regions and the basal ganglia of patients with CIS suggestive of multiple sclerosis, are characterized by increased rCBV and $\mathrm{rCBF}$ values compared to the respective values of the healthy subjects, probably reflecting diffuse inflammation, while there is no analogous involvement of the corpus callosum and thalami. This finding suggests that diffuse perivascular inflammation at the stage of CIS suggestive of MS, precedes the vascular occlusion and chronic ischemia at the stage of clinically definite MS.

\section{TH3:3}

\section{ULTRA-HIGH-FIELD MR IMAGING IN PATIENTS WITH CLINICALLY ISOLATED SYNDROME}

K. KOLLIA ${ }^{1}$, N. PUTZKI ${ }^{2}$, S. MADERWALD ${ }^{3}$, E.R. GIZEWSKI ${ }^{1}$, M. SCHLAMANN ${ }^{1}$, J.M. THEYSOHN ${ }^{1}$, M.E. LADD ${ }^{3}$, M. FORSTING ${ }^{1}$, I. WANKE ${ }^{1,4}$

${ }^{1}$ UNIVERSITY HOSPITAL ESSEN - DEPARTMENT OF DIAGN. \& INTERV. RADIOLOGY AND NEURORADIOLOGY, ESSEN, GERMANY, ${ }^{2}$ KANTONSSPITAL ST. GALLEN - DEPARTMENT OF NEUROLOGY, ST. GALLEN, SWITZERLAND, ${ }^{3}$ UNIVERSITYDUISBURG-ESSEN - ERWIN L. HAHN INSTITUTE FOR MAGNETIC RESONANCE IMAGING, ESSEN, GERMANY, ${ }^{4}$ NEUROZENRUM ZÜRICH -KINIK HIRSLANDEN, ZÜRICH, SWITZERLAND

\section{PURPOSE}

Ultra-High-Field MRI (7 Tesla) has already shown an improved visualisation and detection of white and gray matter lesions in patients with multiple sclerosis (MS). The purpose of this study was to evaluate the potential of 7 Tesla MR Imaging and investigate whether it has an impact on the classification in patients with clinically isolated syndrome (CIS) suggestive of MS, according to MR imaging.

METHODS

Twelve consecutive patients with CIS were examined in a prospective intraindividual study with a $1.5 \mathrm{~T}$ and $7 \mathrm{~T}$ MR imaging system (Avanto and Magnetom 7 T, Siemens Medical Solutions, Erlangen), including axial sections of high-resolution proton density (PD)_ T2-weighted turbo spin echo, T2*-weighted gradient echo (GRE) and sagittal T1-weighted 3D magnetisationprepared rapid acquisition of gradient echo before and after injection of macrocyclic gadobutrolum.

RESULTS

The sequence parameters at $7 \mathrm{~T}$ had to be modified because of specific absorption rate (SAR) restrictions while keeping contrast parameters equivalent to $1.5 \mathrm{~T}$. White matter lesions were better detected and delineated from adjacent structures at $7 \mathrm{~T}$ compared with 1.5 T. Five patients fulfilled more MR imaging criteria at 7 Tesla. One of these patients fulfilled the criterion of dissemination in space (DIS) according to the first definition of McDonald criteria, which is based on imaging criteria alone.

CONCLUSION

Ultra-High-Field MRI showed better lesion detection in patients with CIS. 7 Tesla MR imaging could have a substantial influence on the classification of patients with CIS according to imaging, leading to consequences for prognostic classification and imaging guidelines.

\section{TH3:4}

\section{CORRELATION OF CORTICAL LESIONS \\ WITH NEUROPSYCHOLOGIC AND CLINICAL MEASURES IN MULTIPLE SCLEROSIS PATIENTS}

\author{
M. GAVRA ${ }^{1}$, M. PAPATHANASIOU ${ }^{1}$, K. VOUMVOURAKIS ${ }^{2}$,

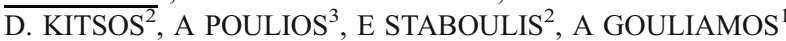 \\ ${ }^{1}$ 2ND DEPARTMENT OF RADIOLOGY, UNIVERSITY OF \\ ATHENS, ATTIKON UNIVERSITY HOSPITAL, ATHENS, \\ GREECE, ${ }^{2}$ 2ND DEPARTMENT OF NEUROLOGY, UNIVERSI- \\ TY OF ATHENS, ATTIKON UNIVERSITY HOSPITAL, ATHENS, \\ GREECE, ${ }^{3}$ DEPARTMENT OF PSYCHOLOGY, UNIVERSITY OF \\ ATHENS, ATHENS, GREECE
}

\section{PURPOSE}

To investigate the correlation of cortical lesions, with cognitive, motor and cerebellar function in patients with multiple sclerosis (MS).

METHODS

Fourty patients with clinically definite MS underwent brain MR using a 1,5 $\mathrm{T}$ imager. Cortical lesions were well depicted on double inversionrecovery sequence (DIR) with $3 \mathrm{~mm}$ contiguous slices in the axial plane. Lesions were classified according to their location in three anatomic regions: intracortical, mixed gray-white matter and juxtacortical. Patients' function was estimated by the Multiple Sclerosis Functional Composite (MSFC) scale. The Pearson $r$ coefficient was used in order to investigate the correlation between the MSFC score, and each score that constitutes it and the cortical lesions (total and each category).

\section{RESULTS}

No correlations were found between total number of cortical lesions and each category with motor and cerebellar function. A significant inverse correlation was found between the number of mixed lesions and cognitive function, as measured by Paced Auditory Serial Addition Test (PASAT) $(\mathrm{r}=-0,36, \mathrm{p}<0,05)$. A multivariant analysis showed that of all cortical lesions and the subcategories of them, only mixed lesions $(p=0,001)$ were independent factors most related to cognitive function.

CONCLUSIONS

Our results suggest that the number of cortical lesions, either in total or specifically the three categories, detected on DIR sequence, does not correlate with motor and cerebellar function in MS patients. Among the three categories of cortical lesions, only mixed lesions correlate significantly with cognitive function and could be an independent predictor of it.

\section{TH3:5}

\section{RESTRICTED DIFFUSION IN INFLAMMATORY LESIONS IN CHILDREN}

$\underline{\text { M. SEVERINO }}^{1}$, C DEVILLE $^{2}$, DE SAUNDERS ${ }^{1}$

${ }^{1}$ DEPARTMENT OF RADIOLOGY, GREAT ORMOND STREET HOSPITAL, LONDON, UNITED KINGDOM, ${ }^{2}$ DEPARTMENT OF NEUROLOGY, GREAT ORMOND STREET HOSPITAL, LONDON, UNITED KINGDOM

\section{AIM}

Diffusion-weighted imaging (DWI) has a well-established role in the assessment of acute ischaemic infarction in adults and children demonstrating the characteristic cytotoxic oedema. On the other hand, 
the wide application of this technique during the last decade has widened the spectrum of central nervous system disorders associated with restricted diffusion, including inflammatory and demyelinating disorders.

METHODS

We report a small series of four children ( 3 females, mean age 6 years, range 2,5-10 years) with different types of inflammatory lesions showing only restricted diffusion at presentation.

RESULTS

Two patients presented with clinically mild encephalitis/encephalopathy and callosal and hemispheric white matter lesions with reversible restricted diffusion following a short viral illness ("extended MERS"). The third patient was diagnosed an acute disseminated encephalopathy (ADEM) and presented with bilateral asymmetric periventricular and subcortical white matter abnormalities with marked restricted diffusion throughout the lesions. The last patient presented with an acute onset of left 3rd nerve palsy, diplopia, right upper motor neurone facial palsy, mild right hemiparesis and ataxia. The MRI scan showed a unilateral midbrain lesion with restricted diffusion. Vascular imaging was normal, neurological recovery was rapid and the lesion was thought to be inflammatory in origin.

\section{CONCLUSIONS}

Restricted diffusion is not confined to acute ischaemic infarction. Inflammatory and demyelinating lesions demonstrate decreased diffusivity on DWI and may be reversible and associated with a benign clinical course.

\section{TH3:6}

\section{PERTINENT MRI FINDINGS OF WERNICKE'S ENCEPHALOPATHY IN A PEDIATRIC PATIENT}

\author{
N. SIDDIQUI, I LOMA, G ZUCCOLI \\ University of Pittsburgh Medical Center, Pittsburgh, PA, USA
}

\section{PURPOSE}

Wernicke's encephalopathy caused by thiamine (vitamin B1) deficiency can be fatal if untreated. Post-mortem studies indicate that Wernicke's encephalopathy is underdiagnosed in the pediatric population. The aim of our study is to describe pertinent MRI findings, through an unusual case of Wernicke's encephalopathy, which should raise the clinical concern for this diagnosis in the pediatric age group.

METHODS

Multiplanar and multiecho MRI imaging of the brain was performed emphasizing the relative $\mathrm{T} 1, \mathrm{~T} 2 *$ and diffusion weighted signal characteristics using a $1.5 \mathrm{~T}$ MRI scanner. Clinical evaluation of the patient and relevant history from the family was obtained.

RESULTS

A ten year old male with a history of acute lymphoblastic leukemia presented with nonspecific mental status changes and cognitive decline. Symmetric high signal intensity alterations in the mamillary bodies, medial thalami, tectum of the midbrain, peri-aqueductal gray matter, medial vestibular nuclei, prepositus hypoglossal nuclei, substantia nigra, dentate nuclei, frontal cortex and cingulum cortex were noted on MR imaging. These findings raised the suspicion of Wernicke's encephalopathy which was confirmed on further clinical evaluation.

CONCLUSION

MR imaging is crucial in the diagnosis of Wernicke's encephalopathy, as the diagnosis in this case was not suspected prior to imaging. As demonstrated by our case report, atypical imaging features of
Wernicke's encephalopathy seen in the adult nonalcoholic population can also be present in the pediatric age group; these findings include symmetric high signal intensity in the periaqueductal gray matter, mamillary bodies and medial thalamus.

\section{TH3:7}

\section{SCHWANNOMAS OF THE CERVICAL SYMPATHETIC CHAIN}

\section{A. ANIL GOPINATHAN, T Y TAN}

DEPARTMENT OF RADIOLOGY, CHANGI GENERAL HOSPITAL, SINGAPORE, SINGAPORE

\section{PURPOSE}

To assess the role of cross sectional imaging in pre-operative diagnosis of schwannomas of the cervical sympathetic chain (CSCS). MATERIAL AND METHODS

This study included 12 patients with a proven schwannoma of the CSCS . A pre-operative diagnosis was given on CT and/ or MRI for all these patients. We have correlated the radiological inferences with surgical as well as histological findings and also reviewed the images for further useful clues to diagnose this pathology.

\section{RESULTS}

A pre-operative diagnosis of schwannoma was accurately made in 11 of the 12 cases. Meanwhile sympathetic trunk was correctly identified as the nerve of origin in 10 of the 12 cases. All the tumors were solitary and located in the carotid space, medial to the vessels of the carotid sheath. Anterolateral displacement of the internal carotid artery (ICA) was seen in 9 of the 12 cases, neutral position of the artery was noted in 2 cases and paradoxical posterolateral displacement was seen in a single case. Unlike vagal schwannomas none of these lesions, save one, caused separation of ICA and IJV ( internal jugular vein). Splaying of the carotid bifurcation was seen in 4 cases. The masses were well defined and predominantly hypodense on CT scan with poor enhancement. On MRI they were heterogeneously hyperintense on T2WI with marked inhomogeneous enhancement on post gadolinium T1WI.

CONCLUSION

At CT and MR imaging, CSCS can be confidently distinguished from lymph nodes, carotid body tumors and ectopic salivary neoplasm, which are the main differentials for this pathology. Imaging is also fairly reliable in separating CSTS from Vagal schwannoma.

\section{Saturday, September 19, 2009 - Terpsichore Room}

\section{TE4}

\section{1:10-12:10 - Imaging of the spine and spinal cord}

\section{TE4:1}

\section{SPINAL CORD DTI AND FIBER-TRACKING AFTER STEM CELLS THERAPY IN ALS PATIENTS}

A. STECCO $^{1}$, L. MAZZINI ${ }^{2}$, L. TESTA ${ }^{2}$, F. MONACO ${ }^{2}$, $\overline{\text { A. SAPONARO }}^{1}$, N.P. NUZZI ${ }^{1}$, A. CARRIERO ${ }^{1}$

${ }^{1}$ SCDU RADIOLOGIA - AOU MAGGIORE CARITA', NOVARA, ITALY, ${ }^{2}$ SCDU NEUROLOGIA - AOU MAGGIORE CARITA', NOVARA, ITALY 


\section{METHOD AND MATERIALS}

Between January 2005 and march 2008 we enrolled 12 patients with clinically defined ALS, who underwent to stem cells transplantation. The patients had a MR scan before and after (15 days, 3 months, 6 months, 9 months, 12 months, 18 months, 24 months). The MR examination has been performed on a $1.5 \mathrm{~T}$ magnet, with a pulse's protocol inclunding FLAIR, SE T1 and DTI on the brain parenchima, and SE T1, before and after gadolinium, SE T2, STIR and DTI on the spine.

Spine DTI has been acquired by mean of a coronal Multi-shot EPI pulse, and then post-processed by mean of a proprietary software. We measured FA, ADC of the fibers reconstructed in two sites, looking at the axial section of the model: at the site of implant and peripheral to that area.

The measurements have been repeated two times, to average the measure's error, and repeated at the same sites in every follow-up examination. We analyzed statistically (Student $t$ test), for FA and $\mathrm{ADC}$, the differences between the means of lesional and control sites, and the temporal changes of of these parameters in the follow-up scans.

RESULTS

Our data show that in the site of implant there is a post-treatment decrease of FA, in the following MR scans has a increasing trend to achieve a final FA value similar to that measured before the transplantation. These study is actually a work in progress and data will be further elaborated with new patients and more follow-up scans. Functional and Clinical data have been correlated to DTI metrics results.

CONCLUSION

This data demonstrates the absence of a irreversible damage to the spinal cord, while signal alteration that can be observed after transplant could be due to posptprocedural edema and the substrate into which are injected the stem cells. The FA values explore the neuronal integrity and density and can be useful to combine DTI measurments with the clinical assesment.

\section{TE4:2}

\section{COMPARISON OF GADOBENATE DIMEGLUMINE AND GADODIAMIDE IN THE EVALUATION OF SPINAL VASCULAR ANATOMY WITH MAGNETIC RESONANCE ANGIOGRAPHY}

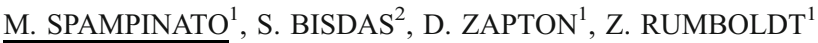

${ }^{1}$ MEDICAL UNIVERSITY OF SOUTH CAROLINA, CHARLESTON, SC, USA, ${ }^{2}$ DIAGNOSTIC AND INTERVENTIONAL NEURORADIOLOGY, EBERHARD KARLS UNIVERSITY, TUBINGEN, GERMANY

\section{PURPOSE}

To prospectively compare gadobenate dimeglumine with gadodiamide ( $0.2 \mathrm{mmol}$ per kilogram body weight) in the assessment of the normal anatomy of the spinal vasculature using contrast - enhanced magnetic resonance angiography (MRA).

MATERIALS AND METHODS

8 males and 12 females underwent two temporally separated contrastenhanced MRA exams of the spine, one with gadobenate dimeglumine and one with gadodiamide at a dose of $0.2 \mathrm{mmol} / \mathrm{kg}$ in a randomized order. Multiplanar reformation and maximum intensity projection reconstructions were evaluated separately and in matched pairs by two blinded observers who rated the studies on a series of qualitative parameters on a scale of 1 to 5 (background homogeneity, sharpness, continuity of the vascular structures, contrast enhancement). Delineation of the anterior spinal artery (ASA), length of the visualized portion of the ASA, delineation of the artery of Adamkievicz (AKA), delineation of the hairpin configuration of the ASA-AKA for each study were also recorded. During matched-pairs evaluation each observer indicated which of the two matched studies he / she thought was overall of the best diagnostic quality. RESULTS

According to both observers gadobenate dimeglumine was superior to gadodiamide in the representation of vascular continuity and contrast ( $p$-value $<0.05$ ). Background homogeneity was not significantly different between gadobenate dimeglumine-enhanced and gadodiamide-enhanced MRA studies. One of the observers favored gadobenate dimeglumine over gadodiamide in the demonstration of vascular sharpness, while the second observer did not find any significant difference between the two contrast agents. There was no significant difference between the two contrast agents in the visualization of the ASA, of the overall visualized length of the ASA, of the AKA, of the hairpin- shaped connection between the ASA and AKA.

CONCLUSION

Significantly improved image quality and vascular contrast enhancement of spine MRA at 1.5 Tesla is achieved with gadobenate dimeglumine compared to gadodiamide at equivalent doses.

\section{TE4:3}

\section{EVALUATION WITH CT PERFUSION OF THE RADIATION THERAPY EFFECTS ON SPINAL CORD HEMODYNAMICS IN PATIENTS WITH HEAD AND NECK MALIGNANCIES}

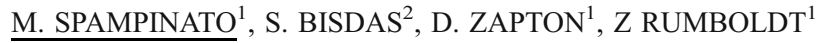 \\ ${ }^{1}$ MEDICAL UNIVERSITY OF SOUTH CAROLINA, CHARLES- \\ TON, SC, USA, ${ }^{2}$ DIAGNOSTIC AND INTERVENTIONAL \\ NEURORADIOLOGY KARLS EBERHARD UNIVERSITY, \\ TÜBINGEN, GERMANY
}

\section{OBJECTIVE}

We used CT perfusion (CTP) to evaluate the effects of radiation therapy (RT) on spinal cord (SC) hemodynamics in patients without symptoms of myelopathy. We hypothesized that SC perfusion can be acutely altered during RT.

METHODS

Neck CTP studies obtained in 36 patients (N1) with head and neck malignancies were reviewed. Sixteen patients had previously undergone RT of the head and neck (median dose $=70 \mathrm{~Gy}$, median interval between RT and imaging $=12$ months) and twenty patients had never been treated with RT. In a separate group of 6 patients (N2) neck CTP studies were obtained before RT, after administration of $40 \mathrm{~Gy}$, and after treatment completion (median dose $=70$ Gy). CTP studies included the area treated with RT. The vertebral artery and internal jugular vein were used as arterial input and venous output function. Spinal cord blood flow (scBF), blood volume (scBV), mean transit time (MTT) and capillary permeability surface product $(\mathrm{CP})$ maps were obtained. Region of interest analysis was conducted outlining the entire section of the spinal cord. Mann-Whitney, Independent Sample t-tests and Friedman test were used for statistical analysis. Results were considered significant when $\mathrm{p}<0.05$. RESULTS

Perfusion measurements were not significantly different between patients who did and did not receive RT $(\mathrm{N} 1=36)$. In the sample of patients evaluated prior to, during and after RT $(\mathrm{N} 2=6), \mathrm{scBF}$ and $\mathrm{CP}$ were increased on CTP study obtained during treatment compared to 
the baseline and post-RT (chi-square scBF: 10.33, $\mathrm{p}=0.006$; chisquare CP: 7.9, $\mathrm{p}=0.019$ )

CONCLUSION

RT of the head and neck may cause transient perturbations of SC perfusion that seem to reverse after treatment. There are no definite chronic effects of RT on SC perfusion at the typical doses administered during treatment of head and neck malignancies

\section{TE4:4}

\section{DIAGNOSTIC VALUE AND SURGICAL IMPLICATIONS OF THE MAGNETIC RESONANCE IMAGING IN THE MANAGEMENT OF ADULT PATIENTS WITH BRACHIAL PLEXUS PATHOLOGIES}

\section{S. GEREVINI}

\section{SAN RAFFAELE HOSPITAL, MILAN, ITALY}

Imaging of the brachial plexus cannot easily be detected because of the extension of the region to be studied, different compositions of the adjacent anatomic structures and need of small acquisition thickness. We show our experience with a brachial plexus MRI protocol based on small thickness and multiplanar acquisition. Brachial plexus was imaged with FSE T2, T1, DP fat sat and STIR sequences on coronal sagittal and axial plane before Gd injection and axial and coronal T1W segmented Inversion recovery after a bolus of Gd-DTPA. Myelo MRI was done.

We studied 306 patients (54\% male; mean age 46,4 years old) over a 5 years period. 81 pts presented post- traumatic plexus disease, 43 neoplastic, 110 inflammatory disease, 44 with thoracic outlet disease. 28 pts doesn't not demonstrate a brachial plexus disease.

In the post traumatic group, beyond radicular damage (pre or post ganglionic) MR identified three kind of MRI aspects, that we correlate with axonal damage: neurotmesic, when radicolar avulsion is present and two other different types of axonal damage when the continuity of the nerve is preserved (neuropraxic and axonotmesic). The possibility to evaluate the single nerve volume modification, signal alteration and gadolium enhancement can help in define different types of nerve damage expecially when lesion is in continuity, and this, matched together with clinical and neurofisiolocal evaluation, leads to a correct management of the traumatic patient. In neoplastic pts MRI provide a topographic localization of the tumour showing nerve dislocations or infiltration. In inflammatory plexopathies MRI suggested the diagnosis and possible surgical implications about the site of confirming biopsy. In TOS BP MRI is helpful in analyzing the dynamically induced compression.

\section{TE4:5}

\section{DYNAMIC CERVICAL SPINE MRI: A NEW VIEW OF CERVICAL STENOSIS}

\section{SHAH, N LAZZARO, R WIGGINS, E QUIGLEY, U RASSNER}

\section{UNIVERSITY OF UTAH, SALT LAKE CITY, UT, USA}

\section{PURPOSE}

To introduce a novel application of the real-time balanced steady state free precession (bSSFP) imaging for the evaluation of cervical spinal stenosis.

\section{MATERIAL AND METHODS}

At our institution we have added bSSFP sequences to the degenerative cervical spine protocol (sagittal T1, T2, STIR and axial T2). The bSSFP parameters are as follows: field of view 280, phase anterior to posterior, phase 100, $10 \mathrm{~mm}$ slice, TR / TE 143.63 / 1.18, bandwidth 1395, temporal resolution 2 seconds, imaging time 2 minutes. All scans are performed on $1.5 \mathrm{~T}$ or $3.0 \mathrm{~T}$ MRI scanners with multichannel head and neck coil. The patient is instructed to repeatedly flex and extend move his/her head in a slow steady manner. RESULTS

Preliminary results suggest that the bSSFP images are vital in accurately demonstrating motion induced narrowing of the cervical spine in addition to statically visualized deformity of the cervical cord due to degenerative factors traditionally imaged (e.g. disc osteophyte complexes, ligamentum flavum redundancy, facet arthropathy). These sequences are supplementary to conventional MR sequences.

CONCLUSION Static conventional MRI sequences can be suboptimal in showing the positional causes of cervical spinal stenosis. This new application of bSSFP imaging reveals the dynamic causes using currently available MRI scanners and software.

\section{TE4:6}

\section{IDIOPATHIC TRANSVERSE MYELITIS IN CHILDREN: ANALYSIS OF MRI FINDINGS}

G ALPER $^{1}, \underline{\text { KA PETROPOULOU }}{ }^{2}$, CR FITZ $^{2}$, C MOORE $^{3}$

${ }^{1}$ DIVISION OF CHILD NEUROLOGY, DEPARTMENT OF PEDIATRICS - UNIVERSITY OF PITTSBURGH MEDICAL CENTER, PITTSBURGH, PA, USA, ${ }^{2}$ DIVISION OF NEURORADIOLOGY, DEPARTMENT OF RADIOLOGY - UNIVERSITY OF PITTSBURGH MEDICAL CENTER, PITTSBURGH, PA, USA, ${ }^{3}$ CENTER FOR RESEARCH ON HEALTH CARE DATA - UNIVERSITY OF PITTSBURGH MEDICAL CENTER, PITTSBURGH, PA, USA

\section{PURPOSE}

To delineate the MRI features of idiopathic transverse myelitis in children METHODS

Spine MRIs of pediatric patients (age less $=18$ years) who met the criteria for ATM by Transverse Myelitis Consortium Working Group and had been imaged within the 4 week of disease onset were retrospectively analyzed by two neuroradiologists blinded to specific clinical findings and outcome. The studies included a minimum of T1W, T2/FSET2 W and post contrast T1W sequences in sagittal and axial planes. The anatomic regions, vertebral segmental length, gray or white matter involvement, cord expansion, gadolinium enhancement, hemorrhage and presence of syrinx were examined. RESULTS

Thirty five patients fulfilled criteria for idiopathic transverse myelitis at first presentation. After mean follow-up of 6.09 years (0.04-20.64) 33 patients were diagnosed with idiopathic transverse myelitis, two with relapsing neuromyelitis optica and none with multiple sclerosis.

Mean age of onset was 10.05 years ( 0.50-16.89). Spinal MRIs of 27 children were available to review. The mean interval between symptom onset and MRI was 1.74 days (4.3-19). Spinal MRIs were abnormal in $21(78 \%)$ children while six patients had normal results. There were 30 lesions with a mean segment length of 5.0 per lesion. All patients had gray matter involvement. In 7 patient the abnormal 
signal marginally extended to central white matter as well. Majority of patients $(67 \%)$ demonstrated long segment lesions defined as $=3$ vertebral segments. Five lesions enhanced. Cervico-thorasic region was most frequently involved.

CONCLUSION

Spinal cord lesions of ATM in children typically involve gray matter. Majority of patients demonstrate longitudinally extensive lesions.

TE4:7

\section{DIFFUSION TENSOR MRI STUDY OF THE SPINAL CORD IN PATIENTS WITH MULTIPLE SCLEROSIS}

\author{
J. VON MEYENBURG ${ }^{1}$, B. WILM ${ }^{2}$, A. WECK $^{3}$, J. PETERSEN $^{4}$, \\ E. GALLUS ${ }^{1}$, E. SCHÄTZLE ${ }^{1}$, M. SCHUBERT ${ }^{4}$, N. GOEBELS ${ }^{3}$, \\ S.S. KOLLIAS ${ }^{1}$ \\ ${ }^{1}$ UNIVERSITY HOSPITAL ZÜRICH, INSTITUTE OF NEURORA- \\ DIOLOGY, ZÜRICH, SWITZERLAND, ${ }^{2}$ UNIVERSITY \& ETH \\ ZÜRICH, INSTITUTE FOR BIOMEDICAL ENGINEERING, \\ ZÜRICH, SWITZERLAND, ${ }^{3}$ UNIVERSITY HOSPITAL ZÜRICH, \\ DEPARTMENT OF NEUROLOGY, ZÜRICH, SWITZERLAND, \\ ${ }^{4}$ BALGRIST UNIVERSITY HOSPITAL, SPINAL CORD INJURY \\ CENTER, ZÜRICH, SWITZERLAND
}

\section{PURPOSE}

Diffusion weighted imaging (DWI) can potentially discern axonal loss and demyelination in white-matter tissue and serve as a marker for loss of tissue integrity $\{1\}$. Limited resolution in DWI has so far impeded focal evaluation of spinal cord tissue i.e. the differentiation between grey and white matter. Recent improvements in MR pulse sequence design have overcome these problems.

METHODS

Imaging was performed on a $3 \mathrm{~T}$ Philips Achieva. DTI data of 28 volunteers and 41 patients with relapsing remitting MS \{RRMS\}, secondary progressive MS $\{$ SPMS $\}$ or primary progressive MS $\{$ PPMS were acquired at the cervical, thoracic and lumbar levels of the spinal cord. In each region 6 transverse slices were acquired using an outer volume suppressed reduced field of view single-shot EPI sequence $\{2\}$. Fractional anisotropy $\{\mathrm{FA}\}$ and apparent diffusion coefficient $\{\mathrm{ADC}\}$ maps were calculated. Diffusivity values were evaluated in the posterior white matter $\{\mathrm{PWM}\}$ in normal appearing white matter.

RESULTS

Mean fractional anisotropy in the PWM was highest in volunteers $\{0.71 \pm 0.05\}$ and lowest in the PPMS group $\{0.61 \pm 0.07\}$. ADC values were lowest in volunteers $\{0.88 \pm 0.09\}$ and highest in the RRMS group $\{0.90 \pm 0.09\}$. In patients the decrease of FA was statistically significant on cervical level and showed a trend on thoracic level as compared to volunteers.

CONCLUSIONS

Correlation between diffusion anisotropy and axonal density in MS lesions has been observed by comparing MR-images and neuropathological findings $\{1\}$. Based on these observations our results suggest that axonal degeneration is most prominent in the PPMS group. The highest ADC values were seen in the RRMS group which might indicate that the degree of myelin loss in the RRMS patients is most prominent. FA difference between patients and the control group was highest at cervical level and decreasing when moving caudally reflecting a decrease of inflammation in a craniocaudal sense $\{3\}$.
Correlations between electrophysiological tests and diffusivity values are ongoing.

\{1\} Mottershead J.P. et al., J Neurol. 2003 Nov; 250\{11\}: 1293 301

\{2\} Wilm B.J. et al, Magn Reson Med. 2007 Mar; 57\{3\}: 625-30

\{3\} Tartaglino L.M. et al, Radiology. 1995 Jun; $195\{3\}: 725-32$

\section{TE5}

15:25-16:50 - Advanced imaging modalities I

\section{TE5:1}

\section{METABOLITE CONCENTRATIONS \\ IN SUPRAVENTRICULAR WHITE MATTER \\ FROM TEENAGE TO EARLY OLD AGE: DEPENDENT ON AGE BUT NOT ON SEX. A SHORT ECHO TIME 1H MRS STUDY}

\author{
$\underline{\text { R. RAININKO }}^{1}$, P. MATTSSON $^{2}$
}

${ }^{1}$ UPPSALA UNIVERSITY - DEPARTMENT OF RADIOLOGY, UPPSALA, SWEDEN, ${ }^{2}$ UPPSALA UNIVERSITY - DEPARTMENT OF NEUROSCIENCE, UPPSALA, SWEDEN

\section{PURPOSE}

To examine the effect of age on the metabolite concentrations measured by $1 \mathrm{H}$ MR spectroscopy (MRS) in normal cerebral white matter using a long repetition time (TR) and a short echo time (TE). This technique reduces quantification errors due to $\mathrm{T} 1$ and $\mathrm{T} 2$ relaxation effects and makes possible to measure metabolites with short $\mathrm{T} 2$ relaxation times.

METHODS

Supraventricular white matter of 57 healthy subjects ( 25 women, 32 men), aged 13 to 72 years, was examined with a single voxel MRS at $1.5 \mathrm{~T}$ using a TR of $6000 \mathrm{~ms}$ and a TE of $22 \mathrm{~ms}$. Quantification of the metabolite concentrations was made with LCModel. Tissue water was used as a reference.

\section{RESULTS}

Myoinositol increased slightly and total $\mathrm{N}$-acetylaspartate (NAA) decreased slightly with increasing age. Glutamine/glutamate complex (Glx) showed U-shaped age dependence with highest concentrations in the youngest and oldest subjects. No significant age dependence was found in total choline and total creatine. No gender differences were found. Macromolecule/lipid (ML) fractions were reliably measurable only in $36 / 57$ or in even fewer subjects and showed very large deviations.

\section{CONCLUSION}

The concentrations of several metabolites in cerebral supraventricular white matter are age-dependent on 1H MRS even in young and middle-aged people and age dependency can be nonlinear. Each $1 \mathrm{H}$ MR spectroscopy study of the brain should therefore take age into account whereas sex does not appear to be so important. The use of macromolecule and lipid evaluations is compromised by less successful quantification and large variations in healthy people.

When the results from different studies are compared, the concentrations of the major metabolites vary very much depending both on MRS techniques and spectrum analyzing programs and on brain regions. 
TE5:2

\section{BRAIN 1H-MRS IN LEBER OPTIC NEUROPATHY AND NON-AFFECTED MUTATION CARRIERS}

\author{
J. OSTOJIC $^{1}$, E. GOTSIS ${ }^{2}$, D KOZIC ${ }^{1}$, J JANCIC ${ }^{3}$, K KOPRIVSEK $^{1}$, \\ J KONSTANTINOVIC $^{1}$, M PRVULOVIC ${ }^{1}$
}

${ }^{1}$ DIAGNOSTIC IMAGING CENTER, INSTITUTE OF ONCOLOGY, SREMSKA KAMENICA, SERBIA, ${ }^{2}$ ADVANCED RESEARCH AND THERAPEUTIC INSTITUTE ENCEPHALOS/EUROMEDIC, ATHENS, GREECE, ${ }^{3}$ CLINIC OF NEUROLOGY AND PSYCHIATRY FOR CHILDREN AND YOUTH, SCHOOL OF MEDICINE, UNIVERSITY OF BELGRADE, BELGRADE, SERBIA

\section{INTRODUCTION}

We investigated the status of brain metabolism in patients with Leber's hereditary optic neuropathy (LHON) and their maternally related family members, clinically asymptomatic mtDNA mutation carriers.

\section{MATERIALS AND METHODS}

Six patients and twelve unaffected carriers from six unrelated families, bearing the homoplasmic 11778 and 3460 mutations and heteroplasmic14484 mutation undergone brain proton magnetic resonance spectroscopy (MRS) at $1.5 \mathrm{~T}$ and analysis of mtDNA sequence. The control group consisted of 50 healthy age matched volunteers, investigated by the same methodology.

RESULTS

The overall difference between group of LHON mutation carriers and control group in cortex was significant (MANOVA, $\mathrm{p}<0.001$; Linear discriminant analysis, $p<0.001)$. ANOVA showed significant difference for absolute [Cho], $(\mathrm{p}<0.001)$ and $\mathrm{Cho} / \mathrm{Cr}(\mathrm{p}<0.001)$. The absolute creatine $[\mathrm{Cr}]$ contributes most to discrimination between groups, followed by $\mathrm{Cho} / \mathrm{Cr}$ and [Cho]. The overall difference between group of LHON mutation carriers and control group in white matter was significant (MANOVA, $\mathrm{p}<0.001$; Linear discriminant analysis, $p<0.001)$. ANOVA showed significant difference for $[\mathrm{Cr}](\mathrm{p}<0.01)$ and $\mathrm{Cho} / \mathrm{Cr}(\mathrm{p}<0.01)$. The NAA/Cr contributes most to discrimination between groups, followed by $[\mathrm{NAA}]$ and $[\mathrm{Cr}]$ CONCLUSION

Decreased absolute $\mathrm{Cr}$ followed by decreased absolute Cho concentration in gray matter and decreased absolute NAA followed by decreased absolute $\mathrm{Cr}$ concentration in white matter have the most significant contribution in discriminating LHON mutation carriers from healthy controls.

\section{TE5:3}

\section{QUANTIFICATION OF [123I] - FP - CIT (DATSCAN) VOLUME IMAGING BY MATLAB FOR THE DIFFERENTIATION AND GRADING OF PARKINSONISM AND ESSENTIAL TREMOR}

M.E. LYRA ${ }^{1}$, M. SOTIROPOULOS ${ }^{1}$, N. LAGOPATI ${ }^{1}$, E. KAPAKI ${ }^{2}$, A. GOULIAMOS ${ }^{1}$, G.S. LIMOURIS ${ }^{1}$

${ }^{1}$ UNIVERSITY OF ATHENS, ARETAEION HOSPITAL, A' RADIOLOGY DEPARTMENT, ATHENS, GREECE, ${ }^{2}$ UNIVERSITY OF ATHENS, AEGINITION HOSPITAL, NEUROLOGY DEPARTMENT, ATHENS, GREECE

\section{PURPOSE}

[123I]-FP-CIT (DaTSCAN) is a cocaine analogue that binds to presynaptic dopamine. Imaging of dopamine transporters, situated in the membrane of dopaminergic neurons could detect degeneration of the dopaminergic nigrostriatal pathway. Aim of this work is to evaluate whether mathematical approach of striatum imaging data, by MatLab program volume processing, can differentiate between Parkinsonian syndromes, of various stages, and Essential Tremor(ET), and thus increase diagnostic accuracy. METHODS

[123I]-FP-CIT Single Photon Emission Computed Tomography (SPECT) imaging of 29 patients with a diagnosis of Parkinsonism and 5 ET diagnosed cases were completed. $110 \mathrm{MBq}$ DaTSCAN was injected intravenously and tomographic studies were performed with a SPECT Elscint Apex4 SPX gamma camera, 3hours post-injection. Images of volume reconstruction of the SPECT slices were processed by MatLab7.0.1 Mathworks program for quantification. Quantification of the results was undertaken by creating the mesh figures over the whole striatum (caudate nucleus, putamen and over an occipital cortex area near the posterior edge of the brain). The ratio of volumetric data of putamen and caudate to the whole striatum was calculated for the two parts, of striatum (left and right) for evaluation of biokinetics symmetry.

\section{RESULTS}

A decreased uptake of tracer in the striatum and an asymmetric distribution in the two lobes was observed, for Parkinson's cases. Volumetric indices were extracted and ratios of specific to nonspecific binding were calculated for the caudate nucleus and putamen volume imaging. Uptake ratio and volume profiles were graded up to 4 abnormal levels. In particular, the lower the ratio was, the highest the grade of Parkinsonism that was finally considered.

\section{CONCLUSION}

Quantitative volumetric analysis of striatum and caudate/putamen intensities (uptake) were consistent with the results of visual inspection and clinical diagnosis. MatLab volume processing and analysis of DaTSCAN images can contribute to the differentiation between Essential Tremor and Parkinsonism.

\section{TE5:4}

\section{MULTI-VOXEL MR SPECTROSCOPY OF THE HEALTHY BRAIN/GENDER DIFFERENCES}

\section{J. KONSTANTINOVIC, D. KOZIC, J. OSTOJIC}

${ }^{1}$ VOJVODINA INSTITUTE OF ONCOLOGY, CENTER FOR IMAGING DIAGNOSTICS, SREMSKA KAMENICA, SERBIA

\section{PURPOSE}

The purpose of this study was to test the differences in metabolite ratios throughout the cingulate gyrus between genders in healthy subjects.

\section{METHODS}

We conducted an ethical-board approved study on 50 healthy righthanded volunteers performing conventional magnetic resonance (MR) imaging and multi-voxel MR spectroscopy on a $1.5 \mathrm{~T}$ scanner, involving supratentorial white and gray matter. Three dominant signals were measured: Choline (Cho), Creatine (Cr) and N-Acetylaspartate (NAA) and expressed as ratios of $\mathrm{Cho} / \mathrm{Cr}$, NAA/Cr and NAA/Cho.

\section{RESULTS}

There was statistically significant $(\mathrm{p}<0.05)$ gender difference for Cho/ $\mathrm{Cr}$ ratio in the anterior part of the cingulate gyrus in the right hemisphere and in the posterior part of the right-side cingulate. In the anterior part of the right-side cingulate gyrus, there was also 
statistically significant $(\mathrm{p}<0.05)$ gender difference for NAA/Cr ratio. For NAA/Cho ratio there were no differences between genders in observed regions. Other areas of the supratentorial cortex and white matter showed no gender-related metabolic differences.

CONCLUSIONS

There is a statistically significant difference between genders considering $\mathrm{Cho} / \mathrm{Cr}$ ratio in two specific regions in the right cingulate gyrus, with additional statistically significant difference in the NAA/Cr ratio in the right anterior cingulate gyrus. The results of this study provide a reference set of normal values for future MR spectroscopy studies of the cingulate gyrus.

\section{TE5:5}

\section{CLINICAL APPLICATIONS OF 320-ROW AREA DETECTOR CT IN THE DIAGNOSIS OF ISCHEMIC CEREBROVASCULAR DISEASES}

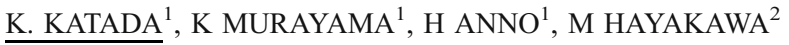 \\ ${ }^{1}$ DEPARTMENT OF RADIOLOGY, FUJITA HEALTH UNIVERSI- TY, TOYOAKE, JAPAN, ${ }^{2}$ DEPARTMENT OF NEUROSURGERY, FUJITA HEALTH UNIVERSITY, TOYOAKE, JAPAN}

\section{PURPOSE}

To evaluate the clinical usefulness of whole brain $\mathrm{CT}$ perfusion using 320-row area detector CT (ADCT) in the diagnosis of cerebrovascular diseases (CVD).

METHODS AND MATERIALS

Forty-five patients with CVD were examined using 320-row ADCT. The scanning parameters employed were 0.5 -mm slice thickness, 20 rotations in 50 seconds at $80 \mathrm{kV}, 100 \mathrm{~mA}$, and $1.0 \mathrm{~s} /$ rot. The acquired data were used to generate whole-brain CT perfusion images, 3D-CT DSA images, and non-contrast and contrast-enhanced CT images. Results were compared with conventional CTP technique. In 19 acute cases, the results were compared with that of MRI diffusion weighted image (DWI) . RESULTS

In all 45 patients, excellent whole-brain CT perfusion data was obtained. Whole brain assessment of CTP is superior to conventional 4-slice technique in 5 patients with parietal and posterior fossa lesions. As for the comparison to the DWI, the regions of reduced CBV matched the areas of high signal intensity in DWI in 16 of 19 lesions. The exposure dose was $5 \mathrm{mSv}$.

CONCLUSION

Whole brain CT perfusion using 320-row ADCT is useful in the diagnosis and management of ischemic CVD.

\section{TE5:6}

IS MTR A RELIABLE PARAMETER FOR THE ASSESSMENT OF PATHOLOGIES IN THE BRAIN? ANALYSIS OF MTR REGARDING QMT PARAMETERS WITH HIGH RESOLUTION BSSFP IMAGING

M. GARCIA ${ }^{1}$, M. GLOOR ${ }^{2}$, S.G. WETZEL ${ }^{1}$, F. JAX ${ }^{1}$, $\overline{\text { E.W. RADUE }}^{1}$, K. SCHEFFLER ${ }^{2}$, O. BIERI ${ }^{2}$

${ }^{1}$ DEPARTMENT OF NEURORADIOLOGY, UNIVERSITY HOSPITAL, BASEL, SWITZERLAND, ${ }^{2}$ DEPARTMENT OF RADIOLOGICAL PHYSICS, UNIVERSITY HOSPITAL, BASEL, SWITZERLAND

\section{PURPOSE}

Magnetization Transfer (MT) imaging is a powerful tool for the characterization of CNS pathologies, since MT is sensitive to protons bound to macromolecules. Frequently, MT effects are assessed by the so-called magnetization transfer ratio (MTR) which, however, gives only an indication of the quantity of bound protons present. In contrast, quantitative MT (qMT) imaging yields the fractional pool size $(\mathrm{F})$, magnetization exchange rate $(\mathrm{kf})$ and pool relaxation properties. In order to assess the sensitivity of MTR for tissue alterations, MTR imaging data of normal appearing brain structures that show similar MTR-values were opposed to qMT imaging.

\section{METHODS}

12 subjects were studied on a $1.5 \mathrm{~T}$ scanner. The $3 \mathrm{D}$ qMT acquisition was completed with 1.3. mm isotropic resolution, including 16 MT-bSSPF sequences using different pulse durations $(230 \mu \mathrm{s}-2100 \mu \mathrm{s})$ and flip angles $\left(5^{\circ}-40^{\circ}\right)$. MTR and qMT parameters, i.e relaxation times (T1, T2), F and $\mathrm{kf}$ were evaluated for 12 white and 11 grey matter structures. Simulations were performed using an MT-bSSFP equation (Gloor et al., MRM 2008). RESULTS

While showing equal MTR-values, several brain structures strongly differed in qMT parameters: Similar MTR-values were found e.g. in the amygdala and globus pallidus, however the globus pallidus showed significantly higher $\mathrm{F}$ and $\mathrm{kf}$ and lower relaxation times. Similar effects were observed in other grey and white matter structures. A simulation of the MTR using measured qMT-values confirmed the finding that various effects can counterbalance and result in an identical MTR.

CONCLUSIONS

Different combinations of qMT and relaxation parameters can result in similar MTR-values, thereby revealing their rather qualitative nature. The significant differences in $\mathrm{T} 1, \mathrm{~T} 2, \mathrm{~F}$ and $\mathrm{kf}$ might primarily be attributed to differences in myelin characeristics and brain tissue water environments. As qMT provides tissue information not discernible on conventional MTR it should be considered to use qMT rather than MTR for the assessment of normal and pathologic brain tissue.

\section{TE5:7}

CLINICAL EVALUATION OF A COMBINED, PROTOTYPE PET-MRI SYSTEM: PRELIMINARY EXPERIENCE IN PROBANDS AND PATIENTS

S. BISDAS, T. NÄGELE, B. PICHLER, H.P. SCHLEMMER, S. CLAUSSEN, U. ERNEMANN

EBERHARD KARLS UNIVERSITY HOSPITAL, TÜBINGEN, GERMANY

\section{PURPOSE}

To evaluate the image quality of combined Positron Emission Tomography (PET) and MR neuroimaging using a prototype PET-MR unit. METHODS

The prototype hybrid PET-MR consists of a newly designed brain-PET and a conventional 3 Tesla MR unit (Trio, Siemens), which facilitate the simultaneous acquisition and coregistration of PET- und MR-images. After optimization of the measurements quality in small animals, five probands were examined using conventional MR protocols after injection of radioactive tracers. Following their combined PET-CT exams, 8 patients ( 2 with nasopharyngeal cancer, 2 with meningeomas, and 4 with astrocytomas) were further examined in the PET-MR unit without additional application of a radioactive tracer.

\section{RESULTS}

All subjects completed their PET-MR exams without complications. The diagnostic quality of the PET images was very good compared to the PET images acquired in the PET/CT scanner. The quality of the MR images was excellent. The fusion of the two imaging modalities 
allowed an exact identification of the neurovascular structures in high-resolution images, an evaluation of critical regions (eg Substantia nigra) and the tumor delineation in all patients. The time spent in the hybrid PET-MR unit was shorter for the patient than the time in the scanner of each modality separately.

CONCLUSION

The new PET-MR technology allows the simulataneous, artifact-free acquisition of PET- and MR images in normal subjects and patients with skull base and brain pathologies.

\section{TE5:8}

\section{HIGH-FIELD 3D WHOLE BODY POST-MORTEM MAGNETIC RESONANCE MICROSCOPY AT 9.4 TESLA: INITIAL EXPERIENCE IN HUMAN FETUSES}

T. YOUSRY, S THAYYIL, J CLEARY, N SEBIRE, R SCOTT, W CHONG, R GUNNY, C OWENS, O OLSEN, A OFFIAH, H PARKES, L CHITTY, A PRICE, N ROBERTSON, M LYTHGOE, A TAYLOR

\section{UCL, LONDON, UNITED KINGDOM}

\section{PURPOSE}

Conventional magnetic resonance (MR) imaging at $1.5 \mathrm{~T}$ does not provide adequate image quality in small fetuses, thus limiting the potential for MR to act as an alternative to invasive autopsy. Highfield whole body MR at 9.4 T provides good imaging in small animal models, but has not been applied to human fetuses.

METHODS

Whole body MR imaging at $9.4 \mathrm{~T}$ and $1.5 \mathrm{~T}$ were performed in 20 fetuses less than 22 weeks, using 3D T2-weighted fast spin echo (FSE) sequences, before autopsy. MR images for each system were compared with invasive autopsy in a blinded way. Tissue contrast measured in 14 different regions on $1.5 \mathrm{~T}$ and $9.4 \mathrm{~T}$ images were also compared and image quality scored on a 4-point scale.

RESULTS

Spatial resolution, tissue contrast and image quality of high-field MR $(9.4 \mathrm{~T})$ images for all organ systems were significantly higher than conventional MR $(1.5 \mathrm{~T})$ images. All structural abnormalities detected by invasive autopsy and internal examination of visceral organs were detected by high-field MR imaging at $9.4 \mathrm{~T}$, whilst conventional MR imaging at $1.5 \mathrm{~T}$ was non-diagnostic in most (78\%) of the cases. CONCLUSIONS

Whole body high-field MR imaging is feasible in human fetuses and offers good tissue characterization even in fetuses as small as 5 grams. The use of 9.4 T imaging may be helpful in the development of a less invasive perinatal autopsy system.

\section{TE5:9}

\section{EXPERIMENTAL HIGH-RESOLUTION MR-IMAGING OF THE PERIODONTAL SPACE WITH A SURFACE COIL AT 3 TESLA}

C. GAUDINO $^{1}$, S. HEILAND ${ }^{1}$, M. PHAM ${ }^{1}$, R. COSGAREA ${ }^{2}$, M. BENDSZUS ${ }^{1}$, S. ROHDE ${ }^{1}$

${ }^{1}$ UNIVERSITÄTSKLINIKUM HEIDELBERG, NEURORADIOLOGY DEPARTMENT, HEIDELBERG, GERMANY, ${ }^{2}$ UNIVERSITÄTSKLINIKUM HEIDELBERG, MUND-ZAHN-KIEFERKLINIK, HEIDELBERG, GERMANY

\section{PURPOSE}

The imaging of inflammatory periodontal disease is usually performed with conventional X-ray or Computed Tomography. This allows the detection of pathological processes only in an advanced stage. Due to high soft tissue contrast Magnetic Resonance Imaging (MRI) might represent an alternative in imaging of the teeth apparatus, especially of the periodontal space. We report the results of experimental high-resolution MRI of the teeth apparatus (pig preparation) with a new 8-channel surface coil at 3Tesla.

METHODS

The examinations were performed on a pig submaxillary preparation, with drilled hole defects, at a high-field MR scan (Trio, Siemens, Erlangen) with an 8-channel surface coil (Multifunction coil-CPC, NORAS, Höchberg). The two 4-channel coil elements were positioned opposite to each other, in order to allow parallel imaging. We have established high resolution 3D-T2-TSE (TR/TE750/123, SL0.6 mm, DF50\%, FOV120 mm) and T1-SE (TR/TE680/13, SL2 mm, DF0\%, FOV105 mm) sequences with highest space resolution and tissue contrast optimisation.

\section{RESULTS}

Both the teeth apparatus (periodontal space, teeth root channel, adjacent soft tissues) and the bony hole defects were imaged accurately with the 3D-T2-TSE sequence (voxel dimensions:0.2 $\times$ $0.2 \times 0.6 \mathrm{~mm})$. The anatomical structures could be displayed on different planes and volume rendered 3D reconstructions.

High-resolution imaging of the contrast agent depots in the periodontal space and in the hole defects was achieved with the T1SE fat-saturated sequence.

\section{CONCLUSION}

High-field MRI of the teeth apparatus and the periodontal space is technically feasible. Excellent depiction of the anatomical structures and inflammatory could be achieved in an experimental setting with an adapted surface coil and optimised high-resolution sequences.

Our results might encourage experimental and clinical MRI-studies of the jaw and the periodontal space, e.g. characterisation of inflammatory periodontal diseases or preoperative planning before implants positioning. In order to verify the feasibility of our MRI-setting in vivo, we are doing first examinations on healthy volunteers and on patients with inflammatory periodontal diseases.

\section{TE5:10}

\section{CEREBRAL METABOLISM IN PATIENT WITH FIBROMYALGIA: A 3 TESLA STUDY}

P. FERACO ${ }^{1}$, A. BACCI ${ }^{1}$, F. PEDRABISSI ${ }^{2}$, V. TUGNOLI ${ }^{3}, \mathrm{~N}$. MALAVOLTA $^{2}$, M. LEONARDI $^{1}$

${ }^{1}$ NEURORADIOLOGY DEPARTMENT, BELLARIA HOSPITAL, UNIVERSITY OF BOLOGNA, BOLOGNA, ITALY, ${ }^{2}$ RHEUMATOLOGY DEPARTMENT, S. ORSOLA-MALPIGHI HOSPITAL, UNIVERSITY OF BOLOGNA, BOLOGNA, ITALY, ${ }^{3}$ DEPARTMENT OF BIOCHEMISTRY G. MORUZZI, UNIVERSITY OF BOLOGNA, BOLOGNA, ITALY

\section{PURPOSE}

Fibromyalgia (FM) is a chronic widespread pain condition that is thought to arise from augmentation of central neural activity. This study was carried out to investigate the dorsolateral prefrontal cortex (DLPFC) and thalamus metabolites level in patients with FM using proton magnetic resonance spectroscopy (1H-MRS) and to compare these findings with healthy controls (HC). 


\section{METHODS}

Six female patients with FM, and 10 healthy age-matched female controls underwent one sessions of Single-voxel H-MRS performed on a General Electric 3.0 T MR scanner (GE, Milwaukee, WI). Patients and controls were receiving no medications known to affect cognitive functioning or central nervous system metabolites. H-MRS was used to assess metabolites level, in particular Glutamate plus Glutamine (Glx) and Glutamate (Glu) concentrations and their ratios on Creatine from both DLPFC and thalami.

RESULTS

$\mathrm{Glx} / \mathrm{Cr}$ and $\mathrm{Glu} / \mathrm{Cr}$ levels of both DLPFC, in particular in the left side, were significantly different between patients and controls $(\mathrm{p}<0.01)$. While the NAA/Cr, Cho/Cr, Cho/Cr, $\mathrm{mI} / \mathrm{Cr}, \mathrm{Gaba} / \mathrm{Cr}$ and $\mathrm{Lac} / \mathrm{Cr}$ ratio showed no differences. No significant differences were found between metabolities and their ratios in both thalami.

CONCLUSIONS

Our data suggest that there are baseline differences in the variability of the brain metabolites concentrations between patients with $\mathrm{FM}$ and $\mathrm{HC}$ in DLPFC. The most significant difference were in $\mathrm{Glx} / \mathrm{Cr}$ and $\mathrm{Glu} / \mathrm{Cr}$ suggesting that this metabolites are implicated in pain perception.

These findings provide direct evidence of abnormal brain chemistry in FM, which may be useful in diagnosis and future development of more effective pharmacological treatments.

\section{TE5:11}

\section{MR-ANGIOGRAPHY AND PLAQUE IMAGING OF THE CAROTID BIFURCATION WITH A NEWLY DEVELOPED 8-CHANNEL TRANSMIT-RECEICE COIL AT 7 TESLA}

T. BREYER $^{1}$, O. KRAFF
S. ORZADA $^{1,2}$, S. MADERWALD
(1,2

${ }^{1}$ INSTITUTE FOR DIAGNOSTIC UND INTERVENTIONAL RADIOLOGY AND NEURORADIOLOGY, ESSEN UNIVERSITY HOSPITAL, ESSEN, GERMANY, ${ }^{2}$ ERWIN L. HAHN INSTITUTE FOR MAGNETIC RESONANCE IMAGING, UNIVERSITY OF DUISBURG-ESSEN, ESSEN, GERMANY

\section{PURPOSE}

Atherosclerosis is one leading cause of morbidity and mortality. The evaluation of the degree of stenosis alone might not be sufficient for risk stratification in patients atherosclerosis. Dedicated MR-imaging allows additional evaluation of the extent and soft tissue components of a atherosclerotic plaque. Currently there are no commercially available radiofrequency (RF) surface coils for bilateral carotid plaque imaging at 7 Tesla (T) allowing parallel imaging. Therefore we developed a dedicated $2 \times 4$-channel-transmit-receive carotid RF coil for $7 \mathrm{~T}$ MRI. In this study we clinically evaluated this coil for the first time.

METHODS

Five healthy volunteers and one patient with relevant atherosclerosis of the carotid bifurcation were investigated (Magnetom 7 T, Siemens, Germany). T1-weighted FLASH-3D (TR/TE $=5,5 / 1,8 \mathrm{~ms}, \mathrm{FA} 15^{\circ}$, voxel size 0,75 mm3, GRAPPA 2, TA 3:11 min.), PD-/T2-weighted $\mathrm{TSE}\left(\mathrm{TR}=550 \mathrm{~ms}, \mathrm{TE}=27 / 81 \mathrm{~ms}\right.$, FA $150^{\circ}$, voxel size $0,4 \times 0,4 \times$ $2 \mathrm{~mm} 3$, GRAPPA 2, TA $1 \mathrm{~min}$.).

RESULTS

The new carotid-coil shows homogenous MR signal distribution and sufficient penetration depths on both sides and allows parallel imaging resulting in a high contrast-to-noise ratio and high spatial resolution of the lateral soft tissues of the neck. The intrinsically high signal of blood in the non-contrast enhanced T1-3D FLASH sequence allows an angiographical visualization of the vessel anatomy. The T2weighted TSE sequence reveals a good contrast between the dark vessel lumen, the vessel wall and adjacent soft tissues and allows also differentiating between different plaque components and depicts the thickness of the vessel wall.

DISCUSSION

In this pilot study the detailed depiction of carotid atherosclerotic plaques and their intraplaque components is feasible at 7 Tesla with a newly developed dedicated carotid-coil. Subsequently we expect this to further improve the carotid plaque imaging compared to lower field strengths. This should lead to further improvements in the risk stratification of patients with atherosclerosis in future.

\section{TE5:12}

\section{CEREBRAL MR-VOLUMETRIC EXAMINATIONS IN THE DIAGNOSIS OF ALZHEIMER DISEASE}

\author{
I. GYURICZA ${ }^{1}$, LR. KOZAK $^{2}$, T. GYORKE ${ }^{3}$, L. SZIDONYA ${ }^{3}$, \\ J. GYEBNAR ${ }^{3}$, T. KOVACS ${ }^{4}$, G. RUDAS ${ }^{2}$, P. BARSI ${ }^{2,5}$
}

${ }^{1}$ STATE HEALTH CENTRE, DEPT. OF RADIOLOGY, BUDAPEST, HUNGARY, ${ }^{2}$ SEMMELWEIS UNIVERSITY, MR RESEARCH CENTRE, BUDAPEST, HUNGARY, ${ }^{3}$ SEMMELWEIS UNIVERSITY DEPT. OF DIAGNOSTIC RADIOLOGY AND ONCOTHERAPY, BUDAPEST, HUNGARY, ${ }^{4}$ SEMMELWEIS UNIVERSITY DEPT OF NEUROLOGY, BUDAPEST, HUNGARY, ${ }^{5}$ SEMMELWEIS UNIVERSITY, CARDIOVASCULAR CENTRE, MRI LABORATORY, BUDAPEST, HUNGARY, BUDAPEST, HUNGARY

\section{OBJECTIVES}

Correlations of data obtained from quantitative volumetric analysis of MRI scans with the clinical diagnosis of Alzheimer disease(AD) and the patients' cognitive performance measured by Mini Mental Scale (MMS)

\section{METHODS}

20 AD patients, clinically diagnosed according to the NINCDSADRDA criteria (probable AD), and 11 healthy controls were examined with a standard MRI protocol containing axial GRE T2*, FLAIR, 3D-MPRAGE and coronal T2 weighted sequences, the latter with thin slices perpendicular to the hippocampi(HC) on a $1.5 \mathrm{~T}$ MR scanner (General Electric, Milwaukee) Patients' average age was $74 \pm$ 11 years at first examination and their dementia was mild(MMS $>21$ ). Controls' average age was $67 \pm 12$ years. 12 patients had follow-up exams ( 3 pt $3 \times, 9$ pts $2 \times)$ within $1-2$ years. MMS was performed at the time of MR examinations. Quantitative volumetric analysis was performed on the 3D-MPRAGE images using SPM5; it consisted of brain normalization, segmentation, gray matter parcellation according to the AAL template (116regions), and volumetric normalization to total brain volume. Group-wise comparisons and correlation analysis was performed on the data.

\section{RESULTS}

The temporal lobes(TL) and HC showed the strongest correlations with MMS. Correlation between MMS and left TL volume was strong $(\mathrm{r}=0.5976, \mathrm{p}=0.001)$ and medium strong on the $\operatorname{right}(\mathrm{r}=0.4999, \mathrm{p}=$ 0.036). There was strong relationship between bilateral $\mathrm{HC}$ volumes and MMS(left:r=0.7042,p $<0.001$ right: $r=0.6738, p<0.001)$. Left TL and HC were significantly smaller(leftTL:8\%, rightTL: $4 \%$, leftHC: $19 \%$, rightHC: $15 \%$ smaller) than those of the controls. Volume decrease became more pronounced by follow-up (left HC:26\% right HC:25\%, left TL:7.9\%, right TL:8.9\%) and there was 
medium strong correlation between volume decrease of bilateral $\mathrm{HC}$ with years (left: $r=-0.3661, p=0-011$; right: $r=-0.4141, p=0.003$ ). We got similar results with bilateral superior TL (left:r $=-0.3124, \mathrm{p}=$ 0.031 ;right: $\mathrm{r}=-0.365, \mathrm{p}=0.011)$, and left $\mathrm{TL}(\mathrm{r}=-0.3071, \mathrm{p}=0.034)$.

CONCLUSION

Our method reliably shows the volume difference of HC and TL between patients and controls. It also registers progression in time. MR volumetric analysis will probably detect the early clinical stages of $\mathrm{AD}$.

TE6

$$
\text { 17:40-18:30 - Free topics }
$$

TE6:1

\section{ENDOVASCULAR TRANSPLANTATION OF STEM CELLS TO THE INJURED RAT CNS}

J. LUNDBERG ${ }^{1}$, K. LE BLANC ${ }^{2}$, M. SÖDERMAN ${ }^{1}$, T. ANDERSSON ${ }^{1}$, S. HOLMIN ${ }^{1}$

${ }^{1}$ DEPARTMENT OF CLINICAL NEUROSCIENCE, KAROLINSKA INSTITUTET AND DEPARTMENT OF NEURORADIOLOGY, KAROLINSKA UNIVERSITY HOSP, STOCKHOLM, SWEDEN, ${ }^{2}$ DEPARTMENT OF STEM CELL RESEARCH, KAROLINSKA INSTITUTET AND DEPARTMENT OF HEMATOLOGY, KAROLINSKA UNIVERSITY HOSP, STOCKHOLM, SWEDEN

\section{PURPOSE}

Transplantation procedures using intraparenchymal injection of stem cells result in tissue injury in addition to associated surgical risks. Intravenous injection of stem cells gives engraftment to lesions but the method has low efficiency and specificity. In traumatic brain injuries (TBI), there is a transient break-down of the blood-brain barrier and an inflammatory response which increase migration of cells from blood to parenchyma. The aim of this investigation was to analyze the effect of intra-arterial stem cell administation on cellular engraftment after TBI. METHODS

Experimental TBI was produced in a rat model. Endovascular technique was used to administer human mesenchymal stem cells, human embryonic stem cells and rat embryonic stem cells in the ipisilateral internal carotid artery. Evaluation of engraftment and side effects were performed by immunohistochemical analysis of the brain and several other organs. The results were compared to intra-venous administration of stem cells.

RESULTS

Intra-arterial transplantation of human mesenchymal stem cells and rat embryonic stem cells resulted in CNS engraftment without thromboembolic ischemic complications. We observed a significantly higher number of transplanted cells in the injured hemisphere after intra-arterial compared to intra-venous administration both 1 day $(\mathrm{p}<$ $0.01)$ and 5 days $(p<0.05)$ after the transplantation. Some cells were also detected in the spleen but not in the other organs analyzed. Intraarterial or intra-venous injection of human embryonic stem cells did not produce any engraftment.

CONCLUSION

Selective intra-arterial administration of certain types of stem cells to the injured CNS is a minimally invasive method for transplantation. The method is significantly more efficient than the intra-venous route and causes no side effects in the current model. The technique can potentially be used for repeated transplantation to the CNS after TBI and in other diseases.
TE6:2

\section{COMPARISON OF RADIATION DOSES TO PATIENTS UNDERGOING CEREBRAL ANGIOGRAPHY WITH CTA AND DSA}

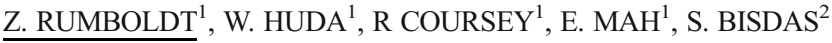 \\ ${ }^{1}$ MEDICAL UNIVERSITY OF SOUTH CAROLINA - DEPARTMENT \\ OF RADIOLOGY AND RADIOLOGICAL SCIENCES, CHARLESTON, \\ SC, USA, ${ }^{2}$ EBERHARD KARLS UNIVERSITY - DEPARTMENT OF \\ NEURORADIOLOGY, TUEBINGEN, GERMANY
}

\section{PURPOSE}

To compare the amount of radiation used to perform cerebral CT angiography (CTA) with the radiation used in bi-plane Digital Subtraction Angiography (DSA).

METHODS

For CTA, the Kerma Area Product (KAP) was determined by combining average kerma values with average exposed areas. CT Kerma were obtained from the intensity of the CT beam at the scanner isocenter and the relative intensities in the fan beam plane to account for the effect of the beam shaping filter. X-ray beam areas were obtained from the known focal isocenter distance and modeling the patient head as an ellipse with radii of $9.5 \mathrm{~cm}$ and $7.4 \mathrm{~cm}$. CTA studies were performed on 16 slice and 64 slice scanners. DSA imaging studies were performed using flat panel detectors. We obtained KAP data for six patients undergoing DSA acquisitions of the right carotid, left carotid, and left vertebral artery injections in frontal and lateral planes, but excluded all fluoroscopic exposures and additional runs. Exposure/KAP coversion factors were included in calculations, since the beam quality is higher with CT: $70 \mu \mathrm{Sv} /$ Gy-cm² for DSA, and $110 \mu \mathrm{Sv} / \mathrm{Gy}-\mathrm{cm}^{2}$ for CTA.

\section{RESULTS}

CTDIvol for head CT angiograms range between $65 \mathrm{mGy}$ and $85 \mathrm{mGy}$, and have a scan length of $15 \mathrm{~cm}$. KAP for head CT examination range from 19 to $24 \mathrm{~Gy}-\mathrm{cm}^{2}$. The average KAP for a single vessel DSA run was $20 \pm 4 \mathrm{~Gy}-\mathrm{cm}^{2}$. A three vessel DSA examination with two planes per vessel, representing the necessary minimum that would provide the similar anatomical information as the CT angiogram, has a total patient KAP of $60 \mathrm{~Gy}-\mathrm{cm} 2$. The effective dose was $2.1 \mathrm{mSv}$ for CTA and $4.2 \mathrm{mSv}$ for DSA.

\section{CONCLUSION}

To visualize the same cerebral vasculature, patient exposures in DSA are at least two times higher compared to those of CTA.

\section{TE6:3}
MEASUREMENT OF THE DIAMETERS OF THE OPTIC NERVE SHEATH AND SUPERIOR OPHTHALMIC VEIN IN BRAIN COMPUTED TOMOGRAPHY: A MEANS TO CONFIRM NEUROIMAGING FINDINGS SUGGESTIVE OF ELEVATED INTRACRANIAL PRESSURE

T. SOLDATOS ${ }^{1}$, D. KARAKYKLAS ${ }^{1}$, P. LAMPROPOULOU ${ }^{1}$, C. SAMARA $^{1}$, E. KROMMIDA ${ }^{1}$, A. KARABINIS ${ }^{2}$, A. GOULIAMOS ${ }^{3}$, C. DROSSOS ${ }^{1}$

${ }^{1}$ DEPARTMENT OF RADIOLOGY AND IMAGING, G. GENNIMATAS GENERAL STATE HOSPITAL, ATHENS, GREECE, ${ }^{2}$ INTENSIVE CARE UNIT, G.GENNIMATAS GENERAL STATE HOSPITAL, ATHENS, GREECE, ${ }^{3}$ SECOND DEPARTMENT OF RADIOLOGY, UNIVERSITY OF ATHENS, ATTIKON HOSPITAL, ATHENS, GREECE 


\section{PURPOSE}

The direct anatomic continuity between the superior ophthalmic vein and the cavernous sinus, as well as between the subarachnoid spaces of the brain and the optic nerve sheath render the above orbital structures sensitive to elevation of the intracranial pressure (ICP). The purpose of this study was to evaluate the fluctuation of the superior ophthalmic vein diameter (SOVD) and optic nerve sheath diameter (ONSD) in patients with neuroimaging findings suggestive of elevated ICP.

\section{METHODS}

From the 178 patients (114 males, $48 \pm 19$ years old) who were evaluated by brain computed tomography (CT), 102 suffered from brain injury and had neuroimaging findings suggestive of elevated ICP, whereas 76 had no pathological findings and served as a control group. In all CT scans the OSND was measured $3 \mathrm{~mm}$ posterior to the papilla and the SOVD closest to the superior aspect of the globe. Based on the severity of the neuroimaging fndings, the CT scans of brain-injured subjects were classified according to a semiquantitative (I to IV) scale (Marshall scale). RESULTS

The mean values of ONSD and SOVD were $6.9 \pm 0.8 \mathrm{~mm}$ and $2.5 \pm$ $0.9 \mathrm{~mm}$ respectively in patients with elevated ICP, and $5.6 \pm 0.5 \mathrm{~mm}$ and $2.0 \pm 0.8 \mathrm{~mm}$ respectively in the control group. The difference between the two groups was significant in both instances $(\mathrm{p}<0.0001)$. In braininjured patients the ONSD measurements were significantly correlated to the neuroimaging scale results $(\mathrm{r}=0.82)$. The best ONSD and SOVD cutoff values for the prediction of elevated ICP were $5.9 \mathrm{~mm}$ (sensitivity= $96 \%$, specificity $=75 \%$ ) and $2.4 \mathrm{~mm}$ (sensitivity $=59 \%$, specificity $=$ $86 \%$ ), respectively.

CONCLUSIONS

Brain-injured adults with CT findings suggestive of elevated ICP exhibit increased ONSD and SOVD. Compared to the SOVD, the ONSD is a more sensitive marker for elevated ICP and correlates with the severity of brain injury, as depicted by brain CT scan. In adult brain injury, measurement of the ONSD and/or SOVD may assist in confirming neuroimaging findings suggestive of elevated ICP.

\section{TE6:4}

\section{THE APPLICATION OF OPTIC NERVE SONOGRAPHY IN THE DIAGNOSTIC EVALUATION OF ADULT BRAIN INJURY}

T. SOLDATOS $^{1}$, D. KARAKITSOS ${ }^{2}$, K. CHATZIMICHAIL ${ }^{3}$, M. PAPATHANASIOU ${ }^{3}$, A. GOULIAMOS ${ }^{4}$, A. KARABINIS ${ }^{2}$

${ }^{1}$ DEPARTMENT OF RADIOLOGY AND IMAGING, G.GENNIMATAS GENERAL STATE HOSPITAL, ATHENS, GREECE, ${ }^{2}$ INTENSIVE CARE UNIT, G.GENNIMATAS GENERAL STATE HOSPITAL, ATHENS, GREECE, ${ }^{3}$ SECOND DEPARTMENT OF RADIOLOGY, UNIVERSITY OF ATHENS, ATTIKON HOSPITAL, ATHENS, GREECE, ${ }^{4}$ FIRST DEPARTMENT OF RADIOLOGY, UNIVERSITY OF ATHENS, ARETAIEIO HOSPITAL, ATHENS, GREECE

\section{PURPOSE}

The anatomic continuity between the subarachnoid spaces of the brain and optic nerve renders the optic nerve sheath diameter (ONSD) sensitive to elevation of the intracranial pressure (ICP). We investigated whether measurements of the ONSD were correlated with simultaneous noninvasive and invasive measurements of the ICP in brain-injured adults. METHODS

From the 83 critical care patients ( 64 males; $49 \pm 18$ years old) who were included in the study, 54 suffered from brain injury, whereas 29 had no intracranial pathology and served as control individuals. Initially, braininjured subjects patients were evaluated clinically (Glasgow Coma Scale, GCS) and using a semiquantitative (I to VI) neuroimaging scale (Marshall Scale, MS). Thereafter, the patients were divided into those with moderate (MS $=\mathrm{I}$ and $\mathrm{GCS}>8, \mathrm{n}=20$ ) and severe (MS $=\mathrm{II}$ to $\mathrm{VI}$ and $\mathrm{GCS}<=8$, $\mathrm{n}=34$ ) brain injury. All subjects underwent noninvasive measurement of the ICP (estimated ICP, eICP) by transcranial Doppler sonography, and synchronous ONSD measurements by optic nerve sonography. Finally, invasive ICP measurement using an intraparenchymal catheter was performed in patients with severe brain injury.

\section{RESULTS}

ONSD and eICP were both significantly increased $(6.1 \pm 0.8 \mathrm{~mm}$ and $26.9 \pm$ $8.3 \mathrm{mmHg}$, respectively; $\mathrm{P}<0.0001)$ in patients with severe brain injury as compared with patients with moderate brain injury $(4.3 \pm 1.3 \mathrm{~mm}$ and $12.0 \pm$ $3.6 \mathrm{mmHg})$ and compared with control individuals $(3.6 \pm 0.8 \mathrm{~mm}$ and $10.9 \pm$ $4.3 \mathrm{mmHg}$ ). In subjects with severe brain injury the ONSD measurements were strongly correlated with eICP values $(\mathrm{r}=0.80, \mathrm{P}<0.0001)$, as well as with the neuroimaging scale results $(\mathrm{r}=0.82, \mathrm{P}<0.0001)$. In the patients with severe brain injury, ONSD measurements correlated with invasive ICP values ( $\mathrm{r}=0.69, \mathrm{P}=0.002)$. The best cut-off value of ONSD for predicting elevated ICP was $5.7 \mathrm{~mm}$ (sensitivity $=74.5 \%$, specificity $=100 \%$ ).

CONCLUSIONS

ONSD measurements correlate with noninvasive and invasive measurements of the ICP, and with neuroimaging findings in brain-injured adults. Optic nerve sonography can alert for the presence of elevated ICP, whenever invasive ICP evaluation is contraindicated and/or is not available.

\section{TE6:5}

\section{NEUROSURGEONS, NEUROLOGISTS AND PSYCHIATRISTS' EXPECTATIONS ON BRAIN IMAGING: WHAT WE (THOUGHT) WE ALWAYS KNEW BUT NEVER DARED TO ASK}

\author{
D. SEIXAS, M. AYRES BASTO
}

SAO JOAO HOSPITAL - DEPT. OF NEURORADIOLOGY, PORTO, PORTUGAL

\section{PURPOSE}

Some of the medical specialities that more often request brain magnetic resonance imaging (MRI) scans are neurosurgery, neurology and psychiatry. To our knowledge, there is no published data in MEDLINE on the expectations of medical doctors of these specialities when requesting brain MRI for their patients.

METHODS

The expectations of 39 medics on brain MRI - 17 psychiatrists, 12 neurologists and 10 neurosurgeons - of a tertiary Portuguese hospital were measured using a tailored questionnaire.

\section{RESULTS}

The attitude towards the inquiry was of distrust, and worry of possible identification. Neurosurgery was by speciality the one that asks more brain scans per year. The main reason for requesting an MRI was for $86 \%$ of the neurologists for follow-up of a known disease, for $56 \%$ of the psychiatrists to exclude other diagnosis, and for $33 \%$ of the neurosurgeons to confirm a diagnostic hypothesis. The prime expectations were for neurologists, in $71 \%$ of the cases a negative result, and for psychiatrists (34\%) and neurosurgeons (33\%) to confirm their diagnostic hypothesis. When questioned on the assessment of the scan's result, psychiatrists mostly ( $83 \%$ ) just read the report, and $36 \%$ of the neurologists and $32 \%$ of the neurosurgeons read both the report and the images. None of the neurosurgeons stated that only the report was read, although $17 \%$ of the neurologists did do so. The mean confidence on the technical quality of 
brain images and reports was, respectively, 78.4\% (3.6) and 72.4\% (5.2) for psychiatrists, $74.8 \%(6.2)$ and $66.1 \%$ (8.0) for neurosurgeons, and $59.3 \%$ (5.5) and $45.2 \%$ (5.8) for neurologists. Psychiatrists $(\mathrm{t}=2.88, \mathrm{p}<$ $0.01)$ and neurosurgeons $(\mathrm{t}=2.06, \mathrm{p}<0.01)$ had significantly more confidence both in the quality of the images and reports than neurologists. Residents had more confidence in the quality of the images than specialists $(t=2.69, p<0.05)$, but there was no difference concerning the degree of confidence in the quality of reports.

CONCLUSIONS

The reason for requesting, the expectations and the method of assessing brain MRI are possibly modelled by experience, namely the nature of the diseases treated by each of the different specialities ("organic" versus "non-organic" disease) and the number of exams requested per year. Our data should be compared with information from other hospitals and types of health care facilities.

\section{TE6:6}

\section{CAN MRI WITH FAST SPIN ECHO T2 REPLACE ENHANCED IMAGES IN FOLLOW-UP OF SURGICALLY TREATED PITUITARY MACROADENOMAS?}

\author{
G. RINGSTAD, J. HALD, T. NOME
}

OSLO UNIVERSITY HOSPITAL - RIKSHOSPITALET, OSLO, NORWAY

\section{PURPOSE}

Consecutive contrast enhanced magnetic resonance (MR) studies are regularly used to monitor patients with pituitary disease in order to identify residual adenoma, postoperative changes, tumor regrowth and normal pituitary tissue. The possibility of Gadolinium (Gd)-induced Nephrogenic Systemic Fibrosis warrants a critical evaluation of the need for Gdenhanced imaging. Our purpose was to characterize the diagnostic accuracy of replacing Gd-enhanced images with a coronal fast spin echo (FSE) T2 in a cohort of patients surgically treated for pituitary macroadenoma.

METHODS

Coronal and sagittal T1-weighted MR images pre and post contrast enhancement and coronal FSE T2-weighted MR images, all with $3 \mathrm{~mm}$ slice thickness, were obtained in 52 consecutive patients. The only selection criterion was a patient history of transsphenoidal surgical treatment for pituitary macroadenoma. A consensus reading was performed by two experienced neuroradiologists in two separate sessions, one included unenhanced and enhanced T1-weighted sequences, and one included unenhanced T1- and FSE T2-weighted sequences. Adenoma extension was graded according to the KnospSteiner- and SIPAP-classification systems. The identification of pituitary tissue was correlated with biochemical parameters.

RESULTS

Pre and post contrast enhanced images demonstrated 48 adenomas in 52 patients. All adenomas were diagnosed on the unenhanced scans and gave 1 false positive diagnosis. Supra- and parasellar extension was graded equally in 41 and 38/39 (right/left) respectively of the 48 adenomas, with a difference of 1 unit on the grading scales in the remaining tumors. Presence of pituitary tissue was identified in 7 cases on FSE T2 only, which all correlated well with biochemical parameters indicating partially or completely intact pituitary function.

CONCLUSION

When enhanced images were replaced by a FSE T2-weighted sequence, all residual adenomas in 52 patients surgically treated for pituitary macroadenomas were diagnosed. FSE T2 also added important information about the presence of pituitary tissue.
TE6:7

\section{SECOND OPINION CONSULTATIONS IN NEURORADIOLOGY: ASSESSMENT OF VALUE}

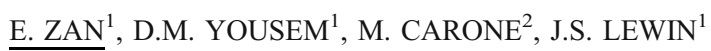

${ }^{1}$ THE JOHNS HOPKINS MEDICAL INSTITUTION, DEPARTMENT OF RADIOLOGY, BALTIMORE, MD, USA, ${ }^{2}$ THE JOHNS HOPKINS BLOOMBERG SCHOOL OF PUBLIC HEALTH, DEPARTMENT OF BIOSTATISTICS, BALTIMORE, MD, USA

\section{PURPOSE}

A policy of official review of studies performed outside our institution was recently implemented. We sought to assess the patient care benefit of implementing this policy. We hypothesized that the incidence of "significant misses" would be similar to the literature examining Emergency Department over-reads. METHODOLOGY

The reports from all outside neuroradiology studies reviewed within calendar year 2008 that had an outside report provided with the images were compared. The reports were graded on a 5 point scale of 1 (no difference), 2 (insignificant difference in detection), 3 (insignificant difference in interpretation), 4 (significant difference in detection), and 5 (significant difference in interpretation). Statistical comparisons of rates were conducted using chi-square tests under two-sided alternatives, with Bonferroni corrections performed when required. Confidence intervals were provided where appropriate. RESULTS

4534 of 7465 studies had an outside report for comparison. There were 347 cases $(7.6 \%)$ in which there were clinically significant differences in the reports (grade $4=233$, grade $5=114$ ). When the final diagnosis was able to be determined from pathology reports, clinical assessments and imaging follow ups $(n=194)$, the internal review was noted to be correct in $163(84 \%)$ of the cases. CONCLUSION

At a $7.6 \%$ significant discrepancy rate, at least 2 patients a day benefits from a second opinion reading in a way that can change management and/ or diagnosis. The rate of significant discrepancies between internal and outside interpretations is nearly twice that reported for discrepancies in emergency department resident versus faculty reviews. Most are discrepancies in detecting abnormalities and, when "proof" was obtainable, the referral center was more accurate by a 5:1 ratio. Review of outside studies benefits patient care.

\section{Saturday, September 19, 2009 - Hesperides Room}

\section{HE4}

11:10-13:15 - Interventional - stroke II

HE4:1

MECHANICAL EMBOLECTOMY WITH THE PENUMBRA STROKE SYSTEM IN ACUTE ISCHEMIC STROKE: A MATCHED PAIR STUDY IN COMPARISON WITH INTRAARTERIAL THROMBOLYSIS

C. TASCHNER $^{1}$, M. TREIER $^{1}$, W. NIESEN ${ }^{2}$, A. BERLIS $^{1}$, J. WEBER $^{1}$, M. SCHUMACHER ${ }^{1}$

${ }^{1}$ DEPT. OF NEURORADIOLOGY, UNIVERSITY HOSPITAL FREIBURG, FREIBURG, GERMANY, ${ }^{2}$ DEPT. OF NEUROLOGY, UNIVERSITY HOSPITAL FREIBURG, FREIBURG, GERMANY 


\section{INTRODUCTION}

Intravenous, combined intravenous (IV) and intraarterial (IA) thrombolysis, as well as mechanical embolectomy for the treatment of acute ischaemic stroke have been subject to clinical studies. The safety, feasibility, and efficacy of mechanical embolectomy with the Penumbra system have been described. No direct comparative study has yet established whether endovascular interventions with the Penumbra system are superior to IA rtPA. A retrospective matched-pair analysis was designed to address this issue.

\section{MATERIALS AND METHODS}

Between 06/2008 and 04/2009 22 consecutive patients (13 women, 9 men, mean age 62 years) with acute ischemic stroke and National Institutes of Health Stroke Scale (NIHSS) scores $>10$ were treated with the Penumbra system at our institution.

RESULTS

Mean NIHSS of the patients treated with the Penumbra system was xyz. 36 target vessels were defined, tandem lesions involving proximal internal carotid and proximal intracranial vessel occurred in 14 , necessitating emergent multilevel treatment including carotid stenting in 6 . The initial thrombolysis in myocardial infarction (TIMI) score was 0 in 33 vessels, and TIMI 1 in 3. Median duration from symptom onset to Penumbra utilization was 5,2 hours. Successful reperfusion (TIMI $2+3$ ) was obtained in $25 / 36(69,5 \%)$ target vessels. The average improvement of NIHSS upon discharge in the remaining xyz patients was xyz. The periprocedural mortality rate was xyz ( $/ 22$ ). Outcomes including the mRS at three months are compared with 22 matching patients treated earlier in our institution with IA thrombolysis. Matches are sought for target vessel, TIMI grade, and NIHSS score at presentation.

CONCLUSION

Mechanical embolectomy devices seem to be promising tools in the treatment of patients with acute ischemic strokes. The indications and the ideal timing for treatment with these powerful tools need yet to be determined.

\section{HE4:2}

CENTRAL RETINAL ARTERY OCCLUSION: LOCAL INTRAARTERIAL FIBRINOLYSIS VERSUS CONSERVATIVE TREATMENT. A MULTICENTER RANDOMIZED TRIAL (EAGLE-STUDY)

M. SCHUMACHER ${ }^{1}$, D. SCHMIDT ${ }^{2}$, B. JURKLIES ${ }^{3}$, C. GALL ${ }^{4}$, I. WANKE $^{5}$, C. SCHMOOR ${ }^{4}$, J. MAIER-LENZ ${ }^{4}$, L. SOLYMOSI ${ }^{6}$, H. BRÜCKMANN ${ }^{7}$, A. NEUBAUER ${ }^{8}$, A. WOLF $^{8}$, N. FELTGEN $^{2}$

${ }^{1}$ UNIVERSITY HOSPITAL DPT. OF NEURORADIOLOGY, FREIBURG, GERMANY, ${ }^{2}$ UNIVERSITY HOSPITAL DPT. OF OPHTHALMOLOGY, FREIBURG, GERMANY, ${ }^{3}$ UNIVERSITY HOSPITAL DPT. OF OPHTHALMOLPGY, ESSEN, GERMANY, ${ }^{4}$ UNIVERSITY HOSPITAL CENTER OF CLINICAL TRIALS, FREIBURG, GERMANY, ${ }^{5}$ UNIVERSITY HOSPITAL DPT. OF NEURORADIOLOGY, ESSEN, GERMANY, ${ }^{6}$ UNIVERSITY HOSPITAL DPT. OF NEURORADIOLOGY, WÜRZBURG, GERMANY, ${ }^{7}$ KLINIKUM GROßHADERN DPT. OF NEURORADIOLOGY, MÜNCHEN, GERMANY, ${ }^{8}$ UNIVERSITY HOSPITAL DPT. OF OPHTHALMOLOGY, MÜNCHEN, GERMANY

\section{BACKGROUND}

Central retinal artery occlusion (CRAO) is a serious ophthalmologic disease. The results of conservative treatment vary consider- ably and although local intraarterial fibrinolysis (LIF) is a promising treatment, outcomes have not been compared in controlled trials.

\section{METHODS}

Prospective randomized multicenter study by the European Assessment Group for Lysis in the Eye (EAGLE) to compare treatment outcomes of conservative standard treatment (CST) and LIF for acute non-arteritic CRAO. Patients (18-75 y) with CRAO not older than $20 \mathrm{~h}$ and best-corrected visual acuity (BCVA) $<0.5$ (logMAR) were randomized to the CST or LIF groups. Primary endpoint was BCVA after 1 month; secondary endpoints were visual fields and safety. RESULTS

Eighty-four patients were recruited (40 CST, 44 LIF) over 5 years and data for 82 patients were analyzed. Mean interval between first symptoms and therapy was $11.0 \pm 5.5$ hours (CST) and $12.8 \pm 5.8$ hours (LIF). Mean BCVA improved significantly in both groups (CST: -4.4; SD 5.5; LIF: -4.5 lines; SD 5.5; p's $<0.0001$ ) and did not differ between groups $(\mathrm{p}=0.69)$. Clinically significant visual improvement was noted in $60.5 \%$ (CST) and $58.5 \%$ (LIF). Visual field improved in both groups. One patient in the CST group and two in the LIF group had serious adverse events. Because of similar efficacy between groups and the higher rate of complications in the LIF group, the study was stopped after the first interim analysis.

CONCLUSIONS

Clinical improvement was equivalent with both therapies. Patients with acute CRAO should undergo CST including acetylsalicylic acid and anticoagulation with heparin within the first 20 hours.

\section{HE4:3}

\section{CONTRAST MATERIAL POOLING IMMEDIATELY AFTER ENDOVASCULAR REVASCULARIZATION IN ACUTE STROKE: A PREDICTOR OF FINAL INFARCT SIZE}

D. SAN MILLAN RUIZ ${ }^{1}$, V. MENDES PEREIRA ${ }^{1}$, R. SZTAZJEL ${ }^{2}$, I. MOMJIAN $^{2}$, C. BONVIN ${ }^{2}$, A.P. NARATA ${ }^{1}$, S. ALTHRICHTER ${ }^{1}$, $\mathrm{K}_{\text {LOVBLAD }}{ }^{1}$

${ }^{1}$ SERVICE OF DIAGNOSTIC AND INTERVENTIONAL NEURORADIOLOGY, DEPARTMENT OF RADIOLOGY, GENEVA UNIVERSITY HOSPITAL, GENEVA, SWITZERLAND, ${ }^{2}$ DEPARTMENT OF NEUROLOGY, GENEVA UNIVERSITY HOSPITAL, GENEVA, SWITZERLAND

\section{PURPOSE}

To report the relationship between contrast material pooling (CMP) after endovascular recanalization (EVR) in acute ischemic stroke (AIS) and final infarct size.

METHODS

Inclusion criteria: 1) anterior circulation AIS treated with EVR; 2) presence of immediate post-procedural CT (IPCT); 3) 24 hours control CT;4)follow-up CT or MRI. CMP, defined as parenchymal hyperdensity on the IPCT, was noted and was correlated with the distribution of final infarct observed on follow-up imaging. Thrombolysis in Myocardial Infarction scores (TIMI) were noted.

RESULTS

15 consecutive patients (ages 40-84 years, 8 females) were studied retrospectively.EVR was obtained with a variety of mechanical 
devices (Penumbra, MERCI, Phenox, and permanent or temporary stent), with or without adjuvant intravenous and/or intraarterial tPA. TIMI 2 was obtained in $86.6 \%$ of the cases and TIMI 3 in $13.3 \%$. In $100 \%$ of the patients cortical and/or basal ganglia CMP was observed and corresponded to areas of brain infarction on follow-up imaging. In 9 patients $(60 \%)$, the area of CMP was smaller than the final infarct, and in 6 patients (40\%) CMP distribution correlated with the final infarct size.

CONCLUSION

CMP appearing on IPCT after EVR for AIS was observed in $100 \%$ of the cases in this study and correlated with infarct size. The observed high incidence of CMP may be related to the high rate of significant recanalization after EVR. As CMP may be a predictor of minimal infarct size, identifying large areas of CMP on IPCT could have clinical implications in terms of hemorrhagic risk assessment, timing of anticoagulation therapy, and alerting to a potential need for decompression craniectomy.

\section{HE4:4}

\section{MULTIMODAL MECHANICAL THROMBECTOMY IN ACUTE ISCHEMIC STROKE WITH THE PHENOX® CLOT RETRIEVER}

\section{S. PROTHMANN, H. LOCKAU, F. DORN, C. ZIMMER, T. LIEBIG}

UNIVERSITY HOSPITAL RECHTS DER ISAR, DEPARTMENT OF NEURORADIOLOGY, MUNICH, GERMANY

\section{PURPOSE}

Endovascular treatment of ischemic stroke has shown to be beneficial in a number of trials. A main factor that influences patient outcome is time-to-reperfusion. With pre-hospital time being largely random, angio-to-reperfusion time mainly depends on the interventional approach and armamentarium.

METHODS

Between 12/2006 and 12/2008, 57 acute ischemic strokes were treated by mechanical thrombectomy (MTE) with the phenox ${ }^{\circledR}$ clot retriever (pCR, $\mathrm{CRC}$ ) alone or in combination with aspiration, angioplasty, permanent and temporary stenting. Of these patients, pre and post procedural NIHSS, $\mathrm{mRS}$ and Barthel Index were recorded when available together with preand per-procedural timings.

RESULTS

The overall rate of recanalisation with distal reperfusion $>50 \%$ (TICI IIb/III) was $63 \%$ with a multimodal approach. The average angio-to-reperfusion time (ART) was 58 min with a minimum of $11 \mathrm{~min}$. Improvement through experience is exhibited by a decreasing average ART over time from 2006 to 2008. During the same interval the average reperfusion result has improved from TICI $2 \mathrm{a}$ to TICI $2 \mathrm{~b}$. No significant influence on patient outcome could be attributed to a specific treatment strategy or device. There were 4 procedural adverse events (AE) that were not related to MTE directly, but to guidewire perforations or access route dissections.

CONCLUSIONS

In conclusion, MTE with the phenox ${ }^{\circledR}$ clot retriever can yield TICI $\mathrm{IIb} / \mathrm{III}$ reperfusion in up to $63 \%$ of the cases, particularly when it is used in combination with other devices. Especially the multimodal approach appears to be a promising technique that may further increase the number of stroke patients with good clinical outcome.
HE4:5

\section{ENDOVASCULAR TREATMENT OF ACUTE ISCHEMIC STROKE WITH MECHANICAL DEVICE FOR THROMBUS ASPIRATION: OUR EXPERIENCE OF 19 CASES}

A. PAOLUCCI, V. CIVELLI, P. SANTALUCIA, M. ISALBERTI, C.M. CINNANTE, C. SINA, A. COSTA, S. AVIGNONE, R. PAPA, V. BRANCA

IRCCS OSPEDALE MAGGIORE POLICLINICO MANGIAGALLI REGINA ELENA-DEPARTMENT OF DIAGNOSTIC AND INTERVENTIONAL NEURORADIOLOGY, MILAN, ITALY

\section{PURPOSE}

Mechanical revascularization of acutely occluded intracranial vessels could be an effective stroke treatment when pharmacological thrombolysis is not indicated.We present our experience of endovascular treatment of acute stroke with a new device (Penumbra Stroke System, Penumbra Inc.USA).

METHODS

From December 2005 to May 200919 patients (15 males, 4 females, mean age $66 \mathrm{yrs}$ ) presenting with acute ischemic stroke up to 8 hours from symptoms onset have been selected for endovascular treatment using the Penumbra Stroke System. Mean time from symptoms onset to treatment was $5.5 \mathrm{hrs}(3.5-7 \mathrm{hrs})$. At angiography: 4 patients presented with ICA occlusion, 3 with ICA-MCA occlusion, 8 with MCA occlusion, and 4 with BA occlusion.

Only three patients were treated with pharmacological thrombolysis after proximal approach to the occlusion with Penumbra.

Clinical follow-up and CT scan were performed at presentation and after the procedure.

RESULTS

Complete vessel recanalization was obtained in 13 cases, in 2 cases it was obtained partial recanalization and in 4 cases the device turned to be ineffective.

\section{CONCLUSIONS}

The Penumbra Stroke System is an effective and low-traumatic approach for endovascular treatment of acutely occluded intracranial vessels.

\section{HE4:6}

\section{STENT ANGIOPLASTY IN SYMPTOMATIC STENOSIS OF DISTAL CEREBRAL ARTERIES}

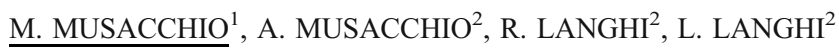

${ }^{1}$ HÔPITAUX CIVILS DE COLMAR - INTERVENTIONAL NEURORADIOLOGY, COLMAR, FRANCE, ${ }^{2}$ SANATORIO SANTA FE - INTERVENTIONAL NEURORADIOLOGY, SANTA FE, ARGENTINA

\section{PURPOSE}

To evaluate feasibility and efficacy of endovascular treatment of symptomatic stenosis of distal cerebral arteries by stent angioplasty METHODS

3 males, aged from 70 to 73 years, with multiple cardiovascular risk factors, were submitted due to acute neurological deficit. Acute clinical presentation (3-5 hours) was observed in 2 patients, without evidence of acute ischemia or haemorrhage at admission CT scan. In one case, symptoms evolved progressively during 6 weeks with periods of partial 
improvement. All patients underwent immediate cerebral angiographic evaluation, and major distal arterial stenosis (left angular artery, right and left insulo-opercular arteries), was diagnosed, topographically congruent with neurological deficit. Intrarterial thrombolytic therapy was tempted in the two patients showing acute clinical presentation, with neither clinical nor morphological improvement. After multidisciplinary discussion, stent angioplasty was decided for all cases. Procedures were performed under neuroleptoanesthesia, IV heparin perfusion and antiplatelet therapy (aspirin + clopidogrel). 2 balloon-expandable (BX Sonic, AVE Inc) and one auto-expandable (Winspan) stents were used. Clinical and radiological follow-up extended from 6 weeks to 13 months, all patients had benefited of a 24-hour angiographic control.

RESULTS

In one case, segmental dissection was detected during angioplasty, resolved by stent deployment. In all cases, secondary branches coming from the stented arterial segment not visible in pre-operative angiography were demonstrated in 24-hour angiographic control. All patients showed significant clinical improvement in the immediate post-operative period, with neither recurring symptoms nor new deficit observed during clinical follow up. Neither hemorrhagic nor ischemic complications were detected in post-operative CT scan. One patient presented asymptomatic, non stenotic myo-intimal hyperplasia in 1-year angiographic control.

CONCLUSION

Endovascular treatment of symptomatic distal arterial stenosis by stent angioplasty is feasible due to development of new material and devices. Immediate segmental dissection and late re-stenosis are major complications directly related to the technique. Long clinical and morphological follow up is mandatory.

\section{HE4:7}

\section{IN-VIVO EVALUATION OF THE PHENOX CRC FOR MECHANICAL THROMBECTOMY IN ACUTE VESSEL OCCLUSION}

\author{
$\underline{\text { P. MORDASINI }}{ }^{1}$, M. HILLER $^{1}$, C. BREKENFELD ${ }^{1}$, M. ARNOLD $^{2}$, \\ G. SCHROTH $^{1}$, J. GRALLA ${ }^{1}$
}

${ }^{1}$ INSTITUTE OF DIAGNOSTIC AND INTERVENTIONAL NEURORADIOLOGY, UNIVERSITY HOSPITAL - INSELSPITAL, BERN, SWITZERLAND, ${ }^{2}$ DEPARTMENT OF NEUROLOGY, UNIVERSITY HOSPITAL - INSELSPITAL, BERN, SWITZERLAND

\section{BACKGROUND AND PURPOSE}

The purpose of this study was to evaluate the efficiency, thrombusdevice interaction and potential complications of the Phenox CRC (Clot retriever CAGE) for distal mechanical thrombectomy in-vivo. MATERIAL AND METHODS

The device was evaluated in an established animal model. Recanalisation rate, thromboembolic events, vasospasm and complications were assessed. Radio-opaque thrombi ( $2 \mathrm{~cm}$ length) were used for the visualization of thrombus-device interaction during retrieval. The Phenox CRC (4 mm diameter) was assessed in 15 vessel occlusions. For every occlusion a maximum of 3 retrieval attempts were performed.

RESULTS

Total recanalisation (TIMI 3) was achieved in $86.7 \%$ of vessel occlusions. In $66.7 \%(10 / 15)$, the first retrieval attempt was successful, in $20 \%(3 / 15)$ the second attempt led to total recanalisation of the parent artery. In two cases $(13.3 \%)$ thrombus retrieval was not successful (TIMI 0). In one case $(6.7 \%)$ a minor embolic event occurred into a small side branch. No distal thromboembolic event was observed during the study.
Thrombus-device interaction illustrated the entrapment of the thrombus by micro filaments and the proximal cage of the device. No significant thrombus compression was observed. No vessel perforation, dissection nor fracture of the device was observed.

CONCLUSION

The Phenox CRC clot retriever is a safe and effective distal device for thromboembolectomy in-vivo. The unique design with a combination of mirco filaments and proximal cage reduces thrombus compression with a consequently high recanalisation and low complication rate.

\section{HE4:8}

\section{INTRACRANIAL ANGIOPLASTY AND STENTING FOR CREBRAL ARTHEROSCLEROSIS : RESULTS OF 93 CONSECUTIVE PATIENTS}

$\underline{\text { D. HWANG }}{ }^{1}, \mathrm{I} \mathrm{KANG}^{1}, \mathrm{ILEE}^{1}, \mathrm{~K} \mathrm{KIM}^{1}, \mathrm{CHUR}^{2}, \mathrm{I} \mathrm{KIM}^{2}$

${ }^{1}$ HANGANG SACRED HEART HOSPITAL, SEOUL, SOUTH KOREA, ${ }^{2}$ SEOUL SAINT MARY HOSPITAL, SEOUL, SOUTH KOREA

\section{PURPOSE}

Stroke is most common cause of life threatening neurological disease and also it is leading cause of adult disability and third leading casuse of death. Intracranial atherosclerosis is 8 to $10 \%$ of all ischemic strokes and reported poor outcome and high rate of morbidity and mortality. METHODS

We evaluated 93 consecutive patients (age mean 60, range 3480 years, ) who underwent intracranial stenting between March 2004 and December 2007. The location of lesion was $\operatorname{MCA}(n=25)$, distal ICA $(n=31)$, Petro-cavernous ICA $(n=6)$, Basilar artery $(n=3)$, Vertebral artery $(n=28)$ and mean stenosis was $72.8 \%$

\section{RESULTS}

The procedural success rate was $93.5 \%$. 6 cases are unable to reach the target and performed Balloon angioplasty. There were overall three complications (3.3\%) within period of follow up (six months); these included one minor strokes $(1.1 \%)$, and one deaths(1.1\%), one restenosis $(1.1 \%)$. The kind of stent was Endeavor $(n=29)$, Vision $(n=$ 15), Cypher $(n=14)$, Neuroform $(n=10)$, Flexmaster $(n=10)$, Arthos pico $(n=7)$, Tsunami $(n=5)$, Guidant $(n=3)$,

CONCLUSIONS

In selected patients, endovascular revascularization of intracranial arteries with stent assisted angioplasty is technically feasible, effective and safe. Randomized multicenter trial comparing angioplasty and stenting with medical management alone must be performed.

Key words: Intracranial stent, Atherosclerosis

\section{HE4:9}

\section{VERTEBROBASILAR THROMBECTOMY USING THE MERCI-SYSTEM: THE KAROLINSKA EXPERIENCE}

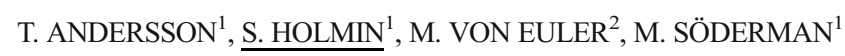

${ }^{1}$ DEPARTMENT OF CLINICAL NEUROSCIENCE, KAROLINSKA INSTITUTET AND DEPARTMENT OF NEURORADIOLOGY, KAROLINSKA UNIVERSITY HOSP, STOCKHOLM, SWEDEN, ${ }^{2}$ DEPARTMENT OF CLINICAL NEUROSCIENCE, KAROLINSKA INSTITUTET AND DEPARTMENT OF NEUROLOGY, KAROLINSKA UNIVERSITY HOSP, STOCKHOLM, SWEDEN 


\section{PURPOSE}

Basilar artery thromboembolism is without treatment a potentially lethal condition. The results from treatment with intravenous rt-PA are generally poor as exemplified by the study by Lindsberg et al (JAMA, $292(15), 1862-6,2004)$. They reported a recanalization rate of $52 \%$. At 3 months follow-up, $40 \%$ of the patients were dead and only $22 \%$ were independent with MRS 0-2 (Modified Rankin Score). Consequently, there is a specific need for alternative treatment methods in this vascular territory. We report our initial experience from vertebrobasilar thrombectomy using the MERCI-device.

\section{METHODS}

The procedure data and immediate results from the thrombectomies were retrospectively reviewed together with chart data from the initial hospitalization. All surviving patients were clinically assessed regarding the long-term functional outcome using the mRS at the out-patient clinic by an independent specialist in neurology 38 months after the procedure in addition to the follow-up done by the responsible specialist in interventional neuroradiology.

\section{RESULTS}

Between September 2005 and October 2008, we performed vertebrobasilar thrombectomies in 18 patients. The procedure was combined with administration of intraarterial rt-PA in 13/18 patients $(72 \%)$. Flow was restored in the basilar artery in $18 / 18(100 \%)$ of the patients. In 10 patients $(55 \%)$, there were small remaining fragments of thrombus, primarily in distal posterior artery branches. There were no complications from the procedure. At late follow-up (3-8 months), $14 / 18(78 \%)$ of the patients were independent (MRS 0-2). 3 patients were $\mathrm{MRS}=0,9$ patients were $\mathrm{MRS}=1$ and 2 patients were $\mathrm{MRS}=2$. $4 / 18(22 \%)$ of the patients were dead, primarily caused by large infarcts in the brainstem and cerebellum.

CONCLUSION

Thrombectomy with MERCI and adjunctive intrarterial rt-PA is safe with excellent recanalisation rate and clinical outcome. The results in this small series are superior to those published for intravenous rt-PA. Thrombectomy may consequently be considered the primary treatment modality for this patient group.

\section{HE4:10}

\section{INTRACRANIAL PTA AND STENTS IN STROKE PREVENTION}

\section{S. BAKKE, T NOME}

\section{OSLO UNIVERSITY HOSPITAL RIKSHOSPITALET, OSLO,} NORWAY

Along with acute stroke treatment noninvasive techniques like CT/CTA or MR/MRA diagnose intracranial stenosis and the work-up of TIA patients usually includes visualization of arteries from the arch,bifurcation and intracranially. Both groups may need to be treated fast. PTA and dedicated intracranial stents are suited, but no randomized study has been performed to confirm the efficacy and patency of such treatment.

We present a single center expirience from last 30 months.

MATERIAL

18 patients presented with symptoms and significant intracranial stenosis, of which two had bilaterally lesion and thus we performed 20 procedures in 16 men and 2 women, $39-66$ years old, all symptomatic in spite of best medical treatment.

\section{RESULT}

Six of the 20 stenosis were in posterior fossae and 14 in ICA (2) and MCA (12).They had all significant stenosis. Three were treated with
PTA only, the rest had also stent (Wingspan,Boston) or Enterprise (Codman). One of the PTA patients needed stent at follow-up. One stent almost occluded,but with no harm for the patient, another two had intima hyperplasia of which one has been retreated by PTA. The rest were patent and none of the patients has so far had a new stroke. One patient stopped double platelet medication and got new TIA, which vanished after the double platelet were reintroduced.

We had no stokes during procedure or the following follow-up.

The follow-up so far is between 3-30 months.

DISCUSSION

PTA and stenting have been without acute complications, but we use 3-5 days or more premedication of Plavix $75 \mathrm{mg}$ and AlbylE $75 \mathrm{mg}$. PTA may be first try, but in most cases we need stent to secure the wall. In most cases the Wingspan procedure were performed with post balloon dilatation with no more the $80 \%$ of original lumen, and we never have expirienced ruptures.

CONCLUSION

Intracranial PTA and stents are safe tools in symptomatic patients.

\section{HE4:11}

\section{TREATMENT OF STENOSES OF THE VERTEBRAL ARTERY ORIGIN USING SHORT DRUG-ELUTING CORONARY STENTS: IMPROVED FOLLOW-UP RESULTS}

\author{
Z. VAJDA ${ }^{1}$, E. MILOSLAVSKI ${ }^{1}$, T. GUETHE $^{2}$, S. FISCHER ${ }^{1}$, \\ G. ALBES , E. SCHMID ${ }^{3}$, H. HENKES ${ }^{1}$ \\ ${ }^{1}$ KLINIK FUER NEURORADIOLOGIE, STUTTGART, GERMANY, \\ ${ }^{2}$ KLINIK FUER KARDIOLOGIE, STUTTGART, GERMANY, \\ ${ }^{3}$ KLINIK FUER NEUROLOGIE, STUTTGART, GERMANY
}

\section{BACKGROUND AND PURPOSE}

Recent studies on stenting of high-grade stenoses at the origin of the vertebral artery reported excellent immediate results. Long-term outcomes, however, were disappointing due to high restenosis rates and stent breakages. In the present study, we evaluated the application of a short, drug-eluting balloon-expandable coronary stent for the endovascular treatment of these frequent lesions.

MATERIALS AND METHODS

In the period of 21 months, 40 patients ( 9 female, 31 male) with a mean age of 68 years (range 46 to 81 years) harboring 45 high-grade ostial vertebral artery stenoses underwent treatment with short $(8 \mathrm{~mm})$, balloon-expandable, paclitaxel-eluting coronary stents (Coroflex Please, B. Braun, Germany). Stents were deployed with the proximal end positioned exactly at the origin of the vertebral artery, applying high inflation pressure. Patients were under continuous medication with ASA and Clopidogrel before and after the treatment. Follow-up clinical assessment and angiography was obtained in all patients.

\section{RESULTS}

Periprocedural complications were not encountered. Stenosis severity was reduced from $63 \pm 2 \%$ (mean $\pm \mathrm{SE}$ ) pre-procedurally to $16 \pm 2 \%$ post-procedurally. Follow-up angiography at $6.3 \pm 0.6$ months revealed a mean stenosis degree of $26 \pm 3 \%$. None of the patients developed posterior circulation symptoms related to the treated segment during the follow-up period. Recurrent stenosis $(>50 \%)$ at follow-up was found in $6(13 \%)$ patients.

CONCLUSIONS

Stenting of high-grade ostial vertebral artery stenosis using short drug-eluting stents is safe and yields good mid-term patency rates as well as excellent protection from posterior circulation ischemia. 


\section{HE4:12}

TREATMENT OF NEUROVASCULAR IN-STENT STENOSES USING A CORONARY PACLITAXEL ELUTING BALLOON (SEQUENT PLEASE, B. BRAUN)

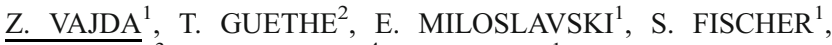
E. SCHMID $^{3}$, B. SCHELLER ${ }^{4}$, H. HENKES ${ }^{1}$

${ }^{1}$ KLINIK FUER NEURORADIOLOGIE, STUTTGART, GERMANY, ${ }^{2}$ KLINIK FUER KARDIOLOGIE, STUTTGART, GERMANY, ${ }^{3}$ KLINIK FUER NEUROLOGIE, STUTTGART, GERMANY, ${ }^{4}$ KLINIK FUER INNERE MEDIZIN / KARDIOLOGIE, HOMBURG / SAAR, GERMANY

\section{PURPOSE}

to evaluate the safety and efficacy of a new coronary Palcitaxel eluting balloon for the treatment of neurovascular in-stent stenoses. MATERIAL AND METHODS

15 patients with asymptomatic but high grade intracranial in-stent stenoses were treated. The previously deployed stents were 11 Enterprise, 1 Coroflex, 1 Solitaire, 1 Fluency and 1 Neuroform. The underlying lesions were 9 atherosclerotic stenoses, 4 vasculitic stenoses, 1 PcomA aneurysm and 1 fibromuscular dysplasia. Target lesions were located at the intradural ICA in 5 patients, at the MCA in 6 patients, at the V4 segment in 3 patients and at the V2 segment in 1 patient. Three patients had undergone several conventional retreatments prior to the angioplasty with a drug eluting balloon (DEB). RESULTS

Balloon angioplasty was successful in all 15 patients with a residual stenosis of less then $50 \%$. No adverse events were encountered. Postprocedural MRI did no show significant lesions related to the site of treatment. No patient presented with clinical signs or symptoms of cerebral ischemia following DEB-angioplasty. In 10 patients with angiographic follow-up, 2 residual stenoses were found after DEBangioplasty, but no recurrent intimal hyperplasia. In 2 patients with several recurrences after treatment of inflammatory distal ICA and proximal M1-stenosis, angiographic follow-up 12 weeks after DEBangioplasty did not show any intimal hyperplasia. All patients are scheduled for DSA 6 and 12 weeks and 6 and 12 months after DEBtreatment.

\section{CONCLUSION}

treatment of in-stent stenoses of supra-aortic and intracranial arteries using the coronary drug eluting balloon SeQuent Please is safe and efficient, at least based on this small series. Initial follow-up results are promising but further data collection in a larger number of patients is certainly required.

\section{HE4:13}

ACUTE STROKE TREATMENT USING A MECHANICAL APPROACH WITH THE PENUMBRA SYSTEM

C. ROTH $^{1}$, I. GRUNWALD ${ }^{2}$, S. WALTER $^{3}$, P. PAPANAGIOTOU ${ }^{1}$, K. FAßBENDER ${ }^{3}$, W. REITH ${ }^{1}$

${ }^{1}$ DEPARTMENT OF DIAGNOSTIC AND INTERVENTIONAL NEURORADIOLOGY, SAARLAND UNIVERSITY, HOMBURG, GERMANY, ${ }^{2}$ DEPARTMENT OF NEURORADIOLOGY, UNIVERSITY OF OXFORD, OXFORD, UNITED KINGDOM, ${ }^{3}$ DEPARTMENT OF NEUROLOGY, SAARLAND UNIVERSITY, HOMBURG, GERMANY

\section{BACKGROUND AND PURPOSE}

This is a single center experience illustrating the effectiveness of the Penumbra System (PS) in the treatment of large vessel occlusive disease in acute ischemic stroke. The PS is an innovative mechanical thrombectomy device, employed in the revascularization of large cerebral vessel occlusions in patients via the utilization of an aspiration platform.

METHODS

This is a prospective, non-randomized controlled trial evaluating the clinical and functional outcome in 29 patients with acute intra-cranial vessel occlusions consequent to mechanical thrombectomy by the Penumbra System either as mono-therapy or as an adjunct to current standard of care. Patients were evaluated by a neurologist and treated by our in house interventional neuroradiologists. Primary end-points were revascularization of the occluded target vessel to TIMI grade 2 or 3 and neurological outcome as measured by an improvement in the NIH Stroke Scale (NIHSS) score after the procedure.

RESULTS

Complete revascularization (TIMI 3) was achieved in 21/29 (72.4\%) of patients. Partial revascularization (TIMI 2) was established in $4 / 29$ $(13.8 \%)$ of patients. Revascularization failed in 4 (13.8\%) patients. Nineteen (19) patients $(65.5 \%)$ had at least a 4-point improvement in NIHSS scores. Modified Rankin scale scores of $<2$ were seen in $37.9 \%$ of patients. There were no device related adverse events. Symptomatic intra-cranial hemorrhage occurred in $7 \%$ of patients. CONCLUSION

The Penumbra System has the potential of exercising a significant impact in the interventional treatment of ischemic stroke in the future.

\section{HE5}

\section{5:25-16:50 - Cerebrovascular disease - imaging I}

\section{HE5:1}

\section{CT ANGIOGRAPHY COVERING CERVICAL AND CEREBRAL ARTERIES ON A 64-ROW SYSTEM WITH CONTRAST AND FLUSH DOSES DETERMINED BY PATIENT WEIGHT}

K. TSUCHIYA, M. IMAI, M. YOSHIDA, A. FUJIKAWA, M. KOYANAGI, T. NITATORI

Kyorin University, Department of Radiology, Tokyo, JAPAN

\section{PURPOSE}

We assessed the feasibility of a CT angiography (CTA) protocol using a contrast agent and a saline flush with doses determined by patient weight on a 64-detector-row scanner to visualize both cervical and cerebral arteries.

METHODS

Our patient group comprised 20 consecutive patients (nine males and 11 females; age range, 44 to 77 years; average, 61 years) referred for cerebral and/or cervical CTA. We injected nonionic contrast agent of $350 \mathrm{mgI} / \mathrm{mL}$ and saline for flush with doses of $1.2 \mathrm{~mL} / \mathrm{kg}$ and $0.5 \mathrm{~mL} /$ $\mathrm{kg}$, respectively. The injection rate was fixed at $3 \mathrm{~mL} / \mathrm{sec}$. Other scanning parameters included $120 \mathrm{kV}, 300 \mathrm{~mA}, 0.5-\mathrm{mm}$ section, $0.4-\mathrm{mm}$ reconstruction interval and $0.75 \mathrm{sec} /$ rotation. We generated volume-rendered and maximum-intensity-projection CTA images using a workstation. Those images were visually assessed by two neuroradiologists paying attention to demonstration branches of the circle of Willis, that of carotid bifurcation, and image degradation of the carotid artery by overlapping of the internal jugular vein using 4-point grading systems. 


\section{RESULTS}

As the average body weight of the patients was $55 \mathrm{~kg}$, the average injected dose of contrast and flush saline were $66 \mathrm{~mL}$ and $27 \mathrm{~mL}$, respectively. Obtained CTA images were sufficient regarding the three evaluated issues with kappa values of $0.86-1.0$ between the two readers.

CONCLUSION

This protocol well works in CTA to visualize both cervical and cerebral arteries with a small dose of contrast material.

\section{HE5:2}

\section{TRANSCRANIAL DOPPLER SONOGRAPHY AS A CONFIRMATORY TEST IN THE DIAGNOSIS OF BRAIN DEATH}

T. SOLDATOS $^{1}$, D. KARAKITSOS ${ }^{2}$, C. CHATZIMICHAIL ${ }^{3}$, M. PAPATHANASIOU ${ }^{3}$, A. GOULIAMOS ${ }^{4}$, A. KARABINIS ${ }^{2}$

${ }^{1}$ DEPARTMENT OF RADIOLOGY AND IMAGING, G.GENNIMATAS GENERAL STATE HOSPITAL, ATHENS, GREECE, ${ }^{2}$ INTENSIVE CARE UNIT, G.GENNIMATAS GENERAL STATE HOSPITAL, ATHENS, GREECE, ${ }^{3}$ SECOND DEPARTMENT OF RADIOLOGY, UNIVERSITY OF ATHENS, ATTIKON HOSPITAL, ATHENS, GREECE, ${ }^{4}$ FIRST DEPARTMENT OF RADIOLOGY, UNIVERSITY OF ATHENS, ARETAIEIO HOSPITAL, ATHENS, GREECE

\section{PURPOSE}

The diagnosis of brain death (BD) is based on clinical examination and is further established by blood flow tests which confirm the cerebral circulatory arrest (CCA). Angiography remains the goldstandard modality to detect CCA, but is invasive. Transcranial Doppler sonography is a non-invasive technique, which has been increasingly advocated in the assessment of cerebral hemodyhamics. We evaluated the ability of TCD to detect CCA in clinically brain dead patients.

METHODS

We evaluated 76 critical care patients (43 males, $47 \pm 18$ years old) with clinically established BD due to head injury in 41 cases $(54 \%)$, subarachnoid hemorrhage in $16(21 \%)$, intracerebral hemorrhage in $13(17 \%)$ and cerebral infarction in $6(8 \%)$. All patients underwent four-vessel angiography, TCD of the basilar and middle cerebral arteries via a transtermpotal approach, and TCD of the internal carotid arteries via a transorbital approach.

RESULTS

Both angiography and TCD confirmed CCA in all subjects. The agreement between the above methods in the confirmation of CCA was $100 \%$. In all subjects angiography demonstrated the absence of filling of intracranial arteries. TCD revealed systolic spikes in 34 cases $(45 \%)$, oscillatory flow in 19 cases $(25 \%)$, and absence of flow in 23 cases $(30 \%)$, in which flow had been documented on a previous examination. Three patients required repeated TCD examinations, because of initial detection of a persistent diastolic flow. In the latter subjects, TCD confirmed CCA after 30 hours of clinical BD.

\section{CONCLUSIONS}

TCD is a sensitive, non-invasive tool to confirm CCA in clinically brain dead subjects, and may be used in the neuromonitoring of patients suspected to develop $\mathrm{BD}$, in order to determine the most appropriate moment for angiography.
HE5:3

\section{CAROTID AND VERTEBROBASILAR ARTERIAL DISSECTION: IMAGING FINDINGS IN CTA AND MRA WITH PATHOLOGIC CORRELATION}

\author{
S. BENAKIS ${ }^{1}$, I.G. SKOURAS ${ }^{1}$, V. OURANOS ${ }^{1}$, K. STEFANIDIS $^{1}$, \\ E. TESTEBASI ${ }^{1}$, V. VANTALI ${ }^{1}$, C. LOUIZAKIS ${ }^{1}$, V. SAVVOPOULOU ${ }^{2}$, \\ D. CHONDROS $^{1}$
}

${ }^{1}$ GENERAL HOSPITAL EVANGELISMOS, ATHENS, GREECE, ${ }^{2}$ GENERAL HOSPITAL THRIASIO, ELEFSINA, GREECE

\section{PURPOSE}

Cervical artery dissection (CAD) accounts for up to $20 \%$ of ischemic strokes occurring before 45 years. Dissections of the extracranial cervical arteries accounts in about $90 \%$ of the cases while only in $10 \%$ there is dissection of intracranial arteries. The purpose of this study is to evaluate the role of CT Angiography (CTA) and MR Angiography (MRA) in the diagnosis and treatment of patients with cervical artery dissections. METHODS

During the last 10 months we studied 15 patients with cervical artery dissection ( 9 women and 6 men with ages between $23-48$ years and a mean age of 41 years). In 11 patients (73\%) the dissection was traumatic while in the rest of them was spontaneous. All patients underwent a a sixteen-slice CTA. In 9 cases there was further investigation with MRA. RESULTS

The most common symptoms were severe headache (73\%), posterior neck pain $(60 \%)$, vertico $(60 \%)$, nausea $(53 \%)$, dysarthria $(40 \%)$ and diplopia (33\%). In 2 patients the dissection was extended intracranial while in 2 more, there was combined incidence of both vertebral and carotid arterial dissections. The imaging findings that were evaluated in both CTA and MRA were including acute ischemic stroke, luminal narrowing, vessel irregularity, wall thickening/hematoma, pseudoaneurysm, and intimal flap. CONCLUSION

CTA is a non invasive, quick and accurate method for the detection and follow up of carotid and/or vertebral artery dissection. In some cases MRA can provide complementary or confirmatory informations mostly because of its better depiction of ischemic complications.

\section{HE5:4}

\section{VESSEL HYPERDENSITY IN PATIENTS WITH ACUTE BRAIN ISCHEMIA ASSESSED BY MEANS OF MULTI-DETECTOR CT: CORRELATION WITH DWI}

A. ROMANO, V. FINOCCHI, O. GAGLIARDO, S. METAMBOU, S. PUGLIESE, L.M. FANTOZZI, A. BOZZAO

\section{NEURORADIOLOGY S.ANDREA HOSPITAL UNIVERSITY SAPIENZA, ROME, ITALY}

\section{PURPOSE}

Aim of the study was to assess sensibility and specificity of multidetector CT (MDCT) in the assessment of vessel hyperdensity in patients evaluated for acute ischemia. Positive DWI MRI was considered as reference.

MATERIALS

82 patients, all studied with CT scan (16 rows detector) were selected based on a positive DWI MRI for acute ischemia performed within 12 hours. Patients were randomized with a comparable control group of 
CT examinations. Two expert neuroradiologists were asked to read the exams looking for hyperdense vessels before and after considering the CT scan of patients with anterior strokes (being aware of the clinical symptoms), also identifying the location (M1 to M3) of the hyperdensity. Consensus was reached. Hyperdense vessels in patients with anterior strokes were correlated with ASPECTS score obtained on DWI MR.

RESULTS

65 patients had anterior (in 28 lesions size over $2.5 \mathrm{~cm}$ ) and 17 (in 12 lesions size over $2.5 \mathrm{~cm}$ ) posterior strokes. Reading of the randomized CT scans lead to a sensibility in hyperdensity assessment ranging from 18 to $19 \%$ and a specificity of $96-100 \%$ with an inter-observes reliability of $84 \%$. Reading of CT exams of patients with anterior strokes (being aware of symptoms) increased sensibility up to $26-31 \%$, specificity and interobserver reliability being unchanged. Consensus reading of CT scan of patients with strokes more than $2.5 \mathrm{~cm}$ in size identified 20/28 (71\%) anterior and 10/12 (83\%) posterior hyperdense arteries. The following ASPECTS scores were identified with respect of hyperdense vessel location: $\mathrm{M} 1=8, \mathrm{M} 1-\mathrm{M} 2=2.8, \mathrm{M} 2=7, \mathrm{M} 2-\mathrm{M} 3=7, \mathrm{M} 3=7.4$.

CONCLUSIONS

In patients with ischemic strokes leading to lesions larger than $2.5 \mathrm{~cm}$ an hyperdense artery as assessed by means of MDCT can be observed in more than $70 \%$ of cases. Proximal hyperdense arteries lead to lower ASPECTS score but M1 location correlates with the highest scores of our series.

\section{HE5:5}

\section{ANGIOGRAPHIC FLAT-PANEL COMPUTED TOMOGRAPHY AFTER INTRAVENOUS CONTRAST AGENT APPLICATION: A NON-INVASIVE FOLLOW-UP TOOL AFTER INTRACRANIAL ANGIOPLASTY AND STENTING}

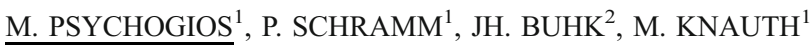

${ }^{1}$ NEURORADIOLOGY, UNIVERSITY HOSPITAL GOETTINGEN, GOETTINGEN, GERMANY, ${ }^{2}$ DIAGNOSTIC RADIOLOGY, UNIVERSITY HOSPITAL HAMBURG, HAMBURG, GERMANY

\section{PURPOSE}

Intracranial artery angioplasty and stenting (ICAS) is a therapeutic option for symptomatic cerebral artery stenosis. Intra-arterial digital subtraction angiography (iaDSA) is the current gold-standard followup examination after ICAS for the detection of in-stent re-stenosis in the course of thrombosis or intimal hyperplasia. In this study we investigated the value of angiographic flat-panel computed tomography after intravenous contrast agent application (ivACT) as a possible non-invasive follow-up examination for patients with ICAS.

\section{METHODS AND MATERIALS}

In 10 patients both ivACT and iaDSA were performed 6 months after ICAS, using a flat-panel detector equipped Axiom Artis angiography suite (Siemens AG, Germany). Postprocessing of ivACT acquisitions was performed using a standard workstation (Leonardo, Siemens AG, Germany). Multiplanar reconstructions of the stent region and other vascular territories with $0.1 \mathrm{~mm}$ isotropic voxel size were generated. Stent configuration and apparent lumen diameter were evaluated and compared to iaDSA. All studies were independently evaluated by two blinded neuroradiologists.

RESULTS

IvACT excluded an in-stent re-stenosis in 6 of 10 patients. These findings were confirmed in iaDSA. In 4 cases ivACT showed a middle- or high-grade re-stenosis, correlating with the results from iaDSA. In two of those cases re-angioplasty was performed. Proper stent deployment was documented in all cases, by thick maximal intensity reconstructions of the ivACT volume dataset. Furthermore ivACT produced high-resolution images of the complete intracranial vasculature enabling diagnosis of other vessel pathology.

\section{CONCLUSION}

IvACT is a promising new non-invasive follow-up examination after ICAS. With its high spatial resolution it can reliably visualize in-stent pathologies. In contrast to iaDSA, it can be performed on an outpatient basis, and therefore might replace iaDSA as a regular follow-up examination after ICAS.

\section{HE5:6}

\section{THE APPLICATION OF ANGIOGRAPHIC COMPUTED TOMOGRAPHY IN THE POSTINTERVENTIONAL CEREBRAL DIAGNOSTIC IMAGING. FINAL RESULTS AFTER 82 CASES}

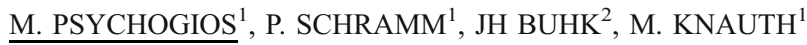

${ }^{1}$ NEURORADIOLOGY, UNIVERSITY HOSPITAL GOETTINGEN, GOETTINGEN, GERMANY, ${ }^{2}$ DIAGNOSTIC RADIOLOGY, UNIVERSITY HOSPITAL HAMBURG, HAMBURG, GERMANY

\section{PURPOSE}

Angiographic computed tomography (ACT) is a technical advancement of rotational angiography. Image acquisition takes place in a flat panel detector-equipped angiography suite. In this study we evaluated ACT as a fast available diagnostic tool after neuroendovascular procedures compared to postinterventional multislice computed tomography (MSCT).

METHODS AND MATERIALS

Digital subtraction angiography and ACT were performed on an Axiom Artis biplane angiography system equipped with flat-panel detectors (Siemens AG, Germany). 82 postinterventional ACTacquisitions were obtained using a 20 -second DYNA-CT protocol: 53 patients underwent coil embolisation of intracranial aneurysms, 17 patients received intracranial angioplasty with stent placement and 12 patients underwent intraarterial thrombectomy and lysis. As postprocessing, multiplanar reconstructions were generated using a standard workstation (Leonardo, Siemens AG, Germany). The postinterventional CT was performed within the first 48 hours after endovascular procedure using either a 16 slice-CT scanner (Aquilion 16, Toshiba, Japan) or a 128 slice-CT scanner (Somatom Definition AS+, Siemens AG, Germany). All studies were independently evaluated by three blinded neuroradiologists using a scaled scoring system.

\section{RESULTS}

ACT images were of sufficient diagnostic quality in all cases, concerning intracranial spatial relations (midline shift, supra-/infratentorial ventricular system). Diagnostic evaluation of the grey matter (basal ganglia, insular cortex, opercula) was possible only in $34 \%$ of the cases. Yet ACT proved to be a reliable tool for the detection of periinterventional subarachnoidal or intracerebral hemorrhage with $93 \%$ sensitivity and $85 \%$ specificity.

\section{CONCLUSION}

After neuroendovascular procedures ACT enables an immediate detection or exclusion of periinterventional hemorrhage or hydrocephalus. However, for the detection of early signs of cerebral infarction or other parenchymal pathologies, ACT is not yet reliable enough. 
HE5:7

\section{EVALUATION OF CEREBRAL ANEURYSMS WITH THREE-DIMENSIONAL CT ANGIOGRAPHY}

T. SOLDATOS, E. KROMMIDA, P. LAMPROPOULOU, A. MIKA, D. KARAKYKLAS, C. SAMARA, G. ZOIS, C. DROSSOS

DEPARTMENT OF RADIOLOGY AND IMAGING, G. GENNIMATAS GENERAL STATE HOSPITAL, ATHENS, GREECE

\section{PURPOSE}

Conventional angiography is considered the gold-standard modality for the detection of cerebral aneurysms, however it is invasive. Three-dimensional CT angiography (CTA) utilizes dynamic contrast-enhanced scans to create volumetric reformations of the cerebral vasculature. We evaluated the application of 3D CTA in the diagnosis and preoperative investigation of cerebral aneurysms, by comparing it to conventional angiography.

METHODS

Forty eight patients ( 25 males, $43 \pm 17$ years old) with clinically suspected or angiographically verified cerebral aneurysms were examined by means of conventional angiography and 3D CTA. A blind review of the imaging findings was retrospectively performed to assess the agreement between the two methods.

RESULTS

In 19 patients conventional angiography demonstrated 26 cerebral aneurysms ranging from 2 to $23 \mathrm{~mm}$ in maximum diameter. Threedimensional CTA detected all aneurysms $>=5 \mathrm{~mm}$, exhibiting $100 \%$ agreement with conventional angiography regarding the morphology and anatomic relationships of the pathologic vessels. However, 3D CTA was less successful in the detection of small aneurysms, revealing $22 \%$ of the latter.

CONCLUSIONS

Three-dimensional CTA exhibits high sensitivity in the detection of cerebral aneurysms $>=5 \mathrm{~mm}$, and could replace conventional angiography in the preoperative evaluation of the above lesions.

\section{HE5:8}

\section{DWI LESIONS AND THEIR INFLUENCE ON COGNITIVE PERFORMANCE AFTER CAS}

S. PILGRAM-PASTOR ${ }^{1}$, K. WASSER ${ }^{2}$, P. WEBER $^{1}$, J. KNAUF $^{2}$, A. KASTRUP ${ }^{2}$, M. KNAUTH ${ }^{1}$

${ }^{1}$ DEP. OF NEURORADIOLOGY, UNIVERSITY HOSPITAL, GÖTTINGEN, GERMANY, ${ }^{2}$ DEP. OF NEUROLOGY, UNIVERSITY HOSPITAL, GÖTTINGEN, GERMANY

\section{INTRODUCTION}

Endovascular treatment strategies for symptomatic or high grade carotid stenosis are carotid endarteryectomy (CEA) or alternative carotid angioplasty and stenting (CAS). Using diffusion-weighted imaging (DWI) to detect new embolic brain lesions after intervention several studies have indicated that CAS is associated with a significantly higher number of microembolic lesions. Although patients often show no clinically symptoms it is unclear if DWI lesions can influence cognitive function.

MATERIALS AND METHODS

A total number of 73 subjects were included in this prospective study. 21 patients underwent CAS, 22 patients underwent CEA and 30 healthy subjects served as a neuropsychological control group. In all patients MRI scans (3 T Tim Trio, Siemens; DWI-, SWI- and Flair-images); clinical examinations and neuropsychology tests were obtained immediately before, within 48 hours and 3 months after CEA or CAS.

\section{RESULTS}

Before each procedure, DWI revealed ischemic lesions in 7/21 (33\%) of the patients treated with CAS and in $5 / 20(25 \%)$ of the patients treated with CEA. While no CEA patient $(0 / 18)$ had a new DWI lesion postoperatively, new DWI lesions were detected among 13/19 $(68 \%)$ of the CAS immediately after treatment $(p<0.01)$. With respect to the total number of pathological neuropsychological measures and across the entire study population there was no significant difference between patients with and without new DWI lesions immediately or after 3 months after treatment.

CONCLUSIONS

In our study new DWI lesions occur more often after CAS than after CEA. However DWI lesions due to microembolic events were clinically silent. Neuropsychological tests support the assumption that microemboli are not responsible for neuropsychological deficits commonly observed in this scenario. The relatively small number of patients involved in this study, on the other hand, induces the risk of misinterpretation due to a Type II error.

\section{HE5:9}

\section{CAN THE STATIN THERAPY REDUCE THE RISK OF STROKE AFTER CAS?}

\section{$\underline{\text { P. PAPANAGIOTOU }}$, C. ROTH, C. KRICK, M. POLITI, C. KRAUS, W. REITH}

CLINIC FOR DIAGNOSTIC AND INTERVENTIONAL NEURORADIOLOGY, HOMBURG, GERMANY

\section{PURPOSE}

This study examines whether there exists a correlation between the use of statin treatment and cerebral ischemic lesions identified by diffusion-weighted magnetic resonance imaging (DW-MRI) after carotid artery stenting (CAS).

METHODS

A retrospective study was conducted in a nonrandomized cohort of 540 patients treated with CAS. Patients were classified into 2 groups: patients receiving preprocedural statin therapy (338-62.6\%) and patients not receiving preoprocedural antihyperlipidemic therapy (202-37.4\%). Diffusion weighted imaging (DWI) was performed before and after intervention in 447 patients. The frequency of new DWI lesions between patients with preprocedural statin treatment and that of patients without preprocedural statin treatment was compared. $\hat{\mathrm{A}}$

\section{RESULTS}

New DW-MRI lesions were seen in $33.3 \%$ of the patients with preprocedural statin treatment and in $26.8 \%$ of the patients without preprocedural statin treatment. The mean size of new DWI lesions was $7.74 \mathrm{~mm}$ in the group with preprocedural statin treatment and $3 \mathrm{~mm}$ in the group without preprocedural statin treatment. There was no statistically significant correlation between the preprocedural statin treatment and the frequency of new cerebral ischemic lesions detected on DW-MRI, however the difference in the size of lesions was statistically signifikant.

CONCLUSIONS

Preprocedural statin therapy not only does not reduce the incidence of cerebral ischemic lesions after CAS but also is associated with 
increased ischemic events. A probable explanation of our results is that the patients receiving statin therapy are higher risk patients due to preexisting hyperlipidemia.

HE5:10

\section{EARLY CT SING OF ISCHEMIA: DO THEY ALWAYS DOT A STROKE?}

R. MARASCO ${ }^{1}$, V. CITTON ${ }^{1}$, C. BRIANI ${ }^{2}$, M. CALDERONE ${ }^{1}$, S. DAL $\operatorname{POS}^{1}$, L. SANTELLI ${ }^{3}$, A. VIDALI ${ }^{2}$, R. MANARA ${ }^{1}$

${ }^{1}$ U.O NEURARADIOLOGIA, OSPEDALE CIVILE DI PADOVA, PADOVA, ITALY, ${ }^{2}$ CLINICA NEUROLOGIA I, OSPEDALE CIVILE DI PADOVA, PADOVA, ITALY, ${ }^{3}$ CLINICA NEUROLOGICA II, OSPEDALE SANT'ANTONIO DI PADOVA, PADOVA, ITALY

\section{PURPOSE}

Trombolytic therapy for acute ishemic stroke is based on clinical assessment, blood test and CT findings. The presence of early CT ischemic change may help support therapeutic decision.

Our aim is to call attention to a likely overlooked stroke mimic, Gliomatosis Cerebri.

METHODS AND RESULTS

Clinical and neuroimaging analysis of three patiens with documented Gliomatosis Cerebri whose acute onset and CT (data lenticuler and ribbon sign and a ipsilateral dot sing) were suggestive of ischemic stroke. CONCLUSIONS

Noncerebrovascular conditions may present with both acute onset and false CT sings of early ischemic stroke. Although rare, Gliomatosis Cerebri needs to be considered among the possible stroke mimic to avoid inappropriate thrombolytic therapy.

\section{HE5:11}

\section{INTRAVENOUS ACETYLSALICYLIC ACID AS A PROPHYLACTIC AND FIRST LINE "RESCUE" AGENT IN THE MANAGEMENT OF THROMBOEMBOLIC COMPLICATIONS DURING INTRACRANIAL ANEURYSM COIL EMBOLIZATION}

K. LOBOTESIS, D BUTTERISS, D MITRA, D BIRCHALL, V JAYAKRISHNAN, A GHOLKAR

NEURORADIOLOGY DEPARTMENT, REGIONAL NEUROSCIENCES CENTRE, THE NEWCASTLE UPON TYNE HOSPITALS NHS FOUNDATION TRUST, NEWCASTLE UPON TYNE, UNITED KINGDOM

\section{PURPOSE}

Thromboembolic events are a well recognised complication of intracranial aneurysm coiling. There is however a lack of evidence based anticoagulation guidelines and more specifically data regarding the use of intravenous acetylsalicylic acid in the prevention and treatment of thromboembolism.

\section{METHODS}

Patients who received intravenous acetylsalicylic acid during aneurysm coil embolization between October 2007 to March
2009 in our centre were reviewed. Both ruptured and unruptured aneurysms were included in this study. Rate of infarction on post embolisation CT and incidents of intracranial haemorrhage were recorded following review of medical records, clinic letters, nursing notes, imaging studies and radiological reports. Clinical outcome was also assessed at discharge according to the modified Rankin scale.

RESULTS

Thirty seven patients between October 2007 to March 2009 in our centre received intravenous acetylsalicylic acid for thromboprophylaxis or as a "rescue" agent. Five patients received intravenous abciximab despite acetylsalicylic acid administration for thrombus propagation or persisting vessel occlusion. Five infarctions and one haemorrhagic complication were observed.

CONCLUSIONS

In this small retrospective series the application of intravenous acetylsalicylic acid as a prophylactic and first line "rescue" agent was demonstrated to be safe and cost-effective. The addition of a second antiplatelet agent did not lead to an increase in complications.

HE5:12

\section{COMPUTED TOMOGRAPHY ANGIOGRAPHY \\ FOR THE EVALUATION OF PATIENTS WITH NON-TRAUMATIC SUBARACHNOID HAEMORRHAGE IN A REFERRAL CENTER}

P. ZAMPAKIS ${ }^{1}$, C. KALOGEROPOULOU ${ }^{1}$, P. KRANIOTIS ${ }^{1}$, V. PANAGIOTOPOULOS ${ }^{2}$, D. KONSTANTINOU ${ }^{2}$, T. PETSAS ${ }^{1}$, D. SIABLIS ${ }^{1}$

${ }^{1}$ UNIVERSITY HOSPITAL OF PATRAS. RADIOLOGY DEPARTMENT, PATRAS, GREECE, ${ }^{2}$ UNIVERSITY HOSPITAL OF PATRAS. NEUROSURGERY DEPARTMENT, PATRAS, GREECE

\section{PURPOSE}

To study the diagnostic accuracy of Computed Tomography Angiography (CTA) for the evaluation of patients with non-traumatic subarachnoid hemorrhage.

PATIENT-METHOD

We retrospectively analyzed 172 patients presented with subarachnoid hemorrhage and no history of trauma, during the last three years.

All patients underwent a cerebral CTA, as this is our standard method of initial investigation, in those cases. They were scanned in our 16row multi-detector CT scanner (GE Lightspeed 500) with a standard protocol examination.

\section{RESULTS}

In 156 patients we found the cause of the bleeding (155 intracranial arterial aneurysms and 1 dissection of the V4 segment of the vertebral artery). In the remaining 16 cases, no aneurysm, dissection or other vascular pathology was found.

In all but one treated cases, the findings of the CT angiography were confirmed by either the surgical exploration (in patients who were clipped) or the digital angiograms (DSA) (in patients who were coiled). In one case, in a patient with 2 aneurysms, there was a discrepancy between the radiologist opinion and the surgical findings, regarding which aneurysm has been ruptured. 
In the 16 negative CTA cases, the repeated DSA or CTA was also negative and the bleeding was more likely to be due to a perimesencephalic venous incident.

CONCLUSION

The multidetector computed tomography $(\times 16)$ is totally adequate and accurate method for the investigation of non-traumatic subarachnoid haemorrhage and should be the first and only method for those patients. Digital angiograms should be reserved only when endovascular treatment is decided.

\section{HE5:13}

\section{CAROTID STENOSIS. EVALUATION WITH MULTI \\ DETECTOR COMPUTED TOMOGRAPHY ANGIOGRAPHY (MDCTA) - HISTOPATHOLOGICAL CORRELATION. PRELIMINARY RESULTS OF A PROSPECTIVE STUDY}

P. ZAMPAKIS ${ }^{1}$, C. KALOGEROPOULOU ${ }^{1}$, G. MOSCHOPOULOS ${ }^{1}$, A. TSAMANTAS ${ }^{2}$, P. KRANIOTIS ${ }^{1}$, I. TSOLAKIS ${ }^{3}$, T. PETSAS ${ }^{1}$, D. SIABLIS ${ }^{1}$

${ }^{1}$ UNIVERSITY HOSPITAL OF PATRAS. RADIOLOGY DEPARTMENT, PATRAS, GREECE, ${ }^{2}$ UNIVERSITY HOSPITAL OF PATRAS. PATHOLOGY DEPARTMENT, PATRAS, GREECE, ${ }^{3}$ UNIVERSITY HOSPITAL OF PATRAS. VASCULAR SURGERY DEPARTMENT, PATRAS, GREECE

\section{PURPOSE}

This prospective study aim to assess the reliability of MDCTA for the measurement of carotid artery stenosis.

\section{MATERIAL AND METHOD:}

Seventeen patients with known severe carotid disease underwent MDCTA, as a routine investigation. The examination was performed in a 16-row multidetector scanner (GE Lightspeed 16) using a standard protocol. Axial images, three-dimensional and multiplanar reconstructions were evaluated in a workstation.

The percentage of internal carotid artery (ICA) stenosis was calculated using the NASCET criteria. We used two different methods, the semi-automatic software of our scanner and a manual calculation. Measurements were performed by two independent radiologists. Both diameter and area stenosis of the ICA were calculated. MDCTA revealed significant stenoses in all patients who underwent endarterectomy. The percentage of ICA stenosis was also calculated in each histopathologic specimen. Measurements from both radiological methods were compared to the histological findings. RESULTS

The calculations of ICA stenosis were significant different $(p<0.5)$ between the two radiological methods. There was an excellent correlation $(\mathrm{r}=0.785)$ between the histological findings and the manual calculation of ICA area stenosis. On the contrary the semiautomatic calculations (diameter and area stenosis) differed significantly from that of the histological measurements $(r=0.112)$ and clearly underestimated the stenosis. The inter-observer reliability for the manual calculations, was very good.

CONCLUSION

Our preliminary results showed that MDCTA is a reliable method for the estimation of carotid disease. The manual calculations of ICA stenosis proved to be the most trustworthy method.

\section{HE6}

17:40-18:30 - Pediatric neuroradiology I

\section{HE6:1}

\section{MRI EVALUATION OF SURGICAL DAMAGE TO THE PROXIMAL EFFERENT CEREBELLAR PATHWAY IN PEDIATRIC PATIENTS WITH CEREBELLAR MUTISM}

$\underline{\text { Z. PATAY }}^{1}, \mathrm{~N} \mathrm{MILLER}^{1}, \mathrm{E} \mathrm{REDDICK}^{1}, \mathrm{~J} \mathrm{GLASS}^{1}, \mathrm{M} \mathrm{KOCAK}^{2}$,

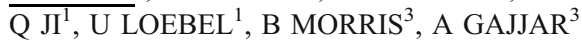

${ }^{1}$ ST. JUDE CHILDREN'S RESEARCH HOSPITAL, DEPARTMENT OF RADIOLOGICAL SCIENCES, MEMPHIS, TN, USA, ${ }^{2} \mathrm{ST}$. JUDE CHILDREN'S RESEARCH HOSPITAL, DEPARTMENT OF BIOSTATISTICS, MEMPHIS, TN, USA, ${ }^{3}$ ST. JUDE CHILDREN'S RESEARCH HOSPITAL, DEPARTMENT OF ONCOLOGY, MEMPHIS, TN, USA

\section{PURPOSE}

Cerebellar mutism (CM), the central clinical manifestation of posterior fossa syndrome (PFS) is a severe post-operative complication recognized in up to $25 \%$ of pediatric patients following posterior fossa (PF) surgery. We hypothesized that cerebellar mutism is due to surgical damage to the proximal components (denate nuclei/DN, superior cerebellar peduncles/SCP, and pontomesencephalic tegmental decussation/PMT) of the efferent cerebellar pathway (ECP). In this study we sought to investigate whether conventional anatomical and diffusion-weighted (DW) MRI analysis of surgical damage to proximal ECP predicts the development of CM.

\section{PATIENTS AND METHODS}

Eleven PF tumor patients (10 M/1F, ages 3-11 years) with CM and 11 age and gender matched patients with no CM following PF surgery were evaluated in a blinded, randomized analysis of the integrity of the proximal ECP using T2-weighted and DW images of the first postoperative MRI study (post-op days 1-14 ). A damage value of 0 to 3 was assigned to each structure (DN, SCP, PMTD) along the left and right proximal $\mathrm{ECP}(0=$ no damage, $1=$ edema only, $2=$ possible structural damage, $3=$ definite structural damage). A value of 3 for any structure on one side indicated disruption of the ipsilateral ECP. Patients were assigned into three groups: no damage, unilateral disruption, and bilateral disruption. Data was analyzed using logistic regression.

RESULTS

Logistic regression analysis showed a point estimate of the odds ratio of 12 (95\% CI: 1.12, 129), suggesting positive correlation between PFS and macroscopic bilateral structural damage to the proximal ECP $(p=0.04)$. The data indicate that patients with bilateral damage are more likely to develop $\mathrm{CM}$ than those with unilateral damage to the proximal ECP.

CONCLUSION

Bilateral surgical damage anywhere along the proximal ECP is the likely cause of cerebellar mutism. These findings are important since they indicate an apparent etiology for $\mathrm{CM}$ which may be preventable through adjusting surgical approaches. 
HE6:2

EVALUATING PEDIATRIC COCHLEAR IMPLANT CANDIDATES WITH LOW-DOSE TEMPORAL BONE COMPUTED TOMOGRAPHY: IMAGE QUALITY AND EFFECTIVE DOSES

C. NAUER ${ }^{1}$, A RIEKE $^{1}$, C ZUBLER ${ }^{1}, \mathrm{P} \mathrm{SENN}^{2}$

${ }^{1}$ UNIVERSITY HOSPITAL, INSTITUTE FOR DIAGNOSTIC AND INTERVENTIONAL NEURORADIOLOGY, BERNE, SWITZERLAND, ${ }^{2}$ UNIVERSITY HOSPITAL, DEPARTMENT OF OTOLARYNGOLOGY, HEAD AND NECK SURGERY, BERNE, SWITZERLAND

\section{PURPOSE}

Temporal bone computed tomography (CT) is routinely used to evaluate cochlear implant (CI) candidates. There is a growing concern over radiation exposure from $\mathrm{CT}$, especially to pediatric patients. The purpose of this study was to retrospectively evaluate a low-dose temporal bone $\mathrm{CT}$ protocol for pediatric cochlear implant candidates regarding image quality and effective radiation dose and to compare doses with dosimetric data from the literature.

METHODS

Retrospective image quality analysis of temporal bone scans of totally 19 infants $(<1$ year $)$ and children $<5$ years respectively performed with a low-dose protocol (CT-Dose-Index (CTDI) 8.8 / 10.8 Milligray (mGy)). Standard-dose scans (CTDI $63 \mathrm{mGy}$ ) were assessed for comparison. 23 anatomical structures were rated (scale 1-5) by three neuroradiologists. Time for review and ideal window center/width were noted. Effective doses were calculated using Monte Carlo simulation software. Medline was searched for protocol recommendations and dosimetric data for pediatric temporal bone CT, effective doses were calculated from the data found, where appropriate.

RESULTS

Overall image quality of the low-dose scans was not significantly worse. All anatomical structures that need to be evaluated in CI candidates were delineated sufficiently. Window width used for the low-dose scans was significantly wider (3300 vs. 1470 HU mean). Time needed per ear was somewhat higher in the low dose scans (7.4 min vs $6.6 \mathrm{~min}$.) Mean effective doses for $<1$ year $/<5$ year old was $0.3 / 0.25$ Millisievert (mSv). Publications on pediatric temporal bone $\mathrm{CT}$ dosimetry are scarce, recent data for conventional protocols indicate effective doses up to $2.6 \mathrm{mSv}$.

CONCLUSION

Pediatric low-dose temporal bone CT can be performed with effective doses resulting several times below doses from conventional protocols while maintaining diagnostic image quality.

\section{HE6:3}

CYCLOSPORINE (CS) NEUROTOXICITY IN PEDIATRIC PATIENTS UNDERGOING HEMATOPOIETIC STEM CELL TRANSPLANTATION (HSCT): CONVENTIONAL MR AND DIFFUSION-WEIGHTED IMAGING FINDINGS

G. MORANA $^{1}$, M. FARACI ${ }^{2}$, A. ROSSI ${ }^{1}$

${ }^{1}$ G.GASLINI CHILDREN'S RESEARCH INSTITUTE, DEPARTMENT OF NEURORADIOLOGY, GENOA, ITALY, ${ }^{2}$ G.GASLINI CHILDREN'S RESEARCH INSTITUTE, DEPARTMENT OF HEMATOLOGY, GENOA, ITALY

\section{PURPOSE}

To correlate conventional magnetic resonance (MR) and diffusionweighted imaging (DWI) features of cyclosporin (Cs)-induced posterior reversible encephalopathy syndrome (PRES) with final imaging outcome in order to evaluate the possible prognostic usefulness of DWI.

METHODS

We reviewed a selected population of 11 pediatric patients with hematological disorders undergoing HSCT who developed Cs-related PRES. Initial and follow-up MR images were evaluated for distribution of the lesions, presence of hemorrhagic foci, findings on DWI, and reversibility.

RESULTS

The most common lesion locations were the occipital lobes $(63 \%)$, parietal lobes (54\%), frontal lobes (45\%), temporal lobes and cerebellum $(36 \%)$. Areas of restricted diffusion were found in 6 patients $(54 \%)$; of these, 1 presented only with restricted diffusion abnormalities, whereas the remainder presented small focal areas of restricted diffusion surrounding vasogenic edema. Two patients also showed hemorrhage. Seven patients $(63 \%)$ underwent complete reversibility of all lesions, while 2 had irreversible gliotic/malacic sequelae and 1 a minimal focal cortical area of residual hyperintensity on FLAIR images. One patient had reversibility of all lesions except for an hemosiderinic area, consequence of a focus of hemorrhage. Of 6 patients with areas of restricted diffusion, 4 had complete reversibility of all lesions. CONCLUSION

DWI is essential to distinguish the type of edema and is a useful complement to conventional MRI in order to provide an appropriate diagnosis of PRES. In this selected population we found a high rate of restricted diffusion areas with complete reversibility on follow-up. Thus, DWI has limitations in predicting the course of PRES.

\section{HE6:4}

\section{MULTINATIONAL CLINICAL EVALUATION OF GADOBENATE DIMEGLUMINE FOR CONTRAST-ENHANCED MR NEUROIMAGING IN CHILDREN}

\author{
M. KUHN ${ }^{1}$, E. CIANCIULLI ${ }^{2}$, C. FONDA ${ }^{3}$, M PASOWICZ $^{4}$, \\ P-Y GAO
}

${ }^{1}$ UNIVERSITY OF ILLINOIS AT PEORIA, PEORIA, IL, USA, ${ }^{2}$ SANTOBONO PAUSILLIPON CHILDRENS HOSPITAL, NAPLES, ITALY, ${ }^{3}$ ANNA MEYER PEDIATRIC HOSPITAL, FLORENCE, ITALY, ${ }^{4}$ KRAKOW HOSPITAL JOHN PAUL II, KRAKOW, POLAND, ${ }^{5}$ BEIJING TIAN TAN HOSPITAL, BEIJING, CHINA

\section{PURPOSE}

To evaluate the safety and efficacy of gadobenate dimeglumine for contrast-enhanced magnetic resonance imaging (CE-MRI) in children with CNS disease.

METHODS

Children (2 - 17 yrs) referred for CE-MRI of the CNS were enrolled at 17 centers in USA, Europe, or China. $0.1 \mathrm{mmol} / \mathrm{kg}$ bw gadobenate dimeglumine $(=<2 \mathrm{~mL} / \mathrm{sec})$ was given IV followed by a saline flush. 3 blinded readers evaluated Predose (T1-w SE, T2-w FSE, and FLAIR) and postdose (T1-w SE) images for lesion enhancement, morphology, and border delineation. Lesion-to-brain ratio (LBR) and contrast-to-noise 
ratio (CNR) were calculated. Safety assessments included vital signs, serial 12-lead electrocardiograms (ECG), and laboratory findings. All subjects were monitored for adverse events (AE) for $72 \mathrm{hrs}$ and followed up at 30 days to determine final diagnosis.

RESULTS

92 children (45 boys, 47 girls; mean age: 10.6 yrs [range: $2.0-$ $17.8 \mathrm{yrs}])$ were enrolled and dosed with 89 children completing all safety evaluations (13 patients $2-5 \mathrm{yrs}, 34$ patients $6-10 \mathrm{yrs}$, and 45 patients $11-17$ yrs). Mean contrast dose was $8.4 \mathrm{~mL}$ (range: $2.0-$ $22.8 \mathrm{~mL}$ ). Diagnoses included 30\% nontumor, $65 \%$ tumor, and $4 \%$ normal parenchyma. Gadobenate dimeglumine provided additional diagnostic information over predose images in $83.7-96.7 \%$ of patients and resulted in significantly greater mean LBR $(\mathrm{p}<0.0001)$ and CNR $(p<0.0016) .9$ AE were reported in 8 children $(8.7 \%)$, with $3 \mathrm{AE}$ in 2 patients considered possibly related to contrast injection. Headache was reported in 2 patients; all other AE occurred once. No serious $\mathrm{AE}$ were reported, and no clinically meaningful changes in vital signs, laboratory values, or ECG were observed.

CONCLUSIONS

Gadobenate dimeglumine was found to be safe and efficacious for CE-MRI of CNS lesions in children. The greater signal intensity with gadobenate dimeglumine in children may provide improved detection of small or poorly enhancing tumors and more precise definition of tumor borders.

\section{HE6:5}

\section{INVESTIGATING SPONTANEOUS "FLUCTUATIONS" OF CONTRAST ENHANCEMENT IN CHILDHOOD PILOCYTIC ASTROCYTOMAS: OUR EXPERIENCE}

\section{S. GAUDINO, T. TARTAGLIONE, G.M. DI LELLA, A.M. COSTANTINI, F.R. QUAGLIO, R CALANDRELLI, C COLOSIMO}

\section{DEPARTMENT OF BIOIMAGING AND RADIOLOGICAL SCIENCES, CATHOLIC UNOVERSITY, ROME, ITALY}

\section{PURPOSE}

Childhood pilocytic astrocytoma (PA)accounts for $10 \%$ of supratentorial astrocytomas and for $85 \%$ of infratentorial astrocytomas. The tumor patterns could be solid or cysts and the solid part may enhance in a homogeneous or a heterogeneous fashion.It has been demonstrated that the assessment of contrast enhancement (CE) pattern is essential for the diagnosis and follow-up.After partial tumor removal we observed $\mathrm{CE}$ modifications in absence of residual dimensional changes in pts who have not received neither chemotherapy nor cortisone therapy.Our purpose was to investigate changes of the residual PA with serial CE MRI in absence of dimensional variation of the residual tumor,in patients off-therapy. METHODS

We retrospectively evaluated 912 MR exams of 140 pts with histologically proven diagnosed PA;the mean age at initial presentation was 8 yo.All pts underwent partial removal or stereotactic brain biopsy of the PA and were followed for an average of 4.5 ys with serial MRI (mean of 7 exams for each pt).All MRI studies were performed on the same $1.5 \mathrm{~T}$ scanner,with 3 orthogonal FSE T1-WI post-gadolinium sequences. We measured 2 orthogonal diameters on the T1-WI post-Gd sections of each enhancing focus and 2 orthogonal diameters on the correspondent T2-WI of the residual tumour. RESULTS

65/140 PA were infratentorial,58/140 supratentorial,17/140 had multiple locations.Of 140 PA we selected 39 pts off therapy,without evidence of NF1 and without dimensional changes of the residual tumor in the serial MRI.12/39 showed a CE changes in term of increase/appear and/or decrease/disappear of the CE.3/12 were infratentorial,8/12 supratentorial (7 optic-diencephalic, 1 hemispheric astrocytoma) and 1/12 endoventricular.

CONCLUSION

In our experience residual PA may show a variable CE during the years, in absence of residual tumor dimensions change. Thus, the CE fluctuation alone is not directly correlated with an increase or decrease of residual tumor size.This fluctuation is probably correlated with the peculiar biological behaviour of PA,lacking a definite explanation.

\section{HE6:6}

\section{CEREBRAL VASCULAR INVOLVEMENT IN LEMIERRE'S SYNDROME IN CHILDREN}

M. SEVERINO ${ }^{1}$, S. LIYANAGE ${ }^{1}$, V. NOVELLI ${ }^{2}$, L. CARR ${ }^{3}$, D.E. SAUNDERS ${ }^{1}$, R. GUNNY ${ }^{1}$

${ }^{1}$ DEPARTMENT OF RADIOLOGY - GREAT ORMOND STREET HOSPITAL, LONDON, UNITED KINGDOM, ${ }^{2}$ DEPARTMENT OF INFECTIOUS DISEASES - GREAT ORMOND STREET HOSPITAL, LONDON, UNITED KINGDOM, ${ }^{3}$ DEPARTMENT OF NEUROLOGY - GREAT ORMOND STREET HOSPITAL, LONDON, UNITED KINGDOM

\section{PURPOSE}

Lemierre's syndrome (LS) is characterised by internal jugular vein (IJV) thrombophlebitis and metastatic septic emboli complicating an anaerobic bacterial infection of the head and neck, usually in previously healthy patients. Although rare, there is evidence of a resurgence of this condition in recent years, possibly related to a decrease in antibiotic-therapy for community-acquired pharyngitis. Intracranial venous and arterial involvement has rarely been described. Our aim was to review the clinical and imaging features of LS in children and adolescents, with particular emphasis on the intracranial vascular involvement and its complications.

METHODS

We reviewed the clinical and imaging features in three patients who presented consecutively to Great Ormond Street Hospital with head and neck infections complicated by LS.

\section{RESULTS}

Two adolescents aged 15-years presented with headache, fever and cranial nerve deficits following a sore throat, one with relatively mild clinical course and full neurological recovery, the other with persisting cranial nerve deficits. The third patient was a 2.5-year-old boy who presented a fatal course of the disease due to extensive cerebral infarction after a short history of fever and nasal discharge. In all of them, CT and MR demonstrated extensive oropharyngeal soft tissue and central skull base bone involvement with the presence of gas loculations, retropharyngeal fluid collections, opacification of the paranasal sinuses, intracranial leptomeningeal involvement and intraspinal epidural collections. All had cavernous sinuses and IJV thrombosis. All patients had involvement of the internal carotid arteries (ICA); the two adolescents had mild ICA narrowing with no clinical sequelae, and one child developed watershed and embolic cerebral infarcts following bilateral ICA occlusions. 


\section{CONCLUSIONS}

LS is a potentially life-threatening condition and both clinician and radiologist should be aware of its presentation. Both intracranial arterial and venous vascular involvement should be carefully sought due to the risk of severe cerebral complications.

\section{Saturday, September 19, 2009 - Thalia Room}

\section{TH4 \\ 11:10-12:10 - Imaging of brain tumors - multimodality approach II}

TH4:1

\section{DETERMINATION OF HIGH GRADE GLIOMA TREATMENT VOLUMES FOR RADIOTHERAPY BY MEAN OF DTI AND PWI METRICS}

A. STECCO ${ }^{1}, \mathrm{MC} \mathrm{PISANI}^{2}, \mathrm{D}^{\mathrm{B}} \mathrm{BELDI}^{2}, \mathrm{~L} \mathrm{MASINI}^{2}, \mathrm{~S}^{2} \mathrm{ZIZZARI}^{1}$,

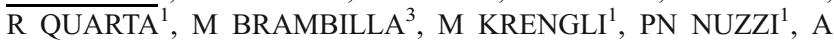
CARRIERO $^{2}$

${ }^{1}$ SCDU RADIOLOGIA - AOU MAGGIORE CARITA', NOVARA, ITALY, ${ }^{2}$ SCDU RADIOTERAPIA- AOU MAGGIORE CARITA', NOVARA, ITALY, ${ }^{3}$ SCDO FISICA SANITARIA - AOU MAGGIORE CARITA', NOVARA, ITALY

\section{PURPOSE}

The present study analysed the role of MR diffusion-tensor-imaging (DTI) and perfusion-weighted imaging (PWI) in the detection of neoplastic tissude for determination of treatment volumes for radiotherapy.

\section{METHOD AND MATERIALS}

Twelve patients affected by high-grade gliomas (WHO III-IV) operated and candidate to adiuvant chemo-radiotherapy have been enrolled thus far.

Prior to radiotherapy, they underwent MRI study with DTI and PWI imaging. The apparent diffusion coefficient (ADC) and the fractional anisotropy (FA) were analysed. ADCs and FA were measured on volumes of interest generated from isotropic DW images represented by the enhancing tumour, hyperintense regions adjacent to enhancing tumor and the normal-appearing WM adjacent to hyperintense regions. The same measurements were performed on simmetric locations in the contralateral hemisphere. In the same fashion we measured the rCBV in PWI images

RESULTS

Student $t$ test analysis, on a retrospective analysis, showed that FA cannot differentiate tissue undergoing to progression of disease from tissue that surely will. The same results for ADC.

rCBV resulted significant in individuate not enhancing tissue that will become an enhancing area several months after.

CONCLUSION

Our data confirm the possible role of PWI (rCBV) in the detection of tumour infiltration in perilesional edema to be included in the CTV. FA and ADC values do not give information on tumour infiltration around the enhancing area, but the limited number of observations does not allow to draw definitive conclusions.
TH4:2

\section{DIFFUSION WEIGHTED IMAGING DOES NOT PREDICT HISTOLOGICAL GRADING IN MENINGIOMAS}

L. SANTELLI ${ }^{1}$, G. RAMONDO ${ }^{1}$, A. DELLA PUPPA ${ }^{2}$, R. SCIENZA ${ }^{2}$, M. ERMANI $^{3}$, D. D'AVELLA ${ }^{2}$, R. MANARA ${ }^{1}$

${ }^{1}$ NEURORADIOLOGY DEPARTMENT, PADOVA, ITALY, ${ }^{2}$ NEUROSURGERY DEPARTMENT, PADOVA， ITALY, ${ }^{3}$ NEUROLOGICAL CLINIC, PADOVA, ITALY

\section{BACKGROUND}

Previous studies have suggested that diffusion weighted imaging (DWI) and apparent diffusion coefficient (ADC) measurements can differentiate benign from atypical/malignant meningiomas and the different subtypes.

MATERIALS AND METHODS

Pre-operative DWI of 102 patients ( 74 females, mean age 58 years, age range 34-85 years) affected by a pathologically proven intracranial meningioma were retrospectively reviewed. DWI signal intensity of tumours was classified as hypo-, iso- or hyper-intense to grey matter. ADC values and normalized ADCratios (ADCmeningioma/ADCnormal appearing white matter) of the neoplastic tissue (avoiding calcifications and cystic or necrotic areas) were measured by two neuroradiologists unaware of each others $i$ i reading. MRI and histological findings were compared.

RESULTS

Meningiomas were histologically graded as malignant (1\%), atypical $(21.5 \%)$ and benign (77.5\%). Meningothelial, transitional and fibrous were the most frequent benign subtypes (44, 16 and 10 cases, respectively). There was no statistical difference between typical and atypical/malignant meningiomas when considering mean $\mathrm{ADC}$ values $(0.964 \pm 0.192 \times 10-3 \mathrm{~cm} 2 / \mathrm{sec}$ vs $0.923 \pm 0.085 \times 10-3 \mathrm{~cm} 2 / \mathrm{sec}, \mathrm{p}=0.3 \mathrm{t}-$ Student) or ADCratio ( $1.266 \pm 0.290$ vs $1.185 \pm 0.115, \mathrm{p}=0.2 \mathrm{t}$-Student). Inter-observer agreement of ADC and ADCratio measurement was high $(r=0.95$ and 0.92 , respectively, Pearson's linear coefficient). ADC values or ADCratio did not differ significantly among eningiomas subtypes although a nearly significant difference was found between meningothelial and transitional (post hoc analysis $\mathrm{p}=0.06$ ). DWI intensity did not reach a significant correlation with meningioma's grading $(\mathrm{p}=0.08)$.

CONCLUSIONS

According to our study, DWI and ADC measurement do not seem reliable in grading meningiomas or identifying histological subtypes. Hence these parameters are not recommended for surgical or treatment planning.

\section{TH4:3}

PRE-SURGICAL PLANNING AND MR-TRACTOGRAPHY UTILITY IN BRAIN TUMOR RESECTION

A. ROMANO $^{1}$, V. FINOCCHI $^{1}$, M. BONAMINI ${ }^{1}$, G. TRASIMENI ${ }^{1}$, V. CIPRIANI $^{1}$, L. SALAMANCA ${ }^{1}$, L. FERRANTE ${ }^{2}$, L.M. FANTOZZI ${ }^{1}$, A. $\mathrm{BOZZAO}^{1}$

${ }^{1}$ NEURORADIOLOGY S.ANDREA HOSPITAL UNIVERSITY SAPIENZA, ROME, ITALY, ${ }^{2}$ NEUROSURGERY S.ANDREA HOSPITAL UNIVERSITY SAPIENZA, ROME, ITALY 


\section{PURPOSE}

Evaluate the possibility to identify trajectories of fiber tracts in patients with brain tumour and to integrate them in a neuro-navigation system for the pre-surgical planning. Patients' clinical condition were used to evaluate the impact of these information on the surgical planning and the procedure. MATERIALS AND METHODS

28 right-handed patients were prospectively and consecutively included in the study. All the patients were clinically evaluated.

All DT-MRI exams were performed on a 1.5-T magnet. Separately pyramidal tract, optic radiation and arcuate fasciculus were reconstructed. The trajectories were considered suitable for surgical planning if there were no interruptions on all the layers at the level of the lesion. Acquired images and tractographic reconstructions were "merged" and sent to the neuronavigation system.

RESULTS

The assessment of the 37 visualized trajectories close to the tumor determined an a priori modification of the surgical approach to corticotomy in 6 patients $(21 \%)$; the impact on the definition of the resection margins during surgery was 64\% (18 patients) (overall impact percentage on the surgical procedure $82 \%$ ). In 27 cases, the symptoms had not changed.

\section{CONCLUSIONS}

MR-tractography provides the neurosurgeon with a new anatomical view which has impact on the surgical resection planning of brain neoplasms.

\section{TH4:4}

\section{PERFUSION MR IMAGING IN DIFFERENTIATING HIGH-GRADE FROM LOW-GRADE GLIOMAS}

G SPARACIA $^{1}$, L FILOSTO ${ }^{2}$, G CAVARRETTA $^{1}$, P PURPURA $^{1}$, M MIDIRI

${ }^{1}$ DI.BI.MEL, SEZIONE DI RADIOLOGIA P. CIGNOLINI, PALERMO, ITALY, ${ }^{2}$ CASA DI CURA DI ALTA SPECIALITÀ LA MADDALENA, PALERMO, ITALY

\section{PURPOSE}

To correlate perfusion MR imaging with histologic grade of cerebral gliomas.

\section{METHOD AND MATERIALS}

Relative cerebral blood volume (rCBV) maps were determined in 22 patients with pathologically proven gliomas ( 11 glioblastomas, 8 anaplastic gliomas and 2 low-grade gliomas) by dynamic contrast-enhanced T2*-weighted MR imaging. MR examination was completed with conventional T1- and T2-weighted imaging. The rCBV maps were calculated with an independent workstation by fitting a gamma-variate function to the contrast material concentration versus time curve. $\mathrm{rCBV}$ ratios obtained between tumor and normal white matter were compared between glioblastomas, anaplastic gliomas and low-grade gliomas by means of receiver operating characteristic (ROC) analysis.

RESULTS

Mean rCBV ratios were $4.85( \pm 1)$ for glioblastomas, $3.87( \pm 0.7)$ for anaplastic gliomas and $1.65( \pm 1.6)$ for low-grade gliomas.ROC analysis demonstrates significantly differences between glioblastomas and anaplastic gliomas $(\mathrm{p}<.05)$, between anaplastic gliomas and lowgrade gliomas $(\mathrm{p}<.05)$ and between glioblastomas and low-grade gliomas $(\mathrm{p}<.01)$. The rCBV ratio cutoff value between high-grade gliomas and lowgrade gliomas was 2.52 with a sensitivity and specificity of $100 \%$ and $75 \%$ respectively.

\section{CONCLUSION}

Perfusion MR imaging is a reliable technique for differentiate highgrade from low-grade gliomas.

\section{TH4:5}

\section{CHANGES IN 1H-MRS IN GLIOMA PATIENTS BEFORE AND AFTER RADIATION THERAPY}

\author{
G SPARACIA $^{1}$, L FILOSTO $^{2}$, G CAVARRETTA $^{1}$, P PURPURA $^{1}$, \\ M MIDIRI \\ ${ }^{1}$ DI.BI.MEL, SEZIONE DI RADIOLOGIA P. CIGNOLINI, \\ PALERMO, ITALY, ${ }^{2}$ CASA DI CURA DI ALTA SPECIALITÀ LA \\ MADDALENA, PALERMO, ITALY
}

\section{PURPOSE}

The evaluation of the response to radiation therapy in brain tumor patients is an important issue. Whereas MRI can measure changes in tumor size, it is difficult to use this imaging modality to evaluate the viability or the proliferation activity of a tumor. In this study we present follow-up metabolite changes in glioma patients using $1 \mathrm{H}-$ MRS from before to after radiation therapy, to verify if metabolic changes occur during therapy.

METHOD AND MATERIALS

Ten patients with histologically proven glioma ( 2 astrocytoma, 3 anaplastic astrocytoma, 5 glioblastoma) were examined by means of 1H-MRS using a point-resolved spectroscopy (PRESS) sequence. The $1 \mathrm{H}-\mathrm{MRS}$ was evaluated by the spectrum pattern. As to radiation therapy, each patient received a total dose of $64.8 \mathrm{~Gy}(1.8 \mathrm{~Gy} /$ fraction) with a $10-\mathrm{MeV}$ linear accelerator.

RESULTS

The results revealed that the concentration of choline-containing compounds (Cho) was significantly reduced to 2.69 . $+-.0 .56 \mathrm{mmol} / \mathrm{kg}$ wet weight $(p<0.01)$ after radiation therapy. Moreover, both the $\mathrm{N}$ acetylaspartate (NAA) peak and creatine/phosphocreatine (t-Cr) peak were lower after radiation therapy. The peaks of both the lipids (Lip) and lactate (Lac) were higher after radiation therapy than before. CONCLUSION

In conclusion, monitoring Cho concentration during radiation therapy of gliomas is a useful marker for the evaluation of earl y postradiation response.

\section{TH4:6}

\section{INCIDENCE AND CLINICAL SIGNIFICANCE OF HEMORRHAGIC LESIONS IN DIFFUSE PONTINE GLIOMAS ASSESSED BY 2D T2*-WEIGHTED AND 3D SUSCEPTIBILITY-WEIGHTED IMAGING}

U. LÖBEL ${ }^{1}$, J. SEDLACIK ${ }^{1}$, M. KOCAK ${ }^{2}$, A. BRONISCER ${ }^{3}$, C. HILLENBRAND ${ }^{1}$, Z. PATAY $^{1}$

${ }^{1}$ ST. JUDE CHILDREN'S RESEARCH HOSPITAL, DEPARTMENT OF RADIOLOGICAL SCIENCES, MEMPHIS, TN, USA, ${ }^{2}$ ST. JUDE CHILDREN'S RESEARCH HOSPITAL, DEPARTMENT OF BIOSTATISTICS, MEMPHIS, TN, USA, ${ }^{3}$ ST. JUDE CHILDREN'S RESEARCH HOSPITAL, DEPARTMENT OF ONCOLOGY, MEMPHIS, TN, USA 


\section{PURPOSE}

Both T2-weighted gradient-recalled echo (GRE, T2*) and susceptibility-weighted (SWI) MRI techniques enhance the visualization of magnetically susceptible substances in biological specimens. The recent introduction of angiogenesis inhibitors into treatment protocols for brain tumors has raised concerns about the potential of increased risk of intratumoral hemorrhages during treatment, requiring close monitoring of patients. The aim of this study was to determine the incidence and clinical significance of intralesional hemorrhages in diffuse pontine gliomas (DPGs) and compare the sensitivity and specificity of $\mathrm{T} 2 *$ and SWI.

METHODS

Seventeen children (9F/8 M, age:3-17 y) with DPG were recruited from an IRB-approved phase I clinical study of vandetanib administered simultaneously with conformal radiation therapy. All patients had baseline MR studies and follow-ups at 2 month intervals (up to 280 days), providing 92 exams for analysis. T2* and SWI images were randomized and scored independently by two reviewers. Number and size of lesions were recorded and data analyzed using descriptive statistics and Poisson Regression Mixed Effects Models. RESULTS

The incidence of hemorrhages was $47 \%$ at diagnosis and increased to $93 \%$ at 6 months post-treatment. Lesion diameters ranged between $0.1-2.66 \mathrm{~cm}$ with only $9 \% / 5 \%$ hematomas $(>5 \mathrm{~mm})$ on $\mathrm{T} 2 * / \mathrm{SWI}$, respectively. Both sensitivity and specificity were higher with SWI than $\mathrm{T}^{*}$. Interobserver variations were not significant $(\mathrm{p}=0.11 / 0.75)$. No remarkable neurologic event was recorded in our patients regardless of the number and size of hemorrhages.

CONCLUSION

SWI is more accurate in the identification of hemorrhages and differentiating them from calcifications, necrotic areas or artifacts. True hematomas appear to be rare, likely explaining the lack of significant adverse neurological correlates in our study. Our work contributes to a better appreciation of the incidence and significance of intratumoral hemorrhages in DPGs, which may help reduce the number of patients who need to be excluded from novel therapeutic protocols for concerns of therapy-induced hemorrhagic complications.

\section{TH4:7}

\section{QUANTITATIVE CHARACTERIZATION OF T2 HYPOINTENSE FOCI IN DIFFUSE PONTINE GLIOMAS USING DYNAMIC SUSCEPTIBILITY-WEIGHTED CONTRAST-ENHANCED PERFUSION MR AND DIFFUSION-WEIGHTED IMAGING}

\author{
U. LÖBEL ${ }^{1}$, J. SEDLACIK ${ }^{1}$, Q. JI ${ }^{1}$, M. KOCAK ${ }^{2}$, A. BRONISCER $^{3}$, \\ C. HILLENBRAND ${ }^{1}$, E. REDDICK ${ }^{1}$, Z. PATAY $^{1}$
}

${ }^{1}$ ST. JUDE CHILDREN'S RESEARCH HOSPITAL, DEPARTMENT OF RADIOLOGICAL SCIENCES, MEMPHIS, TN, USA, ${ }^{2}$ ST. JUDE CHILDREN'S RESEARCH HOSPITAL, DEPARTMENT OF BIOSTATISTICS, MEMPHIS, TN, USA, ${ }^{3}$ ST. JUDE CHILDREN'S RESEARCH HOSPITAL, DEPARTMENT OF ONCOLOGY, MEMPHIS, TN, USA

\section{PURPOSE}

Focal anaplasia may be present in low-grade cerebral neoplasms and have been reported to exhibit peculiar MRI features: T2 hyposignal, signal enhancement after contrast injection and restricted water diffusion. In patients with diffuse pontine glioma (DPG) we observed distinct foci characterized by the aforementioned imaging semiology; therefore we speculated that these areas may correspond to anaplasia. To test our hypothesis we used dynamic susceptibility-weighted contrast-enhanced (DSC) perfusion MRI and DTI to quantitatively analyze the hemodynamic and diffusion properties of these tumor components and correlate them with literature data.

METHODS

MR images of 86 patients with DPG were retrospectively reviewed. Intratumoral lesions fulfilling all aforementioned MRI criteria were identified in 10 patients $(11 \%)$. ROIs corresponding to $\mathrm{T} 2$ hypointense (T2HI) and non-hypointense (T2NHI) tumor areas were drawn on apparent diffusion coefficient (ADC) maps and transferred to fractional anisotropy (FA), cerebral blood volume (CBV), cerebral blood flow (CBF) and mean transit time (MTT) parametric maps. Relative $\mathrm{CBV}$ and $\mathrm{CBF}$ values (rCBV/rCBF) were calculated and the Wilcoxon signed-rank test was used for statistical analysis.

\section{RESULTS}

ADC was lower in T2HI than in T2NHI $(1.2 \pm 0.4$ vs. $1.8 \pm 0.2, \mathrm{p}<$ $0.01)$. FA $(0.2 \pm 0.07$ vs. $0.1 \pm 0.06, \mathrm{p}=0.031)$, MTT $(133.9 \pm 95$ vs. $106.1 \pm 85, \mathrm{p}=0.016)$ and $\mathrm{rCBV}$ values $(1.5 \pm 0.9$ vs. $0.9 \pm 0.4, \mathrm{p}=$ 0.042 ) were higher in T2HI lesion components compared to T2NHI tumor areas. The rCBF differences between T2HI and T2NHI areas $(1.26 \pm 0.66$ vs. $0.96 \pm 0.36, p=0.176)$ were not significant.

\section{CONCLUSION}

Decreased ADC within T2HI components of DPGs indicate hypercellularity. Increased rCBV and MTT likely reflect expansion of intralesional blood pool compartment secondary to angioneogenesis. Hypercellularity and angioneogenesis being the hallmark histopathological features of anaplasia, these findings support our hypothesis that intratumoral $\mathrm{T} 2 \mathrm{HI}$ areas, if associated with contrast-uptake and restricted water diffusion, represent focal anaplasia. Confident recognition of focal anaplasia in BSGs may have impact on treatment strategies and prognosis.

\section{TH4:8}

\section{QUANTITATIVE LONGITUDINAL EVALUATION OF DIASCHSIS-RELATED CEREBELLAR PERFUSION AND DIFFUSION PARAMETERS IN PATIENTS WITH SUPRATENTORIAL HEMISPHERIC HIGH-GRADE GLIOMAS AFTER SURGERY}

\author{
Z. PATAY ${ }^{1}$, C. PARRA ${ }^{1}$, A. GEORGE $^{1}$, M. SCOGGINS ${ }^{1}$, \\ A. BRONISCER ${ }^{2}$, R. OGG ${ }^{1}$
}

${ }^{1}$ ST. JUDE CHILDREN'S RESEARCH HOSPITAL, DEPARTMENT OF RADIOLOGICAL SCIENCES, MEMPHIS, TN, USA, ${ }^{2}$ ST. JUDE CHILDREN'S RESEARCH HOSPITAL, DEPARTMENT OF ONCOLOGY, MEMPHIS, TN, USA

\section{PURPOSE}

Previous investigators have found measurable drop of blood perfusion in cerebellar grey matter (cGM) and evidence of cerebellar white matter (cWM) damage, consistent with crossed cerebellar diaschisis (CCD) in patients after surgery for supratentorial tumors using dynamic susceptibility contrast-enhanced (DSC) MR perfusion and diffusion tensor imaging (DTI). In this study we sought to investigate the longitudinal evolution of these changes.

METHODS

Eight patients $(\mathrm{M} / \mathrm{F}: 5 / 3$, age:8-22y) with suptatentorial high-grade neoplasms, who received surgery were recruited from an IRB- 
approved clinical trial. Initial MRI studies were performed 19-54 days postoperatively. Further follow-ups (up to 8/patient) were done at 23 month intervals. For each study parametric maps (CBV, CBF, FA) of the cerebellum were generated and coregistered to T1-weighted images segemented for cGM and cWM. Aggregate mean values of $\mathrm{CBV}, \mathrm{CBF}$ and FA were obtained separately for cGM and cWM and asymmetry indices (AI:xL-xR/xL+xR) were calculated.

RESULTS

Hemodynamic changes were found to be more robust in cCGM than in cWM. Seven patients showed decreased CBV within cGM contralateral to supratentorial lesion on the first post-operative study. Follow-up studies showed a significant $(p=0.0074)$ positive correlation towards recovery with rebound after one year. DTI changes were more consistent in cWM. FA values showed a „paradoxial” increase initially, but steadily declined thereafter (negative correlation, $\mathrm{p}=$ 0.0013 ) without evidence of recovery.

CONCLUSION

Hemodynamic alterations within cGM are detected on early postoperative studies, but seem to recover over time. Conversely, cWM changes appear to be progressive. Hemodynamic alteration in cGM represent primary diaschisis-related phenomena and may be reversible, whereas myelin changes are likely secondary to underutilization and may be irreversible. Although the clinical impact of CCD is yet poorly understood, it is important to investigate the dynamics of underlying pathophysiological processes in order to improve our understanding of this apparently quite uniform response mechanism in brain.

\section{TH4:9}

\section{EVALUATION OF WHOLE-BRAIN PERFUSION COMPUTED TOMOGRAPHY IN THE DIAGNOSIS OF INTRA-AXIAL TUMORS}

\author{
A. XYDA ${ }^{1}$, P. SCHRAMM ${ }^{1}$, C. BOCK ${ }^{2}$, R. FINZEL ${ }^{1}$, E. KLOTZ ${ }^{3}$, \\ ${\text { G. } \mathrm{ERB}^{4}, \text { M. KNAUTH }}^{1}$
}

${ }^{1}$ DEPARTMENT OF NEURORADIOLOGY, UNIVERSITY GOETTINGEN MEDICAL CENTER, GOETTINGEN, GERMANY, ${ }^{2}$ DEPARTMENT OF NEUROSURGERY, UNIVERSITY GOETTINGEN MEDICAL CENTER, GOETTINGEN, GERMANY, ${ }^{3}$ SIEMENS HEALTH CARE SECTOR, COMPUTED TOMOGRAPHY, FORCHHEIM, GERMANY, ${ }^{4}$ BRACCO IMAGING, KONSTANZ, GERMANY

\section{PURPOSE}

The aim of this prospective study was to evaluate the role of volume perfusion CT (VPCT) covering the whole brain in the assessment of the entire extent of intra-axial brain tumors.

METHODS

22 patients with intra-axial brain tumors were examined with VPCT (Siemens Definition AS+), using $60 \mathrm{ml}$ of highly-iodinated contrast media (Imeron 400, Bracco). Analysis was carried out with standard software (VPCT Neuro, Siemens Medical Solutions). On 3D maximum intensity projection (MIP) maps, volumes of interest (VOIs) including the entire extent of the brain tumor were manually outlined and automatically transferred to 3D-maps of cerebral blood volume (CBV) and volume transfer constant (ktrans). The entire tumor extent on the MIP-images was determined and all perfusion parameters were quantified and compared to those of the healthy contralateral hemisphere.

\section{RESULTS}

On whole-brain PCT, the entire tumor extent was visible in all 22 patients. Histopathologic diagnosis revealed 15 high grade gliomas WHO III or IV and 4 low grade gliomas WHO II. 3 patients suffered from brain metastasis. Contrast-enhancing high grade gliomas and metastasis showed median values for CBV and ktrans of $5.52 \mathrm{ml} /$ $100 \mathrm{ml}$ (range 2.46-8.75) and $4.28 \mathrm{ml} / 100 \mathrm{ml} / \mathrm{min}$ (range $0.78-$ $15.33)$, respectively. These values were significantly $(\mathrm{p}<0.001)$ increased compared to normal brain tissue (median CBV $2.24 \mathrm{ml} /$ $100 \mathrm{ml}$ (range 1.59-2.93); ktrans $1.04 \mathrm{ml} / 100 \mathrm{ml} / \mathrm{min}$ (range 0.12 1.29). For low grade gliomas the perfusion parameters did not differ from normal brain tissue ( $p=0.715$ for CBV, $p=0.197$ for ktrans; median CBV $2.32 \mathrm{ml} / 100 \mathrm{ml}$ (range 2.22-2.39); ktrans $1.62 \mathrm{ml} /$ $100 \mathrm{ml} / \mathrm{min}$ (range 0.69-2.44).

\section{CONCLUSION}

Whole-brain PCT enables 3-dimensional qualitative and quantitative imaging of intra-axial tumors. By determination of ktrans and CBV, VPCT can identify the whole extent of high grade gliomas or metastasis and can separate those lesions from low-grade gliomas. Thus, whole-brain PCT could lead to more precise grading of intraaxial brain tumors.

\section{TH5}

\section{5:25-17:05 - Cerebrovascular disease imaging II}

\section{TH5:1}

\section{HOW USEFUL IS MAGNITUDE SUSCEPTIBILITY WEIGHTED IMAGING (SWIM) IN THE DETECTION OF DEVELOPMENTAL VENOUS ANOMALIES?}

J. MUNUERA DEL CERRO, S. MECHÓ, R. MITJANA, C. AUGER, L. FRASCHERI, A. ROVIRA

MAGNETIC RESONANCE UNIT, DEPARTMENT OF RADIOLOGY (IDI), HOSPITAL UNIVERSITARIO VALL D'HEBRON, BARCELONA, SPAIN

\section{OBJECTIVE}

To analyze the sensitivity of SWIm sequences in the detection of brain developmental venous anomalies (DVAs).

MATERIAL AND METHOD

A prospective MRI study was performed over 15 months in a cohort of 101 patients with various clinical and radiological diagnoses (cavernous angiomas, other cerebral vascular malformations, stroke, and brain trauma or tumor) in whom we assessed the presence and radiologic characteristics of brain DVAs. Imaging analysis included number, localization and depth of DVA, associated signal alterations in surrounding parenchyma, presence of small vessels in caput medusae (microvasculature), width and distance of draining vein, and caput medusa surface. The study protocol included T2W sequences (T2 turbo spin-echo, T2* gradient-echo, and FLAIR), SWIm and contrast-enhanced T1W. All sequences were performed at the same section thickness and position.

\section{RESULTS}

Twenty-eight DVA were found in 23 patients $(23 \%)$. Location was lobar $(57.1 \%)$, basal ganglia $(14.0 \%)$, brainstem $(7.0 \%)$ and cerebellum $(21.0 \%)$. DVA drainage was superficial or deep in equal numbers (39.3\%), and both superficial and deep in $21.0 \%$. We found significantly higher sensitivity in detecting number of DVAs, increase in parenchymal signal abnormalities, identification of microvasculature, and angioarchitecture characteristics of DVAs (drainage vein and caput medusae) with SWIm sequences as compared to the other T2W 
sequences $(\mathrm{P}<0.005)$. No significant differences in sensitivity were observed between SWIm and contrast-enhanced T1WI (reference standard).

CONCLUSION

The acquisition properties and post-processing of SWIm sequences resulted in significantly higher sensitivity for detecting DVAs than conventional $\mathrm{T} 2 \mathrm{~W}$ sequences, reaching a sensitivity at least as high as contrast-enhanced T1WI.

\section{TH5:2}

EXAMINING STENOSIS OF THE EXTRACRANIAL CAROTID ARTERY USING MULTIMODAL

CT- AND MR-ANGIOGRAPHY WITH 3.0 TESLA MRI AND MULTISLICE-CT

O. MOSKE-EICK ${ }^{1}$, R. MACHARZINA ${ }^{2}$, H. MAST ${ }^{1}$, R. SCHWARZWALD ${ }^{1}$, G. IHORST ${ }^{3}$, CHR. TASCHNER $^{1}$, M. SCHUMACHER ${ }^{1}$, J. WEBER ${ }^{1}$

${ }^{1}$ NEURORADIOLOGY, NEUROCENTER, UNIVERSITY MEDICAL CENTER FREIBURG, FREIBURG I. BR., GERMANY, ${ }^{2}$ HEART-CENTER AT BAD KROTZINGEN, BAD KROTZINGEN, GERMANY, ${ }^{3}$ CENTER OF CLINICAL TRIALS, UNIVERSITY MEDICAL CENTER FREIBURG, FREIBURG I. BR., GERMANY

\section{PURPOSE}

The Aim of the study was evaluate the degree of extracranial carotid stenosis with the actual MRI- and CT-modalities, as well as to compare the NASCET-criteria, with a novel area-based calculation, with a view to a better assessment of hemodynamically relevant vessel stenosis.

METHODS

20 patients with medium or high-grade carotid stenosis, verified by duplex ultrasound, were examined $(50-89 \mathrm{y} ; \mathrm{m}=12 / \mathrm{f}=8$, mean age:73 y, SD:10.3 y), using multislice-CT (Sensation16, Siemens/ Erlangen/Germany) and multimodal-MRA (2D-TOF, ceMRA) with a 3.0Tesla MRI (TIM_Trio, Siemens/Erlangen/Germany). Stenosis was evaluated using axial, non-angulated raw data as well as MPRs, adapted orthogonal to the path of the proximal carotid artery. The degree of stenosis was determined, based on 2 methods: first by NASCET-criteria, and second by a novel, detailed calculation of the stenosis area developed by our group. Furthermore, for risk assessment and therapeutic planning, areas and volumes of plaque were calculated and morphologic features evaluated.

RESULTS

CTA and MRA were successfully performed without complications in all 20 patients. In assessing the stenosis, vessel-adapted MPRs were superior to the non-adapted raw images, both with respect to CTA $(p=0.0002)$ as well as TOF-MRA $(p=0.0001)$. Measuring the stenosis based on the novel area method was somewhat superior to the traditional, diameterbased NASCET-method $(p=0.07)$. For evaluating the vessel lumen, CTA proofed significantly superior to both TOF-MRA $(p=0.02)$ and ceMRA $(p=0.02)$. Plaque morphology worked best using CTA $(p=0.0018)$, followed by TOF-MRA $(\mathrm{p}=0.003)$. Due to methodological limitations, plaque morphology could not be described by ceMRA.

CONCLUSIONS

For evaluating the degree of stenosis and plaque morphology, multislice-CTA is superior to TOF-MRA and ceMRA techniques at 3.0Tesla MRI. In either case, MPRs angulated orthogonal to the path of the proximal carotid artery should be used, rather than non-adapted source images. The novel, area-based method is providing a better overall assessment of hemodynamically relevant vessel alterations compared to the NASCET-method.
TH5:3

\section{4-SLICE CT ANGIOGRAPHY IN THE DETECTION OF INTRACRANIAL ANEURYSMS: COMPARISON WITH DSA AND SURGICAL FINDINGS}

S. MILOSEVIC MEDENICA ${ }^{1}$, M. RAKIC ${ }^{2}$, Z. MARKOVIC ${ }^{1}$, V. VUCKOVIC ${ }^{1}$, B. PRSTOJEVIC ${ }^{1}$, J. KOSTIC ${ }^{1}$, B. MILATOVIC ${ }^{1}$

${ }^{1}$ INSTITUTE OF RADIOLOGY, DEPARTMENT OF NEURORADIOLOGY, CLINICAL CENTER OF SERBIA, BELGRADE, SERBIA, ${ }^{2}$ INSTITUTE OF NEUROSURGERY, CLINICAL CENTER OF SERBIA, BELGRADE, SERBIA

\section{INTRODUCTION}

The overall results of 64-slice MSCT angiography published in the last 5 years are very close to results of DSA, which is still a gold standard in the diagnosis of intracranial aneurysms. The aim of this study is to contribute to the confidence in reliability of this method in the patients with suspect intracranial aneurysm.

PATIENTS AND METHODS

In the period from October 2008 to March 2009 we investigated 41 patients by MSCT angiography. 28 patients had a DSA and/or surgical confirmation of MSCTA result. These patients were reffered for SAH in 27 cases and for other reasons in 1 case. There were 23 women and 5 men, aged from 14 to 76 years (average age 53,74). 18 patient underwent DSA after CTA, while 10 patients were operated according to MSCTA findings.

RESULTS

We found 45 aneurysms in 28 patients. In patients who underwent both methods, the findings were in concordance in 18 cases regarding the site and the size of the aneurysm/s. In 2 cases MSCTA gave false positive results about the existence of the additional aneurysm, while in 3 cases it failed to show it. In all false positive and false negative cases the misdiagnosed aneurysms were 1 to $1,5 \mathrm{~mm}$ outpouchings not responsible for SAH. In cases where patients were operated according to MSCTA only, there was a complete concordance with operative results.

CONCLUSION

According to literature, as well to our results, MSCTA has shown as a very reliable method, competent to be used as a diagnostic modality of choice in the patients with SAH or suspect unruptured aneurysm. DSA should be used in cases of negative or uncertain findings on MSCTA. The relative disadvantage of MSCT angiography is a smaller sensitivity in detection of tiny outpouchings, especially in the infraclionid region where this method has limited possibilities.

\section{TH5:4}

\section{DETECTION OF CEREBRAL ANEURYSMS BY CT ANGIOGRAPHY IN PATIENTS WITH NON-TRAUMATIC SUBARACHNOID HEMORRHAGE}

\section{P. MARTHINSEN, T. NOME, S.J. BAKKE, E.A. JACOBSEN}

OSLO UNIVERSITY HOSPITAL - RIKSHOSPITALET, OSLO, NORWAY

\section{PURPOSE}

To evaluate if CT angiography (CTA) is a reliable tool in detection of cerebral aneurysms in patients with non-traumatic subarachnoid 
hemorrhage (SAH), compared to digital subtraction angiography (DSA).

METHODS

From October 2005 to March 2008, 262 patients presented with non-traumatic subarachnoid hemorrhage. All patients underwent a non-contrast CT and a CTA immediately upon admission. All studies were obtained by a 64-detector row CT scanner (VCT; GE Medical Systems, Milwaukee, Wisconsin). Reformatted images were created on a dedicated workstation (Advantage Windows, GE Medical Systems). Hundred and fifty-two patients went directly from CT to surgery, endovascular, or conservative treatment without a full diagnostic biplane DSA (Siemens Axiom Artis, Erlangen, Germany). The remaining 110 patients underwent a full diagnostic DSA.

RESULTS

CTA detected 94 cerebral aneurysms in 63 patients. The aneurysms in 59 patients were detected on both modalities. In one patient with arteriovenous malformation (AVM), DSA showed 2 feeder aneurysms of which one was missed on CTA. The remaining 3 missed aneurysm were extradural at the skull base (1) and 2 small PCOMs. Forty-seven patients had a negative CTA with respect to aneurysms. Two patients had AVMs. Of the forty-five patients, a fusiform aneurysm demonstrated on DSA was misinterpreted as vasospasm on CTA. In one patient with perimesencephalic SAH, DSA showed a small bleb on A1/A2 segment, not seen on CTA,. On the other hand, in 2 cases the initial CTA raised suspicion of blebs that could not be confirmed by DSA, but was later confirmed and treated. All patients with negative CTA/DSA underwent follow-up imaging with CTA and/or DSA. One patient with initial negative CTA and DSA, rebled after 10 days. An ACOM aneurysm was then detected on both modalities. CONCLUSION

CTA is a reliable tool for the diagnosis of cerebral aneurysms in patients with non-traumatic subarachnoid hemorrhage.

\section{TH5:5}

\section{ADVANCED IMAGING OF ACUTE AND SUBACUTE STROKE BY MAGNETIZATION TRANSFER RATIO APPLYING A BSSFP-PROTOCOL}

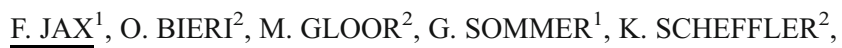
E-W. RADUE ${ }^{1}$, S. WETZEL ${ }^{1}$

${ }^{1}$ DIVISION OF NEURORADIOLOGY , UNIVERSITY OF BASEL HOSPITAL, BASEL, SWITZERLAND, ${ }^{2}$ DIVISION OF RADIOLOGICAL PHYSICS, UNIVERSITY OF BASEL HOSPITAL, BASEL, SWITZERLAND

\section{PURPOSE}

In this study we applied Magnetization Transfer Ratio (MTR) based on a balanced Steady State Free Precession (bSSFP)-protocol in patients suffering from acute and subacute stroke (1). MTR is known to be a predictor of tissue integrity; still knowledge on MTR in cerebral infarcts is very limited $(2,3)$. BSSFP is a recently proposed technique allowing for reduced scan times $(2-3 \mathrm{~min})$ and whole brain coverage at high signal-to-noise. We hypothesize that MTR is changing in cerebral infarcts in chronological sequence with the potential to estimate the age of infarcts.

\section{METHODS}

22 Infarcts in 17 patients ( 9 men, 8 women; mean age 73 years, SD, 10.9; range, 56 to 90 years) with symptoms of acute stroke were examined on a clinical 1.5 T scanner (Avanto, Siemens Medical Solutions, Erlangen, Germany). MTR measurements followed a clinical standard protocol extended by 3D MTR-data collection using MT-sensitized bSSFP $(\alpha=45)$ (1). For MT data acquisition, a repetition time of $\mathrm{TR}=2.7 \mathrm{~ms}$ and a $\mathrm{RF}$ pulse duration of $\tau R F=230 \mu$ s was used, whereas for non-MTR, TR was $4.7 \mathrm{~ms}$ and $\tau R F$ was $2100 \mu \mathrm{s}$ ). DWI and MTR maps were registered spatially and values were measured by manual contouring twodimensional regions of interest (ROI) of the entire abnormal region in DWI which was then transferred into the corresponding MTR map. In each case relative MTR-value between infarct and unaffected parenchyma was calculated.

RESULTS

High linear correlation $(\mathrm{r} \sim 0.9)$ was shown between relative MTR (range: $2.2 \%$ to $18.3 \%$ ) and the age of infarct (range: 4 hours to 10 days). CONCLUSION

MTR-Imaging based on bSSFP in stroke is a promising tool for routine diagnostics and patient care giving advanced information about ischemic tissue destruction and corresponding infarct age. REFERENCES

(1) Bieri et al MRM 2007

(2) Tourdias et al. Stroke 2007

(3) Prager et al. AJNR 1994

\section{TH5:6}

\section{SUSCEPTIBILITY-WEIGHTED IMAGING: CLINICAL} ROLES IN HYPERACUTE ISCHEMIC STROKE

M. IDA, Y. KUBO, S. SUGAWARA, K. HINO, N. YOROZU, Y. KAWAGUCHI

TOKYO METROPOLITAN EBARA HOSPITAL - DEPARTMENT OF RADIOLOGY, TOKYO, JAPAN

Susceptibility-weighted (SW) imaging exploits phase shifts to maximize sensitivity to magnetic susceptibility differences and provides highresolution, blood-oxygen-level-dependent venography of the brain. The purpose was to assess the efficacy of SW imaging for evaluating oxygenation changes and for detecting occluded arteries, and to establish the clinical roles of SW imaging in hyperacute ischemic stroke. 65 patients with hyperacute cerebral ischemia caused by occlusion of major arteries were included. MR imaging was performed during the initial 24 hours after onset using a 1.5-T system. SW images were acquired with an echo time of $40 \mathrm{~ms}$, a repetition time of $48 \mathrm{~ms}$, and gradient-moment nulling in all three directions for flow compensation. SW images were compared with diffusion-weighted images, MR angiograms, FLAIR images and a dynamic-contrast (DC) perfusion study. In $56(86.2 \%)$ patients, increased deoxyhemoglobin was observed as marked hyposignal, within draining veins coming from the territories of perfusion deficits. Increased deoxyhemoglobin was visible as early as approximately 30 minutes after onset, and found in the cortical veins in all 56 patients, as well as in the medullary veins in $35(62.5 \%)$. The area of increased deoxyhemoglobin distribution was almost equal to that of the perfusion abnormality observed in the DC perfusion study. In $83.1 \%$, SW imaging detected intraarterial low signal, corresponding to occlusion or severe stenosis observed on MR angiography. In conclusion, SW imaging can detect early misery perfusion state as well as occluded artery without contrast media. SW imaging plays an important role in deciding whether a subsequent DC perfusion study is necessary in the setting of hyperacute ischemic stroke. SW imaging provides a useful adjunct for the earlier 
detection and prediction of penumbra and candidates for thrombolytic therapy.

\section{TH5:7}

\section{DIAGNOSING DELAYED CEREBRAL ISCHEMIA WITH DIFFERENT CT MODALITIES IN SAH PATIENTS WITH CLINICAL DETERIORATION}

\author{
J.DANKBAAR, N DE ROOIJ, B VELTHUIS, C FRIJNS, G RINKEL, \\ I VAN DER SCHAAF
}

UNIVERSITY MEDICAL CENTER UTRECHT, UTRECHT, THE NETHERLANDS

\section{PURPOSE}

Delayed cerebral ischemia (DCI) after aneurysmal subarachnoid hemorrhage (SAH) worsens the prognosis and is difficult to diagnose. We investigated the diagnostic value of non-contrast CT (NCT), CTperfusion (CTP), and CT-angiography (CTA) for DCI after clinical deterioration in SAH patients.

METHODS

We prospectively enrolled $42 \mathrm{SAH}$ patients who experienced clinical deterioration suspect for DCI (new focal deficit or a decrease in GCS of 2 or more points) within 21 days after hemorrhage. All patients underwent NCT, CTP and CTA scans on admission and directly after clinical deterioration. The gold standard was the clinical diagnosis DCI, made retrospectively by two clinicians who interpreted all clinical data, except CTP and CTA images, to rule out other causes for deterioration. NCT and CTP images were evaluated for signs of ischemia (NCT) or hypoperfusion (CTP), not localized in the neurosurgical trajectory or around intracerebral hematomas. CTA images were evaluated for presence of vasospasm. Diagnostic values for DCI of NCT, CTP, and CTA were assessed by calculating sensitivities, specificities, positive predictive values (PPV), and negative predictive values (NPV) with $95 \%$ confidence intervals (CI). RESULTS

In three patients with clinical deterioration, imaging failed due to motion artefacts. Of the remaining 39 patients, 25 had DCI and 14 did not. NCT had a sensitivity of $0.56(95 \% \mathrm{CI}: 0.37-0.75)$, specificity $=0.71(0.48$ $0.95), \mathrm{PPV}=0.78(0.59-0.97), \mathrm{NPV}=0.48(0.26-0.69)$; $\mathrm{CTP}:$ sensitivity $=$ $0.84(0.69-0.98)$, specificity $=0.79(0.57-1.00), \quad P P V=0.88(0.74-1.01)$, $\mathrm{NPV}=0.73(0.51-0.96)$; CTA: sensitivity $=0.68(0.50-0.86)$, specificity $=$ $0.43(0.17-0.69), \mathrm{PPV}=0.68(0.50-0.86), \mathrm{NPV}=0.43(0.17-0.69)$.

CONCLUSION

As a diagnostic tool for DCI, qualitative assessment of CTP seems overall superior to NCT and CTA. CTP could be of great help when fast and positive diagnosis of DCI is needed for decision making and guiding treatment.

\section{TH5:8}

USEFULNESS OF SWAN SEQUENCE (T2 STAR-WEIGHTED ANGIOGRAPHY) AT 3T IN VASCULAR DISEASES

F. CATTIN $^{1}$, A DAVID ${ }^{1}$, C BILLON-GRAND ${ }^{1}$, S CHAPUY $^{1}$, $\overline{\text { M PERRIN }}^{2}$, JF BONNEVILLE ${ }^{1}$

${ }^{1}$ DEPARTMENT OF NEURORADIOLOGY, UNIVERSITY HOSPITAL OF BESANCON, BESANCON, FRANCE, ${ }^{2}$ GE HEALTHCARE, VELIZY, FRANCE

\section{PURPOSE}

Evaluating SWAN sequence usefulness at $3 \mathrm{~T}$ in cerebrovascular diseases

METHODS

On a 2-months period, we have scanned SWAN sequence at $3 \mathrm{~T}$ in addition to our standard scan protocol regarding cerebrovascular diseases. 40 patients have been included : 7 patients with venous disorders, 13 patients with intracerebral hemorrhage and 20 patients with stroke. SWAN (GE Healthcare) is a 3D multi-echo gradient-echo sequence that produces weighted averaging across images with different TE, providing strong susceptibility weighting. Images can be visualized through a minimum intensity projection $(\mathrm{mIP})$.

\section{RESULTS}

When compared with $\mathrm{T} 2 *$ sequence, more lesions were shown in 1 patient with cavernomatosis. In 2 cases of developmental venous anomaly, the enlarged medullary veins were better seen than on the usual sequences. SWAN sequence brought some confidence in the diagnosis of the straight sinus (1 case) and cortical veins thrombosis (1 case). In a patient with transverse sinus thrombosis medically treated, all the usual sequences showed complete repermeabilization whereas a discrete hypointensity of the transverse sinus was noted on SWAN. In 3/13 intracranial hematomas, images led to evoke the diagnosis of amyloid angiopathy. In 5 cases of acute stroke, markedly hypointense intraarterial thrombus within the proximal segment of the intracranial arteries was more clearly demonstrated than on T2*. In 1 patient, a thrombus was identified in the middle cerebral artery, while T2* and 3D TOF angiography were negative. In 3 cases of ischemic lesions with hemorrhagic transformation, a larger amount of hemosiderin was demonstrated on SWAN sequence when compared with $\mathrm{T} 2 *$

\section{CONCLUSION}

SWAN is a $3 \mathrm{D}$ high-resolution susceptibility-weighted sequence very sensitive in the detection of intravascular venous deoxygenated blood as well as extravascular hemosiderin. Our study suggests that SWAN sequence has a great clinical value in the cerebrovascular diseases such as venous thrombosis, intracranial hemorrhage and ischemic lesions.

\section{TH5:9}

\section{ANGIO CT OF THE NORMAL BASAL VEIN. VARIABILITY AND DIAGNOSTIC IMPORTANCE}

M. BRAUN ${ }^{1}$, P. NAVEL ${ }^{2}$, A.L. DERELLE ${ }^{1}$, M PEREZ $^{2,3}$, T HAUMONT $^{2}$, R ANXIONNAT ${ }^{1,3}$, S BRACARD $^{1,3}$

${ }^{1}$ UNIVERSITY HOSPITAL - DEPARTMENT OF NEURORADIOLOGY, NANCY, FRANCE, ${ }^{2}$ NANCY UNIVERSITÉ - ANATOMY DEPARTMENT, NANCY, FRANCE, ${ }^{3}$ IADI -INSERM - U 947, NANCY, FRANCE

\section{PURPOSE}

The basal vein appears as one of the major venous drainage component on the inferior aspect of the brain. We present here the various courses and drainage variations and the supra and infratentorial hemodynamic solutions.

MATERIAL AND METHODS

50 patients (28 men, 32 women aged 22-82) without expanding lesion were examined prospectively by spiral angio-CT, after $30 \mathrm{ml}$ of contrast medium IV injection with a automatic injector. 300 images were acquired ( $0.6 \mathrm{~mm}$ thickness) in 5 seconds. 


\section{RESULTS}

We could identify the classical three segments course : with the optochiamatic cistern (seg.1), the lateral fissure (seg.2) and the great cerebral vein cistern (seg.3).

Afferences to the basal vein in segment 1 : the middle cerebral v. : 30 of 50 bilateraly $(60 \%), 12$ unilateraly, 8 do not so but drain into the cavernous sinus or the spheno-parietal one ; the olfactory v. : $30 \%$ bilateraly, $45 \%$ unilateraly ; interpeduncular vv. $96 \%$, anterior frontal v. in $50 \%$ bilateraly, $50 \%$ unilateraly. In segment 2 : ventricular vv. are constantly found arising from the choroïd plexus of the temporal horn, lateral mesencephalic v. were identified in $45 \%$ as provider of the basal v.In segment 3 : medial parietooccipital vv. are prominent feeders $22 \%$ bilateraly, $56 \%$ on the left side, $12 \%$ on the right.

The basal vein course display the following variations : $82,5 \%$ showed a complete form ( 3 segments), $12,5 \%$ and $5 \%$ without the segment $1 \& 3$ respectively.

IN CONCLUSION

Spiral post contrast CT allows an excellent overview of the major vessels at the base of the brain amoung them the basal vein. Our results are similar to the litterature although any large group study had ever been published in the past.

\section{TH5:10}

\section{NON-INVASIVE MR IMAGING OF CEREBRAL PERFUSION IN PATIENTS WITH A SYMPTOMATIC CAROTID ARTERY STENOSIS}

R. BOKKERS ${ }^{1}$, H.B. VAN DER WORP ${ }^{2}$, W.M. MALI ${ }^{1}$, J. HENDRIKSE ${ }^{1}$

${ }^{1}$ UNIVERSITY MEDICAL CENTER UTRECHT - DEPARTMENT OF RADIOLOGY, UTRECHT, THE NETHERLANDS, ${ }^{2}$ UNIVERSITY MEDICAL CENTER UTRECHT - DEPARTMENT OF NEUROLOGY, UTRECHT, THE NETHERLANDS

\section{PURPOSE}

Arterial spin labeling MRI with image acquisition at multiple delay times can be used to quantify delays in the arrival of arterial blood to the brain. Herein, we investigated the effect of a symptomatic internal carotid artery (ICA) stenosis on ASL timing parameters, and evaluated the effect of collateral flow via the circle of Willis.

\section{METHODS}

Forty-four functionally independent patients ( 30 men; 14 women; mean age, $73 \pm 9$ years) with a recently symptomatic ICA stenosis $>50 \%$ and 29 matched healthy volunteers were investigated with a pulsed transferinsensitive labeling technique (QUASAR) to regionally quantify CBF, transit time and trailing edge. MR angiography and $2 \mathrm{D}$ phase-contrast imaging were used to assess collateral flow in the circle of Willis.

\section{RESULTS}

In the symptomatic hemisphere, $\mathrm{CBF}$ was significantly lower $(\mathrm{P}<$ 0.01 ) in the anterior-frontal, posterior frontal, parieto-occipital, and occipital regions than in control subjects. The transit times were prolonged in the ipsilateral anterior-frontal, posterior frontal and fronto-parietal regions when compared with the control subjects $(\mathrm{P}<$ $0.01)$. The trailing edge time was prolonged in the ipsilateral frontoparietal region when compared to the control subjects $(\mathrm{P}<0.01)$. In the 27 patients without a contralateral stenosis, the trailing edge was longer in the ipsilateral posterior-frontal, fronto-parietal and parietooccipital regions than in the contralateral regions $(\mathrm{P}<0.01)$. Collateral flow via the circle of Willis did not affect CBF, transit or trailing edge times.

CONCLUSIONS

Arterial spin labeling MRI with image acquisition at multiple delay times can be used to quantify delays in the arrival of arterial blood in patients with a symptomatic ICA stenosis.

\section{TH5:11}

\section{DVA - UNUSUAL PRESENTATIONS}

\author{
J. LUCKMAN $^{1,2}$, S. MAIMON ${ }^{3}$
}

${ }^{1}$ ASSUTA MEDICAL CENTER, TEL AVIV, ISRAEL, ${ }^{2}$ RABIN MEDICAL CENT, PETAH TIKVA, ISRAEL, ${ }^{3}$ SORASKI MEDICAL CENTER, TEL AVIV, ISRAEL

\section{PURPOSE}

To describe unusual presentation DVA's which usualy are considered as anatomical variants and not a real pathology.

METHODS

The imaging of 2 patients will demonstrate unusual presentations of this common pathology.

\section{RESULTS}

Patient 1 is a 40 year old patient who presented after signs of dehydration with convulsions and severe headach, his first imaging on CT was interpreted as subarachnoiud hemmorhage with possible AVM,

aN mri was also obtained and the interpretation changed to tHrombosed large DVA with significant edema.

The patient was treated with clexane and then coumadin and improved clinicaly.

Patient 2 presented with severe headaches. The non contrast CT showed enlarged lateral and third ventricles.

The MRI showed a large DVA passing through the aquaduct of sylvius.

The patient was treated with a VP shunt and improved clinically. CONCLUSION

The DVA are usually benign phenomenon there are uncommon severe presentations like we show.

\section{TH5:12}

\section{ACCIDENT AND EMERGENCY BRAIN CT PERFUSION AND ANGIO CT IN PATIENTS WITH ACUTE STROKE ELIGIBLE FOR THROMBOLITIC THERAPY}

\section{MALAGOLI, M. COBELLI, S. VALLONE, P. CARPEGGIANI}

UNITÀ SANITARIA DI MODENA NUOVO OSPEDALE CIVILE S.AGOSTINO ESTENSE, UNITÀ OPERATIVA DI NEURORADIOLOGIA, MODENA, ITALY

\section{MATERIAL AND METHODS}

Between 2008 and 2009, 26 selected patients with a clinical diagnosis of acute ischemic stroke, eligible for thrombolysis, were screened on admission to A\&E, Nuovo Ospedale Civile, Modena, Italy with multimodal CT: unenhanced CT of the brain, perfusion CT (PCT) and CT angiography (CTA). The neuroradiologist on call visually evaluated the scans and produced, on real time, a verbal report to 
the stroke leader regarding early signs of ischemia on plain CT, ischemic penumbra on PCT and arterial stenosis or occlusion on CTA. A 24 hour follow up CT was always performed.

RESULTS

Multimodal CT was administered within a median time window of 17 minutes from door to CT table (range 10-25minutes), the radiologists spent a median of 14 minutes for imaging acquisition, elaboration and oral reporting (range 7-27 minutes). The door to needle time was recorded and resulted comparable to previous stroke unit audit results.

Out of the 26 patients studied, 9 patients did not show alteration in CBV and CBF, follow up CT showed basal ganglia lacunar stroke in 5 cases and no lesions in 4 . The remaining 17 patients had a positive PCT, 14 showed a significant area of ischemic penumbra whereas in 3 cases the CBF and CBV maps were almost overlapping therefore no penumbra was reported. Follow up CT scans showed areas of definitive ischemia sympathetic with the multimodal CT results and the clinical progression.

DISCUSSION

Stroke is the main cause of disability in developed countries and despite the emphasis on new therapies it remains surrounded by preconcepts of unavoidability and it is still largely undertreated. In our early experience multimodal CT can be performed and analyzed rapidly within the A\&E setting without causing any treatment delays. The neuroradiologists on call has easily applied the standardized protocol. The visualization of the brain tissue at risk and the potential benefit of early treatment has offered the physician vital information to modulate his therapeutic options and will give on future analysis important insights on patient selection for thrombolysis.

\section{TH5:13}

\section{MR IMAGING OF BILATERAL PARAMEDIAN THALAMIC AND MESENCEPHALIC INFARCTIONS}

G SPARACIA, E DI GIOVANNA, G CAVARRETTA, V MULARO, $\overline{M E ~ F I A M M A}$

UNIVERSITY OF PALERMO - DIBIMEL - DEPARTMENT OF RADIOLOGY, PALERMO, ITALY

\section{PURPOSE}

To describe the artery of Percheron variation of the thalami and midbrain arterial supply and the symmetrical bilateral paramedian thalamic and mesencephalic infarctions due to this variation.

METHOD AND MATERIALS

Brain MR imaging in two patients admitted to emergency room with mental confusion, respiratory impairment and deep drowsiness were obtained using Fast Spin Echo (FSE) T1-weighted and T2-weighted images, FLAIR T2-weighted images and Diffusion Weighted Imaging (DWI) sequences. Post-contrast FSE T1-weighted images were also obtained.

RESULTS

FLAIR-T2W images showed symmetrical high signal intensity bilaterally in paramedian thalami and rostral midbrain, with a butterfly wings pattern. The evidence of a hypointense signal in FSE-T2W images is referred to desossihaemoglobin due to bleeding. In DWI images high signal intensity was demonstrated as restriction of water diffusion. In postcontrast FSE-T1W images, the lesion showed moderate contrast enhancement. These findings were inter- pretated as infarctions in the typical distribution of the artery of Percheron, a rare variation of the thalami and midbrain arterial supply. CONCLUSION

Bilateral infarctions in the middle aspects of thalami and brain stem should be recognized as due to occlusion of a possible single rare artery that is a normal anatomic variant and not be interpreted as an occlusion of multiple vascular territories or other pathologic conditions such vasculitis or infectious disease.

\section{TH5:14}

\section{INCIDENCE OF INTRACRANIAL VERTEBROBASILAR DISSECTION IN OUTPATIENTS WITH NO OR MINOR SYMPTOMS}

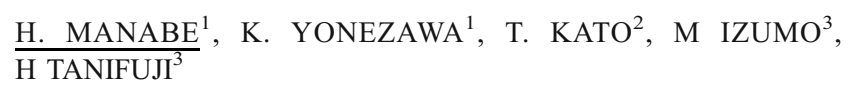

${ }^{1}$ NATIONAL HAKODATE HOSPITAL, DEPARTMENT OF CLINICAL RESERCH, HAKODATE, JAPAN, ${ }^{2}$ HAKODATE SHINTOSHIL HOSPITAL, DEPARTMENT OF NEUROSUGERY, HAKODATE, JAPAN, ${ }^{3}$ HAKODATE SHINTOSHI HOSPITAL, DEVISION OF RADIOLOGY, HAKODATE, JAPAN

\section{PURPOSE}

To clarify an incidence of intracranial vertebrobasilar dissection (VBD). METHODS

We prospectively investigated the VBD on outpatients presenting with no or minor clinical sign. High resolution MRI/MRA (1.5 or $3.0 \mathrm{~T}$ ) examination was performed on consecutive out patients coming to non-emergency neurological outpatient room to detect VBD. The diagnosis of VBD was made for patients who filled the following 1st or/and 2nd condition and 3 rd condition, 1) high signal on the vertebrobasilar arterial wall on T1 weighted image, 2) double lumen on the arterial wall on SPGR image, 3) pearl and string sign or pearl sign or string sign on MRA. The patients who agreed to receive follow-up study were followed clinically and neuroradiologically on 3, 6 and thereafter every $6 \sim 12$ months after the diagnosis.

RESULT

Since 2006 June to 2009 January, 523 patients were included in this study (294 females, mean age; 59.9). All patients had a clear conciousness. BVD was found in 20 patients $(3.8 \%) ; 5$ patients had acute brain stem ischemic minor symptoms (limb numbness or weakness, vertigo, ataxia and headache) related to the dissection (acute dissection, 0.96\%), 15 patients did not have any symptoms (silent dissection, 2.9\%). All 5 patients of acute dissection could be followed both neuroradiologically and clinically, and 13 patients of silent dissection could be followed clinically, and 9 patients neuroradiologically. None of the 5 acute dissection showed repeat stroke and the 13 cases of silent dissection remained asymptomatic on follow-up period (2-33 months). Three cases of the acute dissection and none of the silent dissection showed significant change of MRI and/or MRA findings on follow-up study (218 months).

CONCLUSIONS

1) Incidence of BVD among outpatients with no or minor symptoms was $3.8 \%$. 2) BVD may occur asymptomatically in larger population than we have ever thought. 
Sunday, September 20, 2009 - Terpsichore Room

TE7 - 10:55-12:00 - Head and neck imaging and intervention

TE7:1

\section{IMAGING FEATURES OF TYPANOSCLEROSIS}

N. CHOTAI, PAUL SEE, GOH JULIAN, LOKE SC

TAN TOCK SENG HOSPITAL, SINGAPORE, SINGAPORE

\section{OBJECTIVES}

Postinflammatory ossicular fixation has been described as taking three pathological forms: fibrous tissue fixation (often resulting from adhesive chronic otitis media), hyalinization of collagen (tympanosclerosis), and fibro-osseous sclerosis(new bone formation). We attempt to describe the various presentations of tympanosclerosis with illustrations.

MATERIALS AND METHODS

A retrospective review of $400 \mathrm{HRCT}$ temporal bone scan was performed between January 2007 and December 2008. Unenhanced multislice axial imaging through the bone with coronal reconstruction were performed. The images were analysed for features of tympanosclerosis.

RESULTS

30 cases of tympanosclerosis were detected; there were 9 males and 21 females. Features involving all three forms were noted. Some of the patients had operative correlation.

CONCLUSION

Tympanosclerosis can be diagnosed on CT studies. In our study, the hyalinised form was most common, with calcification of the tympanic membrane and thickening of the ossicles among the most common features. The low pick-up of fibrous tissue fixation may be due to under-reporting.

TE7:2

ORGAN PRESERVING CONCURRENT INTRA-ARTERIAL CHEMORADIATION THERAPY FOR ADVANCED LARYNGEAL CARCINOMA

N. TANAKA $^{1}$, T. ABA $^{1}$, Y. UCHIYAMA $^{1}$, G. SUZUKI $^{1}$, M. TSUJI $^{1}$, T. NAKASHIMA ${ }^{2}, \mathrm{~N}^{\text {HAYABUCHI }}{ }^{1}$

${ }^{1}$ DEPARTMENT OF RADIOLOGY, KURUME UNIVERSITY HOSPITAL, KURUME, JAPAN, ${ }^{2}$ DEPARTMENT OF OTOLARYNGOLOGY, HEAD AND NECK SURGERY, KURUME UNIVERSITY HOSPITAL, KURUME, JAPAN

\section{PURPOSE}

In patients with advanced laryngeal cancer, organ preservation is difficult and radical laryngectomy has been a standard therapy nowadays. We prospectively evaluated our clinical results and feasibility of organ preserving concurrent intraarterial (IA) chemoradiation therapy for patients with advanced laryngeal cancer. Study design is prospective and primary end point is preservation of the larynx.

MATERIALS AND METHODS

The patients with advanced laryngeal cancer, who rejected radical laryngectomy or can not refer to the surgery due to medical condition, were enrolled into our protocol. Eligibility for this study requires histological proof of squamous cell carcinoma, staging as T3, T4, or transglottic T2. Chemotherapy was administered intra-arterially in the angiography suite via superselective transfemoral catheterization of the feeding arteries. During the external beam radiation therapy of $60 \mathrm{~Gy}$, the patients received 4 weekly IA infusions of cisplatin $(75 \mathrm{mg} /$ body $)$ with simultaneous intravenous administration of sodium thiosulfate, a neutralizing agent.

\section{RESULTS}

12 patients were enrolled onto our protocol since June, 2006, including 4 supraglottic, 7 glottic and 1 subglottic cancer. Disease-free survival with laryngeal preservation was achieved in all 12 treated patients during mean following period of 24.1 months. There was no catheter related CNS thromboembolic complication and acute adverse events above Grade 3 were observed in 3 patients ( $25 \%$ ).

\section{CONCLUSION}

In the patients with advanced laryngeal cancer, radiation therapy combined with selective concurrent weekly IA infusion of $75 \mathrm{mg}$ cisplatin can be a therapeutic option for laryngeal preservation without severe adverse events.

\section{TE7:3}

\section{STANDARD UPTAKE VALUE MEASUREMENTS IN THE EVALUATION OF RESIDUAL / RECURRENT SQUAMOUS CELL CARCINOMA OF THE ORAL CAVITY AND OROPHARYNX WITH [18F] FLUORODEOXYGLUCOSE POSITRON-EMISSION TOMOGRAPHY}

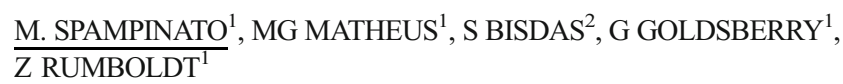

${ }^{1}$ MEDICAL UNIVERSITY OF SOUTH CAROLINA, CHARLESTON, SC, USA, ${ }^{2}$ DIAGNOSTIC AND INTERVENTIONAL NEURORADIOLOGY KARLS EBERHARD UNIVERSITY, TÜBINGEN, GERMANY

\section{PURPOSE}

We assessed the clinical value of standard uptake value (SUV) measurements using [18F] Fluorodeoxyglucose Positron-Emission Tomographic CT (PET-CT) in the evaluation of recurrent or residual loco-regional disease in previously treated patients with oral cavity and oropharyngeal squamous cell carcinoma. We hypothesized that maximal SUV ratios would be more reliable predictors of persistant disease than maximal primary tumor site SUV.

\section{METHODS}

We reviewed records of 39 patients referred for PET/CT imaging to evaluate for residual or recurrent cancer. Maximal SUV were recorded for the primary tumor area and were normalized to the maximal SUV of the pons. In all cases pathology correlations and/ or clinical follow-up of at least 12 months were available. MannWhitney test was used for statistical analysis. Results were considered significant when $\mathrm{p}<0.05$. Receiver operating characteristic analysis provided potential cutoff values for identification of tumor recurrence. 


\section{RESULTS}

Maximal primary tumor site SUV and primary tumor site/pons SUV ratios were significantly different between pathology proven recurrent tumors and cases without disease at pathology or clinical follow-up (respectively $\mathrm{Z}=2.633, \mathrm{p}<0.05 ; \mathrm{Z}=3.883, \mathrm{p}<0.05$ ). There was no significant difference in maximal pons SUV between groups $(\mathrm{Z}=1.87, \mathrm{p}=0.061)$. A threshold value of 0.85 for maximal primary tumor site/pons SUV ratio provided the best combination of sensitivity, specificity and accuracy for the detection of residual/ recurrent disease at the primary site (respectively $80 \%, 91 \%$ and $86 \%$ ). A threshold of 4.5 for maximal tumor site SUV provided the best combination of sensitivity, specificity and accuracy (respectively $82.5 \%, 59 \%$, and $61 \%$ ).

CONCLUSION

The use of quantitative SUV data and especially maximal primary tumor site/pons SUV ratios can be a useful adjunct to the interpretation of $[18 \mathrm{~F}]$ PET-CT studies in the detection of residual/recurrent head and neck carcinoma of the oral cavity and oropharynx.

\section{TE7:4}

\section{DIFFERENCES IN THE DIAMETER OF THE SUPERIOR OPHTHALMIC VEIN ON MDCT BETWEEN PATIENTS WITH MINOR AND SEVERE HEAD TRAUMA}

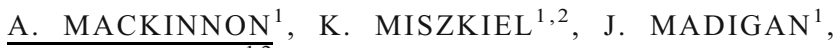 \\ I. DAVAGNANAM ${ }^{1,2}$
}

${ }^{1}$ NATIONAL HOSPITAL FOR NEUROLOGY AND NEUROSURGERY, LONDON, UNITED KINGDOM, ${ }^{2}$ MOORFIELDS EYE HOSPITAL, LONDON, UNITED KINGDOM

\section{PURPOSE}

Superior ophthalmic vein (SOV) diameter measurements performed on MRI have been shown to correlate with intracranial pressure. The SOV is readily appreciable and can be measured with greater accuracy on multi-detector CT. There is a lack of data on CT-based evaluation of the SOV in near normal individuals and in patients with severe head injury. Our purpose was to devise a standardised and reproducible method of measuring the SOV, establish baseline values and assess any difference in SOV diameters between patients with severe versus minor head injury.

METHODS

SOV size was measured retrospectively in 50 consecutive patients, 39 with minor head injury (Group 1) and 11 with severe head and facial injuries (Group 2). The diameters of both SOVs and optic nerve sheath complexes (ONSC) were measured. SOV measurements were made at the mid point of the superior rectus muscle and repeated $5 \mathrm{~mm}$ posteriorly. The ONSC was measured immediately posterior to the globe.

RESULTS

There was no significant difference in age between the two groups: Group1, 47.8 years (17-95); Group2, 47 years $(27-87) ; \mathrm{p}=0.86$. In both groups, the SOV and ONSC measurements showed good correlation between left and right sides (all $\mathrm{p}<0.001$, correlation 0.71-0.95). The combined mean values were therefore obtained for further comparisons. There was a significant difference in mean(SD) SOV diameter between the groups, Group $1,0.21+/-0.05 \mathrm{~mm}(0.14$ $0.32 \mathrm{~mm})$ and Group 2, 0.37+/-0.07 mm $(0.26-0.53 \mathrm{~mm}) ; \mathrm{p}<0.001$.
This relationship was not observed for ONSC diameters, Group 1, $0.62 \mathrm{~mm}$ and Group 2, $0.65 \mathrm{~mm} ; \mathrm{p}=0.396$. The SOV/ONSC ratio was significantly higher in Group 2 , $(0.58$ versus $0.35, \mathrm{p}<0.001)$. No correlation between Group 1 age and $\operatorname{SOV}(\mathrm{p}=0.374)$ or ONSC diameter $(p=0.329)$ was observed. CONCLUSIONS

The SOV diameter lies within a narrow range, of up to $3 \mathrm{~mm}$, in a select group of near normal patients. The SOV diameter is significantly larger in patients with severe head injury.

\section{TE7:5}

VALUE OF PERFUSION ESTIMATION IN SQUAMOUS CELL CARCINOMA OF THE UPPER AERODIGESTIVE TRACT: LONG-TERM RESULTS OF BASELINE PERFUSION CT MEASUREMENTS

S. BISDAS $^{1}$, Z. RUMBOLDT ${ }^{2}$, K. SURLAN-POPOVIC ${ }^{3}$, T. PLOTAS ${ }^{4}$, M. BAGHI ${ }^{5}$, M.G. MACK ${ }^{5}$

${ }^{1}$ EBERHARD KARLS UNIVERSITY HOSPITAL, TÜBINGEN, GERMANY, ${ }^{2}$ MEDICAL UNIVERSITY OF SOUTH CAROLINA, CHARLESTON, USA, ${ }^{3}$ CLINICAL CENTRE LJUBLJANA, LJUBLJANA, SLOVENIA, ${ }^{4} \mathrm{CT}$ AND MRI PELOPONNISOU, CORINTH, GREECE, ${ }^{5}$ JOHANN WOLFGANG GOETHE UNIVERSITY HOSPITAL, FRANKFURT, GERMANY

\section{PURPOSE}

Perfusion CT studies hold short-term predictive value in patients treated with (neo)adjuvant chemoradiotherapy. Our aim was to examine the long-term predictive value of baseline perfusion CT studies for local tumor control and overall survival in squamous cell carcinoma (SCCA) of the upper aerodigestive tract treated with neoadjuvant chemoradiotherapy.

\section{MATERIALS AND METHODS}

Eighty-four patients underwent perfusion CT and neoadjuvant chemoradiation. The acquired perfusion maps represented blood flow $(\mathrm{F})$, blood volume $(\mathrm{V})$, mean transit time $(\mathrm{t})$, and permeability surface area product (PS). Visual analysis of the parametric maps for identification tumor perfusion patterns was also conducted. T-test, ROC-curves, and Kaplan-Meier survival curves were plotted for local disease-control and overall survival.

RESULTS

The median time of local tumor control time was 24 months. The $\mathrm{F}$ and PS values were significantly higher in patients who had no recurrence than those with local failure $(p=0.02)$. The $F$ and PS were predictive for local tumor control $(\mathrm{p}=0.0006)$; $\mathrm{V}$ and $\mathrm{t}$ held no significant predictive values for local tumor control. The patients with high $F$ and PS had a longer local tumor control than the patients with hypoperfused tumors $(p=0.0007)$. A visuallydetected F-V mismatch had sensitivity/specificity of $63 \% / 66 \%$ $(\mathrm{p}=0.03)$ and $59 \% / 69 \%(\mathrm{p}=0.03)$ for local tumor control and OS, respectively. Patients without mismatch lived significantly longer than patients with mismatch $(\mathrm{p}=0.01)$. CONCLUSIONS

F, PS as well as mismatch of F-V are significant predictors for local tumor controlafter neoadjuvant chemoradiation in SCCA of the upper aerodigestive tract. 
TE7:6

\section{PERFUSION CT FOR MONITORING INITIAL RESPONSE IN ADVANCED SQUAMOUS CELL CARCINOMA OF THE HEAD AND NECK TREATED WITH CONCOMITANT CHEMORADIOTHERAPY}

\author{
S. BISDAS ${ }^{1}$, K. SURLAN-POPOVIC ${ }^{2}$, T. PLOTAS $^{3}$, U. ERNEMANN $^{1}$, \\ P. STROJAN ${ }^{2}$ \\ ${ }^{1}$ EBERHARD KARLS UNIVERSITY HOSPITAL, TÜBINGEN, \\ GERMANY, ${ }^{2}$ CLINICAL CENTRE LJUBLJANA, LJUBLJANA, \\ SLOVENIA, ${ }^{3}$ CT AND MRI PELOPONNISOU, CORINTH, GREECE
}

\section{PURPOSE}

To prospectively evaluate changes in primary tumor perfusion parameters during concomitant cisplatin-based chemoradiotherapy of locoregionally advanced squamous cell carcinoma of the head and neck (SCCHN) and to evaluate their predictive value for response of the primary tumor to therapy.

METHODS

Fifteen patients with locoregionally advanced SCCHN underwent perfusion CT scans before therapy and after completion of 40 Gy and 70 Gy of chemoradiotherapy. Blood flow (BF), blood volume (BV), mean transit time (MTT), and permeability surface area product (PS) of primary tumors were quantified. Differences in perfusion and tumor volume values during the therapy as well as between responders and non-responders were analysed and Receiver Operator Characteristic (ROC) curves were used to assess predictive value of the baseline and follow-up functional parameters.

RESULTS

No significant differences were observed between perfusion parameters at 0,40 , and $70 \mathrm{~Gy}$ in the pooled patients. The tumor volume at 40 Gy and at 70 Gy was significantly lower compared to baseline value $(\mathrm{p}=0.007$ and $\mathrm{p}=0.014)$. In the nonresponders ( 8 patients), measurements at 40 Gy showed a non-significant trend of increased $\mathrm{BF}, \mathrm{BV}$ and PS values compared to the baseline values. As predictors of primary tumor response to chemoradiation were identified: at 0 Gy - BV ( $p=0.01)$; at $40 \mathrm{~Gy}-\mathrm{BF}, \mathrm{BV}$ and MTT (in all three, $\mathrm{p}=0.03$ ); at 70 Gy - BV $(p=0.01)$ and PS $(p=0.03)$.

CONCLUSIONS

The results suggest that in advanced SCCHN the perfusion CT monitoring might be of predictive value for identifying tumors that may respond to the cisplatin-based chemoradiotherapy.

\section{TE7:7}

\section{SCLEROTIC INTRAOSSEOUS SPHENOID RIDGE MENINGIOMA: CT AND MRI FEATURES OF 24 CASES}

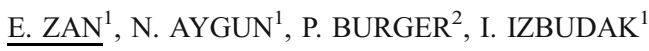

${ }^{1}$ THE JOHNS HOPKINS MEDICAL INSTITUTION, DEPARTMENT OF RADIOLOGY, BALTIMORE, MD, USA, ${ }^{2}$ THE JOHNS HOPKINS MEDICAL INSTITUTION, DEPARTMENT OF PATHOLOGY, BALTIMORE, MD, USA

\section{PURPOSE}

Sclerotic intraosseous meningioma might be mistaken for fibrous dysplasia, sclerotic metastasis or primary bone neoplasm on the basis of radiologic appearances. Even though intradural meningioma is the most common benign intracranial neoplasm, purely intraosseous meningioma is amongst the rarest extradural forms. In this study we aimed to analyze and demonstrate the MRI and CT characteristics of this entity specifically in the sphenoid ridge which is the most common location according to our experience.

METHOD AND MATERIALS

We retrospectively reviewed our pathology database between 2000 and 2008. We found $45(\mathrm{~F}=35, \mathrm{M}=10)$ cases of pathologically confirmed meningiomas within the bone. Twenty-four of the intraosseous meningiomas were exclusively in the sphenoid ridge without accompanying prominent dural masses. The average age was 63.6 years. Proptosis was the most common presentation.

RESULTS

The shared MR findings of all 24 cases were: 1) prominent expansion of the sphenoid ridge, 2) replacement of the intraosseous fat with hypointense $\mathrm{T} 1$ and $\mathrm{T} 2$ signal, 3) adjacent dural thickening with enhancement and calcification /ossification without prominent dural mass, 4) irregular solid periosteal enhancement at the temporal and orbital surface of the sphenoid ridge.

The common CT findings were: 1) expansion of the sphenoid ridge with diffuse sclerosis/ hyperostosis (diploe, outer and inner table were indistinguishable), 2) adjacent dural calcification/ossification, 3) spiculated periosteal reaction.

Even though intraosseous meningioma was within the differential diagnosis in the CT and/or MRI reports of these 24 cases, it was not favored over fibrous dysplasia, primary or metastatic sclerotic bone tumors.

CONCLUSION

Intraosseous sphenoid ridge meningioma is a rare entity. However if above described CT and MR imaging findings are demonstrated in a middle aged female patient presenting with proptosis we suggest the radiologist could favor intraosseous meningioma over the fibrous dysplasia and primary or metastatic sclerotic bone tumors.

\section{TE7:8}

\section{VISUAL LOSS, MRI AND OPTIC NERVE ENHANCEMENT: CLUES TO THE BEST DIAGNOSIS}

\section{F. HERAN}

\section{FONDATION ROTHSCHILD, PARIS, FRANCE}

\section{INTRODUCTION}

Visual loss may be due to optic nerve lesion. On MRI, discrete contrast enhancement of the peri optic meningeal sheath is frequent, optic nerve enhancement is always pathological. Study of the location and the type. of this enhancement may suggest its aetiological diagnosis PATIENTS AND METHOD

Among anterior optic tract MRI (thin slices, always coronal and T1 with injection and fat suppression) of all the patients with unilateral or bilateral visual loss, we made a selection of 350 cases (mean age 38, 2 female / 1 man) with abnormal contrast enhancement (CE) along one or both optic nerves (within, meningeal or near). Location, length of the $\mathrm{CE}$ as well as brain study to depict other lesions were studied.

RESULTS

$48 \%$ of CE were within the optic nerve ( $82 \%$ optic neuritis with $4 \%$ post radiation, $10 \%$ tumor, $8 \%$ inflammation), $28 \%$ of the $\mathrm{CE}$ were due to 
lesions compressing the optic nerve (mainly $62 \%$ meningiomas, $12 \%$ cavernous hemangiomas of the apex, $9 \%$ metastases, $7 \%$ inflammatory masses), and $24 \%$ were due to infiltration of the perioptic tissue $(48 \%$ optic nerve meningiomas, $30 \%$ inflammation with $10 \%$ sarcoïdosis, $10 \%$ malignant disease). Complementary informations were given by clinical data and $\mathrm{T} 1$ and $\mathrm{T} 2$ study of the brain.

DISCUSSION AND CONCLUSION

When a visual loss seems due to anterior optic tract lesion, MRI with T1 after gadolinium and fat suppression is mandatory. Contrast enhancement of or around the optic nerve gives clues to the diagnosis of visual loss, which is mainly due to meningiomas and inflammation of the optic nerve (MS, sarcoïdosis ). Complementary brain sequences may be useful to confirm these diagnosis (high signal T2 lesions, other meningiomas..).

\section{TE7:9}

\section{DIFFUSION-WEIGHTED MR IMAGING SEQUENCE TO RULE OUT RECURRENT CHOLESTEATOMA AND AVOID UNNECESSARY SECOND-LOOK MASTOIDECTOMY}

\author{
S. TAL ${ }^{1,3}$, L. MIGIROV ${ }^{2}$, A. EYAL ${ }^{3}$ \\ ${ }^{1}$ RADIOLOGY DEPARTMENT ASSUTA MEDICAL CENTER, \\ TEL-AVIV, ISRAEL, ${ }^{2}$ DEPARTMENTS OF OTOLARYNGOLOGY \\ AND HEAD AND NECK SURGERY, SHEBA-MEDICAL, \\ TEL-HASHOMER, ISRAEL, ${ }^{3}$ RADIOLOGY DEPARTMENT, \\ SHEBA MEDICAL CENTER, TEL-HASHOMER, ISRAEL
}

\section{PURPOSE}

To present our experience in using diffusion-weighted sequence magnetic resonance (MR) imaging for diagnosis and follow up of recurrent cholesteatoma in patients who underwent mastoidectomy for cholesteatoma.

MATERIALS AND METHODS

Thirty patients (19 female, age range 12-56 years) who had undergone mastoidectomy for cholesteatoma were referred for MR imaging to exclude recurrence. MR imaging was performed with a 1.5-T unit by using diffusion-weighted echo planar and Non echo planar imaging (SIMENS HASTE sequences), high resolution T2weighted imaging,FSE T 2, unenhanced fat saturation T1-weighted SE imaging and delayed contrast material-enhanced fat saturation T1weighted imaging.

\section{RESULTS}

The MRI diagnosis of recurrent cholesteatoma was confirmed at surgery in 10 patients and was not confirmed in one. The MR study was negative for presence of cholesteatoma in one patient and only chronic eustacheitis was diagnosed during the endoscopic revision surgery in this case. Two patients with positive MR findings are scheduled for revision surgery in the near future, and since cholesteatoma had not been detected in the other 16 patients, they are scheduled for a repeated MRI 2 years after the first one. To date, our series demonstrated 10 true positive, one true negative and one false positive results.

CONCLUSIONS

Non echo-planar and echo planar diffusion-weighted MRI enables the depiction of recurrent cholesteatoma in patients who have undergone cholesteatoma surgery and helps in avoiding unnecessary revision/ second look procedures.

Sunday, September 20, 2009 - Hesperides Room

HE7

08:30-10:00 - Spinal interventions

HE7:1

\section{OZONUCLEOLYSIS IN PROLAPSE CERVICAL} DISCS-EXCELLENT RESULTS

\section{U. RASHID}

\section{LAHORE GENERAL HOSPITAL, LAHORE, PAKISTAN}

Direct injection of ozone has been proven to be effective alternative to surgery for patients suffering from disc herniation in many centres around the world. We report our experience with ozonucleolysis between June 2006 to December 2008 with 500 patients affected by pain cervical region (Bracehalgia) due to disc herniation including of postoperative recurrence disc prolapse.

All these cases treated by intradiscal, or paravertabral oxygen - ozone injections. Patients age between 20 to 70 years underwent percontaneous ozonuclealysis under angiofluro with aseptic technique and short hospital stay.

No side effects were reported at short and long term follow up clinical results hence evaluated with the modified MaNab method sharing $85 \%$ success rate.

In our experience, Ozone Gas Therapy in treatment of herniated disc has revolutionized the percutenous approach to nerve root disease making it safer cheaper and easier to repeat than treatments currently in use.

HE7:2

IMAGE-GUIDED PROCEDURES WITH THE XPERGUIDE SYSTEM IN INTERVENTIONAL NEURORADIOLOGY

C. TASCHNER ${ }^{1}$, T. WOLTER ${ }^{2}$, J. WEBER ${ }^{1}$, A. LINDER $^{1}$,

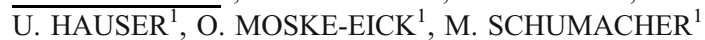

${ }^{1}$ DEPARTMENT OF NEURORADIOLOGY, FREIBURG, GERMANY, ${ }^{2}$ DEPARTMENT OF NEUROSURGERY, FREIBURG, GERMANY

\section{PURPOSE}

Evaluation of the Xperguide technique for image-guided procedures in interventional Neuroradiology. Introduction: Static CT data for percutaneous image guided procedures lack real-time information. Fluoroscopic guidance does not provide information on the soft tissue. We present a technique that combines CT information and fluoroscopic controls for image-guided, percutaneous interventions. 


\section{METHODS}

The procedures were performed with the Allura Xper FD20/20 (Philips, Best, the Netherlands). An initial XperCT data set was acquired with the C-arm flat panel system. Based on the XperCT data entry and target points were defined using dedicated software (Xperguide). The needle path could be visualised in various reconstructed trajectories, and be corrected if necessary. For percutaneous interventions, the entry view (overlay of entry and target point), the progression view (perpendicular to the entry view), as well as two additional views can automatically be piloted to with the $\mathrm{C}$-arm system. Needle navigation was supported with the SeeStar (Radi, Uppsala, Sweden). In the progression view the needle can be navigated along the planned trajectory displayed on an overlay of reconstructed XperCT data and the fluoroscopy image. Correct needle positioning was confirmed with a second XperCT.

RESULTS

The proposed technique is routinely applied for vertebral body biopsies, for facet joint and nerve root infiltrations. Accuracy of the technique as well as radiation doses are compared to standard CT guided procedures and instructive cases are demonstrated.

\section{CONCLUSION}

The Xperguide system for image guided percutaneous interventions is practicable and turned out to be an interesting alternative to CT guided procedures.

\section{HE7:3}

\section{A BI-PHASIC CERAMIC BONE SUBSTITUTE FOR THE TREATMENT OF VERTEBRAL COMPRESSION FRACTURES: EARLY CLINICAL RESULTS}

\section{H. HATTEN, JR.}

\section{INDIAN RIVER RADIOLOGY, VERO BEACH, FL, USA}

Spinal fractures \& osteoporosis are major worldwide problems which considerably impair quality of life. Pain improvement with vertebral body augmentation is typically seen in greater than $90 \%$ of patients. PMMA has been the material of choice to date. Injection of PMMA stabilizes the fracture preventing micro motion. However adjacent segmental fractures have been as high as $20 \%$ within the first year leading to further surgical intervention. A cement of altered modulus that represents the properties of trabecular bone may reduce this risk. Presented is the first U.S. series of vertebroplasty with bi-phasic ceramic bone substitute with mechanical properties similar to cancellous bone.

The bi-phasic material (Cerament ${ }^{\mathrm{TM}}$, Bone Support AB) is an injectable bone substitute which reinforces decalcified bone allowing the patient's own bone tissue to grow \& replace the implanted material. The attached micrograph of a 6 month biopsy of a wrist fracture treated with the bi-phasic material demonstrates the controlled creeping substitution of new bone as the material resorbs.

The material is non-exothermic and remodels to bone. It provides the appropriate mechanical environment for stability of the VCF and pain prevention. Its construction delivers a compressive strength similar to that of cancellous bone when implanted and this restores initial strength to aid pain prevention. The stiffness is also similar to that of cancellous bone to help prevent additional fractures in adjacent vertebrae.

12 patients have been treated to date in this first U.S. clinical series. Pain improvement has been seen in all patients with a VAS score (in the 0 to 10 range) reducing from 8.4 to 1.0 on average. Patients have been able to return to aerobic activity, as in the example for the pre-operative and post-operative scans below. In this case a 77 year old female returned to regular tennis within two weeks of surgery.

\section{HE7:4}

\section{CERVICAL VERTEBROPLASTY:INDICATIONS AND RESULTS}

M. MUTO, G. GUARNIERI, G. AMBROSANIO, P. VASSALLO, F. ZECCOLINI, A. LAVANGA

\section{NEURORADIOLOGY SERVICE CARDARELLI HOSPITAL, NAPLES, ITALY}

\section{PURPOSE}

To illustrate the validity of the treatment with vertebroplasty (VP) in patients with vertebral haemangioma $(\mathrm{VH})$ or with primary or secondary neoplastic lesion at cervical level.

MATERIALS AND METHODS

8 patients were treated with VP, for a total of 8 vertebral bodies: 2 symptomatic $\mathrm{VH}$ at $\mathrm{C} 5$ and $\mathrm{C} 4,2$ cases of Multiple Myeloma at $\mathrm{C} 2$ and $\mathrm{C} 4 ; 4$ patients affected by vertebral metastasis from breast or lung cancer at $\mathrm{C} 2, \mathrm{C} 4$ (two cases) and C5. All the patients complained a pain syndrome resistant to continuous medical medication. All procedures were performed under general anaesthesia by antero-lateral approach under CT or Fluoroscopy control with manual dislocation of the carotid axis. For the treatment of C2 lesion a trans-oral approach under fluoroscopy was performed. Bone biopsy never been performed. In two patients, VP was performed to prevent fracture after implantation of double discal protesis.For patients affected by multiple myeloma, VP was performed to prevent new vertebral fracture. In 3 patients affected by metastasis VP was performed before of radiotherapy, and in one case just after.

\section{RESULTS}

Results have been evaluated with the Visual Analogue Scale and the Oswestry Disability Index methods. In $90 \%$ of patients, in the following 24-72 hours, a successful outcome has been observed with a complete resolution or partial reduction of pain symptom. At 3 months follow-up, we registered a reduction of 4 scores in the VAS evaluation and a $25 \%$ reduction in the ODS score. No extra-vertebral vascular or discal cement leakage was observed. At 3 months, a X-ray control showed a stable result.

\section{CONCLUSIONS}

Percutaneous treatment with VP foe benign or malignant vertebral cervical lesion is a valuable, mini invasive and quick method that allows a complete and enduring resolution of the painful vertebral symptoms without findings of fracture of a vertebral body adjacent or distant to the one treated 
HE7:5

PRELIMINARY EXPERIENCE WITH NEW SYNTHETIC CERAMIC BONE SUBSTITUTE -CERAMENTTM SPINE SUPPORT- IN VERTEBRAL COMPRESSION FRACTURE (VCF): SHORT TERM FOLLOW-UP AT 3 MONTHS ABOUT 15 CASES

M. MUTO, G GUARNIERI, G AMBROSANIO, P. VASSALLO, A. LAVANGA

\section{NEURORADIOLOGY SERVICE CARDARELLI HOSPITAL, NAPLES, ITALY}

\section{PURPOSE}

To illustrate our preliminary experience about a new synthetic ceramic bone substitute -Cerament ${ }^{\mathrm{TM}}$ Spine Support- in the treatment of Vertebral Compression Fracture(VCF) showing our clinical results at 3 months short term follow-up.

MATERIAL AND METHODS

15 patients (9F,6 M, ages means 55 years) affected by osteoporotics VCFs $(13 / 15)$ and by traumatic VCFs (2/15).All pts. were studied by MRI protocol (Sagital T2W,STIR,T1W). VCF distribution was:5 at level L2,6 L4,2 T12, 2 T11.All procedures were performed under local anesthesia with trans-peduncolar approach.A new synthetic ceramic bone substitute -Cerament ${ }^{\mathrm{TM}}$ Spine Support- was used to intend for augmentation of the vertebral body. It's constituted by $60 \%$ alpha-calcium sulfate (á-CaS) and 40\% hydroxyapatite (HA). A clinical short term follow-up at 3 months was performed with VAS and ODS.

RESULTS

VP was successfully performed and led to an excellent outcome in all pts with clinical improvement. No vascular,extraforaminal or epidural leakage or other adverse events were observed. At 3 months VAS and ODS decreased about of $40 \%$ from pre-treatment to post treatment in all pts with complete cement reabsorption and complete bone's substitution.

\section{CONCLUSIONS}

VP for osteoporotic or traumatic VCF was archived.Ceramic bone substitute -Cerament ${ }^{\mathrm{TM}}$ Spine Support - is new cement safe and effective to use for osteoporotic and traumatic cement. A long term follow-up is recommended.

\section{HE7:6}

VERTEBROPLASTY: A MINIMALLY INVASIVE APPROACH TO VERTEBRAL PAIN. SINGLE CENTER EXPERIENCE WITH 432 TREATED LEVELS

\author{
I. FRAGATA, J. RAMALHO, J. REIS
}

CENTRO HOSPITALAR DE LISBOA CENTRAL, EPE; DEPARTMENT OF NEURORADIOLOGY, LISBON, PORTUGAL

\section{LEARNING OBJECTIVES}

To describe the indications, technique, results and main complications of percutaneous transpedicular vertebroplasty, based on our center experience with 432 vertebrae treated.

BACKGROUND

Vertebroplasty is worldwide accepted as an effective minimally invasive technique for treatment of refractory pain caused by vertebral fractures. Our purpose in this exhibit is to describe our experience with this technique, the indications, technical aspects, results and complications. Between January 2004 until September 2008, a total of 432 vertebrae were treated in our center.

PROCEDURE DETAILS

Under sedation and local anesthesia, with the patient prone, a uni- or bipedicular approach is used to insert a needle in the vertebral body. Injection of cement is performed under fluoroscopic guidance, until a satisfactory and symmetric filling of the vertebral body is achieved. Our complications with this technique are described. Pain relief was immediate in most cases, and patients were discharged home on the same day.

CONCLUSION

Osteoporotic and malignant vertebral compression fractures have been increasingly treated with minimally invasive bone augmentation techniques such as vertebroplasty. Complications from percutaneous vertebroplasty are rare, and this technique has proven to be an effective means of pain relief.

\section{HE7:7}

\section{INTRAOPERATIVE VERTEBROPLASTY COMBINED WITH POSTERIOR CORD DECOMPRESSION: REPORT OF FIFTEEN CASES}

\author{
L. SAITTA ${ }^{1}$, L. ALLEGRETTI ${ }^{1}$, N. MAVILIO ${ }^{1}$, C. SILVESTRO $^{2}$, \\ R. SPAZIANTE ${ }^{2}$, L. CASTELLAN ${ }^{1}$ \\ ${ }^{1}$ DEPARTMENT OF DIAGNOSTIC AND INTERVENTIONAL \\ NEURORADIOLOGY, SAN MARTINO HOSPITAL, GENOA, \\ ITALY, ${ }^{2}$ DEPARTMENT OF NEUROSURGERY, SAN MARTINO \\ HOSPITAL, GENOA, ITALY
}

\section{PURPOSE}

Percutaneous vertebroplasty (PV) is a relatively simple and minimally invasive technique for the treatment of vertebral pathology providing early vertebral stabilization and pain relief. In some cases, complicated by spinal cord compression, $\mathrm{PV}$ alone cannot be performed free of risks. We describe a double approach in which decompressive laminectomy and intraoperative vertebroplasty (IV) are performed during a single session.

MATERIALS AND METHODS

Among the 252 vertebroplasties performed in our center in the past 3 years, 15 (5 symptomatic haemangiomas, 6 metastatic fractures, 4 osteoporotic fractures) were done in association with surgery in patients with pain and spinal cord compression at a dorsal level. All were treated with decompressive laminectomy and IV (mono/bipeduncular or medianposterior trans-somatic access). Four patients with symptomatic haemangiomas were treated with endovascular embolization prior to the combined approach. In one of these, with a paravertebral mass, a thoracotomy was performed to remove the pathologic tissue. Four cases required posterior segmental fixation. A VAS (visual analog scale) was applied to assess pain intensity before and after surgery.

\section{RESULTS}

In all cases benefit from pain and neurological deficits was observed. The mean VAS score decreased from 7 to 3 after operation. No clinical complications were observed. In one case a CT showed a foraminal accumulation of PMMA, but the patient referred no symptoms.

CONCLUSIONS

According to our short term results, we observed that the association of surgical approach with IV is beneficial. This technique allows to 
perform decompression of dural sac and vertebral body stabilization, possibly avoiding segmental fixation.

HE7:8

\section{FREQUENCY AND RISK FACTORS OF ADJACENT FRACTURES AFTER VERTEBROPLASTY}

\author{
$\underline{\text { Z. KULCSAR }}^{1}$, M MAROSFOI $^{2}$, Z BERENTEI $^{2}$, I SZIKORA $^{2}$
}

${ }^{1}$ KLINIK HIRSLANDEN, ZURICH, SWITZERLAND, ${ }^{2}$ NATIONAL INSTITUTE OF NEUROSURGERY, BUDAPEST, HUNGARY

\section{BACKGROUND AND PURPOSE}

Percutaneous vertebroplasty (PVP) proved to be very effective in the treatment of pain caused by osteoporotic vertebral compression fractures. A certain proportion of patients however suffer a new fracture after treatment. Our purpose was to analyze the frequency of new fractures, and to estimate the causative role of PVP in the treated population.

\section{PATIENTS AND METHODS}

The restrospective study reviewed all consecutive patients treated with PVP for osteoporotic compression fractures during a 5,5 years period. The study group was comprising those patients, who suffered a new fracture during the follow up. The primary endpoint was the frequency of new fractures. The secondary endpoint was the occurence of new fractures in a timeframe of 90 days after treatment, that were adjacent to the previously treated segments. The causative role of PVP was estimated to be the highest in this subgroup.

RESULTS

Altogether 396 consecutive patients were treated with PVP for osteoporotic compression fractures. The mean age was $68+11$ years, and $23 \%$ of the population was male. The study group was comprising 73 patients $(18,4 \%)$. In this subgroup the patients had an avarage of 3.8 vertebral fractures. After PVP adjacent fractures were significantly more probable, than distal fractures. Altogether 44 patients (11\% of the entire population) suffered an adjacent fracture in 90 days after PVP. In this group there were significantly less male patients as compared to the entire population.

CONCLUSION

After PVP almoast every fifth patient is at risk for developing a new fracture, however the vertebral augmentation will probably have a bioemchanical effect only on every tenth subject. Female patients with severe osteoporosis are probably facing the highest risk for developing new fractures.

\section{HE8 \\ 11:20-12:30 - Advanced imaging modalities II f-MRI, DTI}

HE8:1

ARTERIAL SPIN LABELLING FOR FUNCTIONAL MRI USING MOTOR TASK

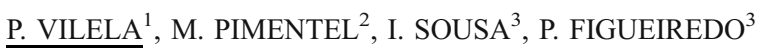

${ }^{1}$ HOSPITAL DA LUZ, LISBON, PORTUGAL, ${ }^{2}$ FACULDADE DE CIÊNCIAS E TECNOLOGIA. UNL, LISBON, PORTUGAL, ${ }^{3}$ INSTITUTO SUPERIOR TÉCNICO. UTL, LISBON, PORTUGAL

\section{BACKGROUND AND PURPOSE}

The new clinically available arterial spin labelling (ASL) sequences present some advantages relatively to the blood oxygenation level dependent (BOLD) method for functional brain studies, namely the fact of being potentially quantitative and more reproducible. The aim of our study was to compare two functional clinical protocols, using BOLD and ASL, in terms of the activation detected in a predetermined region of interest (ROI).

\section{MATERIALS AND METHODS}

Both ASL and BOLD imaging were performed on a Siemens Verio 3.0 $\mathrm{T}$ scanner. Eight healthy adult volunteers performed a motor finger tapping task. The BOLD protocol used a block design consisting of 4 cycles alternating 30 seconds of task with 30 seconds of rest. The ASL protocol consisted on the acquisition of one image during rest and another during the task. Post-processing was performed using Siemens Syngo MR and an anatomical ROI was identified by a neuro-radiologist. For the BOLD protocol, the General Linear Model (GLM) was used to produce t-statistics maps of activation. For the ASL protocol, the rest and activation perfusion images were subtracted to produce an activation map. The scales of the BOLD and ASL activation maps were both normalized to 1 and evaluated in the pre-defined ROI.

RESULTS

The mean (and standard error) activation observed for the BOLD and ASL protocols in the ROI was, respectively: $0.956(0.035)$ and $0.943(0.044)$. No significant differences were observed between the between the activation information provided by each protocol.

\section{CONCLUSION}

Our data suggest that the functional imaging protocol using ASL produces comparable results to a conventional BOLD protocol.

\section{HE8:2}

\section{NEURORADIOLOGY MEETS NEUROSCIENCE: HOW IS BOLD FMRI DIFFERENT IN THE CLINICAL AND RESEARCH SETTINGS?}

\author{
$\underline{\text { D. SEIXAS }}^{1}$, M. AYRES BASTO ${ }^{1}$, J. ANDERSSON $^{2}$
}

${ }^{1}$ SAO JOAO HOSPITAL - DEPT. OF NEURORADIOLOGY, PORTO, PORTUGAL, ${ }^{2}$ UNIVERSITY OF OXFORD - OXFORD CENTRE FOR FUNCTIONAL MAGNETIC RESONANCE IMAGING OF THE BRAIN (FMRIB), OXFORD, UNITED KINGDOM

Neuroradiologists are frequently involved in pre-operative cortical mapping using BOLD fMRI, as well as in neuroscience research using the same technique. Although there are methodological similarities, there are also important distinctions. Based on the authors' experience/literature search, we aim to review and discuss the main differences in using fMRI for clinical or research purposes. The key issue in the clinical setting is the single subject, whereas in research interest is at the group level. Considering participants' motivations, as opposed to the case when recruiting healthy volunteers for research, patients rarely refuse such brain studies, because they will benefit either directly in the planning of their surgery, or at least indirectly, in the advance of knowledge on their disease. Patients often have altered consciousness or neurological deficits that can increase head movement or make tasks harder. Motion artefacts can be reduced prospectively or during processing, but are more easily dealt at the group level. Planning fMRI tasks can 
be challenging both in clinics and research. There are no standardized tasks or normative data for patients. Due to the nature of research questions, logistics can become challenging. Registration of functional to anatomical data can be difficult in single patient studies; brain anatomy is often distorted and lesions may originate susceptibility artefacts. Using field-maps for distortion correction, or EPI, T2 or T1 post-contrast images can be useful. Perfusion/diffusion MRI can also be of help. Concerning statistics, scanning time may have to be increased to ensure sufficient sensitivity to detect activations in a single subject. Thresholding is a source of discussion, and several techniques can be used. For group studies the main concern is with controlling the rate of false positives, so as not to publish false claims. However, this means that sensitivity is often low with less than $50 \%$ chance of detecting an actual activation. In a patient this is unacceptable and could potentially lead to the resection of functionally crucial areas. Hence, in a patient the focus should instead be on minimising the false negative rate, i.e. to maximise sensitivity. Several differences with potential implications in data acquisition, processing and interpretation were identified, depending on the type of application of BOLD fMRI. The resourceful imager should be aware of them.

\section{HE8:3}

\section{WHITE MATTER ANISOTROPY IN PATIENTS WITH HEREDITARY SPASTIC PARAPLEGIA: SPG11 VERSUS SPG4 MUTATION}

A. MESCHINI ${ }^{1}$, P.E. ASSAKO ONDO ${ }^{1}$, F.G. GARACI ${ }^{1}$, $\overline{\text { F. } \text { BOLACCHI }^{1}}$, G. MANENTI ${ }^{1}$, S. MARZIALI ${ }^{1}$, R. FLORIS ${ }^{1}$, F. SANTARELLI ${ }^{2}$, G. SIMONETTI ${ }^{1}$

${ }^{1}$ UNIVERSITÀ DI ROMA TOR VERGATA - DIPARTIMENTO DI DIAGNOSTICA PER IMMAGINI, ROME, ITALY, ${ }^{2}$ OSPEDALE BAMBIN GESÙ - ROMA, ROME, ITALY

\section{PURPOSE}

Aim of our pilot study was to compare by high field magnetic resonance diffusion tensor imaging (MR-DTI) the white matter anisotropy in HSP patients with SPG11 and SPG4 mutations.

PATIENTS AND METHODS

Seven HSP patients were included in the study (mean age 32 years old, range 30-35 years). Twenty healthy subjects were used as controls. MR-DTI was performed with a 3-Tesla MR scanner. Fractional anisotropy (FA) maps were automatically created. Regions of interest (ROIs) were positioned over the FA maps in the semioval centers, corpus callosum, internal capsule, periventricular and subcortical white matter anteriorly, paratrigonal white matter, cerebral peduncles and cerebellar white matter.

RESULTS

There was a significant decrease in FA values in SPG11 patients with respect to controls subjects in all the CNS areas analysed $(\mathrm{p}<0.05)$, except in the cerebral peduncles and in the cerebellar white matter $(p>0.05)$. On the contrary SPG4 patients showed only a significant decrease in FA values in the semioval centers and in the internal capsule with respect to control patients $(p<0.001)$. When compared to SPG4 patients, SPG11 patients showed a significant reduction in the FA values in the semioval centers and in the paratrigonal white matter $(\mathrm{p}<0.001)$.

CONCLUSION

White matter anisotropy shows to be a promising tool to distinguish SPG11 HSP from SPG4 HSP, thus suggesting that it may play a role as disease-related indicator. Further studies with increased patient numbers are necessary to confirm our preliminary results

\section{HE8:4}

\section{INVESTIGATION OF THE MANGINA-TEST WITH FMRI IN CHILDREN AFFLICTED WITH ADHD-COMBINED TYPE}

CA MANGINA $^{1}$, S KARAKAS ${ }^{2}$, Z BARAN $^{2}$, A OZKAN-CEYLAN ${ }^{2}$, E DOGUTEPE-DINCER ${ }^{2}$, HM KARAKAS ${ }^{3}$, ET TALI ${ }^{3}$, H BEUZERON-MANGINA ${ }^{1}$

${ }^{1}$ MONTREAL RESEARCH AND TREATMENT CENTER FOR LEARNING ABILITIES AND DISABILITIES - COGNITIVE PSYCHOPHYSIOLOGY LABORATORY, MONTREAL, CANADA, ${ }^{2}$ HACETTEPE UNIVERSITY - COGNITIVE PSYCHOPHYSIOLOGY RESEARCH UNIT, ANKARA, TURKEY, ${ }^{3}$ GAZI UNIVERSITY DEPARTMENT OF RADIOLOGY - SECTION OF NEURORADIOLOGY, ANKARA, TURKEY

\section{PURPOSE}

Currently, there are conflicting findings with respect to the neurological basis of Attention Deficit Hyperactivity Disorder (ADHD). In this FMRI study, children with "Pure" ADHD of the combined subtype (ADHD-C) were studied using the Mangina-Test as a research paradigm.

METHOD

Sample included 16 unmedicated males with ADHD-C (mean age $128.6 \pm 18.71)$ and age-matched $(128.9 \pm 16.77)$ normal controls. All were right-handed. There were no comorbid disorders. Stimulation was performed using computerized Mangina-Test, a neuropsychometric diagnostic tool which measures varying degrees of analytical-specific visual perception relating to learning abilities and disabilities. There were five runs of increasing task difficulty; each included eight simple and complex figures. Detection of simple stimulus masked into a more complex configuration was indicated by motor response. A single run GLM was prepared for each participant and a multi-subject random effects analysis was performed.

RESULT

Group effect and difficulty were studied using $2 \times 5$ ANOVA. There was significant difference in the activated brain areas between ADHD-C and control groups (for different areas, values changed between $F(1,30)=6.06, p<.02$ and $F(1,30)=22.85, p<.00001)$ and between levels of difficulty (values changed between $\mathrm{F}(5,150)=3.95$, $\mathrm{p}<.002$ and $\mathrm{F}(5,150)=5.22 \mathrm{p}=0001)$.

CONCLUSIONS

The study revealed increased signal intensity in the ADHD-C group in prefrontal cortex, association areas of the parietal and visual cortex. For simpler tasks, activation began in mainly frontal cortex. Future research will explore the brain responses in ADHD and normal populations to specific stimulus categories in the Mangina-Test and expand the findings on populations suffering from comorbid ADHD with Learning Disabilities and Pure Learning Disabilities as compared to age-matched normal controls.

This international joint academic research project was partially funded by the Scientific Research Grants Foundation of the Montreal Research and Treatment Center for Learning Abilities and Disabilities, Montreal, Quebec, Canada. 


\section{HE8:5}

\section{FUNCTIONAL MR IMAGING-DIFFUSION TENSOR IMAGING REVEALS THE SOMATOTOPIC ORGANIZATION OF MOTOR CORTICOSPINAL AND CORTICOBULBAR TRACTS IN GLIOMA PATIENTS}

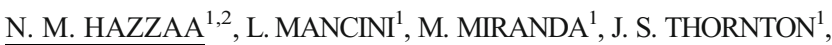 \\ T. A. YOUSRY ${ }^{1}$
}

${ }^{1}$ INSTITUTE OF NEUROLOGY- THE NATIONAL HOSPITAL FOR NEUROLOGY \& NEUROSURGERY - UNIVERSITY COLLEGE LONDON HOSPITALS, LONDON, UNITED KINGDOM, ${ }^{2}$ MENOUFIA UNIVERSITY HOSPITAL - RADIOLOGY DEPARTMENT, SHEBEEN ELKOOM - MENOUFIA, EGYPT

\section{PURPOSE}

Previous studies have suggested a somatotopic arrangement of the corticospinal tract (CST) foot $(\mathrm{F})$ and hand $(\mathrm{H})$ fibres. However, there has been little success in mapping in vivo corticobulbar tract (CBT) lips (L) and tongue (T) fibers. Furthermore, alterations to the CST/ CBT due to the vicinity of a tumor (information relevant for the preoperative assessment of patients) are poorly understood (1). Aims: to investigate 1) the somatotopic organization of the motor CST/CBT (M-CST/CBT) F/H/L/T fascicles by combining motor-task fMRI and diffusion tensor imaging tractography; 2) the influence of the vicinity of intrinsic tumors on these fascicles.

METHODS

Data were acquired at $3 \mathrm{~T}$ from three healthy volunteers and at $1.5 \mathrm{~T}$ from five healthy controls and nine tumor patients. Eighty-nine percent of patients had history of seizures and $56 \%$ had focal neurologic function deficit related to the vicinity of the tumor to the left (8 patients) or right (1 patient) M-CST/CBT. MR imaging data were analysed with SPM5 and FSL (probabilistic tractography 2tensor model). The highest intensity peaks in the SPM $\{\mathrm{t}\}$ maps within the precentral gyrus were used as seed regions for the tractography. RESULTS

Hand-MCST was tracked in $100 \%$ of patients and $80 \%(1.5 \mathrm{~T}), 100 \%$ $(3 \mathrm{~T})$ of controls; feet-MCST in $89 \%$ of patients and $60 \%(1.5 \mathrm{~T})$, $67 \%(3 \mathrm{~T})$ of controls; lips- and tongue-MCBT in $78 \%$ of patients and $60 \%(1.5 \mathrm{~T}), 100 \%$ (3 T) of controls. Some degree of overlap between the fascicles was observed. All four fascicles were identified in five patients and two $(1.5 \mathrm{~T})$ and two $(3 \mathrm{~T})$ controls.

CONCLUSION

Our results confirmed M-CST/CBT-somatotopic organization with cephalo-caudal body representation from medial to lateral along the cerebral peduncle transverse axis and from anterior to posterior along the posterior limb of internal capsule/cella media long axis. Tumors close to the CST/CBT displaced the motor-fascicles without affecting their topographic organization.

\section{HE8:6}

\section{NEUROBIOLOGICAL EFFECTS OF ATYPICAL ANTIPSYCHOTICS AND COGNITIVE REMEDIATION}

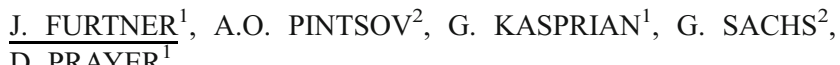

${ }^{1}$ MEDICAL UNIVERSITY OF VIENNA, DEPARMENT OF RADIOLOGY, VIENNA, AUSTRIA, ${ }^{2}$ MEDICAL UNIVERSITY OF VIENNA, DEPARMTENT OF PSYCHIATRY, VIENNA, AUSTRIA

\section{PURPOSE}

Cognitive deficits in schizophrenic patients, especially related to working memory tasks, seem to be correlated with a dysfunction of the prefrontal cortex. Purpose of this study is to examine whether this dysfunction may be detected using functional MRI (n-back test) and whether improvement may be shown after therapy.

MATERIAL AND METHODS

Functional MRI (fMRI) was used during performance of the n-back working memory task (one-back test) to assess working memory in a total of 8 cases. A baseline fMRI examination was performed in 6 drug-naïve patients who met the DSM-IV criteria for schizophrenia and in 2 healthy controls. After the baseline fMRI examination patients were randomly assigned into different cohorts. Patients in the first cohort received only atypical antipsychotics while patients in the second cohort received atypical antipsychotics in combination with cognitive therapy. To date there have been 2 patients in the first and 1 patient in the second cohort respectively. They had a second fMRI examination after 4 weeks of therapy. MR-imaging was performed on a 1.5 Tesla unit in conjunction with an 8-element Sense Head-Coil. Data was processed by using the analyzing software package Brainvoyager.

RESULTS

In the baseline fMRI examination all schizophrenics showed an exaggerated activation, especially in the right dorsolateral prefrontal cortex, in comparison with the healthy controls. This can be interpreted as a prefrontal dysfunction in terms of a greater effort being required to perform a one-back working memory task. The patient, who received atypical antipsychotics in combination with cognitive therapy showed a greater reduction of activation after 4 weeks than the patients who received antipsychotics only. CONCLUSION

Preliminary data show that cognitive therapy in schizophrenics may improve prefrontal cortex dysfunction. Furthermore, cognitive outcome might be a predictor for social performance and fMRI data might be used as a marker for certain aspects of the disease.

\section{HE8:7}

\section{ANATOMICAL AND FUNCTIONAL ALTERATIONS OF CORTICO-CEREBELLO-CORTICAL LOOPS IN HIGH FUNCTIONING AUTISM}

M. BRAUN ${ }^{1}$, M AMIRAULT ${ }^{2}$, O PERIOT $^{2}$, W MAYO ${ }^{2}$, S FOSCOLO $^{1}$, AL DERELLE $^{1,3,4}$, M ALLARD $^{2}$

${ }^{1}$ UNIVERSITY HOSPITAL-DEPARTMENT OF NEURORADIOLOGY, NANCY, FRANCE, ${ }^{2}$ UNIVERSITÉ DE BORDEAUX 2 UMR CNRS 5231, BORDEAUX, FRANCE, ${ }^{3}$ IADI-INSERM U947, NANCY, FRANCE, ${ }^{4}$ NANCY UNIVERSITÉ, NANCY, FRANCE

\section{BACKGROUND}

The cerebellum is one of the most consistent site of neuroanatomic abnormality in autism, however the pathophysiological role of this structure in the autistic pathology is still unclear. The involvement of the cerebellum in cognitive functions is now admitted and a critical role of the reciprocal relationships between the cerebellum and several cortices has been proposed. The purpose of the present investigation was to examine the anatomical and functional connectivity between the cerebellum and neocortical areas in autistic patients and to study their relationships with the neuropsychological status of patients. METHODS

We studied eight high functioning autistic patients and eight matched normal subjects using diffusion tensor imaging and functional 
connectivity at rest. Eight patients with High Functioning Autistic Syndrome Disorder (ASD) (all males; mean age : $23.38 \pm 2.10$ years, mean VIQ : $89 \pm 7.89$ and PIQ : 78 \pm 8.06 ) and 8 normal participants (all males; mean age : of $23.05 \pm 2.02$ years, mean VIQ : $128.33 \pm 4.58$ and PIQ : $116 \pm 4.40$ ) participated in the study. Autistic patients included in this study respond to ICD 10 criteria for autistic disorder, based on Autistic Diagnostic Interview and to the DSM-IV criteria.

RESULTS

Autistic individuals showed significantly decreased fractional anisotropy (FA) in the left fronto-pontine tract, and an alteration of the functional connectivity between the left prefrontal cortex (BA46) and the cerebellar vermis (VII). The attentional performance was inversely correlated with the left fronto-pontine FA values.

CONCLUSIONS

These results strongly suggest a pathophysiological role of the alterations of the cortico-cerebello-cortical loops in cognitive deficits associated with the autistic pathology.

\section{HE8:8}

\section{OPTIC NERVE AND OPTIC RADIATION NEURODEGENERATION IN GLAUCOMA PATIENTS: AN IN VIVO ANALYSIS WITH 3 TESLA MR DIFFUSION TENSOR IMAGING}

$\underline{\text { E. ASSAKO ONDO }}^{1}$, E. MESCHINI ${ }^{1}$, F. GARACI $^{1}$, F. BOLACCHI $^{1}$, G. MANENTI ${ }^{1}$, M. MELIS ${ }^{1}$, R. FLORIS ${ }^{1}$, C. NUCCI ${ }^{2}$, G. SIMONETTI $^{1}$

${ }^{1}$ UNIVERSITY OF ROME TOR VERGATA- DIPARTMENT OF DIAGNOSTIC IMAGING AND INTERVENTIONAL RADIOLOGY, ROME, ITALY, ${ }^{2}$ UNIVERSITY OF ROME TORVERGATADIPARTIMENTO DI OCULISTICA, ROME, ITALY

\section{PURPOSE}

The aim of the present study was to evaluate by high field magnetic resonance diffusion tensor imaging (MR-DTI) the axonal architecture of the optic nerves and optic radiations in glaucoma patients and to assess whether MRI DTI derived parameters correlate with disease severity.

\section{PATIENTS AND METHODS}

The study was approved by the institutional review board. Informed written consent was obtained from all participants. Sixteen patients with primary open-angle glaucoma were included in the study. Glaucoma severity was clinically assessed by a six stages system based on static threshold visual field parameter). Ten healthy subjects were used as controls. MR-DTI was performed with a 3-Tesla MR scanner. Mean diffusivity (MD) and fractional anisotropy (FA) maps were automatically created. Regions of interest (ROIs) were positioned over the MD and FA maps and a mean MD value (mMD) and mean FA value (mFA) were calculated for each optic nerve and optic radiation.

RESULTS

The optic radiations and the optic nerves of patients with glaucoma presented statistically significant higher MDs and lower FAs than those of control subjects. The mMD values of the optic nerve and the glaucoma stages varied together consistently $(r=0.8087, p<0.0001)$. A negative correlation was found between the mFA values of the optic nerves and the glaucoma stages $(\mathrm{r}=-0.7464, \mathrm{p}<0.0001)$.

CONCLUSIONS

Glaucoma is a complex neuro-disease that affects optic nerves and optic radiations. MR-DTI derived MD and FA of optic nerves correlate with glaucoma severity, suggesting that they could play a role as complementary indicators of disease severity.
HE8:9

\section{EVALUATION OF THE ACTIVITY CHANGES IN THE BRAIN OCCURING DURING MOTOR TASKS IN PATIENTS WITH MULTIPLE SCLEROSIS BY USING FUNCTIONAL MAGNETIC RESONANCE IMAGING}

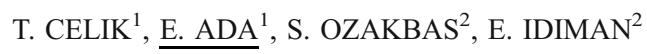

${ }^{1}$ DOKUZ EYLÜL UNIVERSITY MEDICAL SCHOOL RADIOLOGY DEPARTMENT, IZMIR, TURKEY, ${ }^{2}$ DOKUZ EYLÜL UNIVERSITY MEDICAL SCHOOL NEUROLOGY DEPARTMENT, IZMIR, TURKEY

\section{PURPOSE}

To evaluate the functional adaptive changes in the brain occurring during basic motor tasks in Relapsing-Remitting Multiple Sclerosis (RRMS) and Clinical Isolated Syndrome (CIS) by using functional Magnetic Resonance Imaging (fMRI).

MATERIAL AND METHOD

30 subjects ( 8 CIS, 12 RRMS, 10 healthy) were examined by fMRI performing flexion-extension movement with the fingers of their right hand during the dynamic imaging. Z-score values were obtained for 11 different cortical regions for both cerebral hemispheres. For the statistical evaluation, non-parametric tests and personal ki-square test were used. Spearman correlation analysis was made.

RESULTS

High activities (Z-score>5) were detected in left precentral, postcentral and superior frontal gyri in RRMS, left precentral, left and right postcentral gyri in CIS group; left precentral and postcentral gyri in control group. Z-score value has found significantly higher in right postcentral and in left anterior cingulate gyri in the CIS group than RRMS group. Activity decreased in right and left postcentral gyri in RRMS group, increased at left middle frontal gyrus in CIS group, decreased at left talamus in control group by age. Differences between the type of the treatment and the activity in the right posterior singulate girus were significant in RRMS.

\section{CONCLUSION}

This study showed adaptive mechanisms help the MS patients to sustain their normal functions against the damages in CNS. The basic motor tasks are comprehended as new or more complex due to the damage. New studies which will help us to reach more comprehensive results that may be applied practical clinics.

\section{HE8:10}

\section{PULSE TRIGGERING CAN IMPROVE THE QUALITY OF DIFFUSION TENSOR IMAGING DATA IN NEONATAL SUBJECTS}

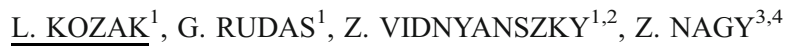

${ }^{1}$ SEMMELWEIS UNIVERSITY - MR RESEARCH CENTER, BUDAPEST, HUNGARY, ${ }^{2}$ HUNGARIAN ACADEMY OF SCIENCES, PAZMANY PETER CATHOLIC UNIVERSITY, SEMMELWEIS UNIVERSITY - NEUROBIONICS RESEARCH GROUP, BUDAPEST, HUNGARY, ${ }^{3}$ UNIVERSITY COLLEGE LONDON - WELLCOME TRUST CENTRE FOR NEUROIMAGING, LONDON, UNITED KINGDOM, ${ }^{4}$ KAROLINSKA INSTITUTE - DEPARTMENT OF WOMAN AND CHILD HEALTH, STOCKHOLM, SWEDEN 


\section{PURPOSE}

Performing MRI examinations on newborn infants is becoming common practice. Many protocols include diffusion tensor imaging (DTI), a technique that is susceptible to image degradation from the pulsatile motion of the brain. In adults it has been shown that pulse triggered acquisitions can recover the image quality but this method is usually not implemented when imaging neonates. We aimed to examine the feasibility and need for pulse triggered image acquisition in neonatal subjects.

\section{METHODS}

Imaging protocol included either collection of 16-direction DTI data with and without pulse triggering, or collection of diffusion weighted images along the $\mathrm{z}$ gradient axis 20 times with and 20 times without pulse triggering, on a $3 \mathrm{~T}$ Philips Achieva scanner (Philips Medical Systems, Best, The Netherlands). The ECG signal was used for triggering the acquisition. Data analysis was performed using FSL (FMRIB, Oxford, UK) and custom analysis routines written in Matlab
(MathWorks Inc., Natick, MA, USA). Unidirectional diffusion data was analyzed by employing Bootstrap statistics (a re-sampling method used to perform a non-parametric variant of an F-test).

\section{RESULTS}

Pulsatile artifacts were often visually identifiable in the original data when pulse triggering was not used, and their effects propagated through data processing (e.g. tensor fitting). Contrary to adult data, pulsation artifacts could be observed throughout the brain not only in the brainstem. Pulse triggering could eliminate the observed artifacts. CONCLUSIONS

Pulse triggering is feasible for diffusion-weighted imaging of neonates, especially given their high heart-rate. Lack of pulse triggering results in degraded image quality that likely impairs the interpretation of the collected data. The artifacts are most troublesome the fewer the directions in the DTI dataset. When pulse triggering is not an option, two or more datasets could be collected from which a single dataset may be compiled which is free of pulsatile artifacts. 